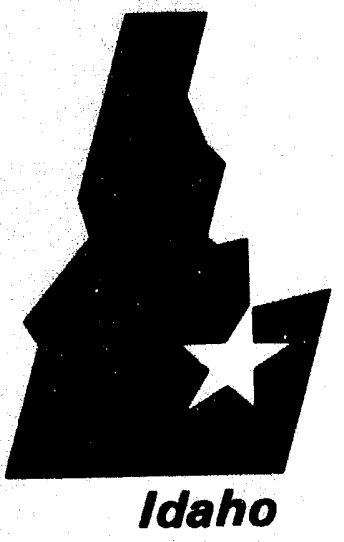

National

Engineering

Laboratory

Managed

by the U.S.

Department

of Energy
EGG-WM-10974

September 1993

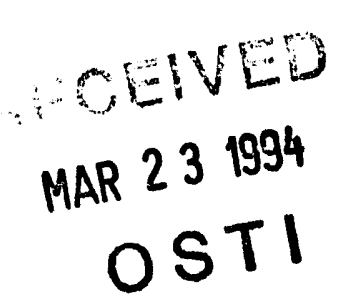

\title{
A Simulation Study of Molsture Movement in Proposed Barriers for the Subsurface Disposal Area, INEL
}

\author{
Swen O. Magnuson
}

\section{¿ EERE}

Work performed under DOE Contract No. DE-AC07-761D01570 
This document contains new concepts or the author(s) interpretation of new calculations and/or measurements; accordingly, EG\&G Idaho, Inc. is required by the United States Government to include the following disclaimer:

\section{DISCLAIMER}

This report was prepared as an account of work sponsored by an agency of the United States Government. Neither the United States Government nor any agency thereof, nor any of their employees, makes any warranty, express or implied, or assumes any legal liability or responsibility for the accuracy, completeness, or usefulness of any information, apparatus, product or process disclosed, or represents that its use would not infringe privately owned rights. References herein to any specific commercial product, process, or service by trade name, trademark, manufacturer, of otherwise, does not necessarily constitute or imply its endorsement, recommendation, or favoring by the United States Govemment or any agency thereof. The views and opinions of authors expressed herein do not necessarily state or refiect those of the United States Government or any agency thereot. 


\title{
A Simulation Study of Moisture Movement in Proposed Barriers for the Subsurface Disposal Area, INEL
}

\author{
Swen O. Magnuson
}

Published September 1993
Idaho National Engineering Laboratory
EG\&G Idaho, Inc.
Idaho Falls, Idaho 83415

\begin{abstract}
Prepared for the
U.S. Department of Energy

Assistant Secretary for Environmental Restoration and Waste Management Under DOE Idaho Operations Office

Contract DE-AC07-76ID01570
\end{abstract}




\begin{abstract}
This document presents a simulation study that was conducted to investigate moisture movement within two engineered barriers, which are proposed for use in eventual closure of the Subsurface Disposal Area. The results of the study are intended to guide the design and implementation of field test plots that will be constructed to test the barrier designs. Discussed are the sensitivity of barrier performance to changes in the conceptual model, which was used to simulate the barriers, and to changes in hydrologic parameters, which were used to describe the materials composing the barriers. In addition, estimates are presented concerning the time required for the moisture profile within the barriers to come into equilibrium with the meteorological conditions at the surface. In addition, the performance of the barriers under conditions of supplemental precipitation and ponding is presented.
\end{abstract}




\section{EXECUTIVE SUMMARY}

A simulation study was conducted to investigate moisture movement within two proposed engineered barriers being considered for use in eventual closure of low-level waste pits in the Subsurface Disposal Area. The two barrier designs are slated to be field tested in order to evaluate their performance in limiting drainage of meteoric water down through the barriers. The study had three objectives related to providing guidance in planning the field barrier evaluations.

The first objective in the simulation study was to determine where to place emphasis on sampling as part of the barrier evaluation effort. This was accomplished through a two-part sensitivity analysis of the UNSAT-H (Fayer and Jones, 1990) numerical modeling in Keck (1992), which resulted in the selection of the two proposed barrier designs. First, the sensitivity of barrier performance was tested by making changes in the conceptual model used to describe water movement within the barrier. The second part consisted of testing the sensitivity of the barrier performance to changes in the hydraulic parameters used to describe each of the barrier materials in the model.

The second objective was to provide an estimate of the time required for the barriers to come into equilibrium with the variable meteorological conditions at the surface. After the barriers are built, the initial moisture profile will begin to respond to surface conditions and to gravity and capillary forces. At low moisture conditions, changes in soil moisture can take considerable time, on the order of years. The monitoring period for the field test plots has to be long enough to measure the barrier response to variable surface conditions, not just the redistribution of the initial moisture profile.

The third and last objective related to failure analysis for the barriers. Part of the barrier evaluation project will involve supplemental infiltration. Guidance as to the appropriate water application rates and durations was provided through numerical simulations. In addition, the duration of ponding necessary for catastrophic failure from surface flooding was determined. 


\section{CONTENTS}

ABSTRACT $\ldots \ldots \ldots \ldots \ldots \ldots \ldots \ldots \ldots \ldots \ldots \ldots \ldots \ldots \ldots \ldots$

EXECUTIVE SUMMARY $\ldots \ldots \ldots \ldots \ldots \ldots \ldots \ldots \ldots \ldots \ldots \ldots$

ACKNOWLEDGMENTS $\ldots \ldots \ldots \ldots \ldots \ldots \ldots \ldots \ldots \ldots \ldots \ldots \ldots \ldots$

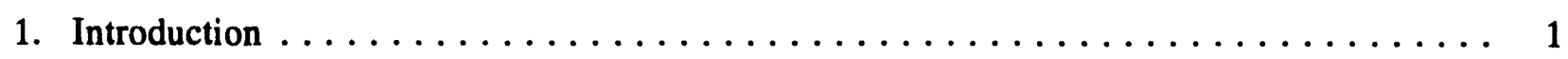

1.1 Background $\ldots \ldots \ldots \ldots \ldots \ldots \ldots \ldots \ldots \ldots \ldots \ldots \ldots \ldots \ldots \ldots \ldots$

1.2 Purpose and Objective $\ldots \ldots \ldots \ldots \ldots \ldots \ldots \ldots \ldots \ldots \ldots \ldots \ldots \ldots \ldots$

2. DESCRIPTION OF TWO BARRIERS $\ldots \ldots \ldots \ldots \ldots \ldots \ldots \ldots \ldots \ldots$

2.1 Numerical Model $\ldots \ldots \ldots \ldots \ldots \ldots \ldots \ldots \ldots \ldots \ldots \ldots \ldots \ldots \ldots \ldots$

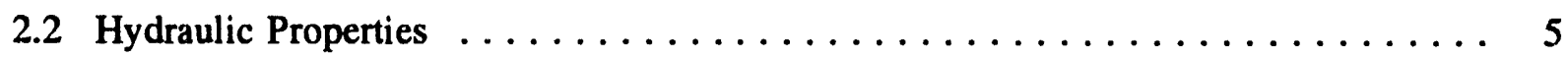

2.3 Grid, Boundary, and Initial Conditions $\ldots \ldots \ldots \ldots \ldots \ldots \ldots \ldots \ldots \ldots \ldots \ldots \ldots \ldots$

2.4 Parameterization of Transpiration $\ldots \ldots \ldots \ldots \ldots \ldots \ldots \ldots \ldots \ldots \ldots \ldots \ldots \ldots \ldots$

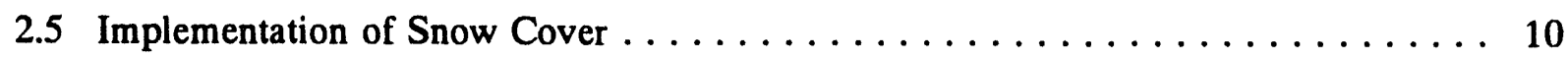

2.5.1 Manipulation of Meteorological Data Base $\ldots \ldots \ldots \ldots \ldots \ldots \ldots \ldots \ldots$

2.5.2 Reduction of Potential Evapotranspiration ............... 11

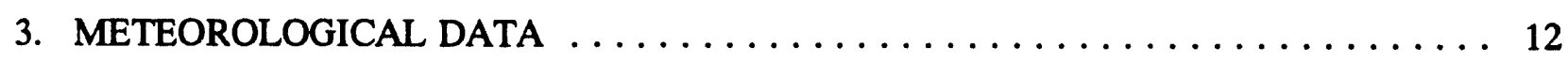

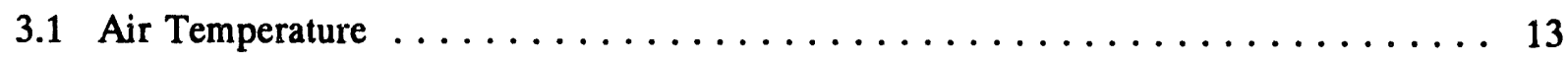

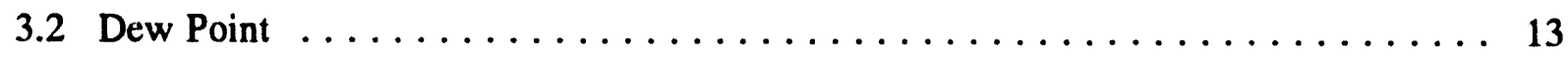

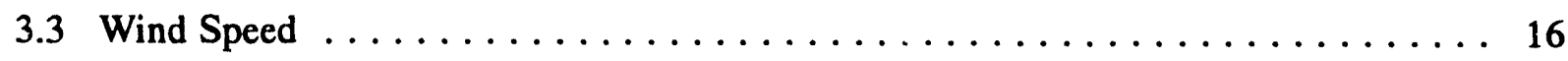

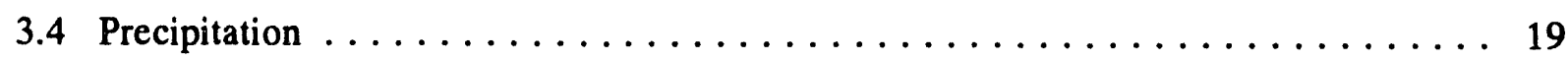

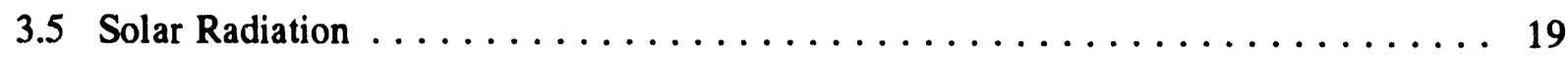

$3.0^{\circ}$ Summary of Meteorological Data Sources $\ldots \ldots \ldots \ldots \ldots$

4. SENSITIVITY STUDY OF BARRIER PERFORMANCE $\ldots \ldots \ldots \ldots \ldots \ldots$

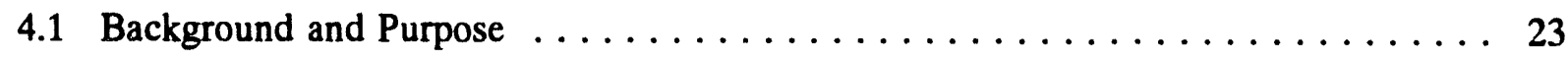

4.2 Performance Measures $\ldots \ldots \ldots \ldots \ldots \ldots \ldots \ldots \ldots \ldots \ldots \ldots \ldots \ldots \ldots$ 


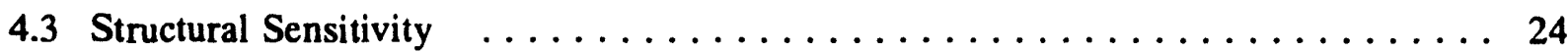

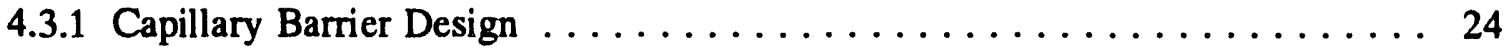

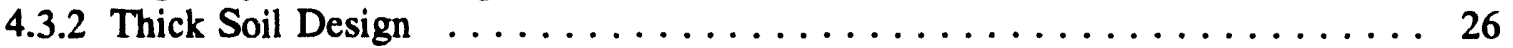

4.3.3 Effect of Infilling in the Gravel and Cobble Layers $\ldots \ldots \ldots \ldots \ldots \ldots 28$

4.3.4 Structural Sensitivity Results Summary $\ldots \ldots \ldots \ldots \ldots \ldots \ldots \ldots \ldots$

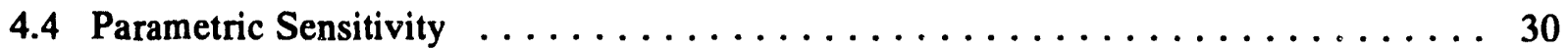

4.4.1 Capillary Barrier $¥ \ldots \ldots \ldots \ldots \ldots \ldots \ldots \ldots \ldots \ldots \ldots \ldots \ldots, 31$

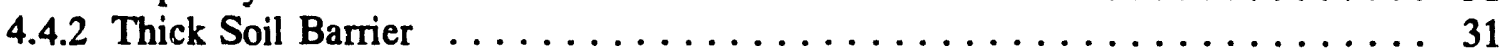

4.4.3 Parametric Sensitivity Results Summary $\ldots \ldots \ldots \ldots \ldots \ldots \ldots \ldots \ldots$

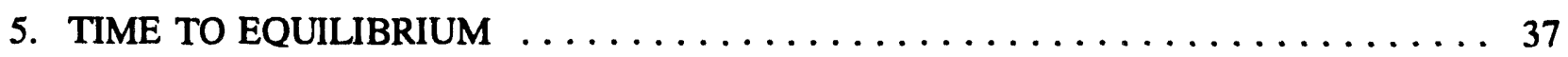

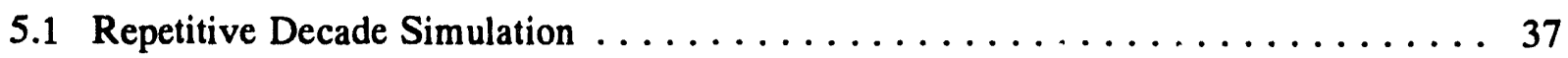

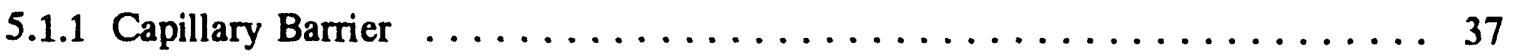

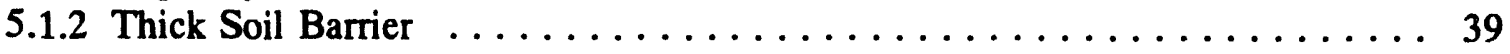

5.2 Repetitive Year Simulation $\ldots \ldots \ldots \ldots \ldots \ldots \ldots \ldots \ldots \ldots \ldots \ldots \ldots$

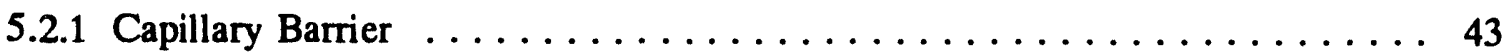

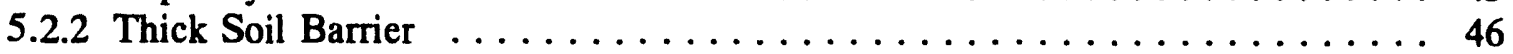

5.3 Summary of Equilibrium Results $\ldots \ldots \ldots \ldots \ldots \ldots \ldots \ldots \ldots \ldots, 46$

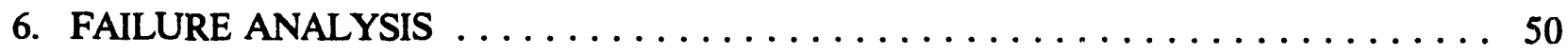

6.1 Supplemental Preripitation Simulation $\ldots \ldots \ldots \ldots \ldots \ldots \ldots \ldots \ldots \ldots \ldots$

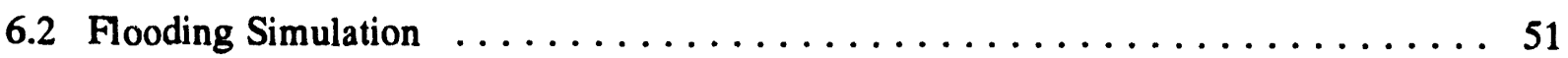

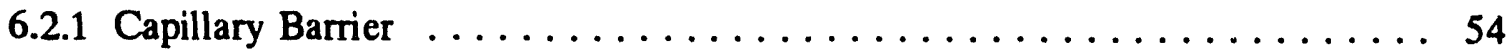

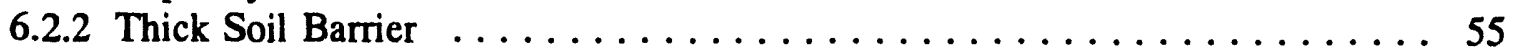

6.2.3 Comparison of Performance During and After Flooding $\ldots \ldots \ldots \ldots \ldots 56$

7. SUMMARY AND FUTURE DIRECTIONS $\ldots \ldots \ldots \ldots \ldots \ldots \ldots \ldots \ldots \ldots$

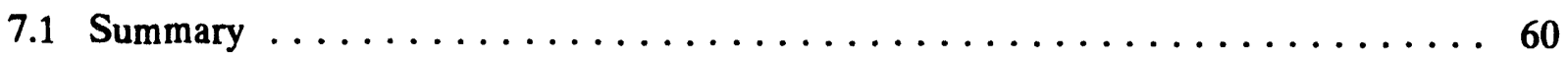

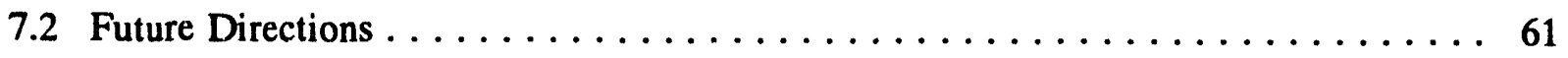

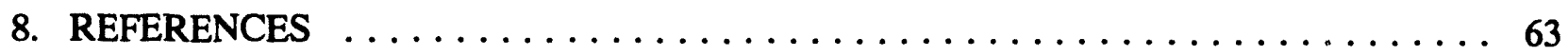

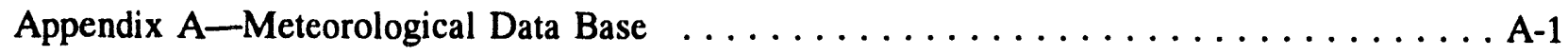

Appendix B-UNSAT-H Capillary Barrier Simulation Data Deck $\ldots \ldots \ldots \ldots \ldots$ B-1

Appendix C-UNSAT-H Thick Soil Barrier Simulation Data Deck $\ldots \ldots \ldots \ldots \ldots \ldots$ C-1 


\section{FIGURES}

1. Location of the Radioactive Waste Management Complex ............. 2

2. Two proposed barrier designs for $\mathrm{RWMC}$ closure $\ldots \ldots \ldots \ldots \ldots \ldots$

3. Brooks-Corey moisture characteristic curves for (a) head-moisture content and (b) head-

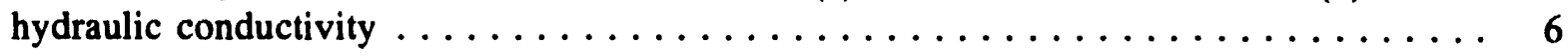

4. Fitted root length density function $\ldots \ldots \ldots \ldots \ldots \ldots \ldots \ldots \ldots$

5. Assumed root growth function for UNSAT-H simulations $\ldots \ldots \ldots \ldots \ldots \ldots$

6. Daily average temperature at CFA and $\mathrm{RWMC} \ldots \ldots \ldots \ldots \ldots$

7. Dew point temperatures at NWS-POC, APT-IF, and RWMC $\ldots \ldots \ldots \ldots \ldots$

8. Dew point temperatures at CFA, NWS-POC, and RWMC $\ldots \ldots \ldots \ldots \ldots \ldots$

9. 1986 average daily wind speeds at CFA, NWS-POC, and RWMC $\ldots \ldots \ldots \ldots$

10. 1987 average daily wind speeds at CFA, NWS-POC, and RWMC $\ldots \ldots \ldots \ldots$

11. Precipitation at CFA, NWS-POC, and RWMC $\ldots \ldots \ldots \ldots \ldots \ldots \ldots \ldots \ldots \ldots \ldots \ldots$

12. WGEN and USGS measured daily solar radiation at the RWMC $\ldots \ldots \ldots \ldots$

13. Daily drainage from the thick soil barrier for the base, transpiration, snow cover, and combined transpiration and snow cover simulations $\ldots \ldots \ldots \ldots \ldots \ldots \ldots$

14. Comparison of minimum and maximum moisture content trace with cobbles replaced by

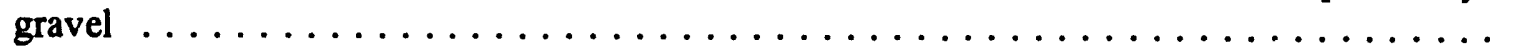

15. Moisture content profile corresponding to day of maximum stored water for three DAB

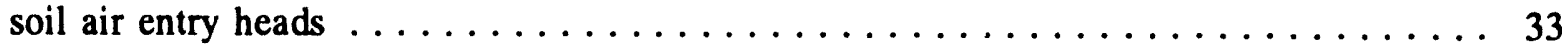

16. Effect of cobble air entry head on (a) maximum moisture content trace in cobbles and b) daily flux down through cobbles $\ldots \ldots \ldots \ldots \ldots \ldots \ldots \ldots \ldots \ldots \ldots$

17. Repetitive decade simulation results for capillary barrier: (a) daily flux near base of DAB soil and (b) cross-correlation between decades

18. Repetitive decade simulation results for capillary barrier: (a) daily flux through the gravel and (b) cross-correlation between decades

19. Repetitive decade simulation results for thick soil barrier: (a) daily flux at $185 \mathrm{~cm}$ in DAB soil and (b) cross-correlation between decades 
20. Repetitive decade simulation results for thick soil barrier: (a) daily flux through the existing soil and (b) cross-correlation between decades

21. Repetitive year simulation results for capillary barrier: (a) daily flux near base of DAB soil and (b) cross-correlation between first and second years.

22. Repetitive year simulation results for capillary barrier: (a) daily flux in gravel and (b) cross-correlation between successive years

23. Repetitive year simulation results for thick soil barrier: (a) daily flux at $185-\mathrm{cm}$ depth in $\mathrm{DAB}$ soil and (b) cross-correlation between successive years . . . . . . . . . .

24. Repetitive year simulation results for thick soil barrier: a) daily flux near top of existing soil and $b$ ) cross-correlation between successive years $\ldots \ldots \ldots \ldots \ldots \ldots \ldots$

25. Simulation results for annual drainage with supplemental precipitation: (a) capillary barrier and (b) thick soil barrier

26. Flux at bottom of capillary barrier simulation domain $(300 \mathrm{~cm})$ in response to variable length flooding

27. Flux at bottom of thick soil barrier simulation domain $(300 \mathrm{~cm})$ in response to variable length flooding $\ldots \ldots \ldots \ldots \ldots \ldots \ldots \ldots \ldots \ldots \ldots \ldots \ldots \ldots \ldots \ldots$

28. Flooding simulation results for daily water storage (cm) for (a) capillary barrier and (b) thick soil barrier

\section{TABLES}

1. Brooks-Corey hydraulic parameters for barrier materials $\ldots \ldots \ldots \ldots \ldots$

2. Cross-correlation between dew point temperatures $\ldots \ldots \ldots \ldots \ldots \ldots \ldots$

3. Cross-correlation between wind speeds $\ldots \ldots \ldots \ldots \ldots \ldots \ldots \ldots \ldots$

4. Cross-correlation between precipitation $\ldots \ldots \ldots \ldots \ldots \ldots \ldots \ldots \ldots \ldots \ldots$

5. Sources of meteorological data from 1981 to $1990 \ldots \ldots \ldots \ldots \ldots \ldots$

6. Maximum stored water, yearly drainage, and mass balance error for the capillary barrier

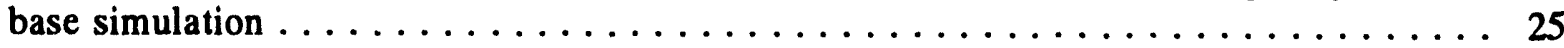

7. Effect of transpiration on maximum amount of stored vater in capillary barrier

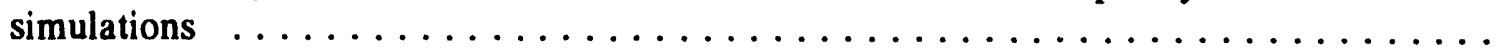

8. Sensitivity of capillary barrier simulation maximum storage results with combined transpiration and snow cover 
9. Yearly drainage and mass balance error for thick soil base case simulation $\ldots \ldots \ldots \ldots 27$

10. Sensitivity of maximum (1986) thick soil barrier yearly drainage to combined

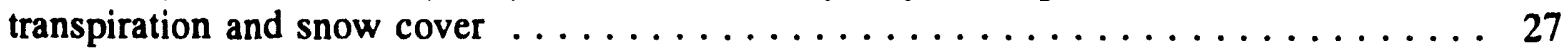

11. Structural sensitivity results from infilling of capillary barrier $\ldots \ldots \ldots \ldots$

12. Parametric sensitivity results for capillary barrier $\ldots \ldots \ldots \ldots \ldots \ldots \ldots$

13. Parametric sensitivity results for thick soil barrier $\ldots \ldots \ldots \ldots \ldots \ldots \ldots$

14. Summary of equilibrium estimates from repetitive decade and repetitive year simulations 49

15. Simulation results for capillary barrier with supplemental precipitation $\ldots \ldots \ldots \ldots 3$

16. Simulation results for thick soil barrier with supplemental precipitation $\ldots \ldots \ldots \ldots 4$

17. Results for flooding of capillary barrier $\ldots \ldots \ldots \ldots \ldots \ldots \ldots \ldots \ldots \ldots \ldots \ldots \ldots \ldots \ldots$

18. Results for flooding of thick soil barrier $\ldots \ldots \ldots \ldots \ldots \ldots \ldots \ldots \ldots$

19. Comparison of peak drainage rate between flooding simulations for capillary barrier and

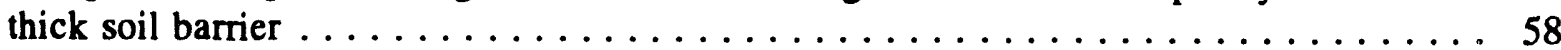




\section{ACKNOWLEDGMENTS}

I wish to thank a number of individuals that contributed to this project. First and foremost, thanks to Ms. M. Beth Sussman for her assistance while I conducted this study. I gratefully acknowledge Dr. Indrek Porro for his extensive review and comments on an early draft of this document. Also, Dr. M. J. Fayer, Pacific Northwest Laboratories, provided insight on several occasions as well. Lastly, thanks to Mr. Tony R. Moser for preparing many graphs and illustrations. 


\section{A Simulation Study of Moisture Movement in Proposed Barriers for the Subsurface Disposal Area, INEL}

\section{INTRODUCTION}

The Radioactive Waste Management Complex (RWMC) is located in the southwest portion of the Idaho National Engineering Laboratory (see Figure 1). Low-level, mixed, and transuranic radioactive wastes have been disposed in shallow pits and trenches at the RMWC from the early 1950s until 1970. Since 1970, transuranic wastes have been disposed in above-grade facilities. A radiological performance assessment (PA) is being conducted on the low-level waste facility at the RWMC (Maheras et al., 1993), as required by $\mathrm{OOE}$ Order 5820.2A. This PA considers the lowlevel waste that is already emplaced and that which is projected to be emplaced over the remaining lifetime of the facility.

The PA results are partly based on numerical simulation of flow and radionuclide transport in the subsurface at the RWMC. This PA modeling takes a conservative approach to predict the performance of a facility. For example, this conservative approach includes only taking credit for reduced infiltration due to an engineered barrier for a limited period of institutional control. The advantage of using a cover is to reduce infiltration in order to provide more opportunity for shortlived nuclides to decay.

\subsection{Background}

Two cover designs, identified by Keck (1992) as likely candidates, are being evaluated for use in eventual closure of low-level waste pits in the RWMC disposal facility. A study is being initiated to construct small-scale field plots of both barrier designs and to monitor them in order to evaluate their effectiveness in reducing infiltration. The field study will provide a basis for including the effects of a cover into the RWMC PA calculations.

The simulations conducted in Keck (1992) to evaluate proposed barrier designs were deterministic in that no variability in hydrologic parameters was considered. In addition, since the barriers are not constructed yet, site-specific descriptions of the hydraulic parameters for each of the barrier materials were not available. In place of site-specific parameters, the hydraulic characteristics of each of the barrier materials were assigned based on default values for U.S. Soil Conservation Service classifications tabulated in the HELP Manual (Schroeder et al., 1988).

\subsection{Purpose and Objective}

In this study, simulations of moisture movement within the proposed barriers were conducted which had the overall purpose of providing guidance to the ongoing cover evaluation project. The guidance was provided through three specific objectives addressed in this study. These objectives are covered in Sections 4, 5, and 6 and are briefly described below. 


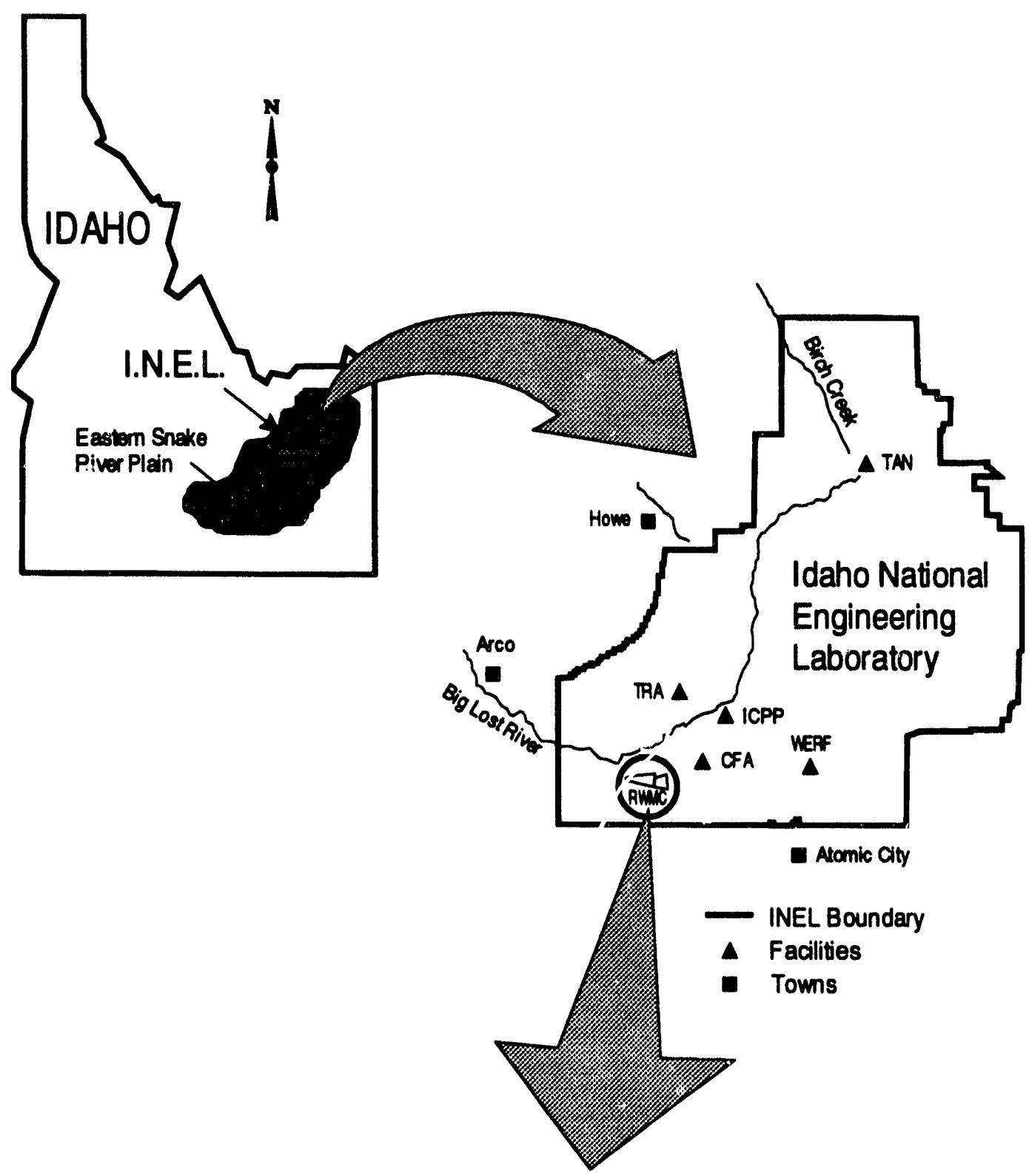

\section{Radioactive Waste Management Complex}

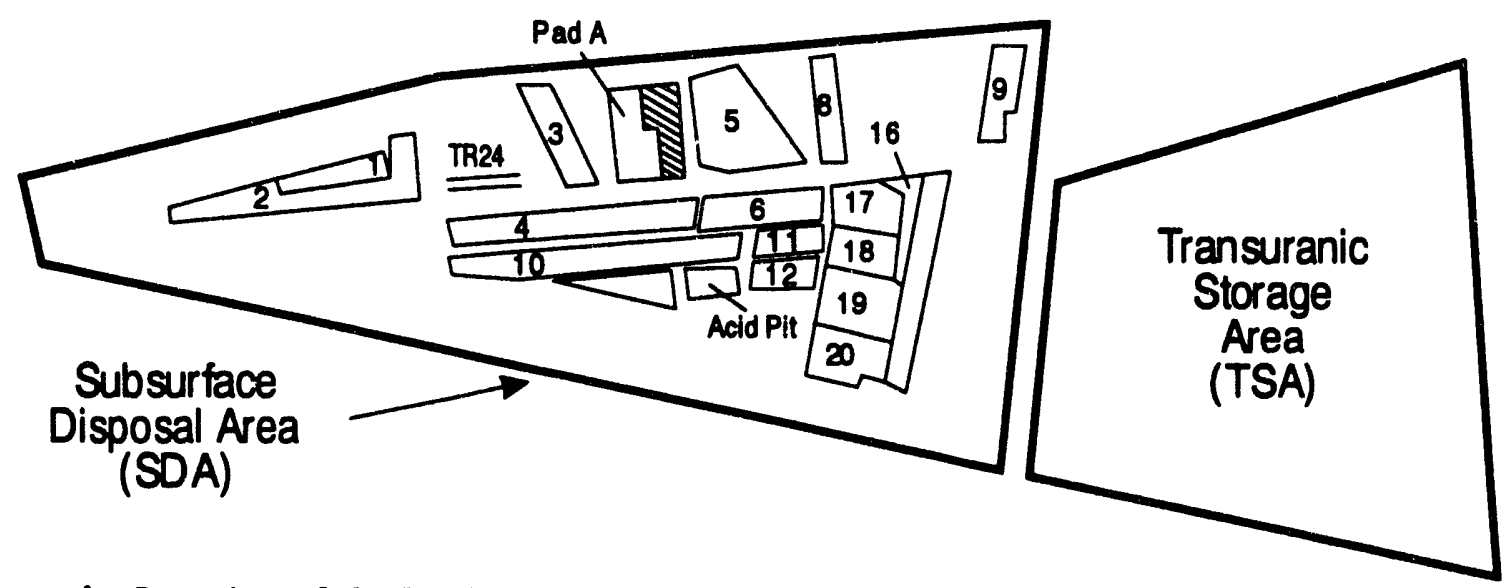

Figure 1. Location of the Radioactive Waste Management Complex. 
The first objective was to perform a sensitivity analysis of the UNSAT-H (Fayer and Jones, 1990) numerical modeling, which resulted in the selection of the two proposed barrier designs. This sensitivity analysis had two parts. The first tested the sensitivity of the modeling results to changes in the conceptual model used to describe water movement in the barrier. For example, one change to the conceptual model was to include the effect of plant transpiration. The intent was to improve the conceptual model used in the simulations by making it more inclusive of the processes that will affect moisture movement within the barriers. The second part consisted of testing the sensitivity of the barrier performance to changes in the hydraulic parameters used to describe each of the barrier materials in the model. This latter part can then be used to determine where to place emphasis on sampling as part of the barrier evaluation effort.

The second objective in the simulation study was to provide an estimate of the time required for the barriers to come into equilibrium with the variable meteorological conditions at the surface. During construction, moisture content of the emplaced materials will be strictly controlled. After the barriers are built, the initial moisture profile will begin to respond to surface conditions and to gravity and capillary forces. At low moisture conditions, changes in soil moisture can take considerable time, on the order of years. The monitoring period for the field test plots has to be long enough to measure the barrier response to variable surface conditions, not just the redistribution of the initial moisture profile. The second objective of the simulation study provided a basis for defining this required monitoring period.

The third and last objective in the simulation study related to failure analysis for the barriers. Part of the ongoing barrier evaluation project involves supplemental infiltration. Guidance as to the appropriate water application rates and durations was provided through numerical simulations. In addition, the duration of ponding necessary for catastrophic failure from surface flooding was determined.

Section 2 of this report contains detailed discussions of the geometry and parameterization of the model that was used for this study. Section 3 presents the sources of meteorological data. Then, the three main objectives of the simulation study are presented in Sections 4, 5, and 6. Lastly, a summary of results and recommendations for further research is given in Section 7. 


\section{DESCRIPTION OF TWO BARRIERS}

The two barrier designs that are being constructed in the field evaluation project are illustrated in Figure 2. The illustration indicates how the barriers were modeled in this study. Subsequent changes to these designs (McElroy et al., 1992) are minor and consist primarily of increasing the thickness of the Dispersal Area $B(D A B)$ soil to $160 \mathrm{~cm}$ from $140 \mathrm{~cm}$. These changes will not affect the results or conclusions of this study. The first design consists of a cover soil with an established vegetative cover over a capillary barrier. The capillary barrier is provided by a $15-\mathrm{cm}$ gravel layer and a $76-\mathrm{cm}$ cobble layer. The cobbles are included to also serve as a biotic barrier. The source for the cover soil will likely be the nearby spreading areas of the Big Lost River diversion. The top portion of the existing soils is also included in the figure as well as in the modeling exercises. This barrier design is intended to function by having the capillary barrier keep water up near the surface. Transpiration then removes any of this excess water that is stored above the capillary barrier.

The second barrier is simpler in design and consists of adding $230 \mathrm{~cm}$ of DAB soil over the existing soil. The operating concept for this design is that transpiration by a vegetative cover will utilize any excess water and thus prevent any infiltration below the rooting zone, which could contact disposed waste (Anderson et al., 1987). The DAB soils for both designs will not be excessively compacted as they are emplaced. Rather, they will be compacted to field bulk density (Keck, 1992) so the soil can support vegetation that will utilize soil moisture.

\subsection{Numerical Model}

The UNSAT-H Version 2.0 simulation code (Fayer and Jones, 1992) was used for all simulations in this study. UNSAT-H uses a finite-difference approximation to solve the one-

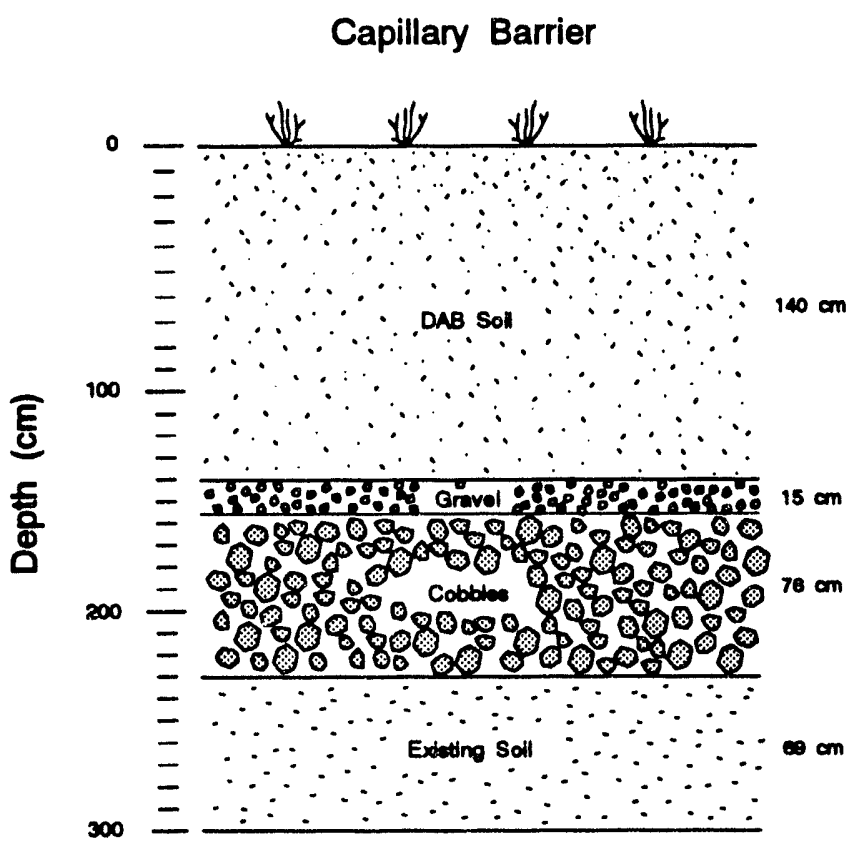

Thick Soil Barrier

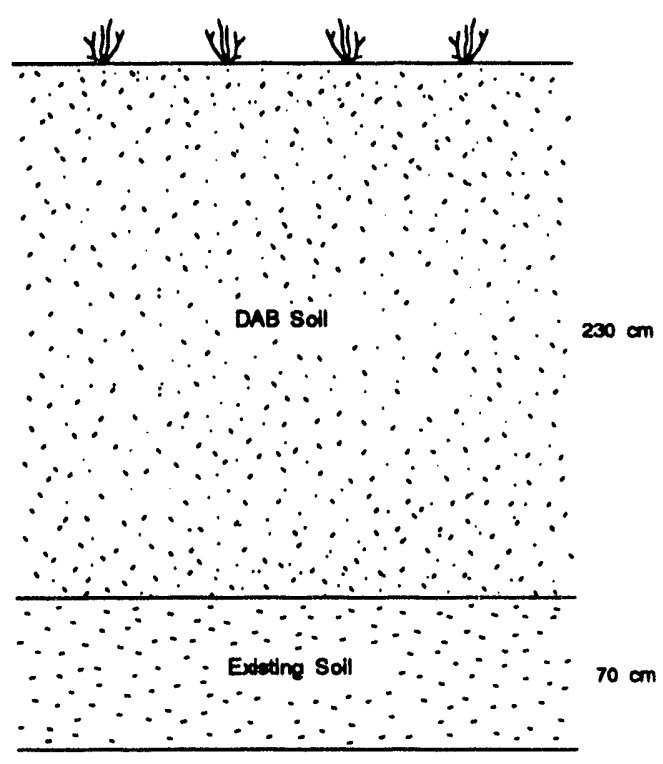

Figure 2. Two proposed barrier designs for RWMC closure. 
dimensional vertical form of Richard's equation, which governs unsaturated moisture movement. UNSAT-H was designed for use in water balance studies and has capabilities to estimate evaporation resulting from meteorological surface conditions and transpiration from plants. The implementation of the Richard's equation solution in UNSAT-H was verified and benchmark tested by Baca and Magnuson (1990).

\subsection{Hydraulic Properties}

The UNSAT-H computer code requires as input the hydraulic conductivity and moisture characteristic curve for each material type present in the barrier. The moisture characteristic curve defines the relationship between degree of saturation and matric potential. There are many functions available to describe moisture characteristic curves. For consistency with the previous modeling study in Keck (1992), the Brooks-Corey (1966) functions were used to describe the moisture characteristic and hydraulic conductivity relations. These equations are

$$
\theta=\theta_{r}+\left(\theta_{s}-\theta_{r}\left(\frac{h_{e}}{h}\right)^{\frac{1}{b}}\right.
$$

and

$$
K=K_{s}\left(\frac{h_{e}}{h}\right)^{\left(2+\frac{3}{b}\right)}
$$

where

$\theta=$ volumetric moisture content

$\theta_{\mathrm{s}}=$ volumetric moisture content at saturation

$\theta_{\mathrm{r}}=$ irreducible moisture content

$h=$ tension head $\left(\mathrm{cm} \mathrm{H}_{2} \mathrm{O}\right)$

$h_{\mathrm{e}}=$ air entry head $\left(\mathrm{cm} \mathrm{H}_{2} \mathrm{O}\right)$

$b=$ inverse pore size distribution index

$K=$ absolute hydraulic conductivity $(\mathrm{cm} / \mathrm{hr})$

$K_{\mathbf{\imath}}=$ saturated hydraulic conductivity $(\mathrm{cm} / \mathrm{hr})$.

For all barrier materials except the existing soil, default values tabulated in the HELP Manual (Schroeder et al., 1988) were used. The existing soil cover was sampled and moisture characteristic curve measurements made by Borghese (1989). A Brooks-Corey curve was fitted to an average of the Borghese (1989) measurements. Table 1 gives a complete listing of all hydraulic parameters for the barrier materials and the existing soil. These values are the same as those used in Keck (1992). The moisture characteristic curves obtained with these parameters are shown in Figure 3. These hydraulic parameters are used as the current best estimates for the material types in this study.

\subsection{Grid, Boundary, and Initial Conditions}

One-dimensional numerical grids were set up to solve for moisture movement within both barrier designs. Both grids simulated a total thickness of $300 \mathrm{~cm}$ (see Figure 2). The grid for the 
Table 1. Brooks-Corey hydraulic parameters for barrier materials.

\begin{tabular}{lccccc}
\hline \multicolumn{1}{c}{ Material } & $\begin{array}{c}K_{i} \\
(\mathrm{~cm} / \mathrm{hr})\end{array}$ & $\theta_{.}$ & $\theta_{x}$ & $\left(\mathrm{~cm} \mathrm{H}_{2} \mathrm{O}\right)$ & $b$ \\
\hline DAB Soil & 0.684 & 0.501 & 0.007 & 20.76 & 4.7393 \\
Gravel & 36.0 & 0.417 & 0.006 & 6.53 & 1.5361 \\
Cobbles & 1800. & 0.5 & 0.003 & 3.00 & 0.6666 \\
Existing Soil & 2.97 & 0.27 & 0.104 & 35.00 & 2.8571 \\
\hline
\end{tabular}

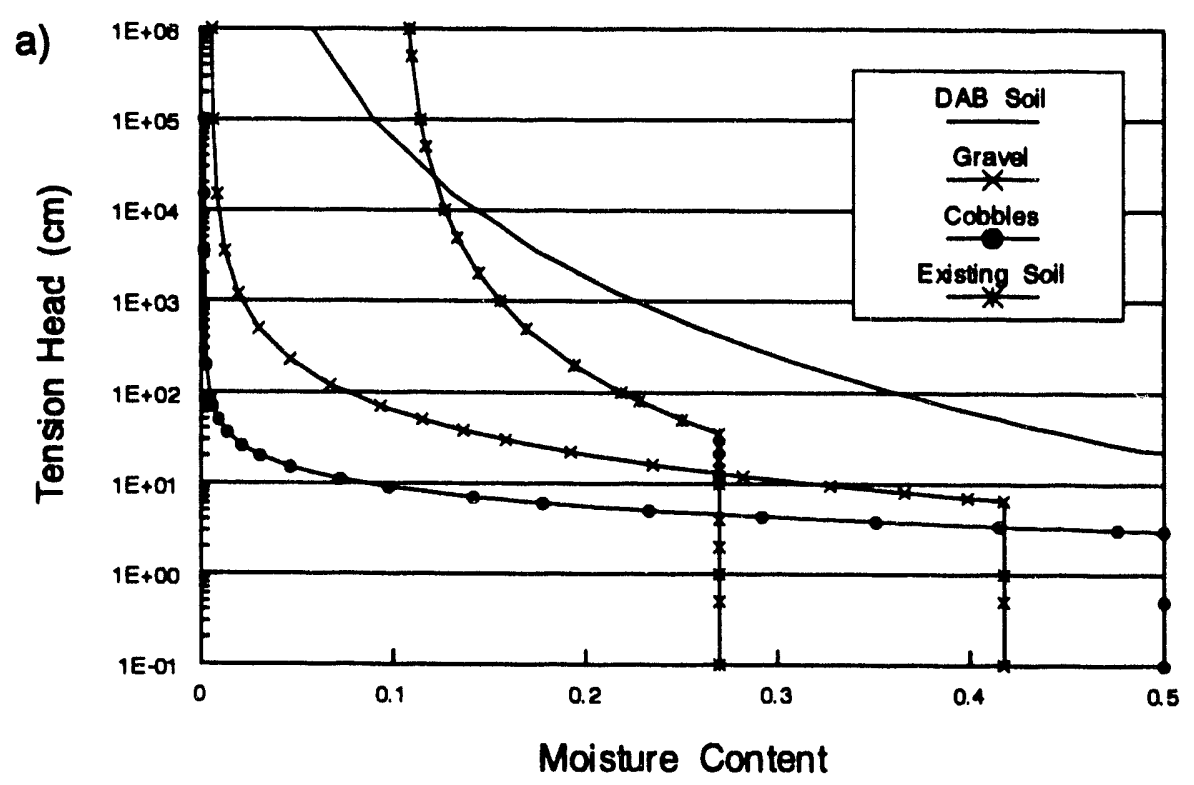

b)

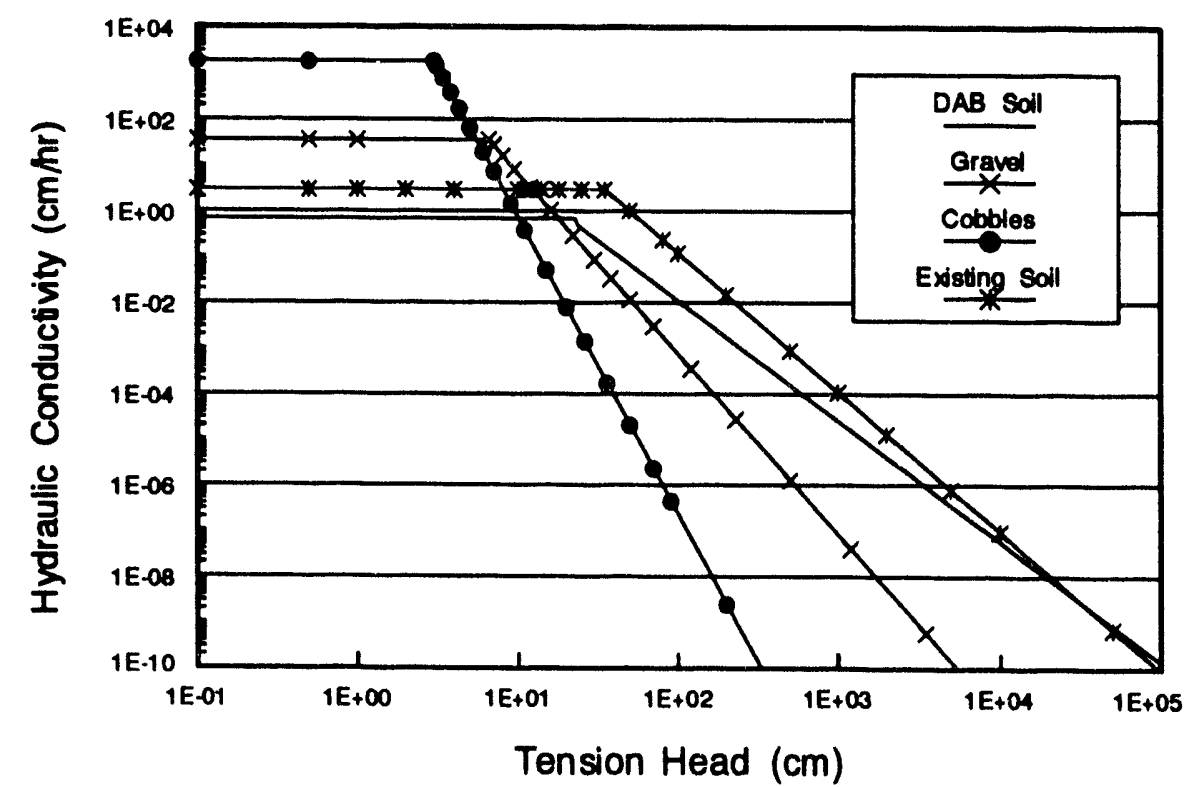

Figure 3. Brooks-Corey moisture characteristic curves for (a) head-moisture content and (b) head-hydraulic conductivity. 
capillary barrier problem used 102 nodes while the grid for the thick soil barrier used 59 nodes. More nodes were required in the capillary barrier grid due to finer discretization at the interfaces with the gravel and cobble layers.

The flux across the upper boundary was calculated as a function of meteorological conditions. The lower boundary was treated as free drainage so that water movement across the lower boundary was only influenced by gravity.

Initial conditions for the simulations in this study were determined through the following method. An optimum moisture content of $22 \%$ for was determined by Golder (1987) for compaction of soil in the existing cover at the RWMC. This was assumed to be the moisture content of the DAB soils as they will be emplaced. With the previously defined Brooks-Corey moisture characteristic curve for the DAB soils, the corresponding initial tension head from Figure $3 \mathrm{a}$ was $600 \mathrm{~cm}$. This same tension head was arbitrarily applied to the gravel and cobbles layers as well. Measured moisture contents in soils at the INEL appear to have an approximate moisture content of $10 \%$ (Anderson et al., 1987). The tension head from the existing soil Brooks-Corey curve corresponding to a $10 \%$ moisture content is $1,000 \mathrm{~cm}$ and was assigned as the initial condition for the deep soil in the simulations.

\subsection{Parameterization of Transpiration}

One objective in this study was to include the effects of transpiration in the barrier moisture simulations. Crested wheatgrass has been used as a vegetative cover on the RWMC (Reynolds, 1990) and will also be planted on the barrier test plots (Keck, 1992). This plant species was chosen for its compatibility with the semi-arid climate and for its ability to crowd out competitors and create stable monocultures (Marlette and Anderson, 1986). The UNSAT-H code requires several parameters to estimate the effect of transpiration on the soil water balance. Where possible, these parameters were based on site-specific data for crested wheatgrass. When such data were not available, values were assumed and identified as such. Required inputs will be discussed in turn.

The first input required by UNSAT-H is the starting day and duration of the growing season. Anderson et al (1987) reported a growing season for 1986 of 117 days starting on Julian day 79 and ending on Julian day 196. These dates correspond to March 20 and July 15. The basis for the seemingly early cut-off date is that senescence is assumed to begin then. These dates were used for the growing season for each year in the simulation period. Obviously, the actual dates would vary from year to year.

UNSAT-H required several parameters related to plant roots. The first was the depth of rooting, which was assigned a value in the simulations of $140 \mathrm{~cm}$. There are a considerable number of references that report values ranging around this number (e.g., Reynolds, 1990; Foxx et al., 1984; Anderson et al., 1987). The second requirement was an exponential root density function. Biomass data from Caldwell and Richards (1986) were fitted with an exponential curve as indicated in Figure 4. The fitted parameters in the figure correspond to the following equation: 


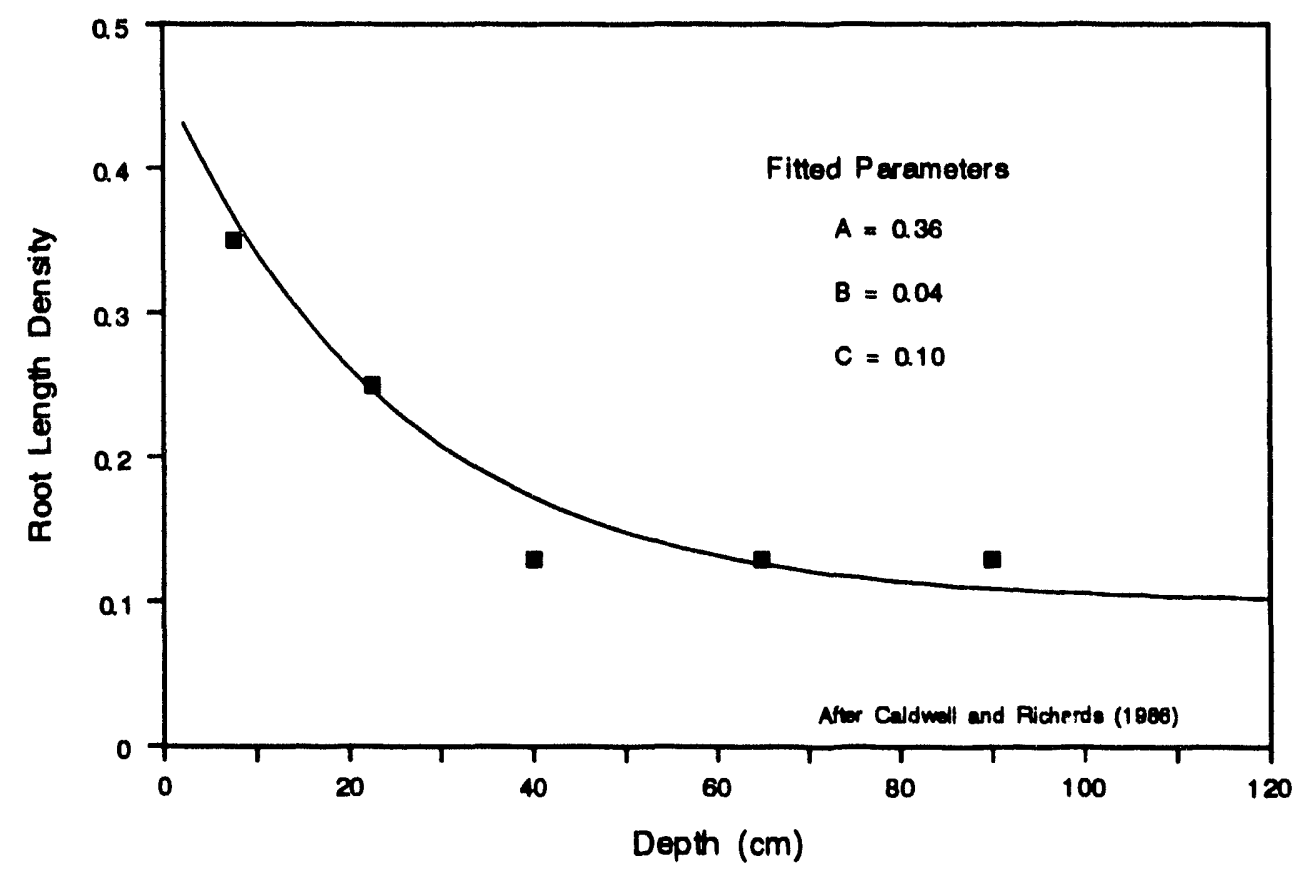

Figure 4. Fitted root length density function.

$$
R L D=A e^{-\mathbf{R z}}+C
$$

where

$$
\begin{array}{ll}
R L D & =\text { root length density }(\mathrm{cm} \mathrm{root} / \mathrm{cm} \text { soil }) \\
A & =\text { root density at surface }(\mathrm{cm} \mathrm{root} / \mathrm{cm} \text { soil }) \\
B & =\text { exponential fitting parameter }(1 / \mathrm{cm}) \\
C \quad & =\text { constant root density at depth }(\mathrm{cm} \mathrm{root} / \mathrm{cm} \text { soil) }
\end{array}
$$

The third input requirement related to roots is an estimate of the growth day on which roots reach the depth corresponding to computational nodes in the numerical model. The roots were assumed to grow linearly beginning on the first growth day of the season from a depth of $0 \mathrm{~cm}$ to the $140 \mathrm{~cm}$ depth on the last day of the growing season. This growth function is shown in Figure 5. Also shown are two alternatively assumed growth functions that were used in the sensitivity analysis. These growth functions also assumed a linear behavior but varied the initially effective root depth on the first day of the growing season. One drawback of the implementation of transpiration in UNSAT-H is the requirement of a growth function for roots. This implies that the roots start from some fixed depth each year and grow downwards. This is correct for the first year but not for subsequent years when the roots are already at depth.

UNSAT-H requires a value for the head corresponding to the water content below which plants wilt and stop transpiring. Anderson et al (1987) reported a lower limit of extraction of 11 to $12 \%$ moisture content for crested wheatgrass, as well as three other species, grown on simulated waste trenches. Using the assumed Brooks-Corey curve for the DAB soil and an $11 \%$ 


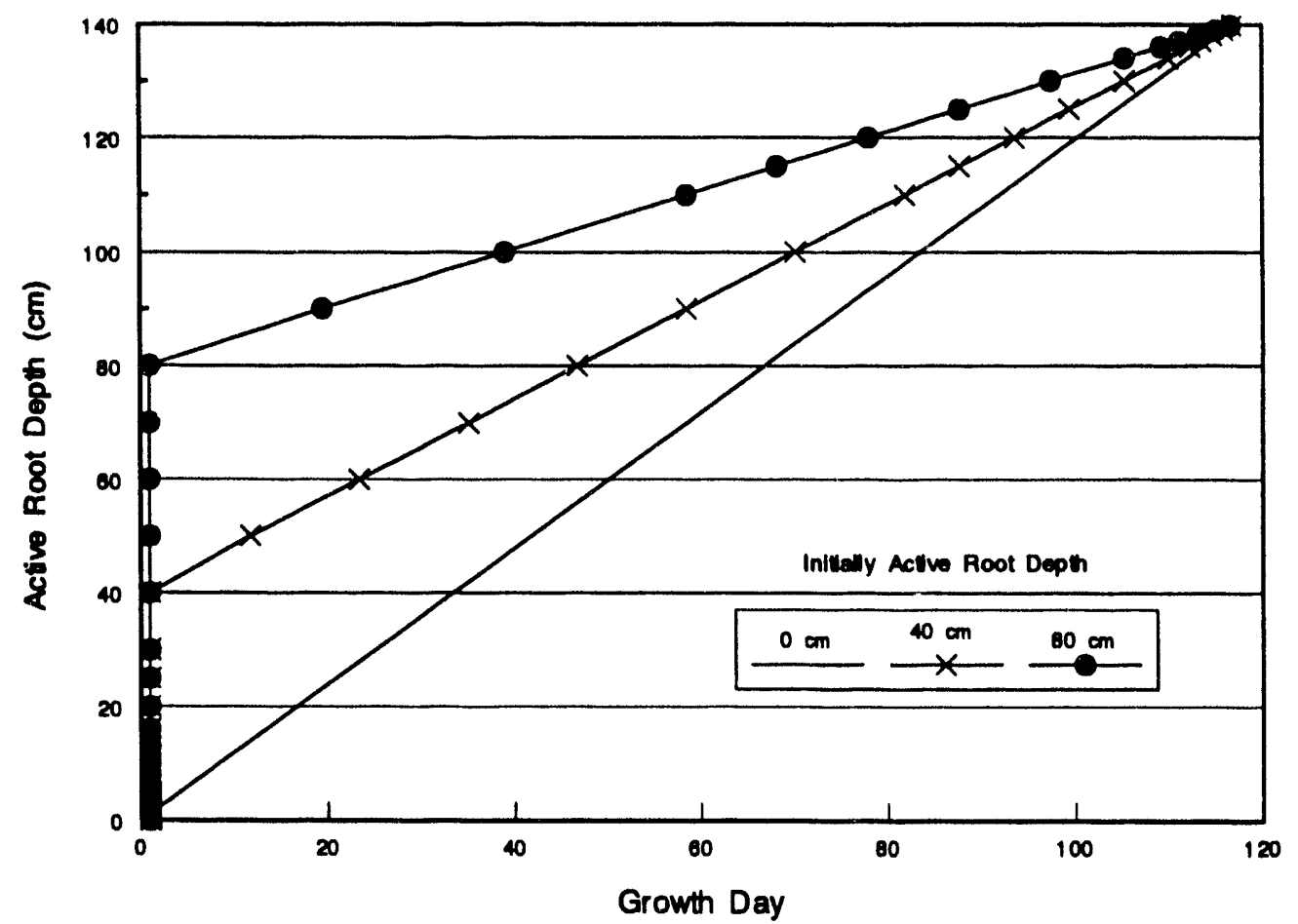

Figure 5. Assumed root growth function for UNSAT-H simulations.

moisture content, the corresponding tension head was $3.5 \times 10^{4} \mathrm{~cm}$. Also required is the head value below which transpiration starts to decrease. This was assumed to happen when the hydraulic conductivity in the DAB soil was reduced two orders of magnitude. The corresponding tension head was $800 \mathrm{~cm}$. Lastly, the head corresponding to the moisture content above which plants do not transpire because of anaerobic conditions was assumed to be the same as the air entry head, $20.76 \mathrm{~cm}$.

Fractional coverage of the soil surface by plants was assigned a value of $35 \%$ based on information from Marlette and Anderson (1986). This value came from a site that was sown with cresied wheatgrass. This parameter was also tested in the sensitivity analysis.

The last plant-related input for UNSAT-H was the plant shoot biomass factor. No information was available, so the default value of $220 \mathrm{~g} / \mathrm{m}^{2}$ was used. This default value was determined for cheatgrass near Hanford, Washington (Fayer and Jones, 1990).

The crested wheatgrass transpiration described by these parameters was used throughout this simulation study any time transpiration was included in a simulation. It is important to note that the method used in UNSAT-H for including transpiration is to partition the potential evaporation into evaporation and transpiration following the method of Hinds (1975). The result of this method is that the same amount of water is lost back to the atmosphere whether transpiration is included in a simulation or not. The difference that occurs when transpiration is included is that some of the water is lost from throughout the effective root zone rather than just at the surface. The appropriateness of this approach should be determined on a site-specific basis. 


\subsection{Implementation of Snow Cover}

Another objective in this simulation study was to include the effect of a snow cover into the UNSAT-H simulations. There were two main components to this implementation. The first involved manipulating the meteorological data base so that precipitation received as snowfall was accumulated and released at a later time when the snow melted. The second consisted of reducing the potential evaporation during periods when a snow cover was present. Both of these changes will be discussed in turn.

\subsubsection{Manipulation of Meteorological Data Base}

Precipitation that falls as snow is stored on the ground and is therefore not immediately available for infiltration. Previous UNSAT-H cover simulations in Keck (1992) did not take this storage of moisture on the surface into account. The method by which this was implemented in the current UNSAT-H simulation study was to (a) f(r each day, calculate the average temperature as the midpoint between the minimum and maximum daily temperatures, $(h)$ for days in which the average temperature was at or below $32^{\circ} \mathrm{F}$, any precipitation was accumulate $u$ as snowfall, and (c) for days in which the average temperature was above $32^{\circ} \mathrm{F}$, any precipitation was treated as rainwater, and snowmelt was calculated by the degree-day method (Mockus, 1972):

$$
\boldsymbol{M}=\boldsymbol{C} \boldsymbol{D}
$$

where

$M=$ snowmelt in inches per day

$C=$ constant that varies with climatic conditions (in $\mathrm{H}_{2} \mathrm{O} /$ degree-day

$D=$ the number of degree-days for a given day.

A degree-day is a day with an average temperature one degree above $32^{\circ} \mathrm{F}$. The number of degree-days is then the difference between the average daily temperature and $32^{\circ} \mathrm{F}$. The constant $C$ was assigned the recommended value of 0.06 in./day/degree-day (Mockus, 1972). The degreeday approach is quite simplistic but serves adequately in this study.

The result of accumulating snowfall during the winter is to concentrate that precipitation into a short period of time during the early spring when the snow melts. This is a reasonable approach based on observations of moisture contents in the surficial sediments of the RWMC (McElroy, 1990). During a 5-year period from 1985 to 1990, moisture contents in surficial soils were measured periodically. Although this period coincided with a regional drought, a substantial snowpack developed on the RWMC during the winter of 1988-1989. When this snowpack melted in the spring of 1989, a pulse of water infiltrated at least through the surficial sediments down to the basalt contact.

One shortcoming of the method used in this study to estimate the effect of the accumulated snowpack on infiltration is that snow deposited on the RWMC due to drifting is not considered. The location of the RWMC in a local topographical depression and the nature of the winters in Southeast Idaho increase the likelihood of drifting snow. Snow survey measurements at the 
RWMC conducted in FY-93 indicate that the amount of additional water brought onto the RWMC by drifting snow can be substantial. This shortcoming is partially addressed in the study in the failure analysis section by considering infiltration due to larger pulses of water.

\subsubsection{Reduction of Potential Evapotranspiration}

When the ground surface is covered with snow, the snow acts as a sealant from the perspective of soil moisture near the surface. Additionally, soil moisture near the surface can freeze, which reduces the open pore area available for flow and thereby reduces the hydraulic conductivity. Lastly, plant transpiration is negligible during the winter. The combination of these processes leaves essentially no mechanism by which soil moisture can be evapotranspirated back to the atmosphere. Previous cover simulations in Keck (1992) did not take into account these effects of a snow cover.

Fayer et al (1992) performed a calibration of an UNSAT-H simulation to soil moisture measurements from test lysimeters at the Hanford facility. They found a marked improvement in the comparison of simulation results for the amount of water stored in the cover to measured results when potential evapotranspiration was reduced to nothing during snow cover periods. Their findings provide a basis for including the effects of a snow cover to the simulations in this study. Periods in which no evapotranspiration was allowed were equivalent to imposing a no-flux boundary condition.

Each year of the meteorological data base, discussed in Section 3, was perused to subjectively determine the last day of snow cover in the spring and the first day of snow cover in the late fall or winter. The last day of snow cover in the spring ranged from 40 to 100 Julian days. The first day of snow cover in the fall ranged from 315 to 350 days. Rather than assign a single value for beginning and ending of snow cover, these parameters were assigned based on the meteorological data base for each year. These dates were used in the portion of the preprocessor to UNSAT-H which calculates potential evapotranspiration from meteorological data and plant transpiration parameters to override the calculated PET with null values.

This manipulation of the meteorological data base to account for snow cover relied on the existence of a meteorological data base. The types of data in this meteorologic data base and the sources from which it was derived is the topic of the following section. 


\section{METEOROLOGICAL DATA}

Daily records of meteorological data are necessary to perform UNSAT-H simulations. This data consists of minimum and maximum air temperature, average dew point temperature, solar radiation, wind speed, cloud cover, and precipitation. Since meteorological data are used in the UNSAT-H infiltration simulations to determine the upper boundary conditions, the importance of having accurate or representative meteorological data cannot be overemphasized. This meteorological data set serves as the driver for all subsequent movement of water in the subsurface. And it is precisely this subsurtace movement that this report is intended to investigate.

Sources of meteorological data for previous infiltration studies have consisted primarily of a mixture of measurements by the National Weather Service at the Pocatello Airport (NWS-POC) and measurements by the National Oceanographic and fatmospheric Administration (NOAA) at the Central Facilities Area (CFA) on the INEL. Both data sources have been necessary in order cover gaps in measurements in the record. Neither of these data sources are exactly representative of weather conditions at the RWMC. However, the assumption used in previous studies (Baca et al., 1992; Keck, 1992) was that geographical proximity provided a reasonable basis for the use of data from nearby locations. Nearby, these cases ranged from $6 \mathrm{mi}$ to CFA to $45 \mathrm{mi}$ to NWSPOC.

The intent in this section is to provide a basis for this assumption of geographical proximity. This basis will be formulated by making graphical and statistical comparisons of weather data at CFA and NWS-POC, with two additional sources of weather data. First, with the Federal Aviation Administration Flight Service Station at the Idaho Falls Airport (IF-APT), which makes hourly observations of temperature, wind speed, cloud cover, and dew point temperature. The second source of data is a United States Geological Survey (USGS) weather monitoring station at the RWMC. This station has been operated periodically. Data are currently available for the second half of 1986 and 1987 . The data consist of measurements of solar radiation, air temperature, dew point temperature (or humidity), wind speed, and precipitation. In short, this station measures all the necessary UNSAT-H parameters except cloud cover. The short period of time covered by the USGS data precludes using these data in UNSAT-H simulations for this study because longer periods are simulated. However, having some data measured at the RWMC provides an excellent opportunity to make comparisons of weather measurements at the RWMC with those taken elsewhere. Since weather patterns vary from year to year, a meteorological data base obtained from an extended period of time is desirable for testing barrier performance. For this reason, the decade from 1981 to 1990 was chosen for this simulation study.

In the following sections, graphical and/or statistical comparisons of air temperature, dew point temperature, wind speed, precipitation, and solar radiation measurements from different locations on the eastern Snake River Plain will be compared to measurements at the RWMC. 


\subsection{Air Temperature}

The weather parameter with the most complete measurements over the longest period of time at CFA is air temperature. A comparison of daily average temperature between the NOAA station at CFA and the USGS station at the RWMC is given in Figure 6. The cross-correlation between the two data sets was 0.947 . This high degree of correlation supports the use of the CFA temferature measurements as being representative at the RWMC.

\subsection{Dew Point}

Weather data for dew point temperatures from 1981 to 1990 are available from four sources: CFA, RWMC, NWS-POC, and IF-APT. None of these data sources have dew point temperatures available for the entire period, except IF-APT, from which data are available only in hardcopy form. The hardcopy data are more difficult to use due to rough averaging that must be used to come up with a daily value. This averaging allows ample opportunity for bias to enter the data set and, as a result, it is advisable to only use this data set when nothing else is available. The NWS-POC dew point measurements begin in 1984, and the CFA dew point measurements begin in 1987. Due to the sporadic nature of the available data, statistical comparisons were calculated for two time periods: August to December 1986, and July to December 1987. The dew point temperatures at the available locations for the two time periods are shown in Figures 7 and 8. Table 2 gives the cross-correlations for the same time noriods.

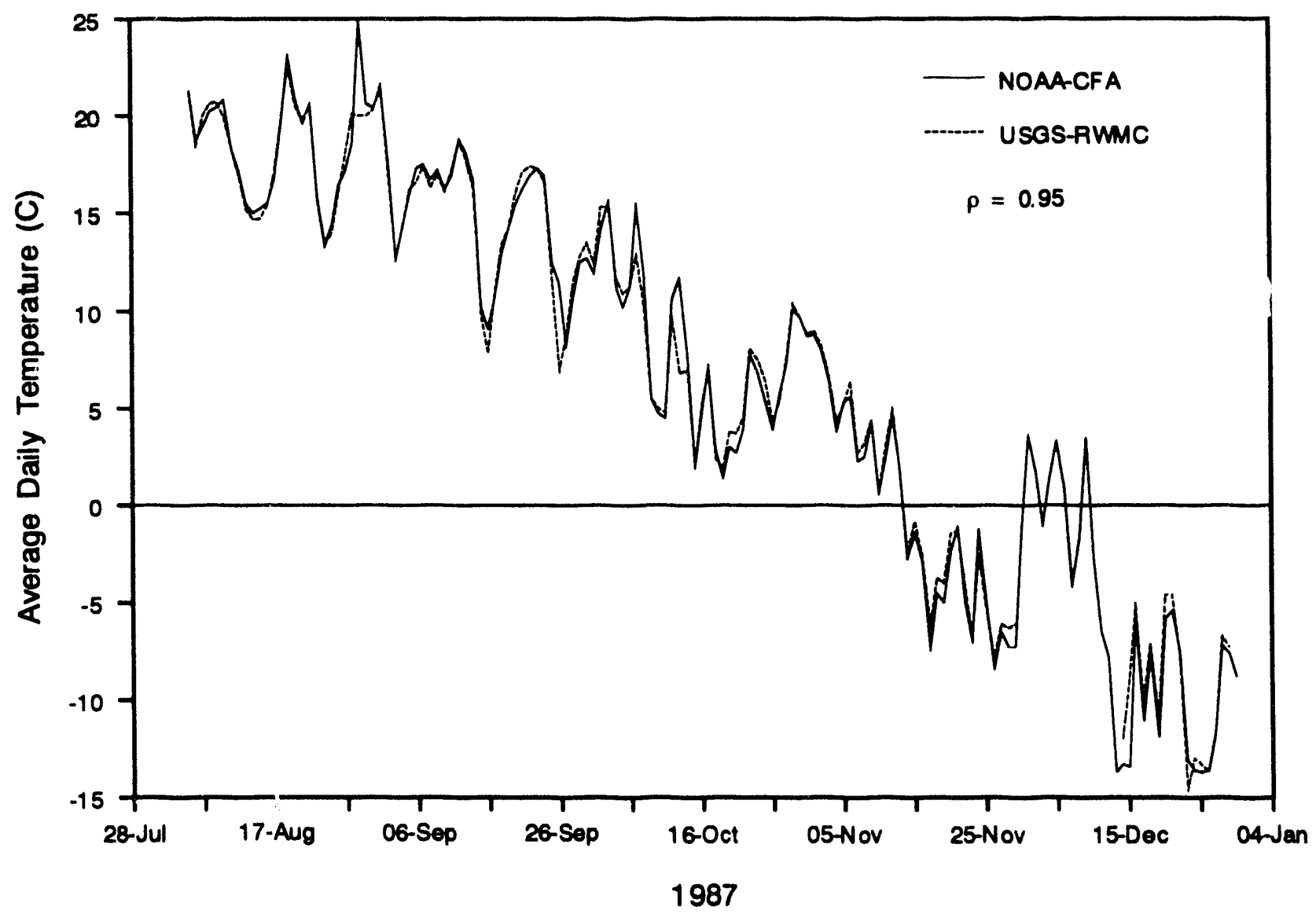

Figure 6. Daily average temperature at CFA and RWMC. 


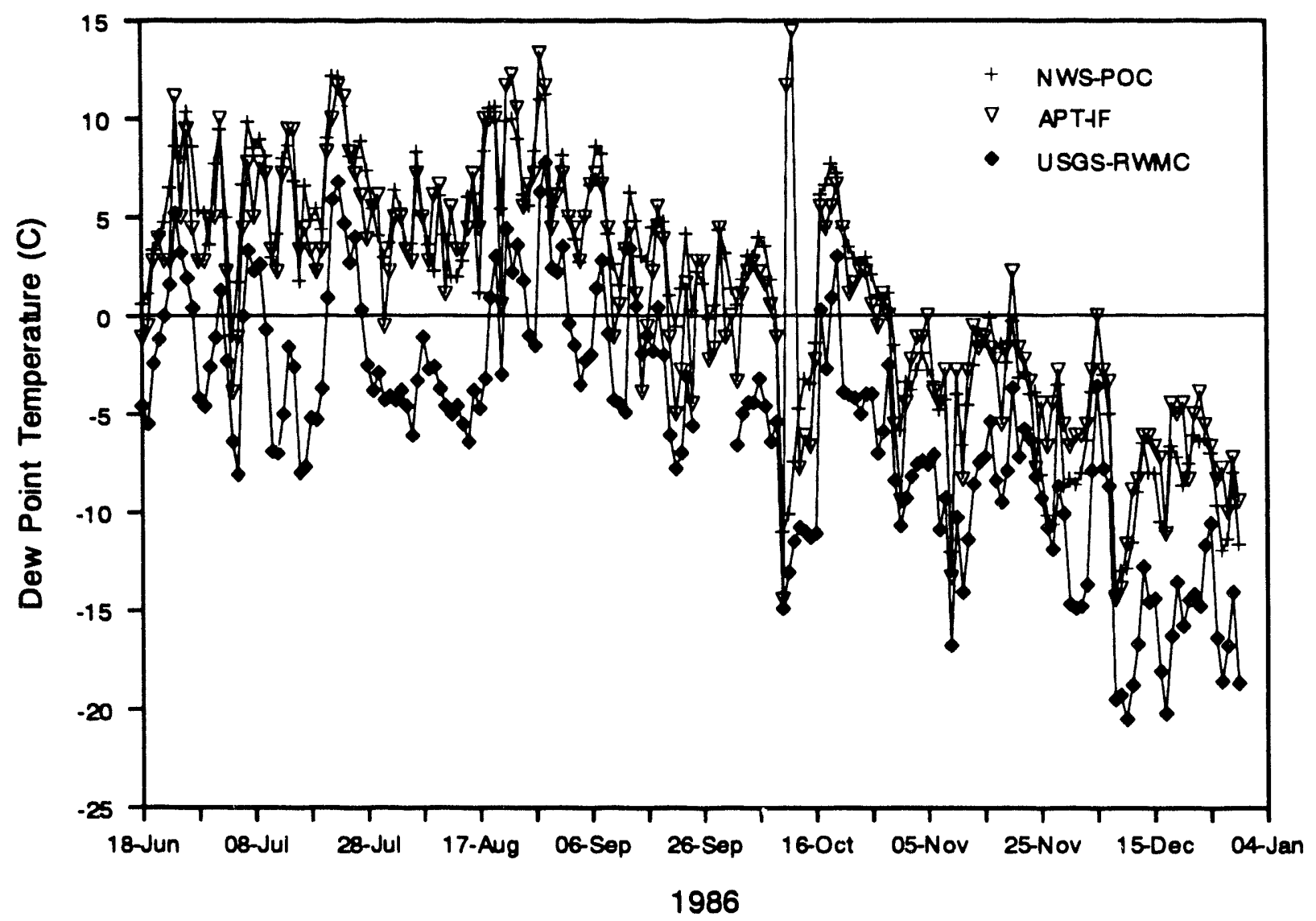

Figure 7. Dew point temperatures at NWS-POC, APT-IF, and RWMC.

As can be seen from the figures and from the cross-correlations, the dew point temperature at each of the four locations behaves nearly the same. The magnitudes differ, however, with the RWMC being considerably lower. The source of this difference could be a result of differences in measurement elevation between locations or some geomorphological feature. In any case, the RWMC dew points are generally less than those at the other locations. Data from each of the other locations (CFA, NWS-POC, and IF-APT) were used to compile the data base used for the UNSAT-H simulations. One option that was considered and not used was to subtract the mean difference in the dew point temperature from each location that was used. This would improve the graphical "fit" between the data sets. This option was not used primarily because, in the latter part of the 1987 data, there is already essentially exact agreement. Down-shifting the dew points would introduce an artificial difference in this case. The effect of using slightly higher dew points from the other locations is to artificially elevate the water saturation in the air, which would result in less evaporation. Therefore, from a barrier performance standpoint, the higher dew point temperatures are conservative. From a time-to-equilibrium viewpoint, it is not known what effect the slightly elevated dew point temperatures have.

The dew points between each location range from correlated to strongly correlated. The distances from CFA to NWS-POC and IF-APT are roughly equidistant. CFA and the RWMC are much closer. Surprisingly, from both the 1986 and 1987 data, NWS-POC dew points agree more with the RWMC than do those from CFA. This is especially true for the 1987 data. This result 


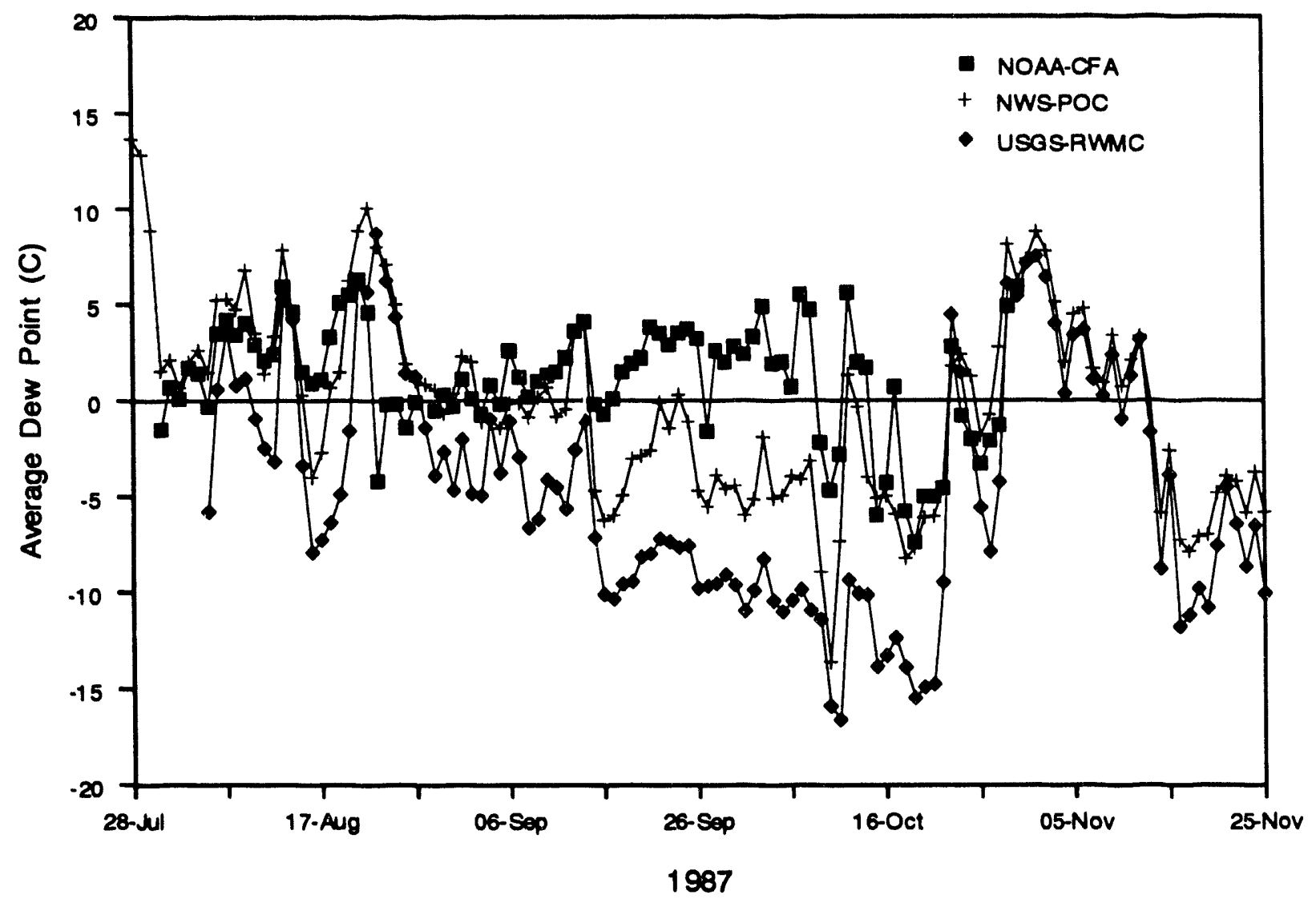

Figure 8. Dew point temperatures at CFA, NWS-POC, and RWMC.

Table 2. Cross-correlation between dew point temperatures.

\begin{tabular}{lccc}
\hline 1986 & NF-APT & NWS-POC & USGS-RWMC \\
IF-APT & 1.00 & 0.88 & 0.85 \\
NWS-POC & -- & 1.00 & 0.94 \\
USGS-RWMC & -- & -- & 1.00 \\
& & & \\
\hline & & & \\
1987 & NOAA-CFA & NWS-POC & USGS-RWMC \\
NOAA-CFA & 1.00 & 0.50 & 0.41 \\
NWS-POC & -- & 1.00 & 0.91 \\
USGS-RWMC & -- & -- & 1.00 \\
\hline
\end{tabular}

is counter-intuitive to the basis that has been used in past studies in which geographical proximity was used to support using data from closer locations over those from farther away. Due to the limited time periods available for comparison, no conclusive determination can be made as to which data set is best to use. The dew points at all four measurement stations show a quite strong correlation. Therefore, use of dew point data was based on two criteria: availability and 
proximity. For this simulation study, only IF-APT dew points were available from 1981 to 1983 , NWS-POC dew points were used from 1984 to 1986, and CFA dew points were used from 1987 to 1990 .

\subsection{Wind Speed}

Wind speed measurements are affected by elevation above the ground. This can be seen in Figures 9 and 10, which show the wind speed measurements at CFA, NWS-POC, and the RWMC for two different time periods. The wind speeds for the 1987 CFA data were measured at $10 \mathrm{~m}$ above the ground. The RWMC wind speeds shown in both figures were measured at $2 \mathrm{~m}$ above the ground. This difference in measurement elevation explains why the CFA wind speeds for 1987 are consistently higher than those from the RWMC. For purposes of compiling the UNSAT-H meteorologic data base, the CFA wind speeds from 1987 to 1990 were decreased uniformly by $0.8 \mathrm{~m} / \mathrm{s}$. This value was determined to be the decrement that gave the best graphical fit to the 1987 RWMC data. Reducing the wind speeds in this fashion is also conservative from a barrier performance standpoint since lower wind speeds result in less evaporation.

The measurement elevation on the CFA data prior to 1987 was not ascertained, but it is reasonable to assume that it is the same, $10 \mathrm{~m}$. However, a comparison of the $1986 \mathrm{RWMC}$ and CFA data does not show the same difference as the 1987 data. For this reason, the CFA wind speeds prior to 1987 were not adjusted.

Figures 9 and 10 also show the wind speed measured at NWS-POC. Although the height of the muasurement location at NWS-POC was not ascertained, it must be higher because the wind speed is generally greater than either CFA or the RWMC stations. In any case, the NWS-POC data were included in this comparison to illustrate that, in the case of wind speed, geographical proximity does result in increased correlation. This is shown in Table 3, which shows crosscorrelations for both the 1986 and 1987 measurement periods between CFA, NWS-POC, and the RWMC.

In summary, the wind speeds from CFA that were entered in the UNSAT-H weather data base quite closely mimic conditions at the RWMC in both periodic character and in magnitude. They certainly do so more than the NWS-POC data base entries for dew point temperatures.

Table 3. Cross-correlation between wind speeds.

\begin{tabular}{lccc}
\hline 1986 & & & \\
& NOAA-CFA & NWS-POC & USGS-RWMC \\
NOAA-CFA & 1.00 & 0.67 & 0.90 \\
NWS-POC & -- & 1.00 & 0.75 \\
USGS-RWMC & -- & -- & 1.00 \\
& & & \\
\hline
\end{tabular}

1987

\begin{tabular}{lccc} 
& NOAA-CFA & NWS-POC & USGS-RWMC \\
NOAA-CFA & 1.00 & 0.70 & 0.87 \\
NWS-POC & -- & 1.00 & 0.70 \\
USGS-RWMC & -- & -- & 1.00 \\
\hline
\end{tabular}



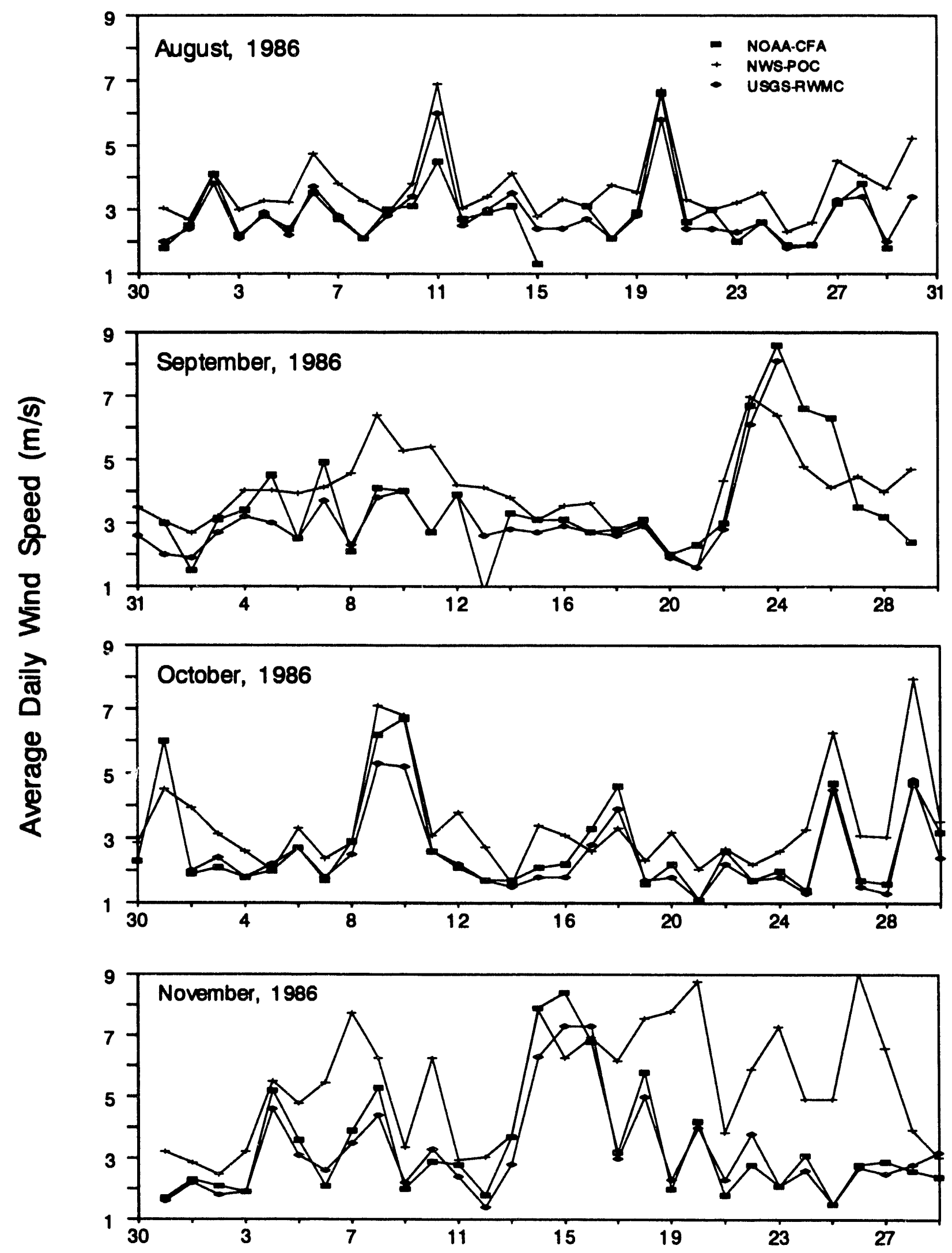

Figure 9. 1986 average daily wind speeds at CFA, NWS-POC, and RWMC. 

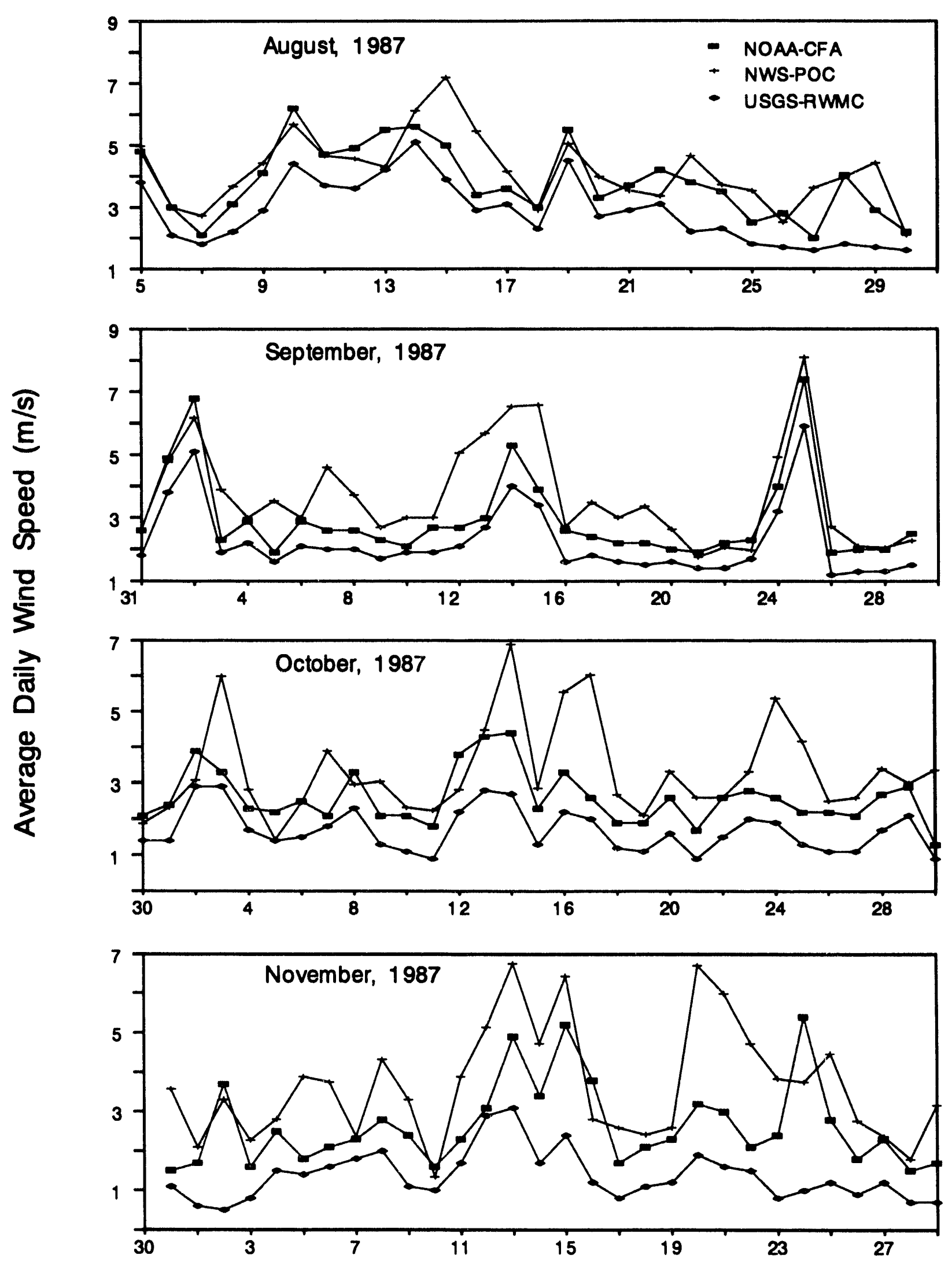

Figure 10. 1987 average daily wind speeds at CFA, NWS-POC, and RWMC. 


\subsection{Precipitation}

Precipitation is likely the easiest of all the necessary weather parameters to measure. As a result, precipitation is available at all locations except the RWMC for the entire period. The USGS meteorological station at the RWMC collects precipitation measurements but it has not operated continuously. From Figure 11, it can be seen that precipitation is the least correlated of the measured parameters. This is also evident from Table 4 , which gives the cross-correlation between precipitation at CFA, NWS-POC, and the RWMC. In the case of precipitation, geographical proximity definitely results in much greater correlation. There is almost no correlation between NWS-POC and either CFA or RWMC. From this, it can be concluded that the use of CFA precipitation measurements for the RWMC is adequate but that NWS-POC precipitation measurements are not.

\subsection{Solar Radiation}

Solar radiation is not measured as a matter of course at any of the locations except the RWMC. At the RWMC, it is measured as part of an ongoing infiltration study being conducted by the USGS. The solar radiation values used in the UNSAT-H simulations are synthetically generated using the WGEN computer code (Richardson and Wright, 1984). The radiation values are conditioned on actual daily precipitation results at CFA, as well as statistical summaries of probabilities of dry and wet day relationships. In the interest of testing the data base values, the WGEN results were compared to measurements taken at the RWMC (see Figure 12). The results show a strong agreement in trend and variation. The cross-correlation between these two data sets was $\mathbf{0 . 8 7}$. This high degree of correlation is not surprising and indicates that the WGEN results are more than adequate for simulating conditions at the RWMC.

\subsection{Summary of Meteorological Data Sources}

Based on the correlation results of the various meteorological parameters, the best available data were used for the UNSAT-H simulations. The sources of data that were used for the period from 1981 to 1990 are given in Table 5. Occasionally, a value in the CFA data base was missing. In these cases, data were substituted from locations with the highest degree of correlation, if possible. For completeness, Appendix A contains the meteorological data for the period indicated in Table 5. The data are in the format required for input into UNSAT-H and has been revised to account for snow accumulation and snowmelt as described in Section 2.5.1. 

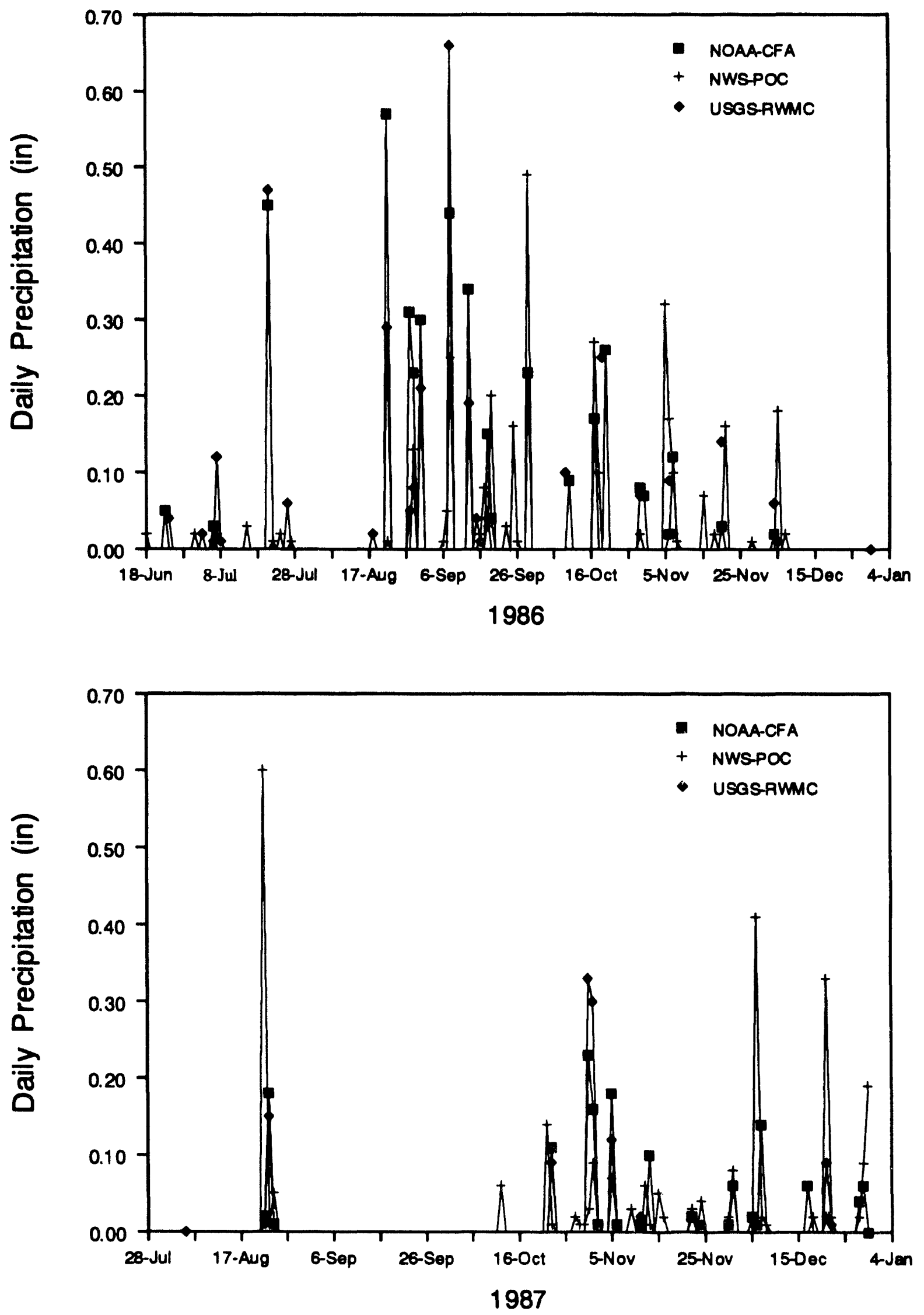

Figure 11. Precipitation at CFA, NWS-POC, and RWMC. 
Table 4. Cross-correlation between precipitation.

\begin{tabular}{lccc}
\hline 1986 & & & \\
& NOAA-CFA & NWS-POC & USGS-RWMC \\
NOAA-CFA & 1.00 & 0.31 & 0.77 \\
NWS-POC & -- & 1.00 & 0.27 \\
USGS-RWMC & -- & -- & 1.00 \\
& & & \\
\hline & & & \\
1987 & & NWS-POC & USGS-RWMC \\
NOAA-CFA & NOAA-CFA & 0.14 & 0.82 \\
NWS-POC & 1.00 & 1.00 & 0.16 \\
USGS-RWMC & -- & -- & 1.00 \\
\hline
\end{tabular}

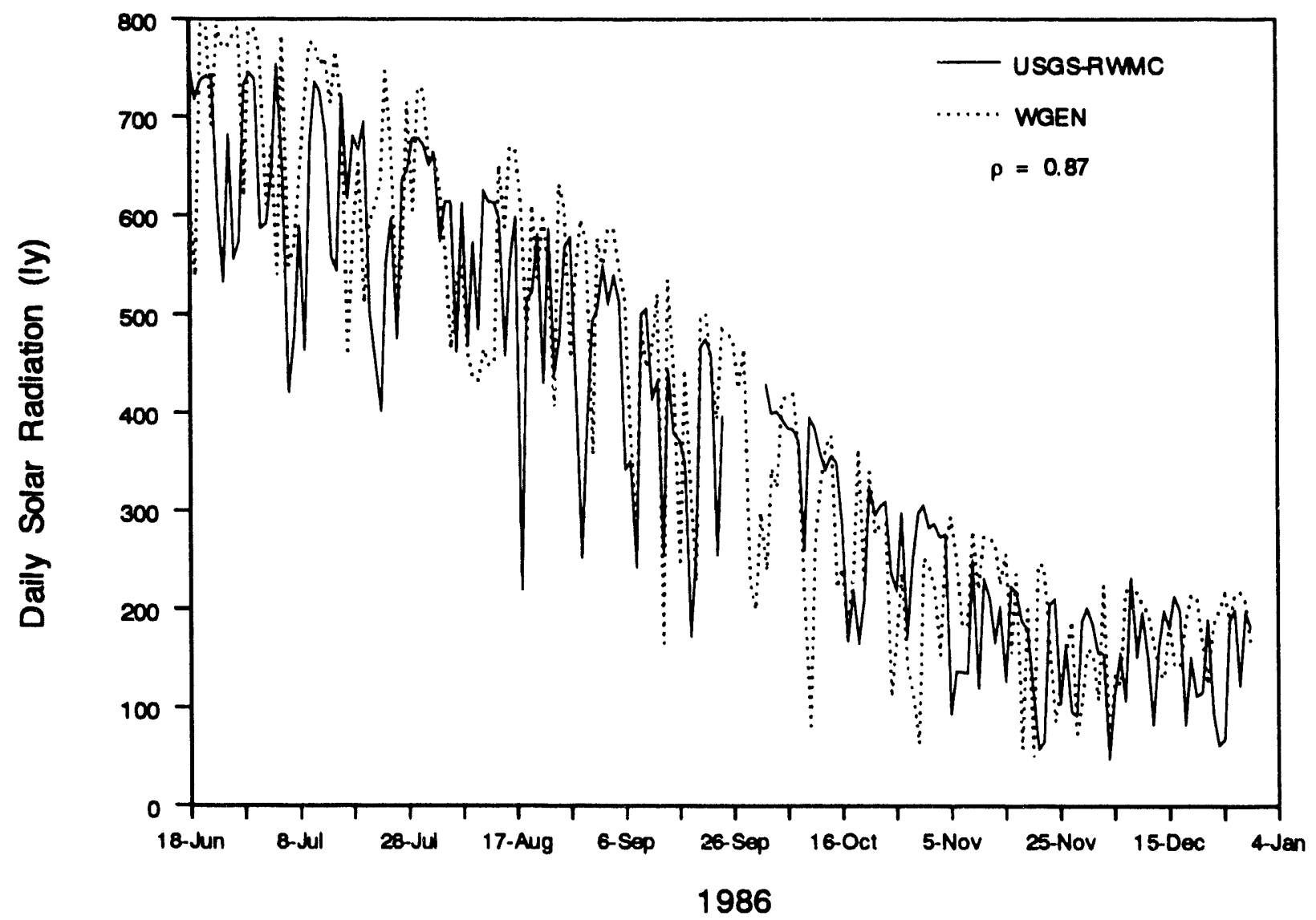

Figure 12. WGEN and USGS measured daily solar radiation at the RWMC. 
Table 5. Sources of meteorological data from 1981 to 1990.

\begin{tabular}{|c|c|c|c|c|c|c|}
\hline Year & Temp. & Dew pt. & Radiation & Wind speed & Cloud Cover & PPT \\
\hline 1981 & CFA-81 & $I F-81$ & WGEN & CFA-81 & POC-81 & CFA-81 \\
\hline 1982 & CFA-82 & $I F-82$ & WGEN & CFA-82 & $P O C-82$ & CFA-82 \\
\hline 1983 & CFA-83 & $I F-83$ & WGEN & CFA-82 & POC-83 & CFA-83 \\
\hline 1984 & CFA-84 & $P O C-84$ & WGEN & CFA-82 & POC-84 & CFA-84 \\
\hline 1985 & CFA-85 & $P O C-85$ & WGEN & CFA-85 & POC- 85 & CFA-85 \\
\hline 1986 & CFA-86 & POC- 86 & WGEN & CFA-86 & POC- 86 & CFA-86 \\
\hline 1987 & CFA-87 & CFA-87 & WGEN & CFA-87 & POC- 87 & CFA-87 \\
\hline 1988 & CFA- 88 & CFA-88 & WGEN & CFA-88 & POC- 88 & CFA-88 \\
\hline 1989 & CFA-89 & CFA-89 & WGEN & CFA-89 & POC-89 & CFA-89 \\
\hline 1990 & CFA-90 & CFA-90 & WGEN & CFA-90 & POC-90 & CFA-90 \\
\hline
\end{tabular}




\section{SENSITIVITY STUDY OF BARRIER PERFORMANCE}

A sensitivity study looks at responses in system performance to changes in the numerical model that is used to represent the system. The changes can be to the conceptual model, i.e., the assumptions implemented within a numerical model, or to the parameters used to describe material properties within the numerical model. Both types of changes were considered in the sensitivity study that was conducted for the two proposed barrier designs. First, conceptual or structural changes were considered. These structural changes consisted of adding in the contributions of plant transpiration, a snow cover during the winter, and infilling of materials from overlying layers into underlying layers. Then, using one consistent conceptual model that included plant transpiration and a snow cover, parametric changes were evaluated as to their effect on system performance. The parameters tested were saturated hydraulic conductivity, effective porosity, residual saturation, and air-entry head for each material type.

The remainder of this section consists of discussions of the background and purpose for conducting this barrier performance sensitivity study, the performance measures used, the structural sensitivity results, the parametric sensitivity results, and lastly, conclusions.

\subsection{Background and Purpose}

A previous modeling study (Keck, 1992) investigated performance of four proposed barrier designs by comparing drainage and moisture contents at selected depths. The previous study was deterministic in that single values were assigned for each of the required hydraulic input parameters. A field-scale study is currently being initiated to construct test plots for two of the designs identified as feasible in Keck (1992). These field plots will be monitored for a multi-year period to provide estimates of performance. In addition, the monitoring data from these field plots will be used to calibrate numerical models. The calibrated numerical models can then be used to extend the performance predictions using either past or future weather regimes.

One of the tasks in the field study is to measure the hydraulic properties of the barrier materials after they are emplaced. These measurements are used for quality assurance/quality control of construction. Additionally, these measurements will be used in the numerical simulations of barrier performance. The intention in this sensitivity study was to identify the hydraulic parameters for the material types that will be most important in determining barrier performance. This information can be used to determine the precision required for measuring hydraulic parameters.

\subsection{Performance Measures}

Since the primary function of the proposed barriers is to reduce infiltration into disposed waste, the performance measure by which sensitivity was judged was related to infiltration that reaches below the barrier. Water that infiltrated to this depth continued "draining" down into the soil profile. For simulations in which drainage was predicted, the performance measure for comparison between simulations was maximum yearly drainage. 
In the capillary barrier simulations, the predicted drainage was extremely low, on the order of the mass balance error of the simulation. In these cases, an alternative performance measure was required in order to make comparisons. Alternatives considered were maximum simulated moisture content in the cover soil immediately overlying the capillary barrier, maximum amount of infiltrating water at the surface, and the maximum or minimum trace of the moisture content above the capillary barrier. The latter consists of the maximum or minimum moisture content that occurs over a simulation period at each depth in the soil profile. The maximum or minimum at each depth would not all occur at the same time. The alternative performance measure that was finally chosen for the capillary barrier sensitivity study was the maximum amount of water stored at any one time in the soil profile over the simulation period. This measure was felt to be more indicative of the potential for drainage to occur than any of the other alternative performance measures that were considered. However, each of the other alternative performance measures were used at times in order to understand and explain observed hydrologic behavior.

\subsection{Structural Sensitivity}

This portion of the sensitivity study considered the effect of how structural or conceptual changes affected performance of both barrier designs. Several changes were made to the conceptual model that was simulated in Keck (1992). The first change was to include transpiration as described previously. The second change was to include the effect of a snow cover. This was done by both reducing the potential evapotranspiration during periods of snow cover and accumulating or shifting the amount of precipitation that fell as snowfall to a later time when the snow melted. The implementation of these changes was discussed previously. These two conceptual changes were applied and tested on both the capillary and thick soil barrier designs. A further change to the conceptual model for the capillary barrier consisted of infilling either DAB soil or gravel down into the more coarse layers below.

The sensitivity to the structural changes in both the capillary barrier and the thick soil barrier will be discussed in turn. These are followed by the sensitivity results to infilling.

\subsubsection{Capillary Barrier Design}

4.3.1.1 Base Case. As a starting point, a simulation of the same conceptual model as that used in Keck (1992) was performed. The only difference between this simulation and the former was the revised meteorological data base. Since the drainage through the capillary barrier was on the order of the mass balance error of the simulation, the alternative maximum storage performance measure was used. Table 6 shows the yearly maximum storage, drainage, and mass balance error for the 10-year simulation period. As can be seen, the maximum storage of $51.49 \mathrm{~cm}$ occurs in 1986. This value is used as a basis for further comparison in the structural sensitivity analysis of the capillary barrier design.

As mentioned previously, the mass balance errors are essentially on the same order as the drainage. Additionally, the drainage that did occur decreases monotonically and was due to excess water in the underlying soil as a result of the initially assigned moisture content. 
Table 6. Maximum stored water, yearly drainage, and mass balance error for the capillary barrier base simulatior

\begin{tabular}{|c|c|c|c|}
\hline Year & $\begin{array}{l}\text { Maximum Stored } \\
\text { Water (cm) }\end{array}$ & $\begin{array}{l}\text { Yearly Drainage } \\
(\mathrm{cm})\end{array}$ & $\begin{array}{c}\text { Mass Balance Error } \\
\text { (cm) }\end{array}$ \\
\hline $\begin{array}{l}1981 \\
1982 \\
1983 \\
1984 \\
1985 \\
1986 \\
1987 \\
1988 \\
1989 \\
1990\end{array}$ & $\begin{array}{l}44.86 \\
47.05 \\
46.70 \\
48.20 \\
48.56 \\
51.49 \\
46.14 \\
44.48 \\
45.06 \\
44.01\end{array}$ & $\begin{array}{l}4.88 \times 10^{-1} \\
2.00 \times 10^{-1} \\
1.25 \times 10^{-1} \\
9.02 \times 10^{-2} \\
7.02 \times 10^{-2} \\
5.72 \times 10^{-2} \\
4.85 \times 10^{-2} \\
4.19 \times 10^{-2} \\
3.67 \times 10^{-2} \\
3.27 \times 10^{-2}\end{array}$ & $\begin{array}{r}0.69 \times 10^{-2} \\
-0.22 \times 10^{-2} \\
0.26 \times 10^{-2} \\
0.35 \times 10^{-2} \\
0.84 \times 10^{-2} \\
-0.86 \times 10^{-2} \\
-0.27 \times 10^{-1} \\
-0.15 \times 10^{-2} \\
-0.90 \times 10^{-2} \\
-0.34 \times 10^{-2}\end{array}$ \\
\hline
\end{tabular}

4.3.1.2 Addition of Transpiration. The sensitivity of the maximum yearly storage to the addition of transpiration was tested in several ways. In addition to simply adding in transpiration as described previously, two key parameters related to transpiration were tested. These were the fraction of the soil surface covered by plants and the initially active root depth as the growing season began. Table 7 shows the maximum amount of water stored at any one time as a result of these variations. This maximum always occurred in 1986.

The results agree with intuition in that increasing the initially active root depth decreases the maximum amount of water that is stored. Likewise, as more of the soil surface is exposed, evaporation increased and the maximum soil water storage decreased. Overall, each of the transpiration simulations resulted in a decrease in the maximum amount of soil water stored when compared to a simulation without transpiration.

4.3.1.3 Addition of Snow Cover. Soil freezing and snow accumulation were added to the capillary barrier simulation as described previously. The resulting maximum amount of water stored in the soil profile increased to $57.39 \mathrm{~cm}$ from the base simulation of $51.49 \mathrm{~cm}$, an increase of $11.5 \%$. This increase was expected and is the result of preventing water loss during the winter and combining the winter snowmelt into an early spring melting event. Fayer et al (1992) showed a marked improvement in their cover simulation calibration when winter evaporation was reduced. This partially provided the basis for reducing winter evaporation in these sensitivity simulations. As data become available from the field test plots, the appropriateness of reducing winter evaporation can be determined. In this hypothetical study, it will be included in all the parametric sensitivity simulations discussed below.

4.3.1.4 Combining Transpiration and Snow Cover. A capillary barrier simulation was conducted which combined both the effects of transpiration and a snow cover. For clarity, in this combined simulation, the initial rooting depth was $0 \mathrm{~cm}$ and the bare soil surface fraction was 0.65. The results of this simulation are presented in Table 8 along with the previous simulations for comparison.

As can be seen, the effects of transpiration act in the opposite direction from that of soil freezing and snow accumulation. The simulation with all effects included resulted in a maximum 
Table 7. Effect of transpiration on maximum amount of stored water in capillary barrier simulations.

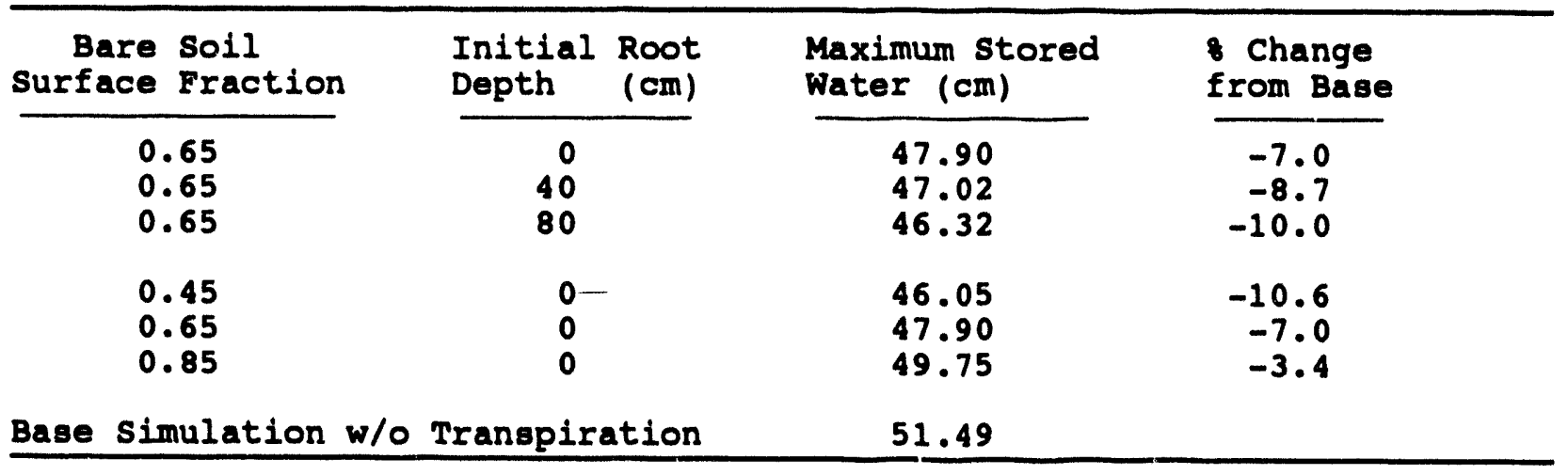

storage value that was damped into the middle range and was close to the result for the base simulation. However, the results are more presumably more realistic because the conceptual model incorporates more realistic processes. This combined simulation was used as the basis for comparison in the capillary barrier parametric sensitivity study discussed in Section 4.4 below). Appendix B contains the UNSAT-H data deck for the combined transpiration and snow cover capillary barrier simulation.

This concludes the structural sensitivity analysis of adding transpiration and a snow cover to the capillary barrier design. A similar suite of simulations were performed for the thick soil design and are discussed next.

\subsubsection{Thick Soll Design}

4.3.2.1 Base Case. In a similar fashion to the capillary barrier sensitivity study, the starting point for the thick soil structural sensitivity study was to simulate the same conceptual model as Keck (1992) with the revised weather data base for the 1981-1990 period. There was a significantly higher drainage for the thick soil barriei compared to the capillary barrier. Table 9 gives the net yearly drainage and mass balance errors for the thick soil cover design base case for the entire simulation period. Similar to the capillary barrier base simulation, the year with the maximum drainage was 1986, excluding the first 2 years of the simulation when excess drainage resulted from the initial conditions that were assigned. The 1986 drainage served as a comparison for the remainder of the structural sensitivity analysis.

Table 8. Sensitivity of capillary barrier simulation maximum storage results with combined transpiration and snow cover.

\begin{tabular}{|c|c|c|}
\hline Simulation & Maximum storage $(\mathrm{cm})$ & $\begin{array}{l}8 \text { Change } \\
\text { from Base }\end{array}$ \\
\hline Base & 51.49 & - \\
\hline Transpiration & 47.90 & -7.0 \\
\hline Snow Cover & 57.39 & 11.5 \\
\hline $\begin{array}{c}\text { Combined Transpiration } \\
\text { and snow Cover }\end{array}$ & 54.40 & 5.6 \\
\hline
\end{tabular}


Table 9. Yearly drainage and mass balance error for thick soil base case simulation.

\begin{tabular}{ccc}
\hline & $\begin{array}{c}\text { Yearly Drainage } \\
(\mathrm{Cm})\end{array}$ & $\begin{array}{c}\text { Mass Balance Error } \\
(\mathrm{Cm})\end{array}$ \\
\cline { 2 - 3 } 1981 & 1.84 & $-1.74 \times 10^{-2}$ \\
1982 & 1.31 & $-1.75 \times 10^{-2}$ \\
1983 & 0.98 & $-4.00 \times 10^{-3}$ \\
1984 & 0.91 & $1.29 \times 10^{-2}$ \\
1985 & 1.05 & $1.43 \times 10^{-2}$ \\
1986 & 1.30 & $-3.00 \times 10^{-3}$ \\
1987 & 1.28 & $-4.20 \times 10^{-2}$ \\
1988 & 0.88 & $-1.04 \times 10^{-2}$ \\
1989 & 0.65 & $-1.98 \times 10^{-2}$ \\
1990 & 0.58 & $-1.34 \times 10^{-2}$ \\
\hline
\end{tabular}

4.3.2.2 Addition of Transpiration. Transpiration was added to the thick soil simulation in exactly the same way as for the capillary barrier cover simulation. For clarity, the initial rooting depth was $0 \mathrm{~cm}$, the maximum rooting depth was $140 \mathrm{~cm}$, and the fraction of bare soil surface was 0.65 . The 1986 simulated drainage was $0.46 \mathrm{~cm}$, a reduction of $64.6 \%$ from the base simulation. The effects of the assumed initial rooting depth and bare surface fraction were tested previously in the capillary barrier analysis and were not simulated for the thick soil cover.

4.3.2.3 Addition of Snow Cover. Soil freezing and snow accumulation were added to the thick soil barrier simulation as described previously. The resulting 1986 drainage was 3.15 $\mathrm{cm}$, an increase of $142 \%$. The effect of the snow cover is dramatic and indicates its importance in the conceptual model. Dynamic visualization of the moisture profile over the simulation period confirms that the method of incorporating the snow cover focuses or concentrates the majority of the infiltration into the spring snowmelt period. Precipitation events during the remainder of the spring, summer, and fall result only in minor wetting front advances to shallow depths.

4.3.2. Combining Transpiration and Snow Cover. Adding both transpiration and a snow cover to the base simulation for the thick soil design resulted in a 1986 drainage of $1.36 \mathrm{~cm}$, a net increase of 5\%. Appendix C contains the complete UNSAT-H data deck for this simulation. Table 10 summarizes the structural sensitivity results for the thick soil design. As expected, transpiration works in the opposite direction as the snow cover. This result can also be seen in Figure 13, which illustrates the daily flux from the bottom of the simulation domain for the

Table 10. Sensitivity of maximum (1986) thick soil barrier yearly drainage to combined transpiration and snow cover.

\begin{tabular}{|c|c|c|}
\hline simulation & Yearly Drainage $(\mathrm{cm})$ & 8 Change \\
\hline Base & 1.30 & - \\
\hline Transpiration & 0.46 & -65 \\
\hline Snow Cover & 3.15 & 142 \\
\hline $\begin{array}{l}\text { Combined Transpiration } \\
\text { and Snow Cover }\end{array}$ & 1.36 & 5 \\
\hline
\end{tabular}




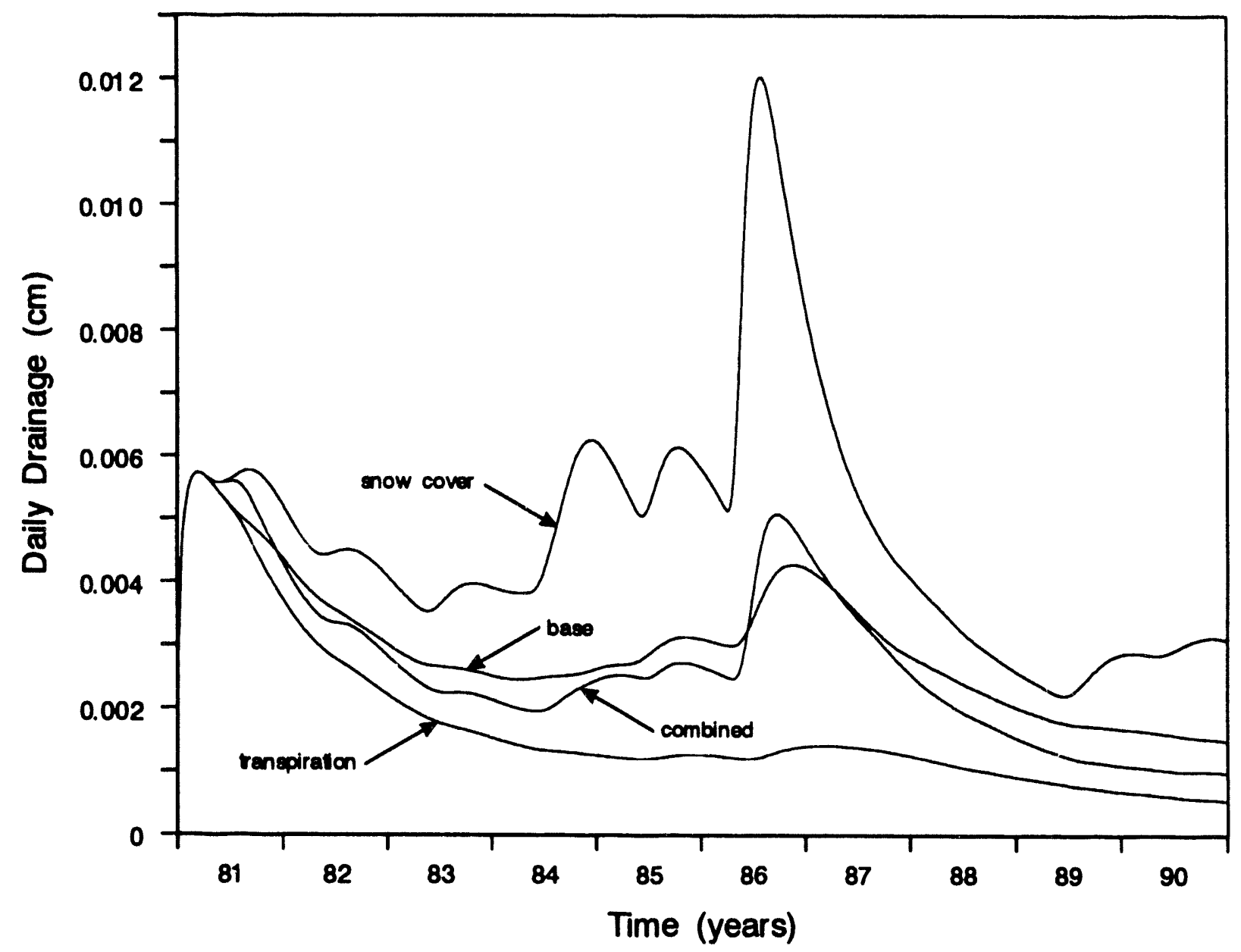

Figure 13. Daily drainage from the thick soil barrier for the base, transpiration, snow cover, and combined transpiration and snow cover simulations.

10-year simulation period. The combined result is very similar to the base case simulation. The difference is that the conceptual model has been improved by including a more realistic description of factors influencing water movement.

\subsubsection{Effect of infilling in the Gravel and Cobble Layers}

An assumption inherent in the previous structural sensitivity simulations of the capillary barrier was that the effectiveness of the capillary barrier layers did not change with time. If the membranes that keep the different layers separate fail either upon emplacement or over time, the hydraulic properties of the capillary barrier will change and its effectiveness will be reduced. $A$ series of simulations were conducted to address this possibility.

In the first simulation, the cobble layer was assumed to be completely infilled by the overlying gravel and, as a result, to have the same hydraulic characteristics as the gravel. The resulting maximum amount of water stored in the profile was $56.13 \mathrm{~cm}$, an increase of $9.0 \%$. Figure 14 illustrates the resulting trace of the minimum and maximum moisture contents for the year 1986 for the gravel and "cobbles replaced with gravel" layers. For comparison, the trace of 


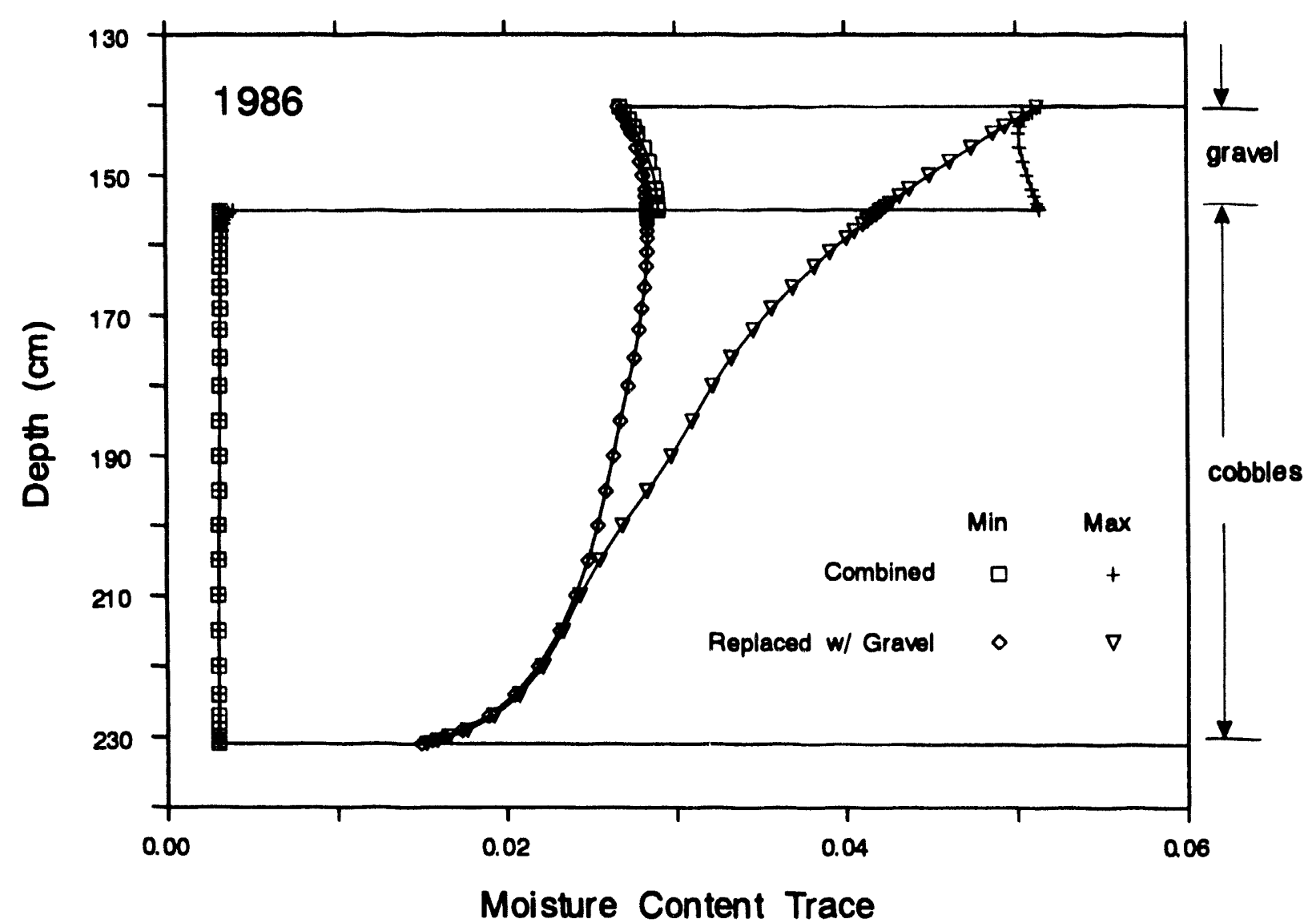

Figure 14. Comparison of minimum and maximum moisture content trace with cobbles replaced by gravel.

the maximum moisture content for the "all effects combined" capillary barrier simulation (Section 4.3.1.4) is also shown. The trace in the DAB soil is exactly the same for each simulation and was not included.

Figure 14 shows that the "cobbles replaced with gravel" simulation allows considerably more water to infiltrate. However, by comparing the maximum and minimum traces for the "cobbles replaced with gravel" simulation, it can be seen that the infiltrating pulses only penetrated to approximately the $210 \mathrm{~cm}$ depth and still did not make it to the underlying soil. The drainage from the bottom of the simulation profiles for the "cobble replaced with gravel" and the all effects combined case was $7.68 \times 10^{-2}$ and $5.68 \times 10^{-2} \mathrm{~cm} / \mathrm{yr}$, respectively. Both simulations show negligible drainage, indicating that maintaining the initial hydraulic properties of the cobble layer separate from those of the overlying gravel layer is not essential from a hydrologic viewpoint.

The second simulation consisted of DAB soil infilling both the gravel and the cobbles. Similar to the previous simulation, the hydraulic properties of the DAB soil replaced those of the gravel and the cobbles. This simulation was essentially the same as the thick soil cover design. The only difference was that this simulation had $231 \mathrm{~cm}$ of DAB soil over the underlying soil, instead of $230 \mathrm{~cm}$ in the thick soil design. This $1-\mathrm{cm}$ difference was neglected, and the results of the thick soil barrier simulation were used. The maximum storage from this infilled DAB soil 
simulation was $73.70 \mathrm{~cm}$, an increase of $35.5 \%$. Once the capillary break provided by either the gravel or the cobbles was gone, some drainage occurred. This is reflected in Table 11, which shows both the maximum amount stored and the maximum yearly drainage for the suite of infilled simulations. The implication from this series of simulations was that maintaining the initial hydraulic properties of either the gravel or cobbles is very important to barrier performance.

Also shown in Table 11 are the maximum storage and drainage for simulations with only one soil for the entire profile. This was done for both the DAB soil and the underlying soil. The simulation with only the DAB soil was represented using a thicker DAB cover. The last simulation with strictly the underlying soil was performed in order to determine the effect of adding the DAB cover soil. Based on the hydraulic descriptions used in the structural sensitivity study, the DAB soil as a cover alone provides a substantial reduction in infiltration compared to the simulation using only the underlying soil. The implication from these two simulations is that increasing the thickness of the DAI il decreases the net drainage. However, er $/$ en with the thicker DAB soil, a significant water component infiltrated the soil, compared to the capillary barrier simulations.

\subsubsection{Structural Sensitivity Results Sumriary}

A wide variation in both maximum water storage and drainage was observed in this study. The effects of both transpiration and a snow cover were important in the thick soil barrier since drainage occurred for all cases examined in all $\mathbf{1 0}$ years simulated. In the capillary barrier simulations, these effects were less important since drainage never occurred. However, this lack of drainage was shown to be dependent on maintaining the hydraulic properties that provided the capillary barrier.

\subsection{Parametric Sensitivity}

In the parametric sensitivity study, input parameters used to describe the hydraulic properties of the material were varied. The resulting change in performance was used as a measure of the sensitivity of each parameter. For both the capillary barrier and the thick soil barrier, the following parameters were varied: saturated hydraulic conductivity, saturated moisture content or effective porosity, air entry head, and residual moisture content. The latter two parameters were Brooks-Corey parameters describing the moisture characteristic curve.

Table 11. Structural sensitivity results from infilling of capillary barrier.

\begin{tabular}{lccc}
\hline \multicolumn{1}{c}{ Simulation } & $\begin{array}{c}\text { Maximum Storage } \\
(\mathrm{cm})\end{array}$ & $\begin{array}{c}\text { Maximum Drainage } \\
(\mathrm{cm})\end{array}$ \\
$\begin{array}{l}\text { Gravel Infilling Cobbles } \\
\begin{array}{l}\text { DAB Soil Infilling Gravel } \\
\text { and Cobbles }\end{array}\end{array}$ & 56.13 & $7.680 \times 10^{-2}$ \\
DAB Soil only (3 m) & 73.70 & $1.365 \times 10^{\circ}$ \\
Underlying Soil only (3 m) & 81.67 & & $7.790 \times 10^{-1}$ \\
\hline
\end{tabular}




\subsubsection{Capillary Barrier}

In the capillary barrier parametric sensitivity study, the suite of hydraulic parameters were varied for DAB soil, gravel, and cobble materials. The properties of the underlying soil were not varied since drainage did not occur. Variations in parameters were assigned for the most part by doubling or halving the base value. Judgement was used to prevent using unrealistic parameter values, and in these cases, a constant delta was used to increment or decrement the base value.

The performance measure by which the results were judged was the maximum amount of water stored in the profile at any one time. This performance measure was used since any drainage that did occur was on the order of the mass balance error in the simulation. The base value for comparison is taken from the combined transpiration and snow cover capillary barrier simulation. This basis was chosen because it represents the best estimate of barrier performance. The results from the capillary barrier parametric study are shown in Table 12.

The results indicate that the maximum amount of water in the profile is most sensitive to the DAB soil parameters. This is not surprising and is a result of the DAB soil being the uppermost in the profile and therefore more influenced by the varying upper meteorological boundary condition. This can be seen in the results of varying the saturated hydraulic conductivity of the capillary barrier. As the hydraulic conductivity increased, the maximum amount of water stored in the profile decreased because, although wetting fronts could penetrate into the DAB soil faster, the infiltrating water could also be extracted back to the surface more easily. Likewise, by increasing either the saturated or residual moisture content, more water can be stored above the capillary barrier.

The effect of increasing the DAB air entry head is less obvious. Figure 15 shows the moisture content profiles on the day the maximum amount of stored water occurs for each air entry heads. Increasing the air entry head improved the extraction of water back to the surface and kept the profile drier. Increasing the air entry head in the gravel or the cobbles had the opposite result, allowing slightly more water to be stored. Figure 16 illustrates this increased storage when the cobble air entry head was increased. Also shown are the daily fluxes through the base of the cobble layer for 1986 as the cobble air entry head was increased. Although the water flow through the cobble barrier is still small (yearly flux of $7.7 \times 10^{-2} \mathrm{~cm}$ with a cobble air entry head of $24 \mathrm{~cm}$ vs. $5.7 \times 10^{-2} \mathrm{~cm}$ for the all effects combined simulation), it appears from the rapidly increasing peak flux in Figure 16 that increasing the cobble air entry head further could result in a significant amount of drainage.

This concludes the parametric sensitivity study for the capillary barrier. A similar suite of simulations was conducted for the thick soil barrier and will be discussed next.

\subsubsection{Thick Soil Barrier}

In the thick soil barrier parametric sensitivity study, the suite of hydraulic parameters were varied for the DAB soil and the native underlying soil. Variations in parameters were assigned in a similar fashion to the capillary barrier hydraulic parameters. The performance measure by which the results were judged was the maximum yearly drainage over the simulation period. The comprehensive results from the thick soil barrier parametric study are shown in Table 13. The 
Table 12. Parametric sensitivity results for capillary barrier.

\begin{tabular}{|c|c|c|c|c|c|c|c|c|}
\hline \multirow[b]{2}{*}{$\begin{array}{l}\text { DAB } \\
\text { Soil } \\
K\end{array}$} & \multirow[b]{2}{*}{$\begin{array}{c}\text { Max } \\
\text { storage } \\
\text { (cm) } \\
\end{array}$} & \multicolumn{5}{|c|}{ Saturated Hydraulic Conductivity, $\pi(\mathrm{cm} / \mathrm{hr})$} & \multirow[b]{2}{*}{$\begin{array}{c}\text { Max } \\
\text { Storage } \\
\text { (Cm) }\end{array}$} & \multirow[b]{2}{*}{ Change } \\
\hline & & Change & $\underset{K}{\text { Gravel }}$ & $\begin{array}{c}\text { Max } \\
\text { Storage } \\
\text { (cm) }\end{array}$ & Change & $\begin{array}{c}\text { Cobbles } \\
R\end{array}$ & & \\
\hline $\begin{array}{l}0.35 \\
0.684^{\circ} \\
1.4\end{array}$ & $\begin{array}{l}54.97 \\
54.40 \\
51.78\end{array}$ & $\begin{array}{c}1.0 \\
- \\
-4.8\end{array}$ & $\begin{array}{l}18 \\
36^{\circ} \\
72\end{array}$ & $\begin{array}{l}54.40 \\
54.40 \\
54.40\end{array}$ & $\begin{array}{c}0.0 \\
- \\
0.0\end{array}$ & $\begin{array}{c}900 \\
1800^{\circ} \\
3600\end{array}$ & $\begin{array}{l}54.40 \\
54.40 \\
54.40\end{array}$ & $\begin{array}{c}0.0 \\
0.0\end{array}$ \\
\hline
\end{tabular}

\section{Saturated Moisture Content, $\theta$.}

\begin{tabular}{|c|c|c|c|c|c|c|c|c|}
\hline $\begin{array}{l}\text { DAB } \\
\text { Soil } \\
\theta .\end{array}$ & $\begin{array}{c}\text { Max } \\
\text { Storage } \\
\text { (cm) }\end{array}$ & Change & $\begin{array}{c}\text { Gravel } \\
\theta .\end{array}$ & $\begin{array}{c}\text { Max } \\
\text { Storage } \\
\text { (Cm) }\end{array}$ & Change & $\begin{array}{c}\text { Cobbles } \\
\theta_{\text {. }}\end{array}$ & $\begin{array}{c}\text { Max } \\
\text { Storage } \\
\text { (cm) }\end{array}$ & Change \\
\hline $\begin{array}{l}0.4 \\
0.501 . \\
0.6\end{array}$ & $\begin{array}{l}48.61 \\
54.40 \\
59.69\end{array}$ & $\begin{array}{r}-10.6 \\
\overline{9} .7\end{array}$ & $\begin{array}{l}0.3 \\
0.417^{\circ} \\
0.5\end{array}$ & $\begin{array}{l}54.30 \\
54.40 \\
54.48\end{array}$ & $\begin{array}{c}-0.2 \\
- \\
0.1\end{array}$ & $\begin{array}{l}0.4 \\
0.5^{\circ} \\
0.6\end{array}$ & $\begin{array}{l}54.40 \\
54.40 \\
54.41\end{array}$ & $\begin{array}{l}0.0 \\
0.0\end{array}$ \\
\hline
\end{tabular}

Residual Moisture Content, $\theta_{r}$

\begin{tabular}{|c|c|c|c|c|c|c|c|c|}
\hline $\begin{array}{l}\text { DAB } \\
\text { Soil } 1 \\
\theta_{r}\end{array}$ & $\begin{array}{c}\text { Max } \\
\text { storage } \\
\text { (cm) }\end{array}$ & $\stackrel{8}{\text { Change }}$ & $\underset{\theta_{\mathbf{r}}}{\operatorname{Gravel}}$ & $\begin{array}{c}\text { Max } \\
\text { Storage } \\
\text { (cm) }\end{array}$ & $\stackrel{8}{\text { Change }}$ & $\begin{array}{c}\text { Cobbles } \\
\theta_{r}\end{array}$ & $\begin{array}{c}\text { Max } \\
\text { Storage } \\
\text { (cm) }\end{array}$ & Change \\
\hline $\begin{array}{l}0.007^{\circ} \\
0.014 \\
0.028 \\
0.056\end{array}$ & $\begin{array}{l}54.40 \\
55.00 \\
56.12 \\
58.52\end{array}$ & $\begin{array}{l}- \\
1.1 \\
3.3 \\
7.6\end{array}$ & $\begin{array}{l}0.006 " \\
0.012 \\
0.024\end{array}$ & $\begin{array}{l}54.40 \\
54.48 \\
54.65\end{array}$ & $\begin{array}{l}- \\
0.2 \\
0.5\end{array}$ & $\begin{array}{l}0.003^{\circ} \\
0.006 \\
0.012 \\
0.024\end{array}$ & $\begin{array}{l}54.40 \\
54.63 \\
55.09 \\
56.00\end{array}$ & $\begin{array}{l}-. \\
0.4 \\
1.3 \\
2.8\end{array}$ \\
\hline
\end{tabular}

Air Entry Head, $h_{0}(\mathrm{~cm})$

\begin{tabular}{|c|c|c|c|c|c|c|c|c|}
\hline $\begin{array}{l}\text { DAB } \\
\text { Soil } \\
h_{e}\end{array}$ & $\begin{array}{c}\text { Max } \\
\text { Storage } \\
\text { (cm) }\end{array}$ & $\stackrel{8}{\text { Change }}$ & $\underset{h_{e}}{\operatorname{Gravel}}$ & $\begin{array}{c}\text { Max } \\
\text { Storage } \\
\text { (cil) }\end{array}$ & Change & $\underset{h_{0}}{\text { Cobbles }}$ & $\begin{array}{c}\text { Max } \\
\text { Storage } \\
\text { (cm) }\end{array}$ & $\stackrel{8}{\text { Change }}$ \\
\hline $\begin{array}{l}20.76^{\circ} \\
40.0 \\
60.0\end{array}$ & $\begin{array}{l}54.40 \\
52.10 \\
50.92 \\
\end{array}$ & $\begin{array}{c}-\overline{-} .2 \\
-6.4 \\
\text { from a } 11\end{array}$ & $\begin{array}{r}6.53^{\circ} \\
12.0 \\
24.0 \\
\text { effects co }\end{array}$ & $\begin{array}{l}54.40 \\
54.58 \\
54.88\end{array}$ & $\begin{array}{c}0.3 \\
0.9 \\
\text { nulation }\end{array}$ & $\begin{array}{r}3.0^{*} \\
6.0 \\
12.0 \\
24.0\end{array}$ & $\begin{array}{l}54.40 \\
54.42 \\
54.49 \\
54.63\end{array}$ & $\begin{array}{l}- \\
0.0 \\
0.2 \\
0.4\end{array}$ \\
\hline
\end{tabular}




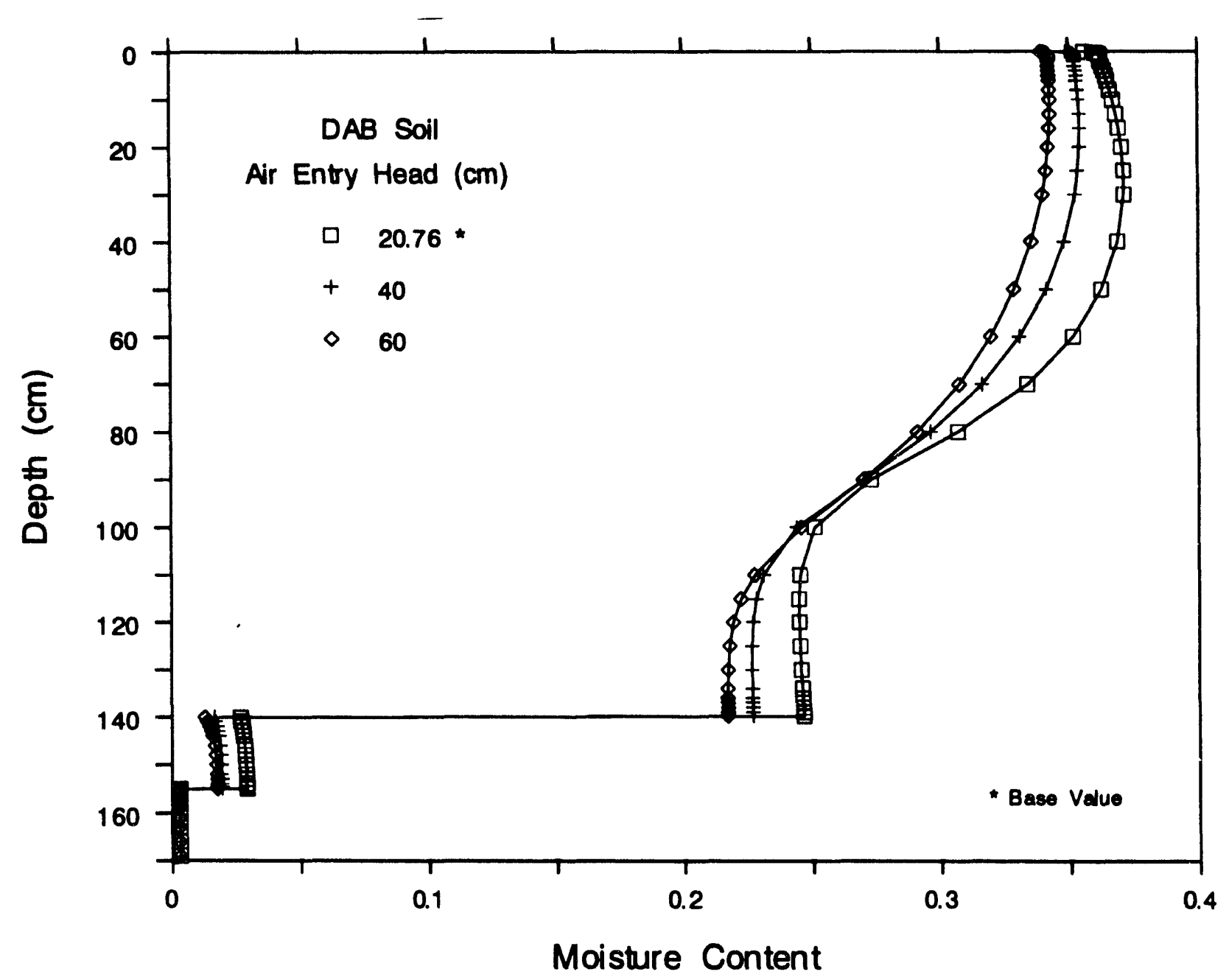

Figure 15. Moisture content profile corresponding to day of maximum stored water for three DAB soil air entry heads. 
a)

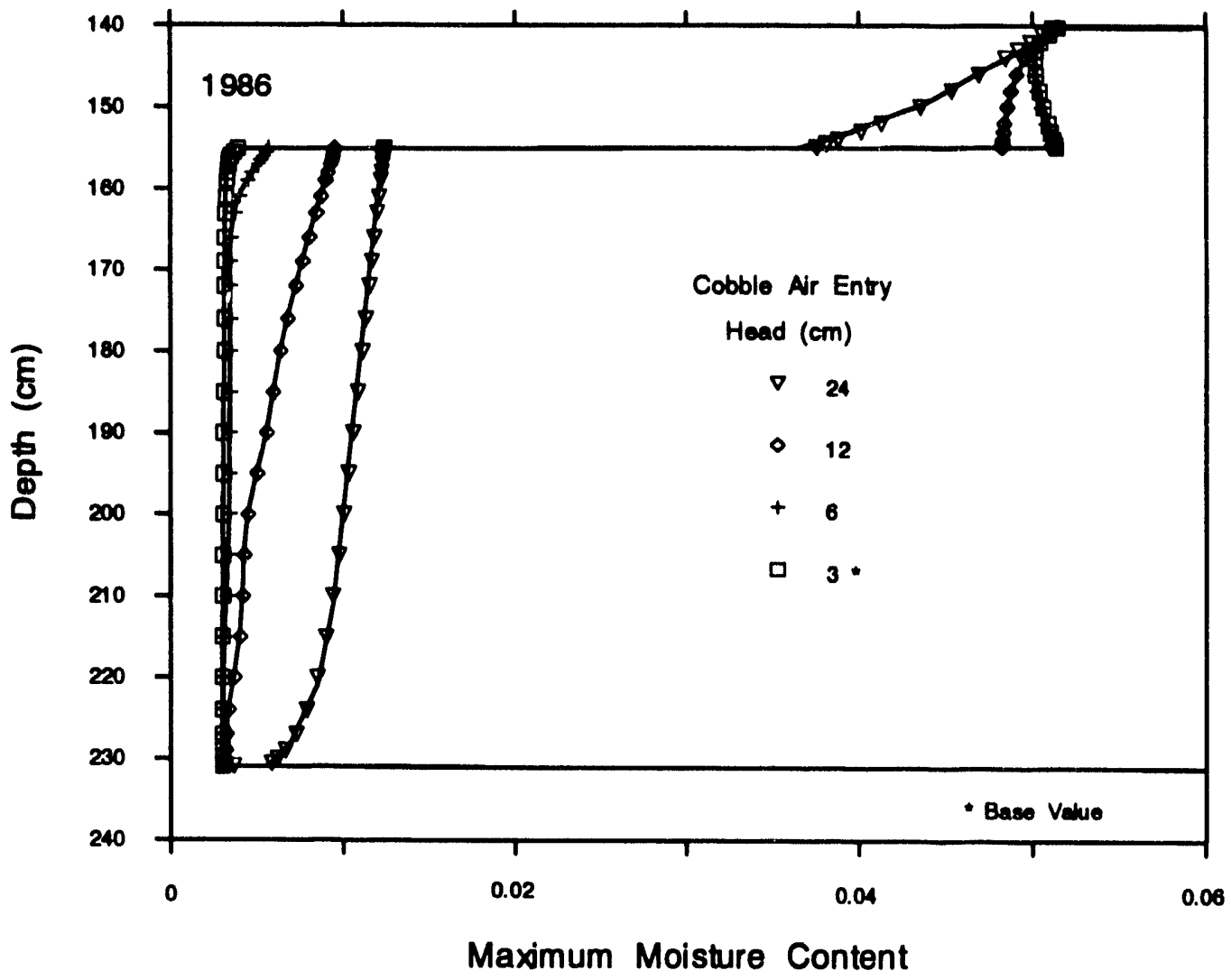

b)

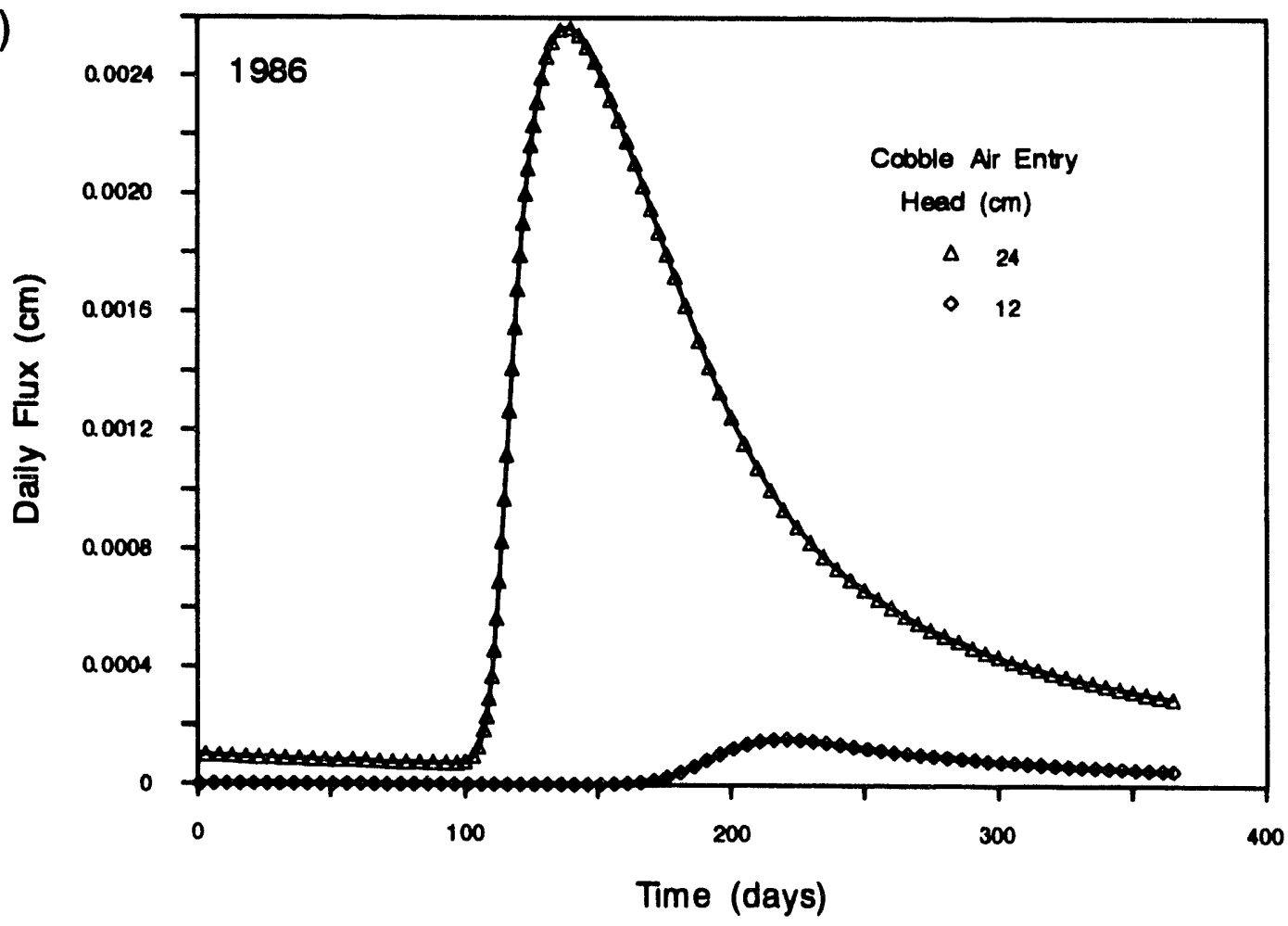

Figure 16. Effect of cobble air entry head on (a) maximum moisture content trace in cobbles and b) daily flux down through cobbles. 
Table 13. Parametric sensitivity results for thick soil barrier.

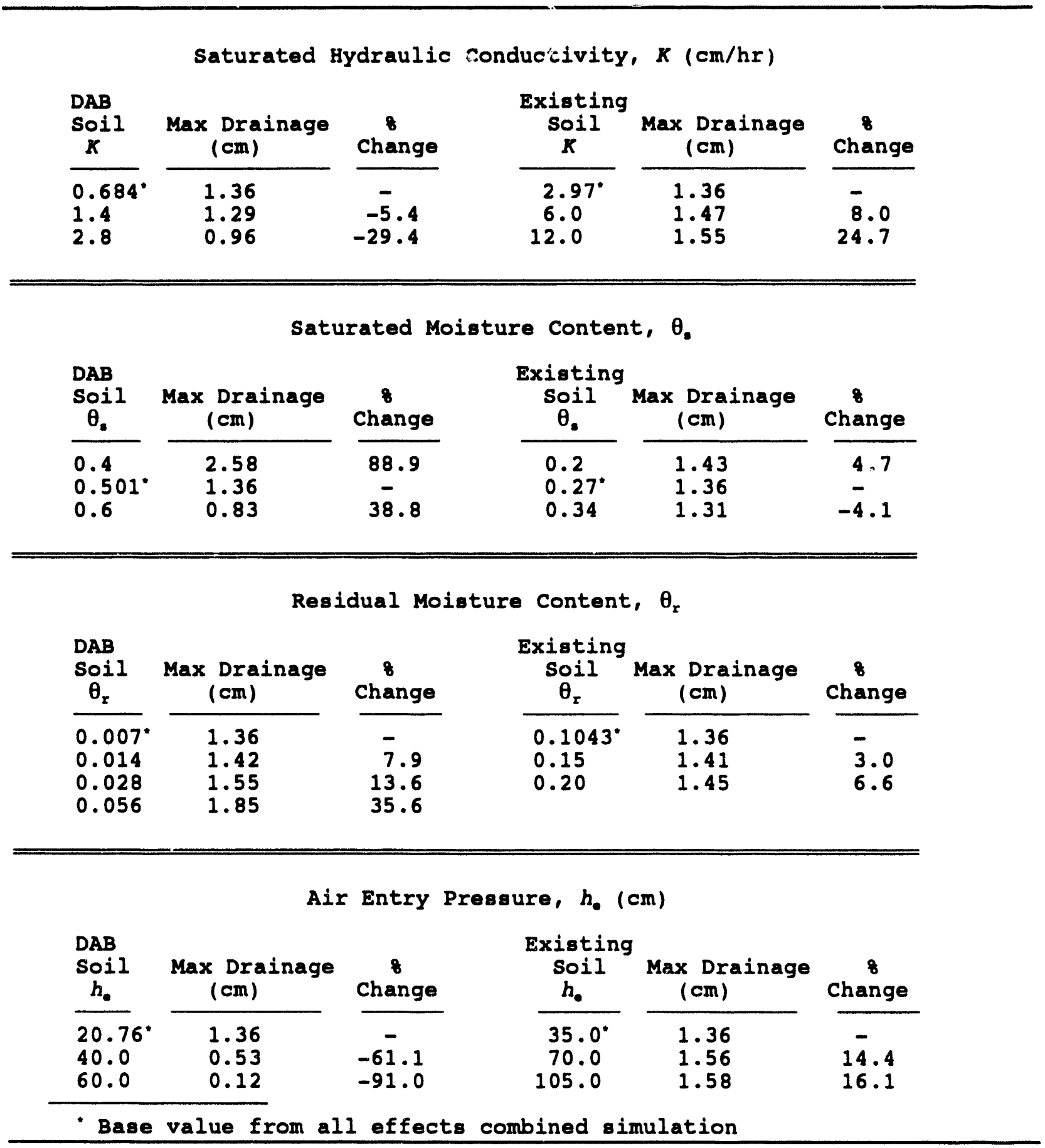


base value in each case was that from the combined transpiration and snow cover thick soil barrier simulation. Again, this basis was chosen because it represents the best estimate of barrier performance based on the proposed designs.

By comparing the results in Table 13, it can be seen that drainage variation is more sensitive to the DAB parameters than the native or underlying soil parameters. This result is reasonable since the DAB soil overlies the native soil and is more affected by the variable meteorological conditions at the upper boundary.

Some interesting results are contained in the table. Firstly, drainage decreases as the DAB soil conductivity increases, while drainage increases as the underlying soil conductivity increases. Increasing the conductivity of the DAB soil allowed wetting fronts to penetrate deeper into the DAB soil, but it also allowed that same water to be extracted back to the surface more easily. In contrast, higher conductivity in the underlying soil allowed any water that did penetrate below the $D A B$ soil to drain more easily. Increasing the effective porosity for both the DAB and the underlying soils resulted in less drainage overall, less for the DAB soil than for the underlying soil. The increased porosity allowed for greater storage, allowing more opportunity for water to be extracted back to the surface. Increasing the residual moisture content for both soils kept the subsurface wetter overall, allowing more drainage. Lastly, increasing the air entry head in the DAB soil allowed infiltrating water to be brought back to the surface more easily. In contrast, increasing the air entry head in the underlying soil allowed water to enter from the DAB soil into the underlying soil more easily and thus increased drainage.

\subsubsection{Parametric Sensitivity Results Summary}

Since the overall performance objective in terms of drainage has yet to be defined, conclusive statements about the precision with which the hydraulic parameters need to be known cannot be made based on the information gained from this parametric sensitivity analysis. However, if the assumption is made that the performance objective will be the same as that for the Hanford cover project, the drainage through the cover should be less than $0.05 \mathrm{~cm} / \mathrm{yr}$ (Fayer, 1990).

In this framework, the values assigned for hydraulic parameters of the gravel layer of the capillary barrier are very important as shown by the simulations with infilling. The gravel parameters need to be determined on a site-specific basis rather than strictly relying on literature values. The properties of the cobble layer were less critical and should be treated as if they were the same as the gravel. The hydraulic characteristics of the DAB soil will need to be defined with considerable precision since it is the uppermost soil in either barrier and is most influenced by meteorological conditions at the surface. The thick soil barrier parametric results showed the greatest sensitivity to the air entry head and the porosity. The saturated hydraulic conductivity and residual moisture content had a lesser effect. The degree of precision with which all these parameters need to be determined will have to be based on the eventual performance measure for the maximum allowed drainage rate. 


\section{TIME TO EQUILIBRIUM}

The second main objective in this simulation study was to estimate the time required for the moisture content profile within both proposed barriers to come into equilibrium with the meteorological conditions at the surface. As the test plots of the two barriers are built, the moisture content will be monitored to ensure uniform compaction. This will result in a uniform soil moisture profile, at least for the DAB soils in each design. Once the cover construction is completed, this soil moisture profile will begin to respond to forces of gravity and capillarity and to the surface meteorological conditions resulting in redistribution of soil water. In unsaturated systems, this movement can be quite slow, on the order of years. The monitoring period for the test plots will have to be long enough to ensure that measurements being taken are representative of the performance of the barrier and not just the redistribution of the initial moisture profile.

Since the meteorological conditions at the surface are variable, a true equilibrium will never be established. Moisture contents will continually vary in response to surface conditions.

However, by looking at the response of the soil moisture profile as a function of depth and time, an estimate of when the system comes into an approximate or quasi-equilibrium can be made.

Two approaches were used to estimate quasi-equilibrium in this study. Both considered the response of the soil moisture profile in terms of daily moisture fluxes near the bottom of the DAB soil layers and either in the gravel layer for the capillary barrier or near the top of the existing soil for the thick soil barrier. The first approach consisted of repetitively simulating a decade of meteorological data. The second considered repeating only 1 year of meteorological data. Using both these methods provided a bounding estimate of the time necessary to reach equilibrium. Each of these approaches will be discussed in turn.

\subsection{Repetitive Decade Simulation}

Simulations were performed for both the capillary and thick soil barriers using the same decade of meteorological data repetitively. For both barriers, the first decade of the simulation was completed previously in the sensitivity study. For the second decade, the ending conditions from the last year of the 1981-1990 simulation was used as the initial condition and the entire 1981-1990 meteorological data was reused as if it were 1991-2000 data. By looking at daily fluxes through selected depths for both the 1981-1990 and 1991-2000 periods simultaneously, an estimate of when equilibrium occurred could be made. For completeness, all the equilibrium simulations included both transpiration and a snow cover.

\subsubsection{Capillary Barrier}

Figure 17a shows the daily flux near the base of the DAB soil layer for both the 1981-1990 and 1991-2000 simulation periods superimposed onto the same 10-year time period. Positive fluxes represent downward water movement, and negative fluxe: represent upward movement. The only difference between these two simulation periods is the starting conditions. The assumed initial conditions for the first decade were quite wet by comparison to those from the second decade. The effects of a prolonged drought from approximately 1986 through 1990 (years 6 through 10) can be seen by the predominance of upward fluxes and the low positive peaks for the 
a)

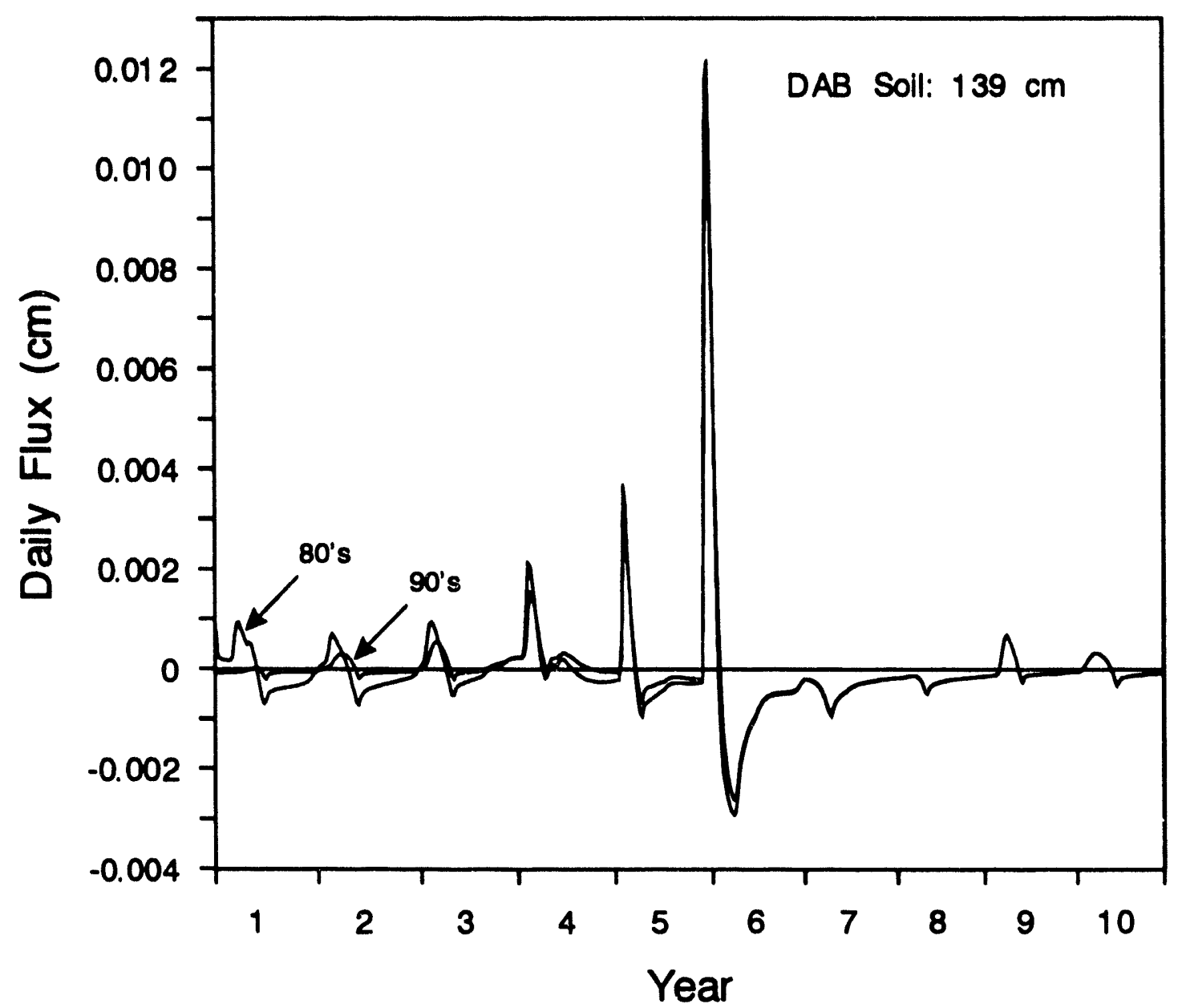

b)

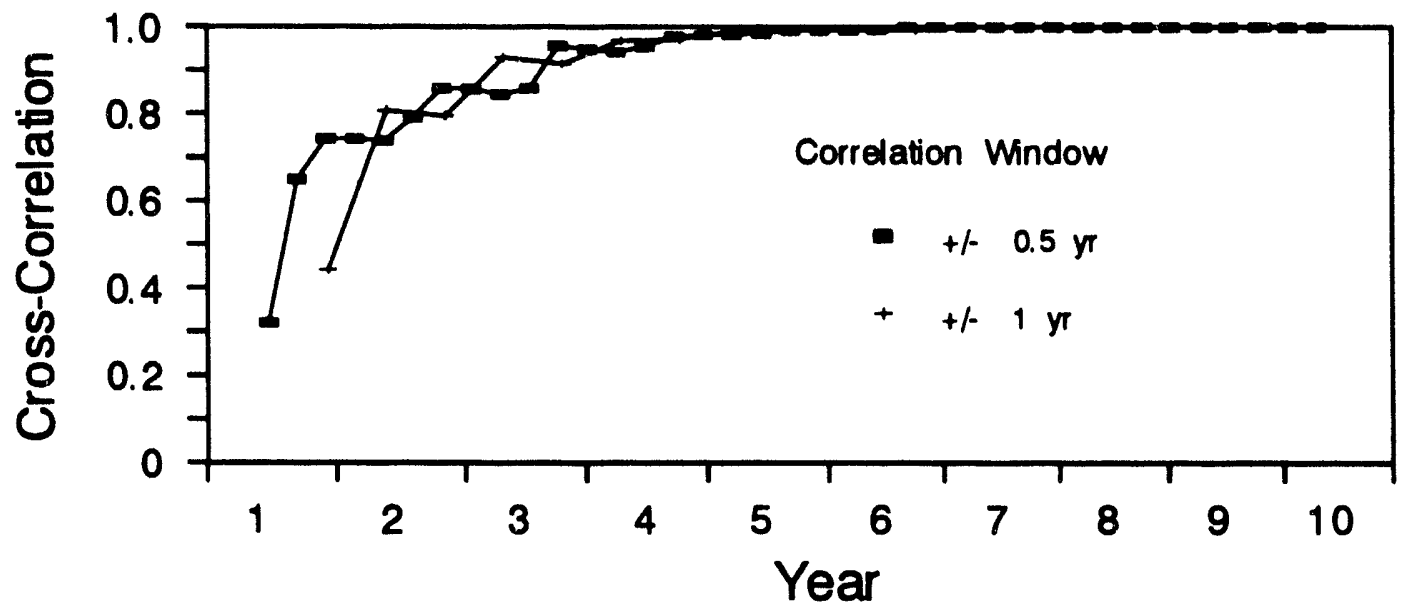

Figure 17. Repetitive decade simulation results for capillary barrier: (a) daily flux near base of DAB soil and (b) cross-correlation between decades. 
occasional downward fluxes. This prolonged drought resulted in a very dry initial condition for the second decade. These dry initial conditions resulted in very slow water movement, especially in the gravel layer, during the first several years of the second decade. As a result, comparing these two simulation periods against each other provides a conservative estimate of the time to reach equilibrium.

Equilibrium can be considered to occur when the two simulations converge. This convergence is qualitatively difficult to determine. After 2 years, the simulations appear, for the most part, to have the same character in increases and decreases in fluxes. Most assuredly, after 5 years, this is the case. To overcome this problem with qualitative estimation, convergence was determined by calculating the cross-correlation between the two simulations. Figure $17 \mathrm{~b}$ shows the cross-correlation between the simulation results for the two decades. Two different windows or lengths of times were used to calculate this cross-correlation to test the sensitivity to the window length. The shorter window, $+/-0.5$ years, would be expected to be more noisy but actually mimics the longer window quite well. For this study, equilibrium was said to be achieved when the correlation between the two simulations reached 0.9 . From Figure $17 \mathrm{~b}$, then, equilibrium can be conservatively said to have occurred after 3.5 years. This estimate is valid from the barrier surface down to the base of the DAB soil layer.

Figure 18a and $18 \mathrm{~b}$ show a similar time history of fluxes for the two decades and their crosscorrelation within the gravel layer. The effect of the prolonged drought at the end of the first decade are even more pronounced in the daily fluxes through the gravel layer at the beginning of the second decade than it was in the DAB soil. Virtually no water movement occurred until the fourth year. The slow response of the water profile in the gravel is due to the extremely dry conditions at the end of the first decade. This slow response provides a conservative estimate of the time required to reach equilibrium.

For the flux through the gravel results, the shorter correlation window is considerably more noisy than the longer window. The cross-correlation between the two decades reached 0.9 after approximately 5 years and thus provides an estimate of the time required to reach equilibrium within the gravel layer.

\subsubsection{Thick Soll Barrier}

A similar repetitive decade simulation was performed for the thick soil barrier. Figures 19a and $19 \mathrm{~b}$ show the daily fluxes at $185 \mathrm{~cm}$ within the DAB layer for the thick soil barrier for the two decades and the cross-correlation between the results. The flux results show a greater difference in magnitude than those from the capillary barrier simulation. Additionally, the flux is always downwards. This difference is due to the capillary barriers performance, which essentially prevents all water from continuing downward. The estimated time to equilibrium for the thick soil barrier repetitive decade simulation is somewhere between 4.5 and 5 years. A strict interpolation of the 0.9 cross-correlation yields 4.8 years. This is approximately 1 year longer than for the DAB soil in the capillary barrier.

The daily flux through the top of the existing soil was also analyzed. These results are shown in Figure 20. The divergence between the fluxes between the decades is slightly more pronounced than in the overlying DAB soil and persists longer. However, an estimate of 
a)

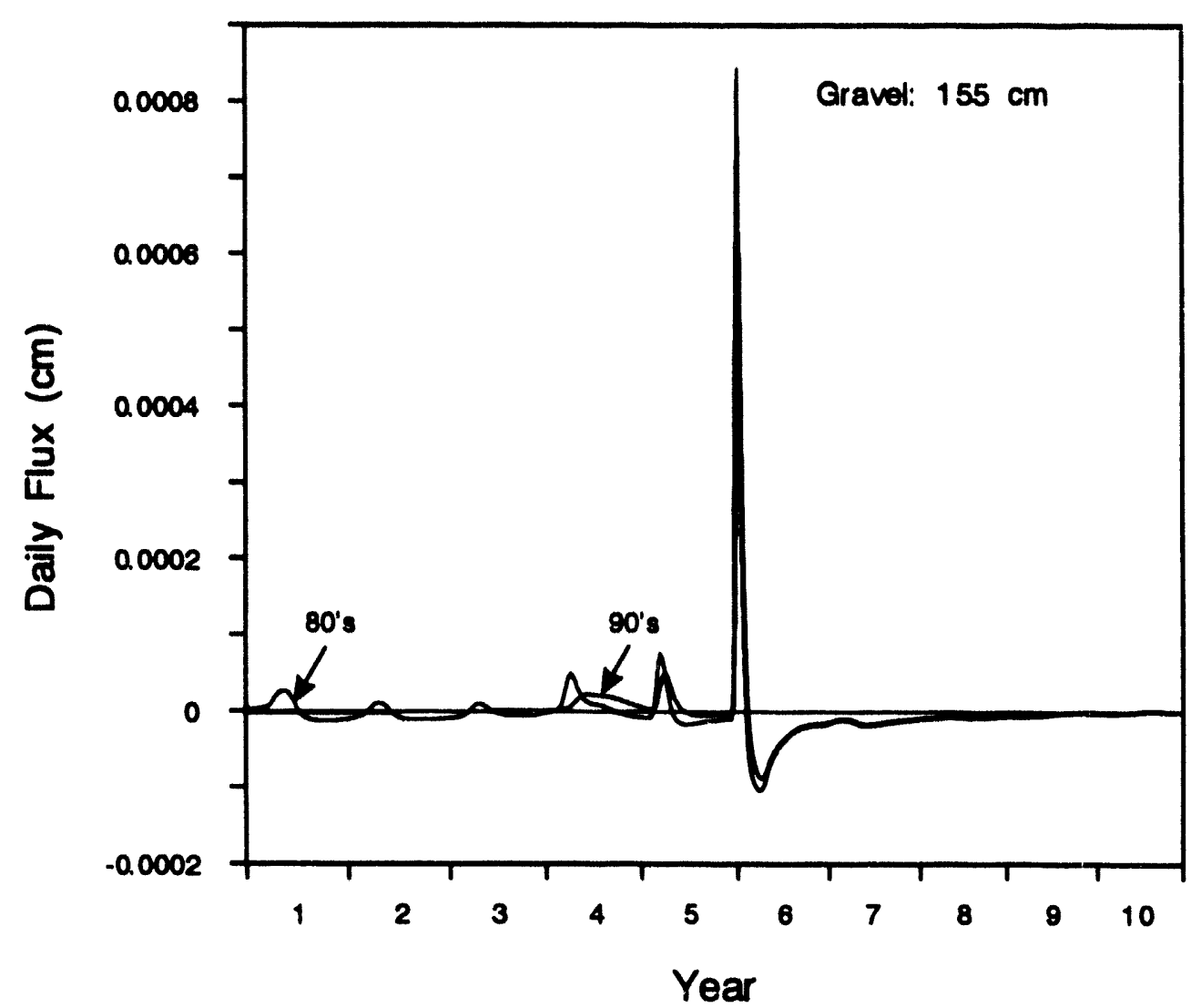

b)

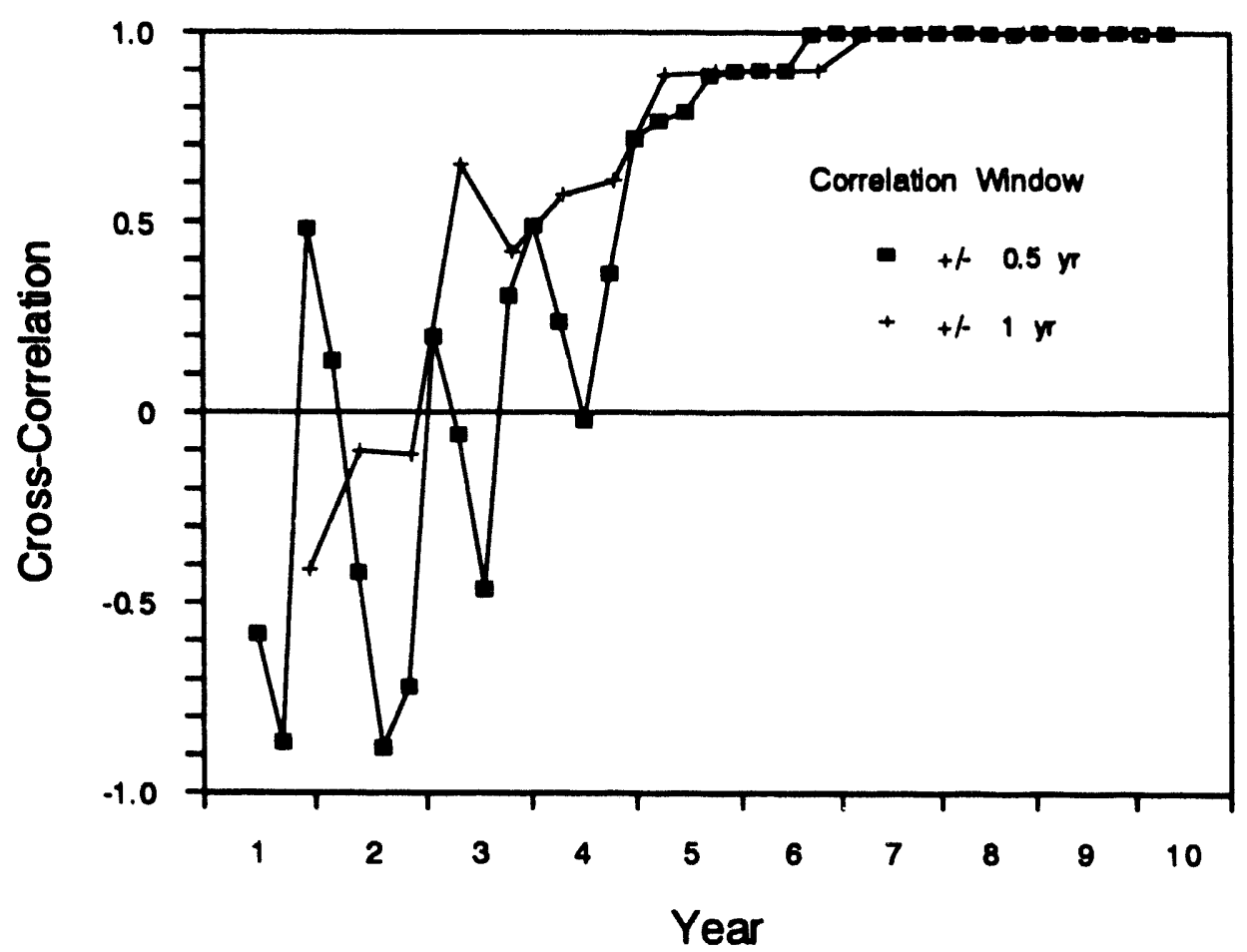

Figure 18. Repetitive decade simulation results for capillary barrier: (a) daily flux through the gravel and (b) cross-correlation between decades. 
a)

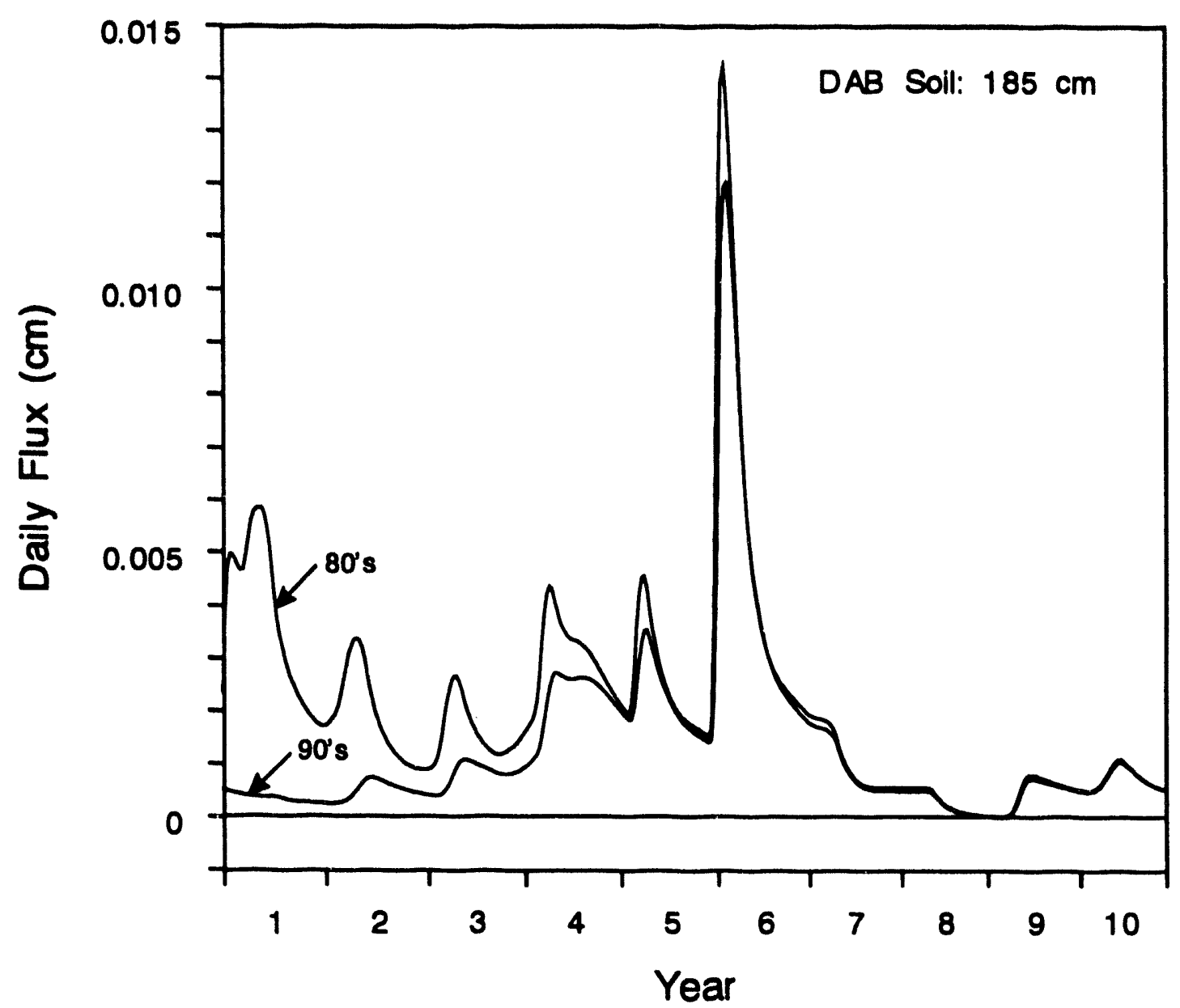

b)

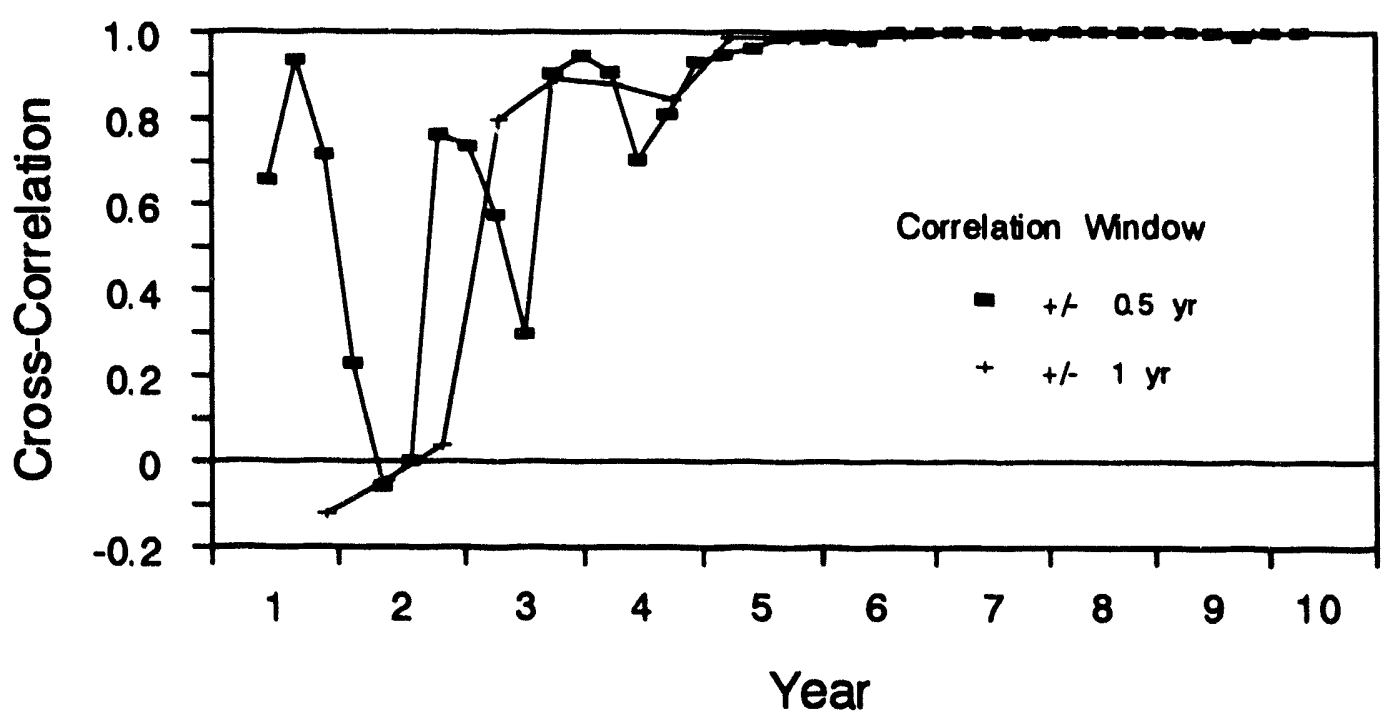

Figure 19. Repetitive decade simulation results for thick soil barrier: (a) daily flux at $185 \mathrm{~cm}$ in DAB soil and (b) cross-correlation between decades. 
a)

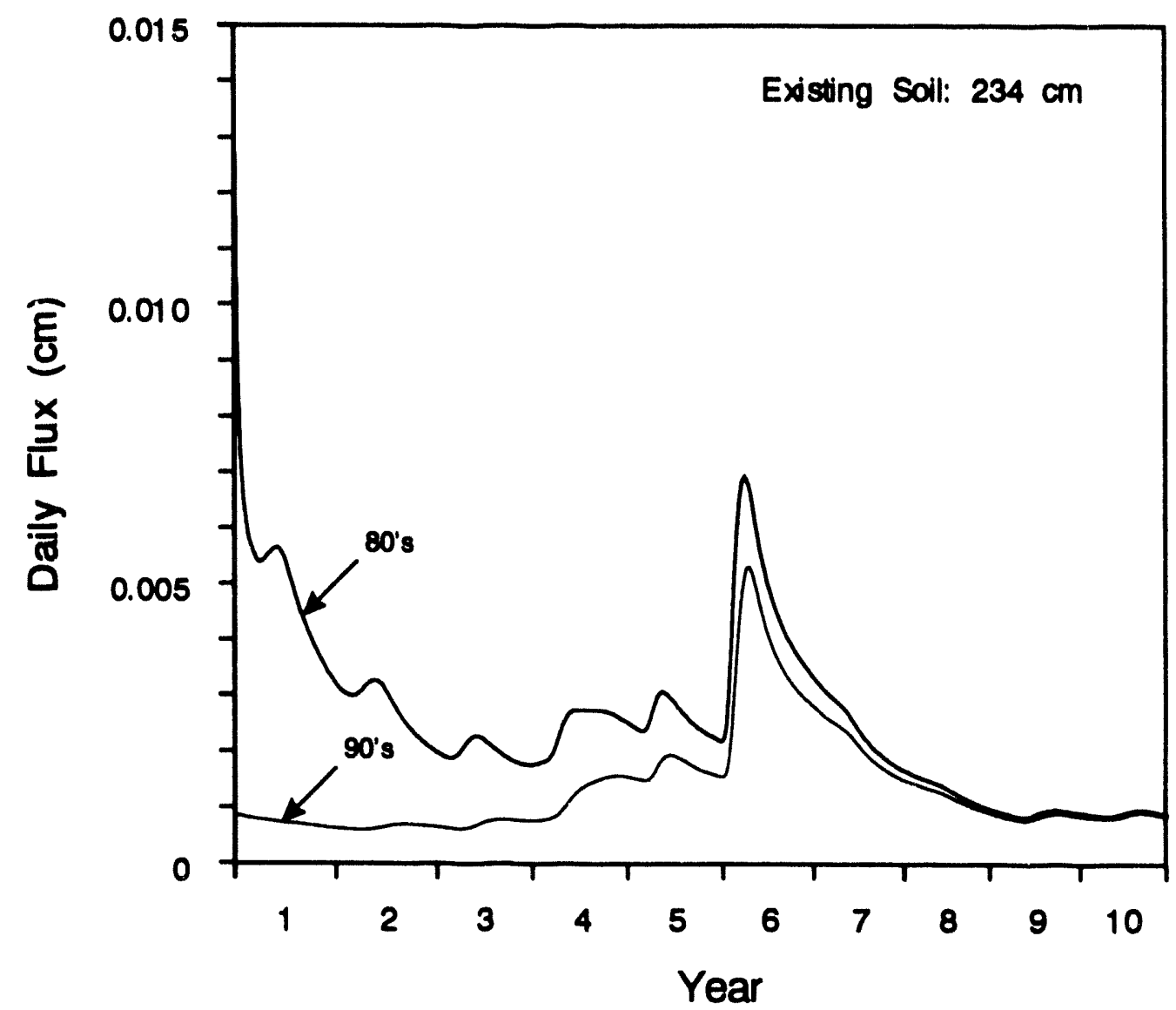

b)

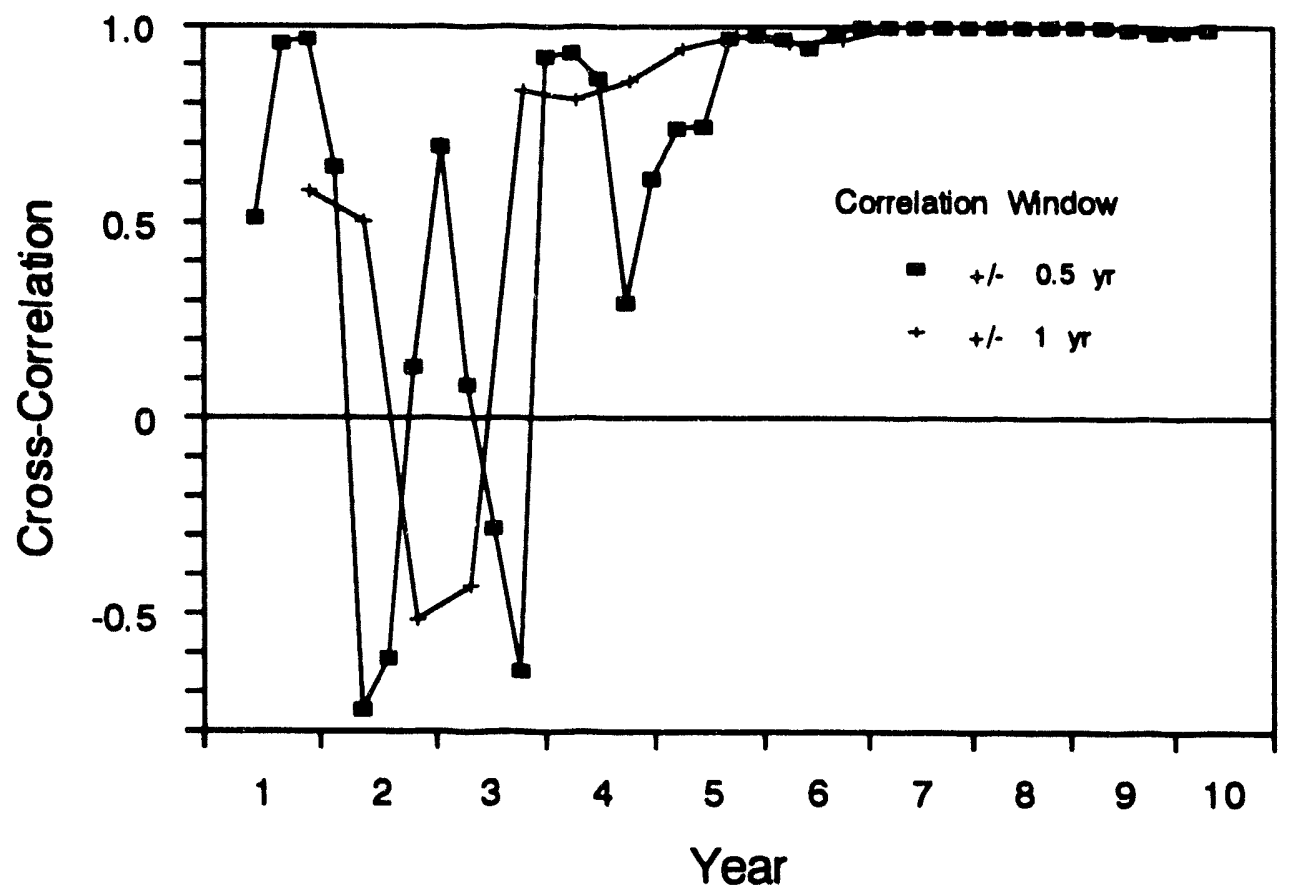

Figure 20. Repetitive decade simulation results for thick soil barrier: (a) daily flux through the existing soil and (b) cross-correlation between decades. 
equilibrium based on 0.9 cross-correlation is 4.5 years, slightly less than for the overlying DAB soil.

\subsection{Repetitive Year Simulation}

Simulations were conducted for both barrier designs using 1 year of meteorological data repetitively. This provided another estimate of the time required to reach equilibrium to compare with that from the repetitive decade simulation. Since the same meteorological conditions occurred from one year to the next, equilibrium should occur more quickly. This provides an optimum or best-case estimate of the shortest time required to reach equilibrium. The year chosen for use in the repetitive simulations was 1981 . Based on the daily flux through the base of the DAB layers (Figure 17), 1981 could be considered a representative year. It certainly is between the wettest year, 1986, and the drought conditions during the latter 4 years of the decade.

The simulations were performed by first using the initial conditions as described previously (Section 2.2) and simulating for 1 year with the 1981 meteorological data. Then, the ending conditions for that year were used as the initial conditions for the second year in which the same 1981 meteorological data were used again. This process was repeated for several years until the fluxes at depths closely followed the same pattern from one year to the next. The results for the capillary barrier simulation will be discussed first followed by those for the thick soil barrier.

\subsubsection{Capillary Barrier}

The daily flux at the base of the DAB soil in the capillary barrier for the repetitive year simulation is shown in Figure 21a. The results from 5 years of simulation are superimposed onto the same 1-year time axis. As expected, the simulation comes quickly into equilibrium as can be seen when years 2-5 essentially mimic each other. The difference in the early part of the first year is due to initial excess drainage as a result of the assigned uniform initial moisture profile. The fluxes appear to converge just after February on the second year. This is bome out in Figure $21 \mathrm{~b}$, which shows the cross-correlation for two different-sized time windows between the first and second years. The cross-correlation reaches 0.9 at slightly over 1.5 months ( 0.1 years).

Slightly deeper in the gravel layer, the daily flux results are similar (Figure 22). Excess drainage also occurs as can be seen by the steep slope on the January segment of the first-year results. The flux appears to take somewhat longer to reach equilibrium, approximately 6 months. The cross-correlations in Figure $22 \mathrm{~b}$ were calculated with slightly longer windows than those for the fluxes at the base of the DAB soil layer. This was necessitated by the noisiness of the crosscorrelations between the gravel fluxes from one year to the next. Correlations for years 1-2, 2-3, and 3-4 are shown. A persistent drop in correlation occurs at the end (or beginning) of each year, which prevents a quantitative estimate of time to equilibrium. This drop in correlation is likely due to the numerical solution being restarted each year with a slight loss of accuracy. For this particular case, the estimate of 6 months to equilibrium will be used based strictly on the convergence of the fluxes. 
a)

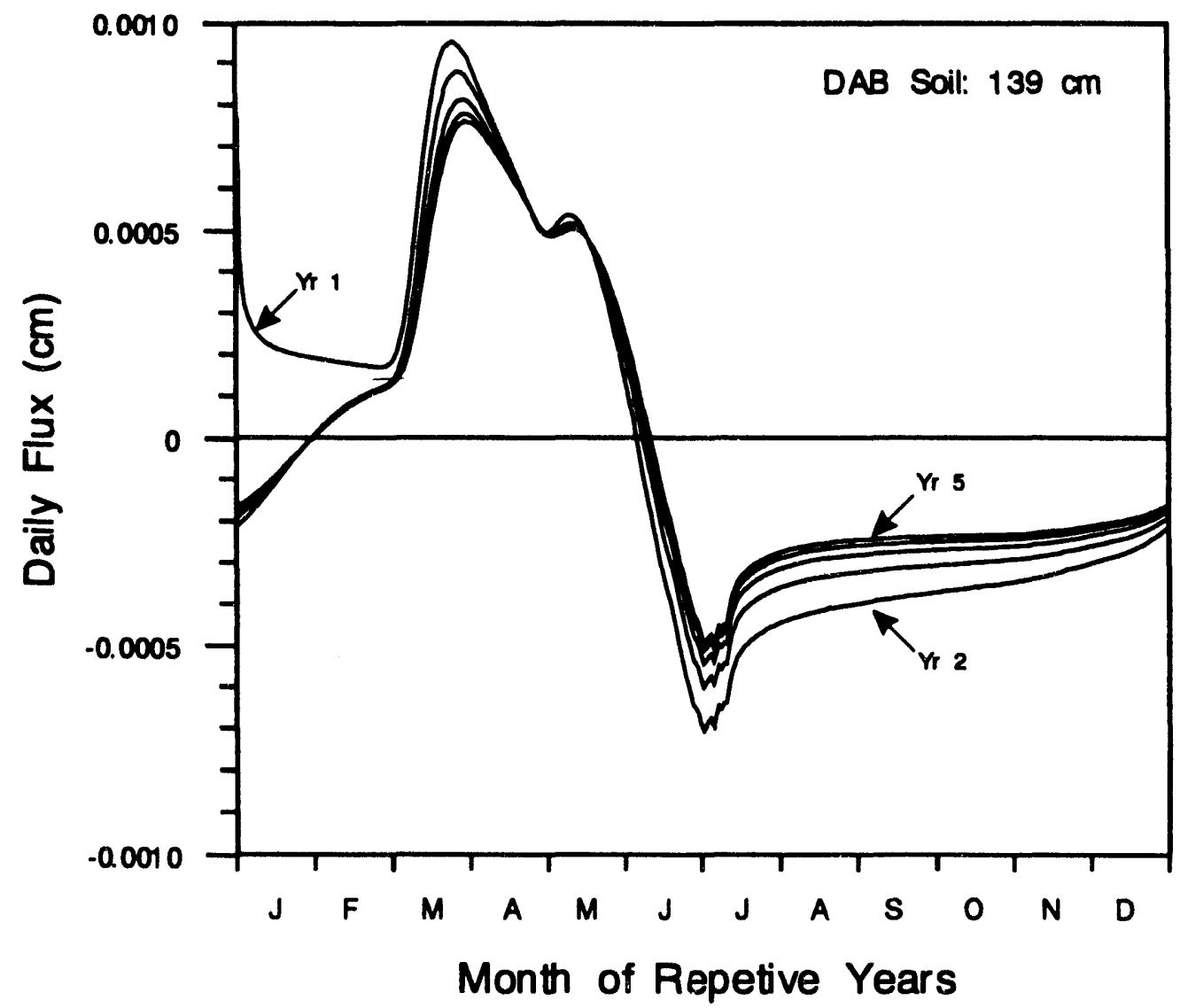

b)

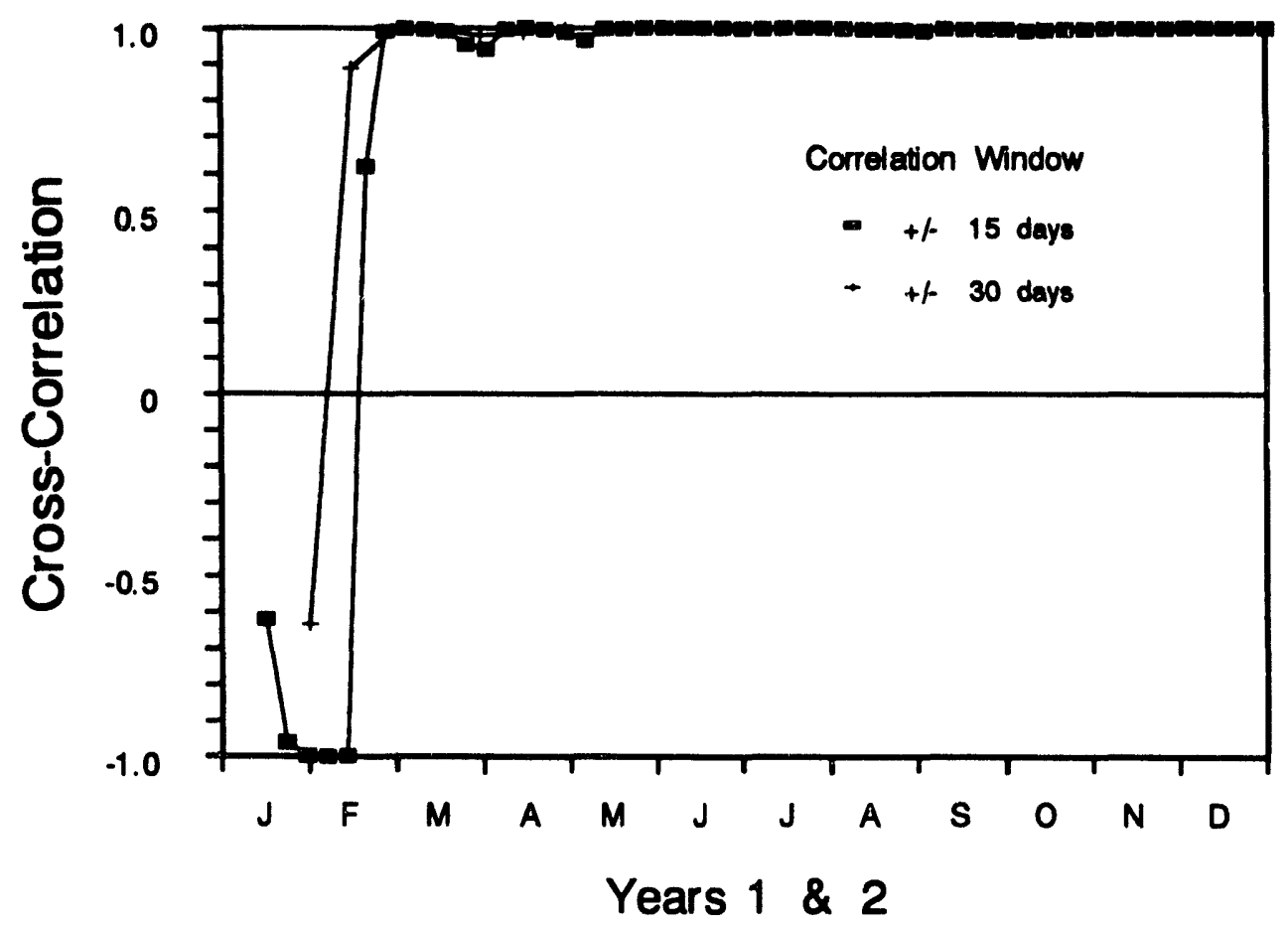

Figure 21. Repetitive year simulation results for capillary barrier: (a) daily flux near base of DAB soil and (b) cross-correlation between first and second years. 
a)

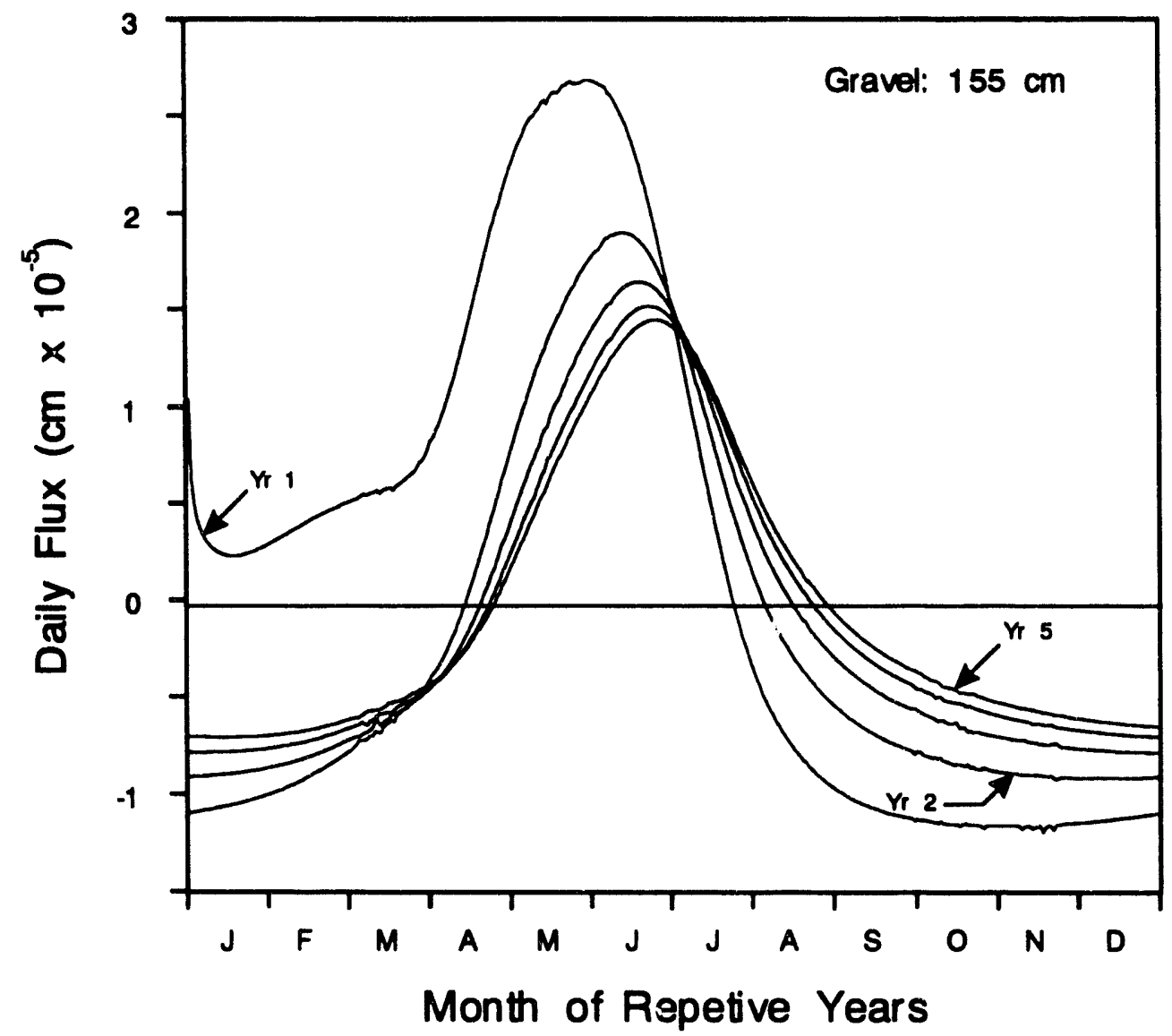

b)

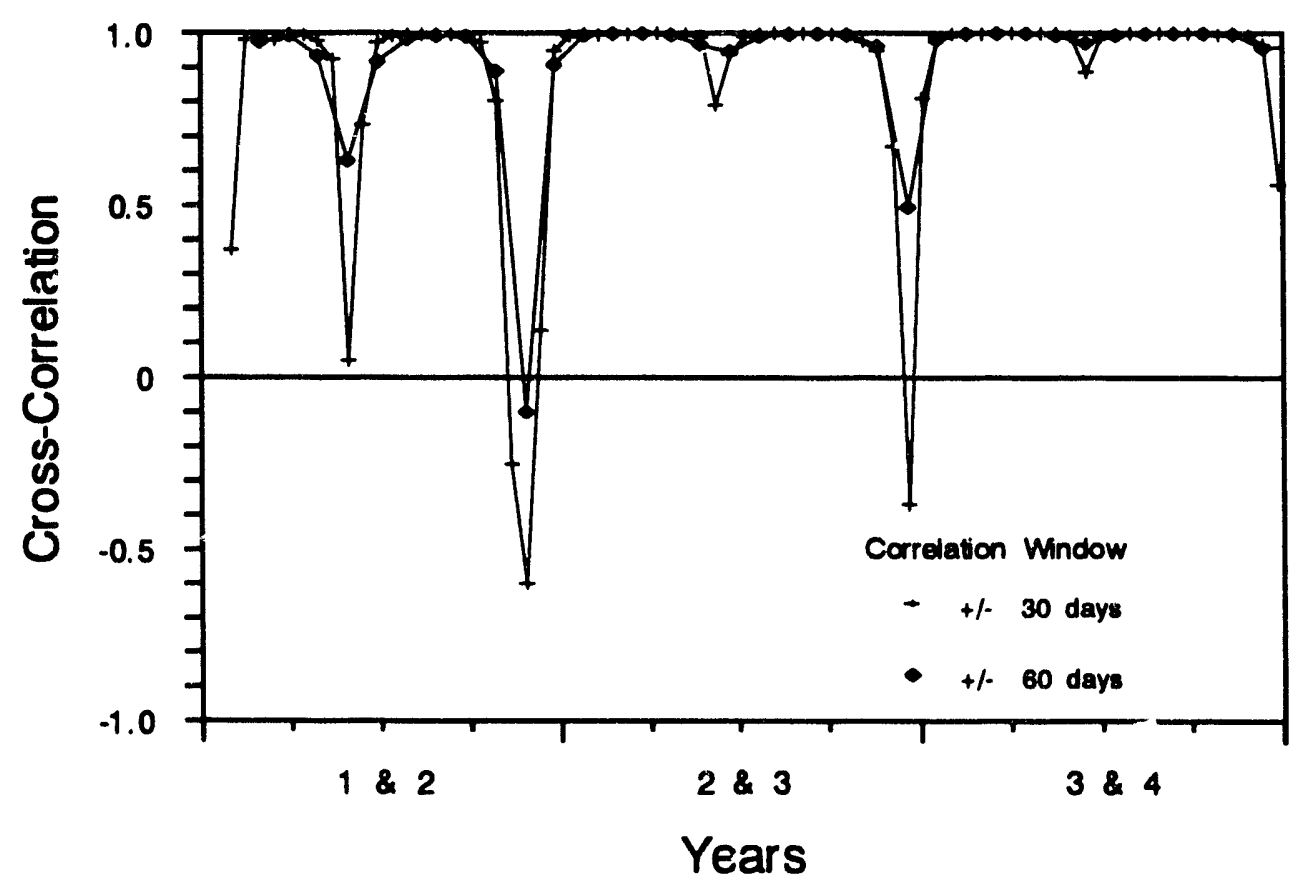

Figure 22. Repetitive year simulat' a results for capillary barrier: (a) daily flux in gravel and (b) cross-correlation between successive years. 


\subsubsection{Thick Soll Barrier}

The same repetitive year simulation process was performed on the thick soil barrier. The daily flux results for the $185-\mathrm{cm}$ depth in the DAB soil are given in Figures 23a and 23b. As can be seen, a longer time is required for the daily fluxes to come into equilibrium, somewhere around August or September. This longer time is due to the absences of the capillary barrier preventing downward movement of water. The time at which the cross-correlation reaches 0.9 is just over 6 months and is estimated as 0.6 years.

Lastly, the daily fluxes near the top of the existing soil are shown in Figure 24a. The vertical axis is truncated at the top to both match the axis from Figure 23a and to allow sufficient detail to be seen in the daily flux results for successive years. The primary difference in the first year is again drainage as a result of the initial conditions. The fluxes appear to begin converging in the latter half of the first years. From the cross-correlations in Figure 24b, this time to convergence was estimated as 0.7 years.

\subsection{Summary of Equilibrium Results}

In summary, the two simulation approaches of repetitive decades and years provided bounding estimates of the time required for the moisture content profiles to reach equilibrium with the surface meteorological conditions. The repetitive decade simulations provided a conservative or maximum time to equilibrium while the repetitive year simulations provided the shortest time. Table 14 summarizes the results of all the equilibrium simulations. The actual equilibration time is likely somewhere between the extremes indicated in the table. The dry initial conditions at the end of the repetitive decade simulation caused by a protracted drought are likely more extreme and less representative than the wetter initial conditions of the repetitive year simulations. For this reason, the equilibrium time is likely closer to that predicted by the repetitive year simulation than by the repetitive decade simulation. How much closer requires subjective judgement at this point. Depending on the sequence of weather during the first several years after construction, it could take anywhere from 1 to 3 years for the soil moisture profile to come into equilibrium, with 3 years certainly being a conservative estimate. The monitoring period for the test plots should consider this initial 1-to-3-year period as the minimum time period after which the performance of the barriers would be representative of a response to surface meteorological conditions rather than to the initial conditions. In any event, evaluation of data collected during this period would provide the best estimates of when equilibrium was reached. 
a)

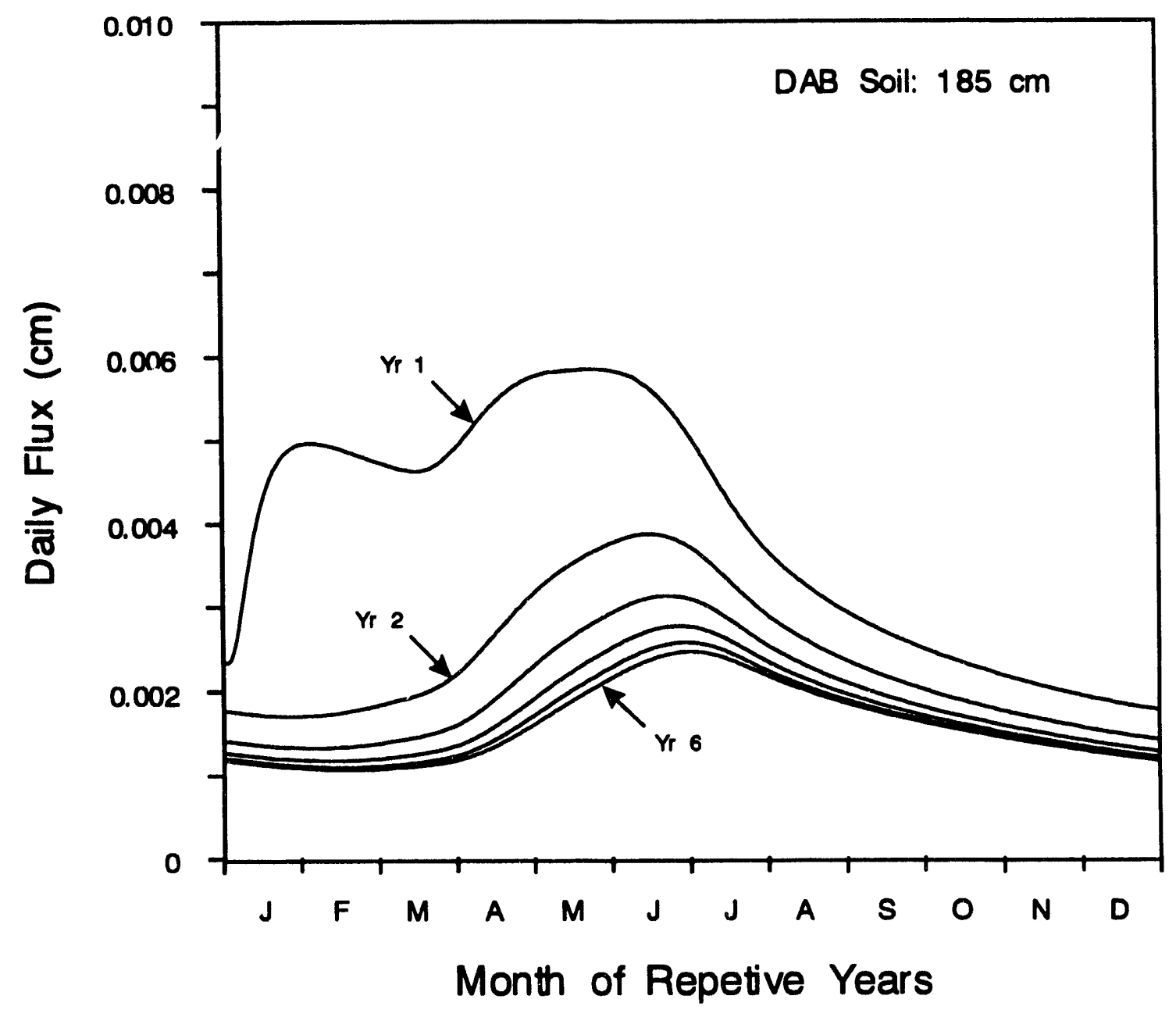

b)

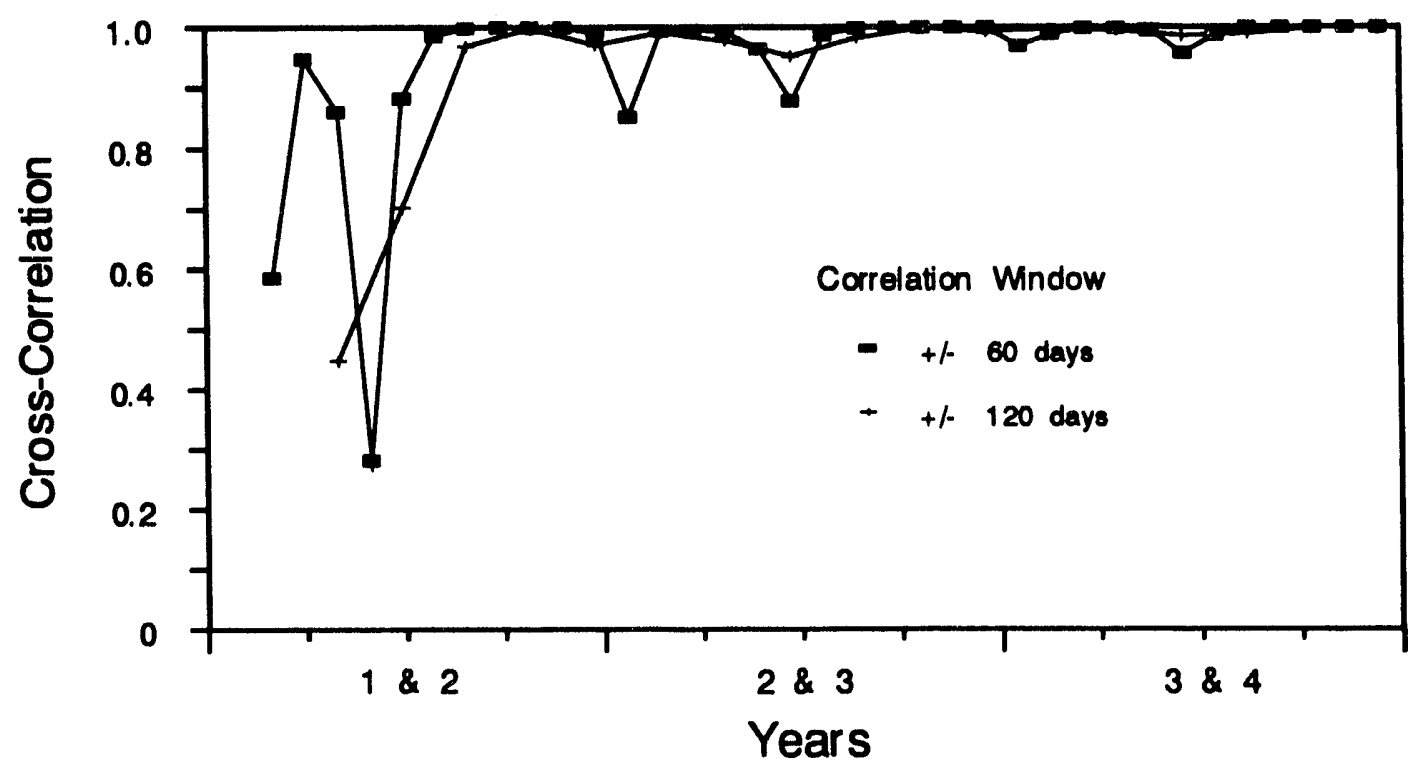

Figure 23. Repetitive year simulation results for thick soil barrier: (a) daily flux at $185-\mathrm{cm}$ depth in DAB soil and (b) cross-correlation between successive years. 
a)

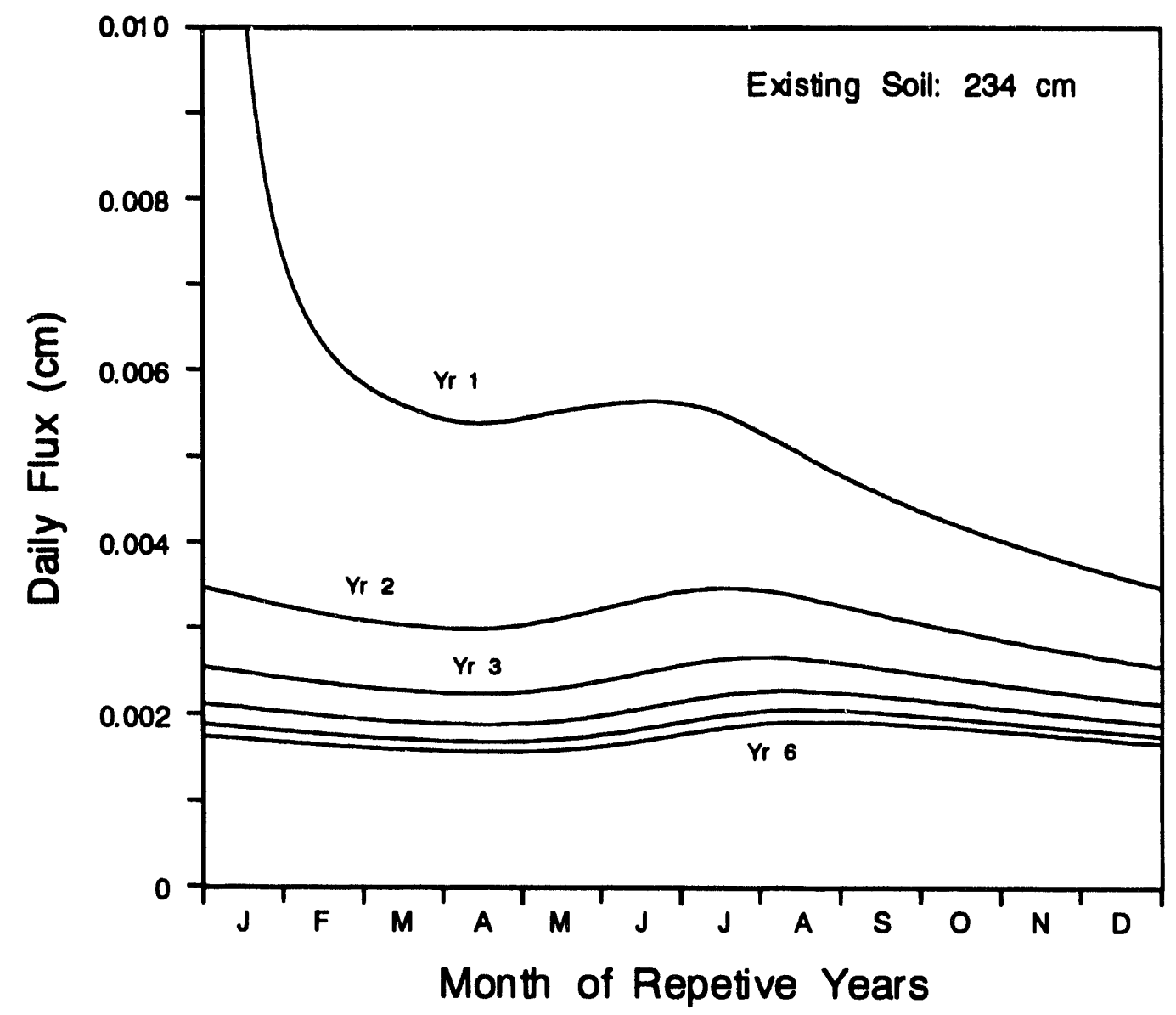

b)

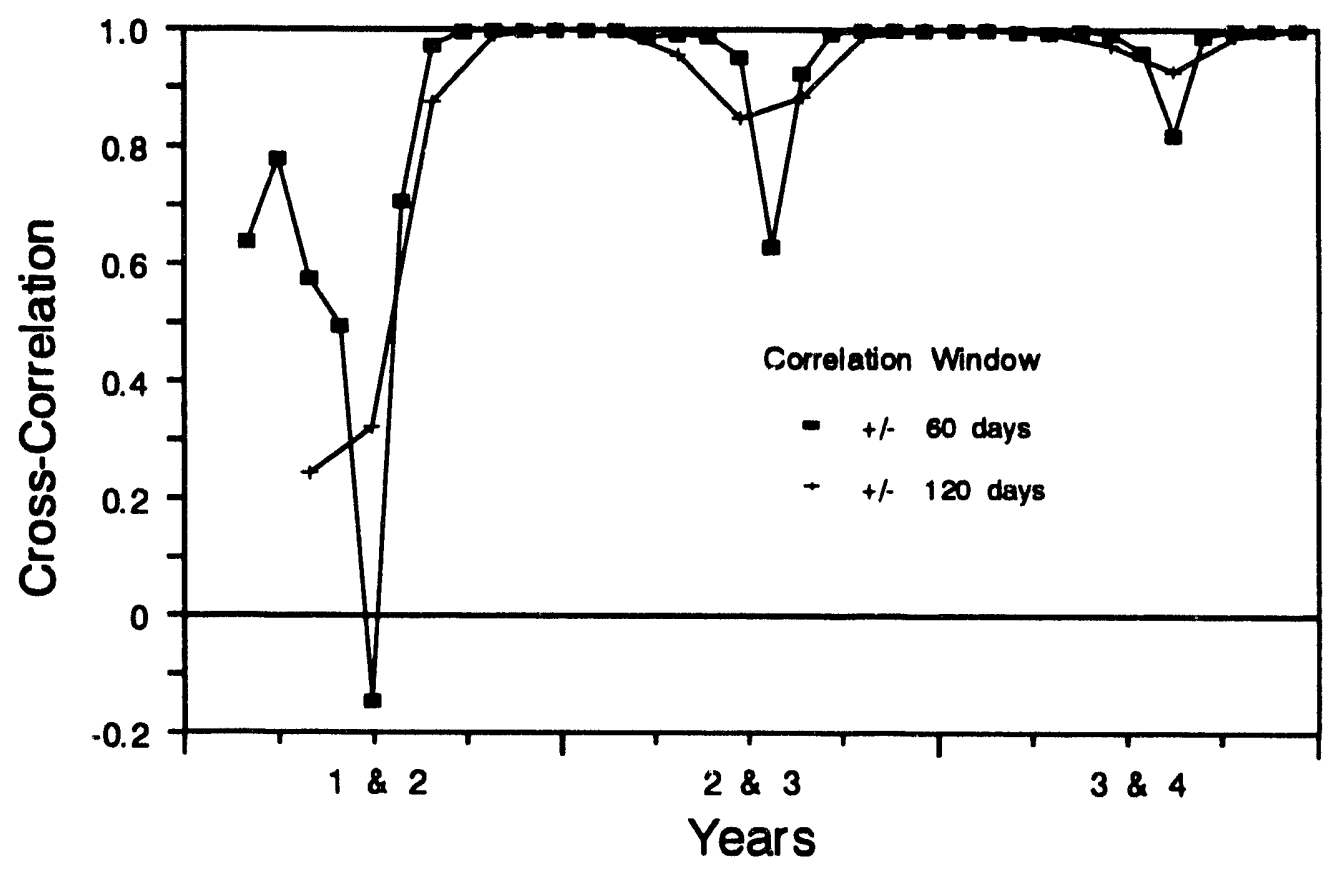

Figure 24. Repetitive year simulation results for thick soil barrier: a) daily flux near top of existing soil and b) cross-correlation between successive years. 
Table 14. Summary of equilibrium estimates from repetitive decade and repetitive year simulations.

\begin{tabular}{|c|c|c|c|}
\hline $\begin{array}{c}\text { Capillary Barrier } \\
\text { Material Type }\end{array}$ & Depth & $\begin{array}{c}\text { Repetitive } \\
\text { Decade }\end{array}$ & $\begin{array}{c}\text { Repetitive } \\
\text { Year }\end{array}$ \\
\hline $\begin{array}{l}\text { DAB Soil } \\
\text { Gravel }\end{array}$ & $\begin{array}{l}139 \mathrm{~cm} \\
155 \mathrm{~cm}\end{array}$ & $\begin{array}{l}3.5 \text { yrs } \\
5.0 \text { yrs }\end{array}$ & $\begin{array}{l}0.1 \text { yrs } \\
0.5 \text { yrs }\end{array}$ \\
\hline Thick Soil Barrier & & & \\
\hline Material Type & Depth & & \\
\hline $\begin{array}{l}\text { DAB soil } \\
\text { Existing soil }\end{array}$ & $\begin{array}{l}185 \mathrm{~cm} \\
234 \mathrm{~cm} \\
\end{array}$ & $\begin{array}{l}4.8 \text { yrs } \\
4.5 \text { yrs } \\
\end{array}$ & $\begin{array}{l}0.6 \text { yrs } \\
0.7 \text { yrs }\end{array}$ \\
\hline
\end{tabular}




\section{FAILURE ANALYSIS}

The third and final major objective in this simulation study was to perform a failure analysis of the two engineered barrier designs. Failure testing will be conducted on the field test plots. The purpose of the a priori simulation study is to guide the design and implementation of these failure tests. By simulating possible responses before the test is conducted, insight into the amounts and duration of additional water that will be necessary to induce failure will be gained.

A definition of failure has yet to be determined for the engineered barrier test facility. By comparison, failure for the Hanford Field Lysimeter Test Facility has been defined as any drainage in excess of $0.05 \mathrm{~cm} / \mathrm{yr}$ (Fayer, 1990). This definition is not necessarily applicable for the engineered barrier test facility. The earlier simulations in this report predict drainages in excess of $0.05 \mathrm{~cm} / \mathrm{yr}$ for the thick soil barrier (see Section 3). The failure definition may be more appropriate for the capillary barrier since predicted drainage exceeded only $0.05 \mathrm{~cm}$ during the first year when excess drainage occurred primarily as a result of assigned initial conditions below the capillary barrier. Rather than use a strict definition of failure, the simulations were conducted and their results analyzed qualitatively in terms of likelihood of failure due to applying additional water.

Based on the failure testing done for the Hanford facility, and the likelihood that similar testing would be done for the engineered barrier test facility, two different methods of applying supplemental water were simulated. The first involved adding additional water every two weeks to simulate an increase in the precipitation rate. The purpose in this approach was to simulate the effect of a long-term climatic change. The second approach consisted of ponding water on the surface of the engineered barriers to simulate flooding and then monitoring the time required for wetting fronts to advance through the barriers. The simulations for each approach will be discussed in turn.

\subsection{Supplemental Precipitation Simulation}

As part of the field study for the engineered barrier test plots, supplemental precipitation will be applied and the barriers performance monitored. This portion of the simulation study was designed to estimate reasonable rates of additional precipitation that could be applied to the barriers to test this performance. Based on the Hanford Field Lysimeter Test Facility methodology, supplemental precipitation was applied twice a month based on the observed precipitation during the previous 2-week period (Campbell et al, 1990). This formed the basis for how additional precipitation was applied in the simulation study. The meteorological data base developed previously for the 1981-1990 period was used for these simulations. This data base had been previously altered to include the effects of accumulated snowfall. A further alteration was performed by summing up the precipitation for each 2-week period and adding either once or twice this additional precipitation back into the data base at the end of each 2-week period.

Simulations were performed for both barriers with these $2 \mathrm{X}$ and $3 \mathrm{X}$ normal preciritation rates for the period 1981-1990. The initial conditions in all cases were the same as those described in Section 2.2. The all-effects-combined simulation performed earlier (Sections 4.3.1.4 and 4.3.2.4) with normal (or $1 \mathrm{X}$ ) precipitation served as the basis for comparison. The net yearly 
drainage results for the supplemental precipitation simulations of the capillary barrier are shown graphically in Figure 25a, and for the thick soil barrier in Figure 25b. Both these figures use a logarithmic scale in order to capture the comparison between the normal or $1 \mathrm{X}$ precipitation performance and that with supplemental precipitation. There is a marked difference in performance, especially for the capillary barrier. The drainage shown in the capillary barrier for the $1 \mathrm{X}$ precipitation clearly results from excess moisture below the capillary barrier due to the exponentially decreasing shape of the curve. With the $2 \mathrm{X}$ precipitation rate, an appreciable amount of water drains through the barrier in years $83-86$, followed by drainage of excess moisture in 87-90. In the $3 \mathrm{X}$ precipitation rate simulation, appreciable drainage occurs in all years except the initial year 81 and in the extreme drought years of 87-88.

Tables 15 and 16 present a summary of yearly results for precipitation, drainage, and mass balance error for the base and supplemental precipitation for both barrier designs. The mass balance results indicate that as the amount of precipitation and drainage increase, the quality of the solution decreases; however, the overall mass balance results for even the wettest $(3 \mathrm{X})$ simulation is quite good since it is less that $3.0 \%$.

Several conclusions can be drawn from the supplemental precipitation simulations. First, the results indicate that a supplemental precipitation factor of $2 \mathrm{X}$ should be sufficient to cause failure of the capillary barrier as long as precipitation is at or above the average of 22 to $23 \mathrm{~cm} / \mathrm{yr}$. Every year in which this condition occurred during the $2 \mathrm{X}$ simulation, an appreciable amount of water drained through the barrier. Second, increasing the precipitation $3 \mathrm{X}$ will almost assuredly result in failure of the capillary barrier in every year except when extreme drought conditions occur. Third and last, since there is already a drainage of approximately $1 \mathrm{~cm} / \mathrm{yr}$ for the thick soil barrier, increasing the precipitation by a factor of either two or three results in appreciably more drainage. Based on these results, a supplemental precipitation factor of $2 \mathrm{X}$ should be significant to test the barrier performance under most conditions. (It is beyond the scope of this document to indicate what the likely amount of additional precipitation would be under climatic change scenarios.)

\subsection{Flooding Simulation}

The second portion of the failure analysis involved simulating the performance of the engineered barriers under flooding conditions. The location of the RWMC in the bottom of the local drainage basin has resulted in localized flooding three times in the past (Barraclough et al, 1976; Wood, 1989). The duration of these flooding events was limited. In the flooding simulations to test performance of the two barriers, the length of the flooding was treated as variable with durations of $0.5,1$, and 2 days. Three aspects of the barrier performance were monitored for each simulation: (a) the advance of the wetting front during flooding, (b) the amount of water that infiltrated through the barriers during the flooding, and (c) the net amount of water that drained through the base of the simulation domain as a result of the flooding. Aspect (c) tested the performance of the barrier after flooding ceased and is a key aspect of barrier performance.

The flooding simulations were performed by selecting a point in time from the all-effectscombined simulations (Sections 4.1.3.4 and 4.3.2.4) and then superimposing a period of flooding. 

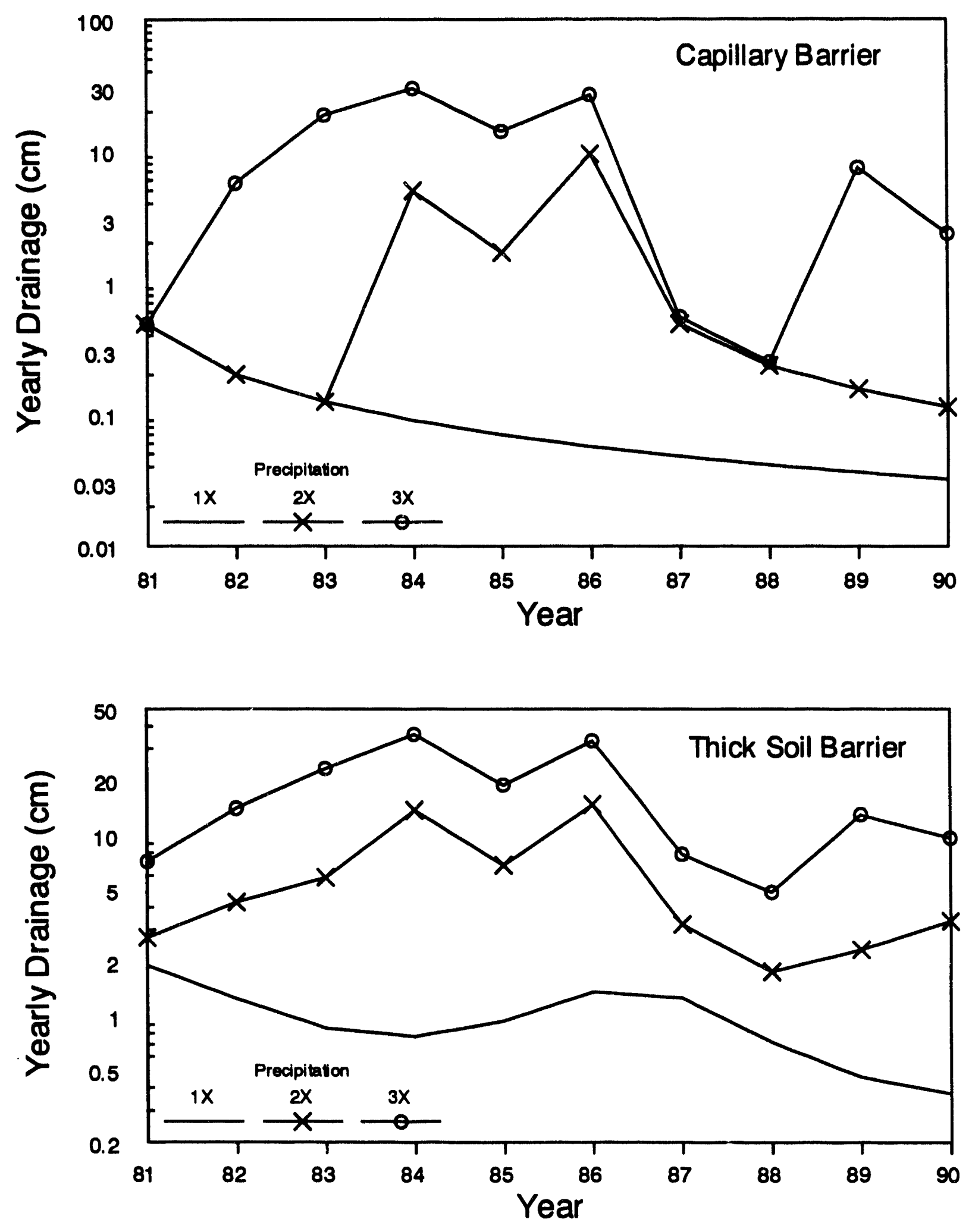

Figure 25. Simulation results for annual drainage with supplemental precipitation: (a) capillary barrier and (b) thick soil barrier. 
Table 15. Simulation results for capillary barrier with supplemental precipitation.

1X (Normal) Precipitation

\begin{tabular}{|c|c|c|c|c|}
\hline Year & $\begin{array}{l}\text { Ppt. } \\
\text { (cm) }\end{array}$ & $\begin{array}{c}\text { Drainage } \\
\text { (Cm) }\end{array}$ & $\begin{array}{l}\text { Mass Balance } \\
\text { Error (Cm) }\end{array}$ & $\begin{array}{l}\text { MBE as a } \\
8 \text { of Ppt. }\end{array}$ \\
\hline $\begin{array}{l}81 \\
82 \\
83 \\
84 \\
85 \\
86 \\
87 \\
88 \\
89 \\
90\end{array}$ & $\begin{array}{r}22.81 \\
22.05 \\
30.23 \\
27.84 \\
22.71 \\
33.00 \\
19.76 \\
9.55 \\
21.06 \\
17.12\end{array}$ & $\begin{array}{l}0.49 \\
0.20 \\
0.12 \\
0.09 \\
0.07 \\
0.06 \\
0.05 \\
0.04 \\
0.04 \\
0.03\end{array}$ & $\begin{array}{r}0.01 \\
-0.00 \\
0.02 \\
0.01 \\
0.03 \\
-0.00 \\
-0.01 \\
-0.00 \\
0.01 \\
0.01\end{array}$ & $\begin{array}{l}0.0 \\
0.0 \\
0.1 \\
0.1 \\
0.1 \\
0.0 \\
0.0 \\
0.0 \\
0.1 \\
0.0\end{array}$ \\
\hline
\end{tabular}

2x Precipitation

\begin{tabular}{lllll}
81 & 45.62 & 0.49 & 0.20 & 0.4 \\
82 & 44.09 & 0.20 & 0.02 & 0.0 \\
83 & 60.45 & 0.12 & 0.08 & 0.1 \\
84 & 55.68 & 4.96 & 0.24 & 0.4 \\
85 & 45.42 & 1.69 & 0.25 & 0.5 \\
86 & 65.99 & 9.43 & 0.14 & 0.2 \\
87 & 39.52 & 0.49 & 0.16 & 0.4 \\
88 & 19.10 & 0.23 & 0.00 & 0.0 \\
89 & 42.11 & 0.16 & 0.42 & 1.0 \\
90 & 34.24 & 0.11 & 0.23 & 0.7 \\
\hline
\end{tabular}

3x Precipitation

\begin{tabular}{llrrr}
81 & 68.43 & 0.49 & 0.60 & 0.9 \\
82 & 66.14 & 5.69 & 0.46 & 0.7 \\
83 & 90.68 & 18.83 & 0.91 & 1.0 \\
84 & 83.52 & 30.01 & 0.99 & 1.2 \\
85 & 68.12 & 14.06 & 0.74 & 1.1 \\
86 & 98.98 & 26.69 & 0.98 & 1.0 \\
87 & 59.28 & 0.55 & 0.62 & 1.0 \\
88 & 28.65 & 0.25 & 0.36 & 1.3 \\
89 & 63.17 & 7.43 & -0.13 & -0.2 \\
90 & 51.36 & 2.36 & 0.26 & 0.5 \\
\hline
\end{tabular}

The date chosen to begin flooding was the end of Julian day 69 in 1983 . This date was chosen because the soil moisture profile in the DAB soil is completely in equilibrium with the surface meteorological boundary (see Section 5) and because it is shortly after snowmelt occurs in 1983 (Julian day 61). Using the initial conditions at the end of Julian day 69 of 1983, the upper boundary was fixed to saturation for periods of $0.5,1$, and 2 days. Then, the upper boundary reverted to a flux boundary in which the evapotranspiration potential was determined from meteorologic conditions. The capillary barrier simulations will be discussed first followed by those for the thick soil barrier. 
Table 16. Simulation results for thick soil barrier with supplemental precipitation.

1X (Normal) Precipitation

\begin{tabular}{|c|c|c|c|c|c|}
\hline Year & $\begin{array}{l}\text { Ppt. } \\
\text { (cm) }\end{array}$ & & $\begin{array}{c}\text { Drainage } \\
\text { (cm) }\end{array}$ & $\begin{array}{l}\text { Mase Balance } \\
\text { Error (Cm) }\end{array}$ & $\begin{array}{l}\text { MBE as a } \\
8 \text { of Ppt. }\end{array}$ \\
\hline $\begin{array}{l}81 \\
82 \\
83 \\
84 \\
85 \\
86 \\
87 \\
88 \\
89 \\
90\end{array}$ & $\begin{array}{r}22.81 \\
22.05 \\
30.23 \\
27.84 \\
22.71 \\
33.00 \\
19.76 \\
9.55 \\
21.06 \\
17.12\end{array}$ & - & $\begin{array}{l}1.91 \\
1.25 \\
0.86 \\
0.77 \\
0.94 \\
1.36 \\
1.26 \\
0.72 \\
0.46 \\
0.37\end{array}$ & $\begin{array}{r}0.00 \\
-0.01 \\
0.01 \\
0.02 \\
0.02 \\
-0.00 \\
-0.03 \\
-0.01 \\
0.00 \\
0.00\end{array}$ & $\begin{array}{r}0.0 \\
-0.1 \\
0.0 \\
0.1 \\
0.1 \\
-0.0 \\
-0.1 \\
-0.1 \\
0.0 \\
0.0\end{array}$ \\
\hline
\end{tabular}

2x Precipitation

\begin{tabular}{ccccc}
81 & 45.62 & 2.72 & 0.23 & 0.5 \\
82 & 44.09 & 4.28 & 0.01 & 0.0 \\
83 & 60.45 & 5.86 & 0.09 & 0.1 \\
84 & 55.68 & 13.71 & 0.56 & 1.0 \\
85 & 45.42 & 6.84 & 0.53 & 1.2 \\
86 & 65.99 & 14.71 & 0.53 & 0.3 \\
87 & 39.52 & 3.22 & 0.12 & 0.0 \\
88 & 19.10 & 1.77 & 0.00 & 1.7 \\
89 & 42.11 & 2.33 & 0.71 & 0.5 \\
90 & 34.24 & 3.36 & 0.17 & \\
$3 \times$ Precipitation & & & & 1.5 \\
81 & 68.43 & 7.17 & 1.06 & 1.6 \\
82 & 66.14 & 14.02 & 0.48 & 1.8 \\
83 & 90.68 & 23.24 & 1.48 & 1.4 \\
84 & 83.52 & 36.11 & 2.30 & 1.4 \\
85 & 68.12 & 18.77 & 0.92 & 1.2 \\
86 & 98.98 & 33.18 & 1.87 & 0.5 \\
87 & 59.28 & 7.87 & 0.84 & 1.4 \\
\hline 88 & 28.65 & 4.85 & 0.34 & 0.33 \\
\hline
\end{tabular}

The hourly flux through the bottom of the simulation domain for the capillary barrier flooding simulations is shown in Figure 26. The shorter duration flood ( 0.5 days) did not result in any additional water draining past the capillary barrier. Rather, the flux that does occur is negligible and is a result of residual drainage still occurring as a result of the initial conditions. The maximum depth to which the wetting front advanced resulting from the 0.5-day flood was $\sim 170 \mathrm{~cm}$ at Julian day 103, 33 days after the flooding ceased. The front advanced just into the cobble layer and could not penetrate any further since the driving force for additional infiltration had previously ceased.

Both the 1- and 2-day flooding periods resulted in additional drainage beneath the capillary barrier. Table 17 gives the depth to which the wetting front penetrated during the flooding period, the amount of water that infiltrated during flooding, the net amount of water that drained beneath 


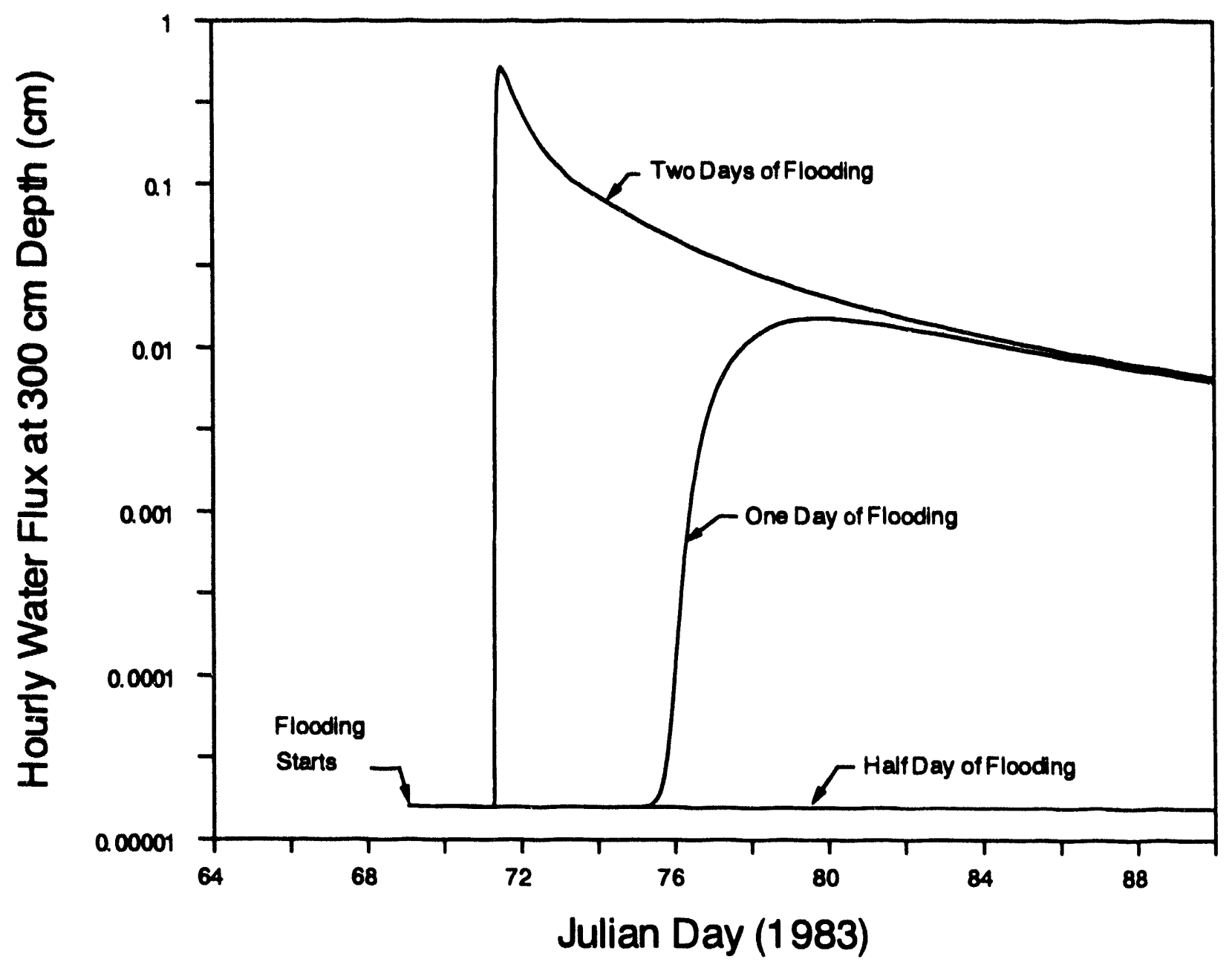

Figure 26. Flux at bottom of capillary barrier simulation domain $(300 \mathrm{~cm})$ in response to variable length flooding.

Both the 1- and 2-day flooding periods resulted in additional drainage beneath the capillary barrier. Table 17 gives the depth to which the wetting front penetrated during the flooding period, the amount of water that infiltrated during flooding, the net amount of water that drained beneath the barrier from the beginning of flooding to the end of 1983. The amount of water that drained prior to flooding was negligible to that occurring after flooding for the capillary barrier.

The indication from the capillary barrier flooding simulations is that there is limited storage capacity in the $140 \mathrm{~cm}$ of DAB soil to absorb water during any extended period of saturation of the surface. In Section 2, it was mentioned that the thickness of the DAB soil in the capillary barrier is actually going to be $160 \mathrm{~cm}$ instead of $140 \mathrm{~cm}$. This will improve the storage capacity slightly but will not markedly affect these results.

\subsubsection{Thick Soil Barrier}

The hourly flux of water through the thick soil barrier is shown in Figure 27. Graphically, the results appear similar to those for flooding of the capillary barrier. However, the peak flux for 
Table 17. Results for flooding of capillary barrier.

\begin{tabular}{|c|c|c|c|c|}
\hline $\begin{array}{l}\text { Flood } \\
\text { Duration } \\
\text { (days) }\end{array}$ & $\begin{array}{l}\text { Wetting Front } \\
\text { Depth at End } \\
\text { of Flooding } \\
\text { (cm) }\end{array}$ & $\begin{array}{l}\text { Amount of Water } \\
\text { Infiltrating } \\
\text { During Flooding } \\
\text { (cm) }\end{array}$ & $\begin{array}{c}\text { Deep Drainage } \\
\text { During } 1983 \\
\text { (day } 70-365 \text { ) } \\
(\mathrm{cm})\end{array}$ & $\begin{array}{l}\text { Mass } \\
\text { Balance } \\
\text { Error } \\
\text { (cm) }\end{array}$ \\
\hline 0.5 & 70 & 15.6 & $9.7 \times 10^{-2}$ & $2.7 \times 10^{-4}$ \\
\hline 1.0 & 110 & 25.6 & $7.1 \times 10^{\circ}$ & $1.4 \times 10^{-2}$ \\
\hline 2.0 & 215 & 44.5 & $2.6 \times 10^{2}$ & $1.2 \times 10^{-1}$ \\
\hline no floodil & & & $9.7 \times 10^{-2}$ & \\
\hline
\end{tabular}

the 1-day flood occurs later in the thick soil simulation. Also, the half-day flood results in additional drainage in the thick soil barrier simulation where it did not in the capillary barrier simulation.

Table 18 gives the advance of the wetting front during flooding, the net infiltration during flooding, the amount of drainage occurring for the remainder of the year after flooding, and the combined mass balance errors during the flooding and recovery stages of the simulation.

\subsubsection{Comparison of Performance During and After Flooding}

Comparison of Tables 17 and 18 reveals that the wetting front advance and amount of infiltrating water during flooding differs only for the 2-day flood. The wetting front advance during the shorter duration floods did not advance past the DAB soil in both simulations so the results should be the same. The differences in the 2-day flood is attributable to the gravel and cobble layers in the capillary barrier simulation.

Table 19 gives a summary of the maximum drainage flux occurring in both the capillary and thick soil barrier simulations, the time of the maximum flux, and the flux that would have occurred without flooding. Several observations can be drawn from this information. First, the peak drainage rates are higher for the capillary barrier than for the thick soil barrier in each case where drainage occurs. This results from faster movement through gravel and cobble layers once failure occurs. Second, the peak flux occurs later for the thick soil barrier than for the capillary barrier. This is also a result of the faster movement through the gravel and cobble layers. Lastly, from Tables 17 and 18, the net increase in drainage during the recovery period is greater for the thick soil barrier than for the capillary barrier for each flood duration. The capillary barrier appears to reestablish itself quick enough to reduce the overall net drainage compared to that of the thick soil barrier.

Figure 28 shows the amount of water in storage in the simulation profile for the complete 1983 simulation period for b $h$ the capillary and thick soil barriers. In both cases, the soil moisture conditions have not recovered to the nonflooding conditions by the end of the year. Part of the explanation for this slow recovery would be slow drainage from below the capillary barrier and from deeper in the thick soil barrier. Once the driving force of additional water at the surface is removed, the residual drainage decreases at an exponential rate, so as time progresses, the 


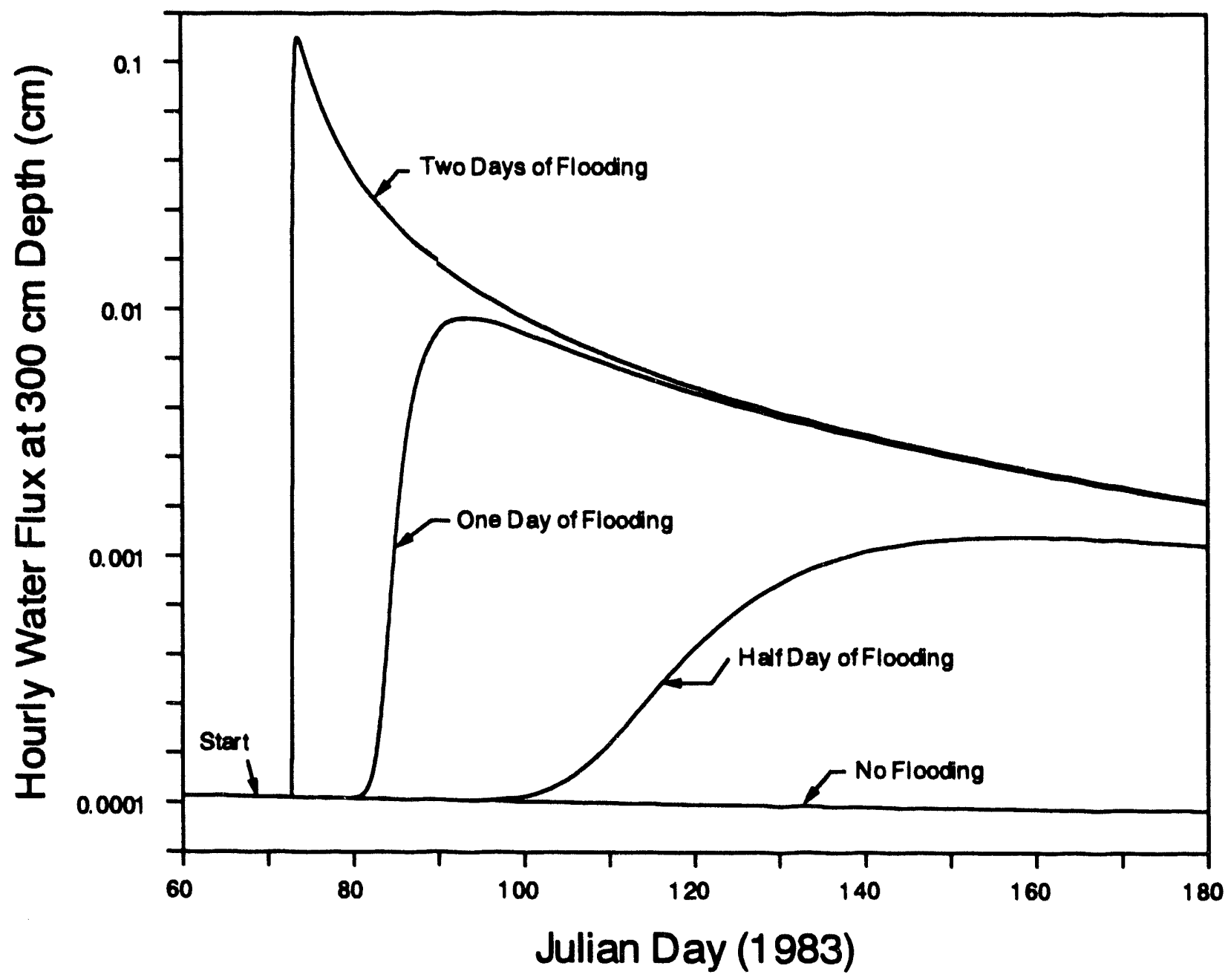

Figure 27. Flux at bottom of thick soil barrier simulation domain $(300 \mathrm{~cm})$ in response to variable length flooding.

Table 18. Results for flooding of thick soil barrier.

\begin{tabular}{|c|c|c|c|c|}
\hline $\begin{array}{l}\text { Flood } \\
\text { Duration } \\
\text { (days) }\end{array}$ & $\begin{array}{l}\text { Wetting Frrnt } \\
\text { Depth at End } \\
\text { of Flooding } \\
\text { (cm) }\end{array}$ & $\begin{array}{l}\text { Amount of Water } \\
\text { Infiltrating } \\
\text { During Flooding } \\
\text { (cm) }\end{array}$ & $\begin{array}{c}\text { Deep Drainage } \\
\text { During } 1983 \\
\text { (day } 70-365 \text { ) } \\
(\mathrm{cm})\end{array}$ & $\begin{array}{l}\text { Mass } \\
\text { Balance } \\
\text { Error } \\
\text { (cm) }\end{array}$ \\
\hline 0.5 & 70 & 15.6 & $4.5 \times 10^{\circ}$ & $1.7 \times 10^{-1}$ \\
\hline 1.0 & 110 & 25.6 & $1.3 \times 10^{1}$ & $1.6 \times 10^{-2}$ \\
\hline 2.0 & 180 & 44.3 & $3.2 \times 10^{1}$ & $5.5 \times 10^{-2}$ \\
\hline no flooding & & & $6.7 \times 10^{-1}$ & \\
\hline
\end{tabular}


Table 19. Comparison of peak drainage rate between flooding simulations for capillary barrier and thick soil barrier.

\begin{tabular}{|c|c|c|c|}
\hline \multirow[b]{2}{*}{$\begin{array}{l}\text { Flood } \\
\text { Duration }\end{array}$} & \multicolumn{2}{|c|}{ Capillary Barrier } & \multirow[b]{2}{*}{$\begin{array}{l}\text { Drainage Rate } \\
\text { w/o Fiooding } \\
\text { ( } \mathrm{cm} / \mathrm{hr})\end{array}$} \\
\hline & $\begin{array}{l}\text { Peak } \\
\text { Drainage } \\
\text { (cm/hr) }\end{array}$ & $\begin{array}{l}\text { Julian Day } \\
\text { at Which } \\
\text { Peak Occurs }\end{array}$ & \\
\hline 0.5 & $-{ }^{*}$ & - & $1.5 \times 10^{-5}$ \\
\hline 1.0 & $1.5 \times 10^{-2}$ & 79.8 & $1.5 \times 10^{-5}$ \\
\hline 2.0 & $5.1 \times 10^{-1}$ & 71.5 & $1.5 \times 10^{-5}$ \\
\hline & Thic & oil Barrier & \\
\hline $\begin{array}{l}\text { Flood } \\
\text { Duration }\end{array}$ & $\begin{array}{c}\text { Peak } \\
\text { Drainage } \\
\text { (cm/hr) }\end{array}$ & $\begin{array}{l}\text { Julian Day } \\
\text { at Which } \\
\text { Peak Occurs }\end{array}$ & $\begin{array}{l}\text { Drainage Rate } \\
\text { w/o Flooding } \\
(\mathrm{cm} / \mathrm{hr})\end{array}$ \\
\hline 0.5 & $1.2 \times 10^{-3}$ & 159 & $9.4 \times 10^{-5}$ \\
\hline 1.0 & $9.2 \times 10^{-3}$ & 94 & $1.0 \times 10^{-4}$ \\
\hline 2.0 & $1.3 \times 10^{-1}$ & 73.6 & $1.1 \times 10^{-4}$ \\
\hline
\end{tabular}

residual drainage decreases very slowly. Also apparent from Figure 28 is how quickly the upper portion of the soil profile begins to behave as if no flooding occurred. This can be seen by looking at the small changes in the storage as quickly as day 120, 50 days after flooding. Although the amount of water stored is different, the behavior is the same.

In conclusion, neither barrier design prevents water from draining through the barriers under almost any extended period of saturation at the surface. Both designs showed large increases in the amount of water that drained past the bottom of the simulation domain. The capillary barrier appeared to offer an advantage in that it began reducing the net drainage faster than the thick soil barrier. 
a)

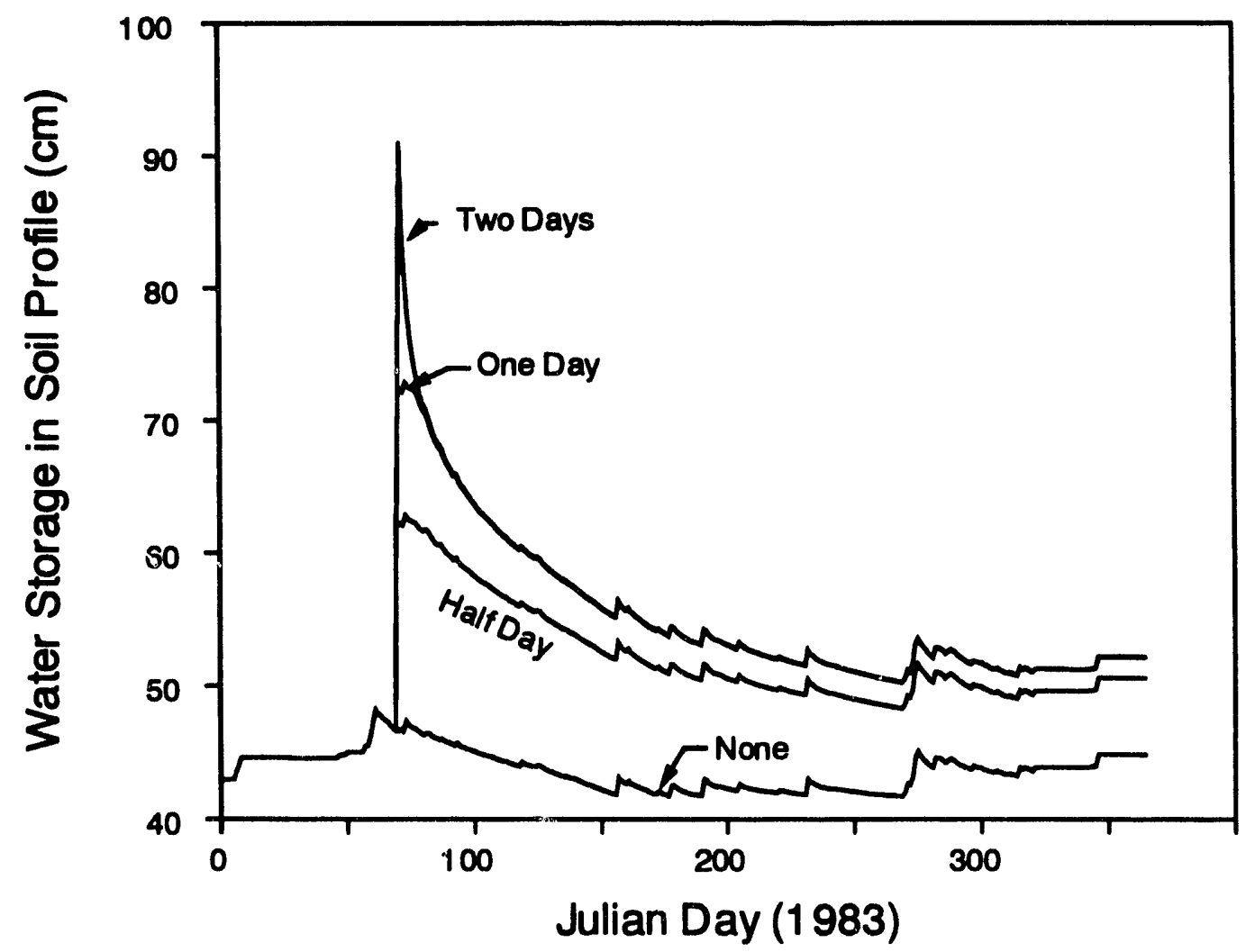

b)

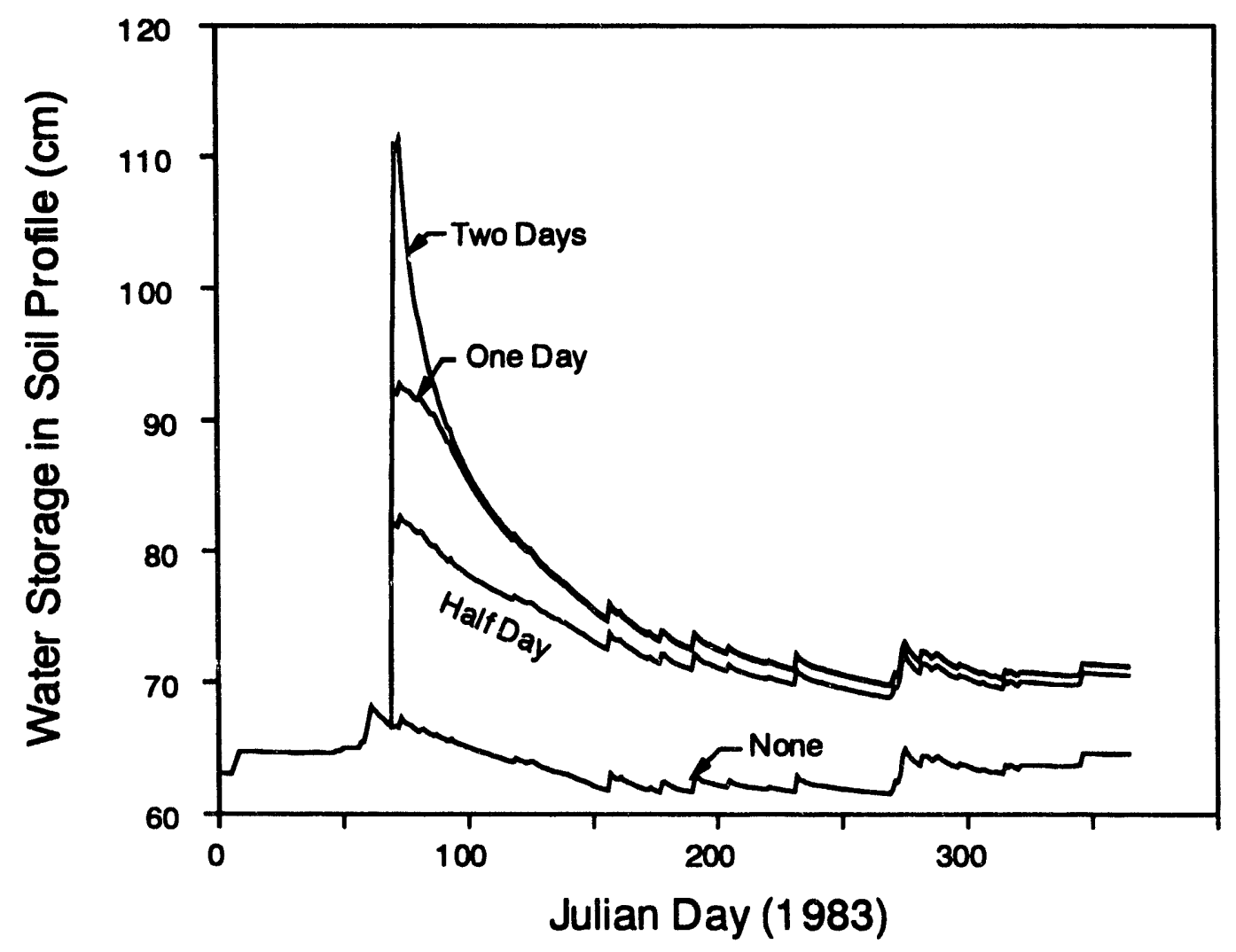

Figure 28. Flooding simulation results for daily water storage $(\mathrm{cm})$ for (a) capillary barrier and (b) thick soil barrier. 


\section{SUMMARY AND FUTURE DIRECTIONS}

\subsection{Summary}

Two proposed engineered barrier designs are being considered for use in eventual closure of the RWMC. Field-scale plots of these two designs are being constructed to provide monitoring data with which to evaluate their performance. A simulation study was conducted to provide guidance in the design of these two barriers. The simulation study considered:

- The sensitivity of barrier performance to the conceptual model and hydrologic parameters used to simulate the test plots

- The time necessary for the moisture profile to attain equilibrium with meteorological conditions after construction of the test plots

- The performance of the barriers in the test plots under failure conditions due to supplemental precipitation or ponding.

In addition, a statistical comparison was performed on meteorological data sources in the general vicinity of the RWMC in order to justify using data from locations other than the RWMC.

The conceptual model that was used to simulate the covers was varied to include effects of plant transpiration, reduced evaporation during periods of snow cover, and degradation of the capillary barrier by infilling of overlying sediments. Including both transpiration and a snow cover tended to counterbalance each other but did result in a more defensible simulation since the simulation was more representative of actual anticipated conditions. Further conceptual model changes that were simulated included degradation of the gravel layer in the capillary barrier by infilling of overlying sediments. This degradation did have a marked effect on reducing the capillary barrier performance as drainage increased. Degradation of the cobble layer by infilling of the gravel layer had a minimal effect since the gravel still performed the function of a capillary barrier. Increasing the depth of the DAB soil in the thick soil barrier reduced the overall net drainage; however, the net drainage was still higher for the thick soil barrier compared to the capillary barrier.

The most sensitive hydrologic parameters were those describing the DAB soil. This was not surprising since the DAB soil is the uppermost in the cover and therefore more subject to meteorological influences. The residual moisture content and air entry potential of the gravel, cobble, and underlying soil were also found to have an influence on the drainage through the barrier. As such, the cobbles and gravel need to be hydrologically characterized as well.

Two different simulation approaches were used to estimate the time necessary for the soil profile within the barriers to come into equilibrium with the meteorological conditions at the surface. The first was to use meteorological data from one decade repetitively and based equilibrium upon when the daily flux at a midpoint in the profile from the second decade reached 0.9 correlation with the flux at the same depth from the first decade. The second simulation approach used 1 year of meteorological data repetitively instead of a decade and based 
equilibrium again on correlation of daily flux at a middle depth in the profile. By using these two approaches, the estimated time to attain equilibrium could be bounded. The necessary time ranged from 0.1 years to 4.8 years. Depending on the actual weather pattern after the barrier plots are constructed, it was estimated that it could take from 1 to 3 years before the soil moisture profile attains equilibrium and is no longer influenced by the initial moisture profile.

In the supplemental precipitation simulations, the precipitation rate was either doubled or tripled, and barrier performance was compared to that under normal precipitation. The simulation results for the thick soil barrier showed increasing drainage with increasing precipitation, as expected. The results for the capillary barrier indicated that additional drainage would be expected to occur for the case of the double precipitation as long as the base precipitation is at or above the long-term average of 22 to $23 \mathrm{~cm} / \mathrm{yr}$. Tripling the precipitation resulted in additional drainage in almost every year except those with extreme drought conditions. As a result, doubling the infiltration rate should prove sufficient to test both barrier designs.

The last section of this simulation study considered the performance of the barriers under flooding conditions. These simulations were conducted by treating the surface as if it were saturated for periods of time ranging from 0.5 to 2 days. Then, the upper boundary reverted to a meteorologically controlled flux, and redistribution of the additional moisture in the soil profile was simulated for the duration of the year that was chosen for the flooding simulations. The simulation results indicated that neither barrier design offered appreciable resistance to flooding. If the surface of the DAB soil in the capillary barrier remained saturated longer than 0.5 days, the storage capacity within the DAB soil was quickly depleted and excess water began draining through the barriers. In the thick soil barrier, excess drainage resulted from even the 0.5 -day saturation period. Simulation of the recovery or redistribution of the soil moisture profile after flooding ended indicated that the capillary barrier would be more effective at reducing overall drainage than the thick soil barrier.

\subsection{Future Directions}

This simulation study was designed to provide guidance in designing the field barrier plots and in conducting experiments to test their performance in limiting infiltrating water. There is at least one design feature that could benefit from an additional simulation study. In particular, a concern has been raised regarding induced vapor transport of moisture due to artificially imposed thermal gradients. These gradients are due to differences in temperature between the soil in the test plots and inside the access trench next to the plots. A simulation study could be performed to determine the amount of insulation required to minimize induced vapor transport below a prescribed level.

Even if this recommended study is not conducted, simulations of barriers at Hanford by Fayer et al. (1992) indicated the importance of considering thermal effects related to vapor movement under conditions of low infiltration such as those found in capillary barriers. This information has been considered in the design of the test barriers for the RWMC in that instrumentation is being included to profile temperatures vertically and horizontally in the plots so that thermal effects can be estimated. 
The parameterization of wheatgrass transpiration used in this study was based on information contained in the literature, primarily related to studies conducted at or near the INEL. Even so, gaps in terms of biomass amounts and root growth functions had to be assumed for purposes of the study. Since a vegetative cover of crested wheatgrass will be used on the test barrier plots, accurate parameterization of transpiration is important to the cover simulations. The transpiration parameterization should be improved by incorporating results from wheatgrass studies that may be ongoing at the Radiological and Environmental Services Laboratory and elsewhere.

The future direction of modeling studies related to the RWMC barrier test plots should be in utilizing monitoring data collected after construction of the barrier plots. These simulations should be directed towards achieving a calibrated simulation of the soil moisture profile within both barrier designs. This calibration should be done for both the normal and supplemental precipitation plots. These simulations should also be conducted to investigate thermal effects such as vapor transport. As such, they will require two-dimensional simulations so the UNSAT-H code will be precluded from use.

By obtaining calibrated simulations of moisture movement through the barrier, different scenarios can then be defensively simulated to determine the amount of water that will infiltrate through the barriers and contact waste emplaced underneath. This information will be required in order that the beneficial effects of engineered covers or barriers can be included in future Performance Assessments for the RWMC. 


\section{REFERENCES}

Anderson, J. E., M. L. Shumar, and N. L. Toft, 1987, "Control of the Soil Water Balance by Sagebrush and Three Perennial Grasses in a Cold-Desert Environment," Arid Soil Research and Rehabilitation, 1, pp. 229-244.

Baca, R. G. and S. O. Magnuson, 1990, Independent Verificaton and Benchmark Testing of the UNSAT-H Computer Code, Version 2.0, EGG-BEG-8811, EG\&G Idaho, Inc., Idaho Falls, ID.

Baca, R. G., S. O. Magnuson, H. D. Nguyen, and P. Martian, 1992, A Modeling Study of Water Flow in the Vadose Zone Beneath the Radioactive Waste Management Complex, EGG-GEO10068, EG\&G Idaho, Inc., Idaho Falls, ID.

Barraclough, J. T., J. B. Robertson, V. J. Janzer, and L. G. Saindon, 1976, Hydrology of the Solid Waste Burial Ground, as Related to the Potential Migration of Radionuclides, Idaho National Engineering Laboratory, Open-File Report 76-471, U.S. Geological Survey, Water Resources Division, Idaho Falls, ID.

Borghese, J. V., 1989, Hydraulic Characteristics of Soil Cover, Subsurface Disposal Area, Idaho National Engineering Laboratory, Masters Thesis, University of Idaho, Moscow, ID.

Brooks, R. H. and A. T. Corey, 1966, "Properties of Porous Media Affecting Fluid Flow," Journal Irrig. Drain. Div., Am. Soc. Civil Eng., 92(IRS), pp. 61-88.

Caldwell, M. M. and J. H. Richards, 1986, "Competing Root Systems: Morphology and Models of Absorption," Proceedings of the Sixth Maria Moors Cabet Symposium on Evolutionary Constraints on Primary Productivity, sugust 1983, Cambridge, MA, Cambridge University Press, pp. 251-273.

Campbell, M. D., G. W. Gee, M. J. Kanyid, and M. L. Rockhold, 1990, Field Lysimeter Test Facility: Second Year (FY 1989) Test Results," PNL-7209, Pacific Northwest Laboratory, Richland, WA.

Fayer, M. J., 1990, Test Plan for Hydrologic Modeling of Protective Barriers, PNL-7152, Pacific Northwest Laboratory, Richland, WA.

Fayer, M. J. and T. L. Jones, 1990, UNSAT-H Version 2.0: Unsaturated Soil Water and Heat Flow Model, PNL-6779, Pacific Northwest Laboratory, Richland, WA.

Fayer, M. J., M. L. Rockhold, and J. J. Holford, 1992, Model Assessment of Protective Barriers: Part III Status of FY 1990 Work, PNL-7975, Pacific Northwest Laboratory, Richland, WA.

Foxx, T. S., G. D. Tierney, and J. M. Williams, 1984, Rooting Depths of Plants on Low-Level Waste Disposal Sites, LA-10253-MS, Los Alamos National Laboratory, Los Alamos, NM. 
Golder Associates, Inc., 1987, Master Evaluation of Cover Alternatives and Surface Drainage Design at the SDA, EGG-LLW-8235, EG\&G Idaho, Inc., Idaho Falls, ID, November.

Hinds, W. T., 1975, "Energy and Carbon Balances in Cheatgrass: An Essay in Autecology," Ecological Monogr., 45, pp. 367-388.

Keck, J. F., 1992, Evaluation of Engineered Barriers for Closure Cover of the RWMC SDA, Engineering Design File \#RWMC-523, EG\&G Idaho, Inc., Idaho Falls, ID.

Maheras, S. J., S. O. Magnuson, A. S. Rood, and M. E. Sussman, 1993, Radioactive Waste Management Complex Low-Level Waste Radiological Performance Assessment, Draft, EGGWM-8773, EG\&G Idaho, Inc., Idaho Falls, ID.

Marlette, G. M. and J. E. Anderson, 1986, "Seed Banks and Propagule Dispersal in Crested Wheatgrass Stands," Journal of Applied Ecology, 23, pp. 161-175.

McElroy, D. L., 1990, Vadose Zone Monitoring at the Radioactive Waste Management Complex at the Idaho National Engineering Laboratory 1985-1989," EGG-WM-9299, EG\&G Idaho, Inc., Idaho Falls, ID.

McElroy, D. L., I. Porro, C. W. Bishop, K. N. Keck, and J. F. Kaminsky, 1992, RWMC SDA Engineered-Barrier Test Plan, Draft, EGG-WMO-10284, EG\&G Idaho, Inc., Idaho Falls, ID, June.

Mockus, V., 1972, "Hydraulic Effects of Land Use and Treatment," Chapter 11, "Estimation of Direct Runoff from Snowmelt," SCS National Engineering Handbook, Section 4, "Hydrology," U.S. Department of Agriculture, Soil Conservation Service, Washington, D.C.

Richardson, C. W. and D. A. Wright, 1984, WGEN: A Model for Generating Daily Weather Variables, USDA Report PB85-107100, United States Department of Agriculture, Agricultural Research Service.

Reynolds, T. D, 1990, "Root Mass and Vertical Root Distribution of Five Semi-Arid Plant Species," Health Physics, 58, 2, pp. 191-197.

Schroeder, P. R., B. M. McEnroe, R. L. Peyton, and J. W. Sjostrom, 1988, The Hydrologic Evaluation of Landfill Performance (HELP) Modeh, Volume IV, Documentation for Version 2, U.S. Environmental Protection Agency, Hazardous Waste Engineering Research Laboratory, Office of Research and Development, Cincinnati, Ohio.

Wood, T. R, 1989, Preliminary Assessment of the Hydrogeology at the Radioactive Waste Management Complex, Idaho National Engineering Laboratory, EGG-WM-8694, EG\&G Idaho, Inc., Idaho Falls, ID. 
Appendix A

\section{Meteorological Data Base}




\section{Appendix A}

\section{Meteorological Data Base}

This appendix contains 1981-1990 data from the meteorological data base used in the UNSAT-H simulation study. The precipitation received during sub-freezing periods is shifted later to nonfreezing periods.

Year 1981

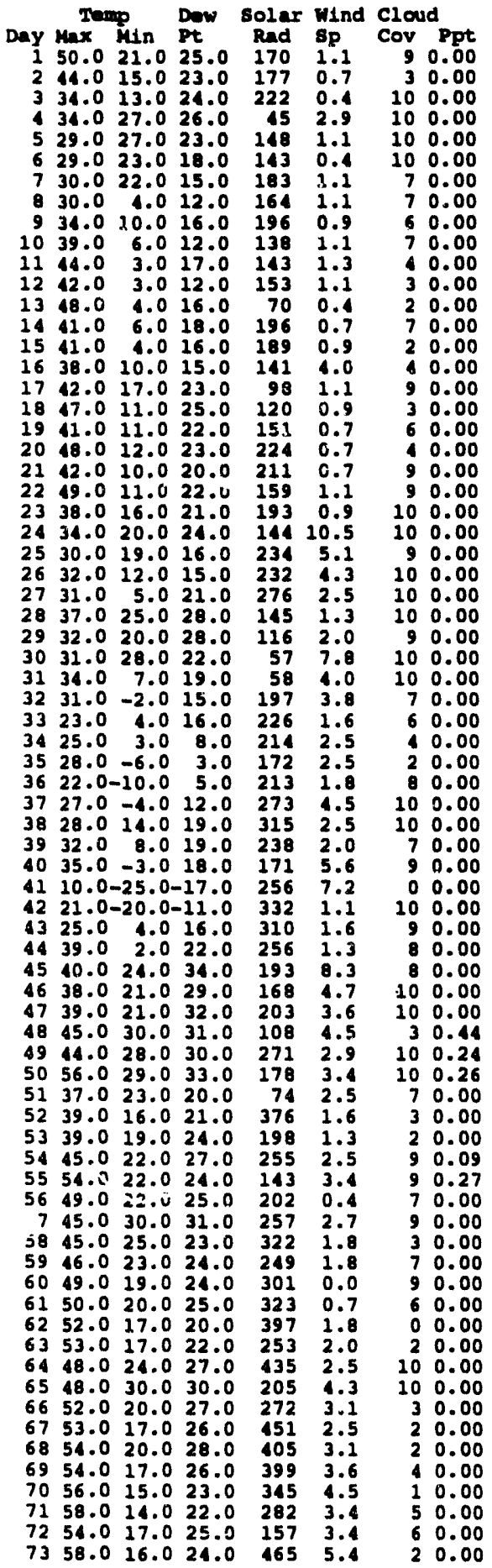

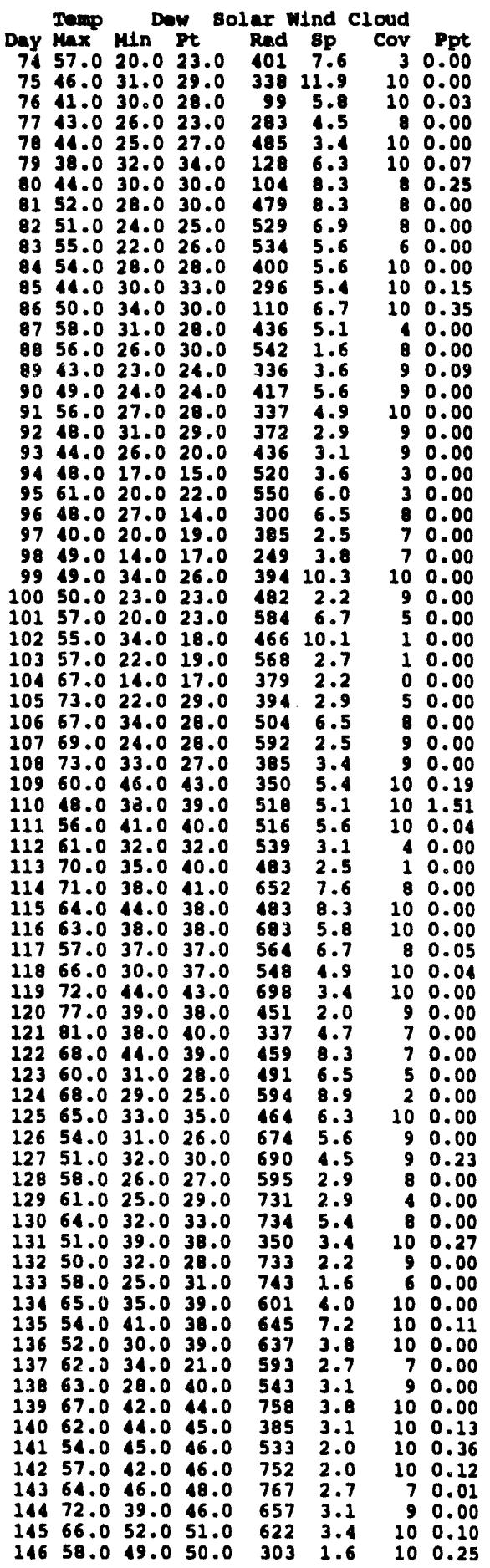

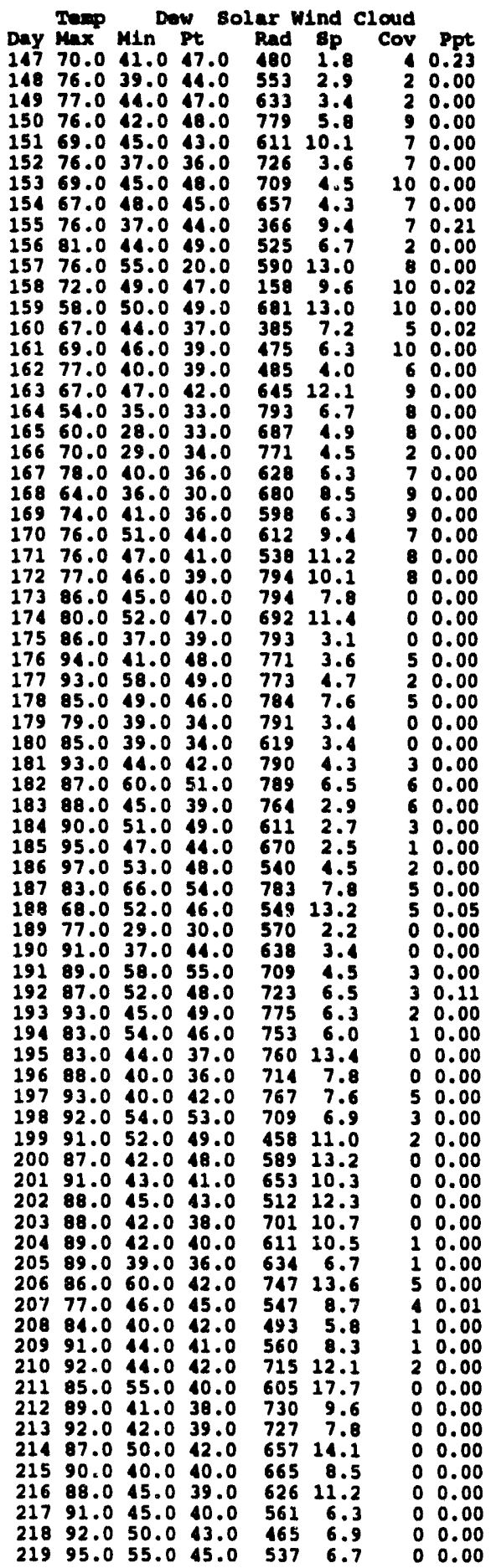


Year 1982 (Cont'd)

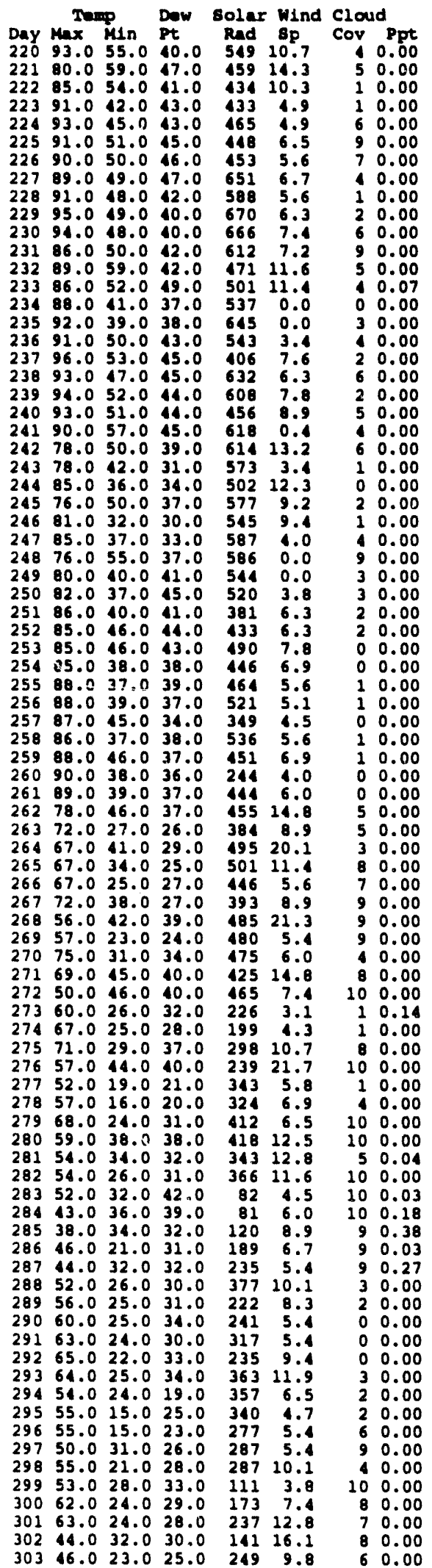

Thap Dow solur wind cloud

Day Max Min Pt Rad 8p Cov Ppt

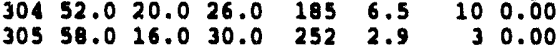
$\begin{array}{llllllll}305 & 58.0 & 16.0 & 30.0 & 252 & 2.9 & 3 & 0.00 \\ 306 & 64.0 & 19.0 & 34.0 & 242 & 3.1 & 2 & 0.00\end{array}$

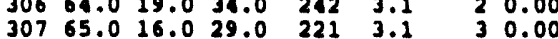

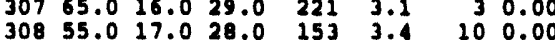
$\begin{array}{llllllll}309 & 57.0 & 25.0 & 30.0 & 264 & 4.0 & 5 & 0.00\end{array}$

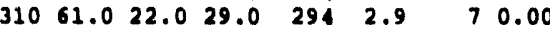

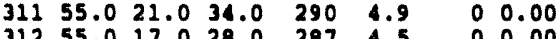

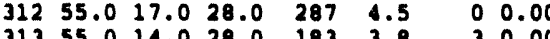

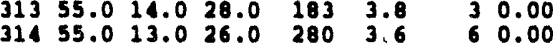

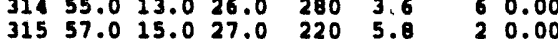
$\begin{array}{llllllll}315 & 57.0 & 15.0 & 27.0 & 220 & 5.8 & 2 & 0.00 \\ 316 & 48.0 & 23.0 & 28.0 & 274 & 4.9 & 8 & 0.00\end{array}$

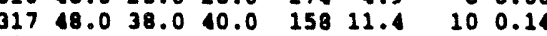
$\begin{array}{lllllllll}318 & 49.0 & 37.0 & 33.0 & 138 & 17.4 & 10 & 0.20\end{array}$

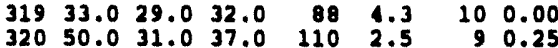
$\begin{array}{llllllll}321 & 47.0 & 32.0 & 33.0 & 156 & 10.3 & 10 & 0.00\end{array}$ $\begin{array}{lllllllllll}322 & 45.0 & 32.0 & 30.0 & 93 & 11.0 & 6 & 0.05\end{array}$

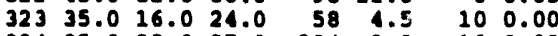
$32435.022 .027 .0 \quad 204 \quad 2.2 \quad 100.00$ $32543.028 .0 \quad 33.0 \quad 153 \quad 7.8 \quad 100.00$

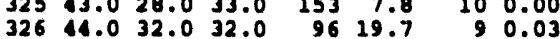

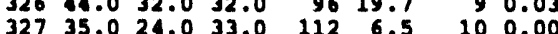

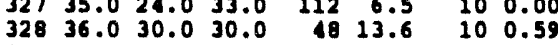
$\begin{array}{llllllll}329 & 36.0 & 22.0 & 20.0 & 06 & 8.7 & 9 & 0.00\end{array}$

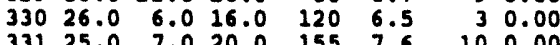
$\begin{array}{llllllll}331 & 25.0 & 7.0 & 20.0 & 155 & 7.6 & 10 & 0.00\end{array}$ $\begin{array}{llllllll}332 & 27.0 & 4.0 & 19.0 & 54 & 3.4 & 8 & 0.00\end{array}$

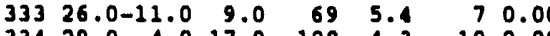

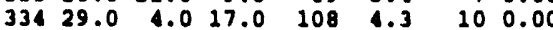

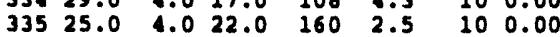

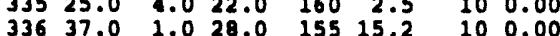

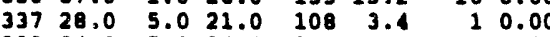
$\begin{array}{llllllll}338 & 34.0 & 5.0 & 24.0 & 224 & 4.5 & 10 & 0.00\end{array}$ $\begin{array}{rrrrrrrr}339 & 37.0 & 9.0 & 20.0 & 208 & 0.4 & 10 & 0.00 \\ 340 & 45.0 & 12.0 & 27.0 & 133 & 0.0 & 10 & 0.00\end{array}$ $\begin{array}{llllll}340 & 45.0 & 12.0 & 27.0 & 133 & 0.0\end{array}$ $\begin{array}{lllllll}341 & 46.0 & 27.0 & 33.0 & 123 & 2.9\end{array}$ $\begin{array}{llllll}342 & 41.0 & 20.0 & 30.0 & 219 & 3.0 \\ 343 & 41.0 & 17.0 & 28.0 & 218 & 4.0\end{array}$ $3446.0 \quad 18.029 .0 \quad 217 \quad 13.9$ $34533.024 .023 .0 \quad 20411.0$ $34627.0 \quad 16.0 \quad 19.0 \quad 197 \quad 3.1$ $34738.021 .027 .0 \quad 168 \quad 2.5$ $348 \quad 39.0 \quad 25.0 \quad 31.0 \quad 4312.0$ $\begin{array}{lllll}349 & 41.0 & 27.0 & 32.0 & 4311.6\end{array}$ $350 \quad 39.0 \quad 25.022 .0 \quad 448.1$ $\begin{array}{llllll}351 & 38.0 & 9.0 & 18.0 & 143 & 4.5\end{array}$ $\begin{array}{llllll}352 & 26.0 & 10.0 & 16.0 & 142 & 4.5\end{array}$ $\begin{array}{llllll}353 & 42.0 & 12.0 & 28.0 & 186 & 4.9\end{array}$ $\begin{array}{llllll}354 & 38.0 & 24.0 & 36.0 & 54 & 18.3\end{array}$ $\begin{array}{rrrrrr}354 & 38.0 & 24.0 & 36.0 & 54 & 18.3\end{array}$

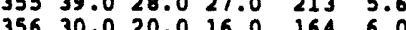
$\begin{array}{lllllll}357 & 26.0 & 5.0 & 12.0 & 124 & 4.0\end{array}$ $\begin{array}{llllll}358 & 24.0 & 5.0 & 16.0 & 185 & 2.2\end{array}$ $\begin{array}{lllllll}359 & 35.0 & 11.0 & 18.0 & 198 & 5.4\end{array}$ $\begin{array}{llllll}360 & 16.0 & 9.0 & 17.0 & 215 & 5.1\end{array}$ $\begin{array}{llllll}361 & 21.0 & 1.0 & 12.0 & 44 & 1.8\end{array}$ $36319.0-3.0212 .02173 .3$

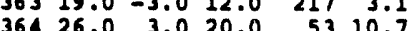

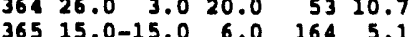
Year 1982

\section{Temp Dew solar wind cloud}

Day Max Min Pt Rad sp Cov Ppt

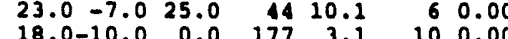

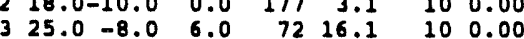

$\begin{array}{rrrrrrr}25.0 & -8.0 & 6.0 & 72 & 16.1 & 10 & 0.00 \\ 30.0 & 20.0 & 20.0 & 45 & 27.1 & 10 & 0.00\end{array}$

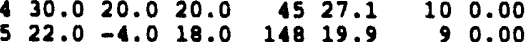

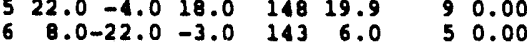

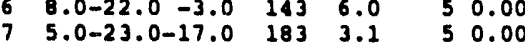

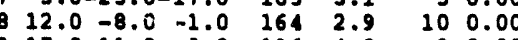

$917.0-11.0 \quad 8.0 \quad 196 \quad 4.0 \quad 90.00$

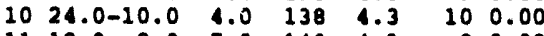

$\begin{array}{llllllll}11 & 18.0 & -8.0 & 7.0 & 143 & 4.9 & 8 & 0.00\end{array}$

$\begin{array}{llllllll}12 & 23.0 & -5.0 & 2.0 & 153 & 6.0 & 8 & 0.00\end{array}$

$\begin{array}{llllllll}13 & 22.0 & 2.0 & 13.0 & 70 & 4.5 & 10 & 0.00\end{array}$

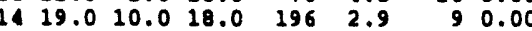

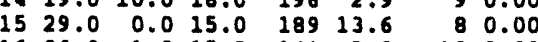

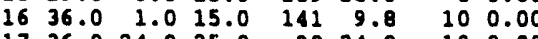

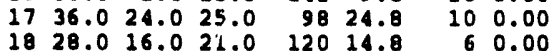

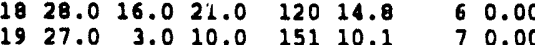

Tump Dew Bolar Wind Cloud Day Max Min Pt Rad 8p Cov Ppt $\begin{array}{llllllll}21 & 22.0 & 15.0 & 20.0 & 75 & 16.3 & 10 & 0.00 \\ 22 & 16.0 & -6.0 & 7.0 & 52 & 17.0 & 9 & 0.00\end{array}$

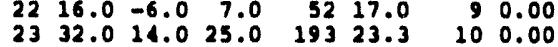
$2436.012 .0 \quad 26.0 \quad 14424.2 \quad 100.00$ $\begin{array}{llllllll}25 & 26.0 & 6.0 & 19.0 & 234 & 3.8 & 10 & 0.00\end{array}$

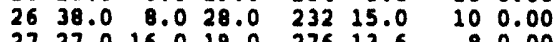

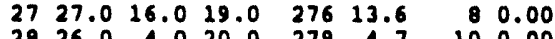
$\begin{array}{llllllll}28 & 26.0 & 4.0 & 20.0 & 279 & 4.7 & 10 & 0.00\end{array}$ $\begin{array}{lllllllll}29 & 22.0 & -7.0 & 18.0 & 116 & 12.1 & 10 & 0.00\end{array}$

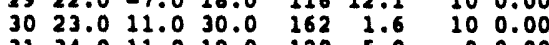

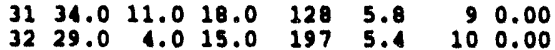
$\begin{array}{llllllll}32 & 29.0 & 1.0 & 15.0 & 197 & 5.4 & 10 & 0.00 \\ 33 & 25.0 & 7.0 & 18.0 & 226 & 3.1 & 10 & 0.00\end{array}$ $\begin{array}{llllllll}34 & 12.0 & 2.0 & -2.0 & 214 & 17.0 & 6 & 0.00\end{array}$

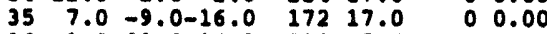
$36 \quad 1.0-32.0-14.0 \quad 213 \quad 5.4 \quad 60.00$ $\begin{array}{llllllll}38 & 15.0 & 0.0 & 5.0 & 315 & 2.0 & 10 & 0.00\end{array}$ $3914.0 .15 .0-5.0 \quad 105 \quad 4.9 \quad 40.00$ $1012.0-12.0 \quad 4.0 \quad 171 \quad 5.4 \quad 100.00$

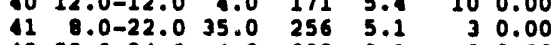

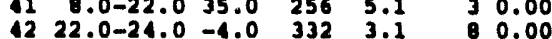
$4325.0-14.0 \quad 9.0 \quad 310 \quad 4.5 \quad 100.00$ $\begin{array}{llllllll}44 & 32.0 & -7.0 & 19.0 & 256 & 5.1 & 10 & 0.00\end{array}$

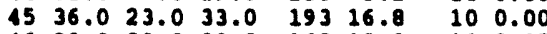

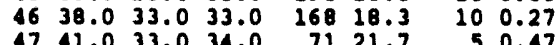

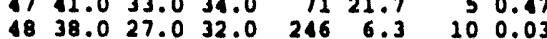
$4934.026 .029 .0 \quad 271 \quad 7.6 \quad 100.00$

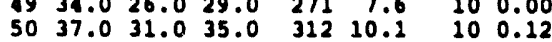

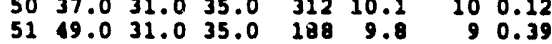

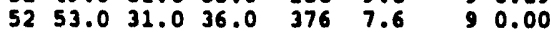

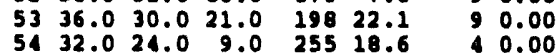
$\begin{array}{rrrrrrr}54 & 32.0 & 24.0 & 9.0 & 255 & 18.6 & 40.00 \\ 55 & 31.0 & 12.0 & 12.0 & 143 & 7.6 & 0.00\end{array}$

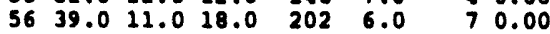

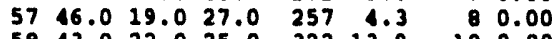

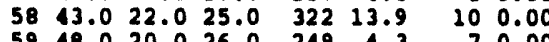

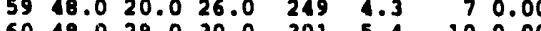

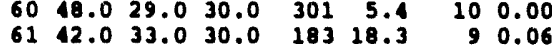
$\begin{array}{llllllll}61 & 12.0 & 33.0 & 30.0 & 183 & 18.3 & 9 & 0.06 \\ 62 & 40.0 & 21.0 & 23.0 & 397 & 12.1 & 9 & 0.00\end{array}$

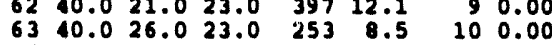

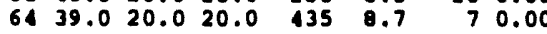
$\begin{array}{llllllll}65 & 39.0 & 20.0 & 20.0 & 205 & 8.7 & 9 & 0.00 \\ 66 & 48.0 & 24.0 & 26.0 & 272 & 9.4 & 5 & 0.00\end{array}$ $\begin{array}{llllllll}67 & 47.0 & 20.0 & 30.0 & 451 & 10.3 & 10 & 0.00\end{array}$ $\begin{array}{llllll}68 & 50.029 .028 .0 \quad 40518.8 & 8 & 0.00\end{array}$ $\begin{array}{lllllll}69 & 52.0 & 31.0 & 28.0 & 399 & 16.8 & 70.00\end{array}$ $\begin{array}{rlllllll}70 & 52.0 & 31.0 & 28.0 & 399 & 16.8 & 7 & 0.00 \\ 76.0 & 33.0 & 345 & 20.8 & 10 & 0.00\end{array}$ $\begin{array}{rrrrrrrr}70 & 19.0 & 36.0 & 33.0 & 345 & 20.8 & 10 & 0.00 \\ 71 & 37.0 & 18.0 & 15.0 & 282 & 15.7 & 6 & 0.00\end{array}$ $\begin{array}{rrrrrrrr}71 & 37.0 & 18.0 & 15.0 & 282 & 15.7 & 6 & 0.00 \\ 72 & 48.0 & 17.0 & 21.0 & 157 & 6.0 & 3 & 0.00\end{array}$

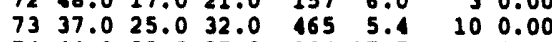
$7444.0 \quad 32.0 \quad 27.0 \quad 264 \quad 17.7 \quad 8 \quad 0.16$

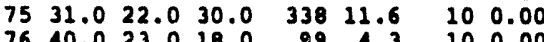

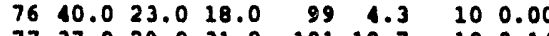

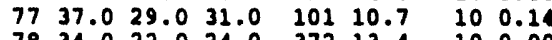
$\begin{array}{llllllll}78 & 34.0 & 22.0 & 24.0 & 372 & 13.4 & 10 & 0.00\end{array}$ $\begin{array}{rrrrrrrr}79 & 36.0 & 23.0 & 18.0 & 307 & 6.3 & 10 & 0.00 \\ 80 & 36.0 & 16.0 & 21.0 & 202 & 3.6 & 7 & 0.00\end{array}$ $8140.018 .020 .0 \quad 479 \quad 7.4 \quad 70.00$

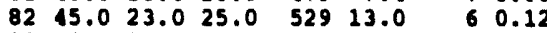

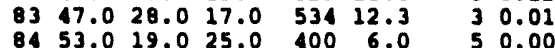

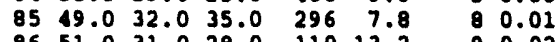

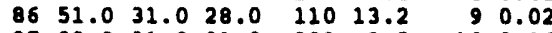

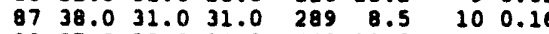

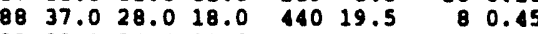

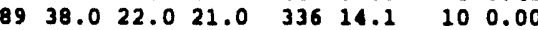
$90 \quad 44.026 .027 .0 \quad 256 \quad 17.2 \quad 100.12$ $9136.0 \quad 31.0 \quad 26.0 \quad 136 \quad 15.0 \quad 100.01$ $9236.016 .022 .0 \quad 184 \quad 14.3 \quad 80.00$ $9344.0 \quad 30.0 \quad 31.0 \quad 276 \quad 18.3 \quad 100.16$ $94 \quad 38.027 .017 .0 \quad 396 \quad 18.3 \quad 80.04$ $96 \quad 4.015 .0 \quad 13.0 \quad 550 \quad 6.7 \quad 30.00$ $9739.019 .022 .0 \quad 385 \quad 8.1 \quad 80.00$

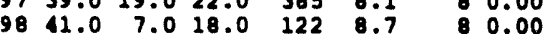
$\begin{array}{rrrrrrrr}98 & 11.0 & 7.0 & 18.0 & 122 & 8.7 & 8 & 0.00 \\ 99 & 16.0 & 24.0 & 18.0 & 394 & 8.3 & 7 & 0.02\end{array}$ $10058.018 .020 .0 \quad 48211.0 \quad 10.00$ $\begin{array}{llllllll}101 & 58.0 & 40.0 & 40.0 & 584 & 12.8 & 10 & 0.00\end{array}$ $\begin{array}{llllllll}102 & 52.0 & 36.0 & 32.0 & 297 & 20.4 & 8 & 0.18\end{array}$

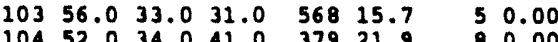
$\begin{array}{lllllllll}105 & 42.0 & 27.0 & 8.0 & 394 & 17.0 & 7 & 0.00\end{array}$ 


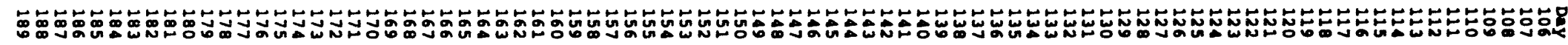

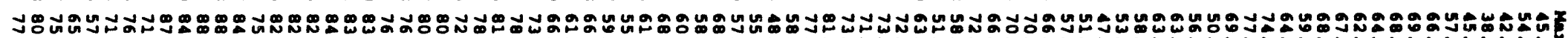

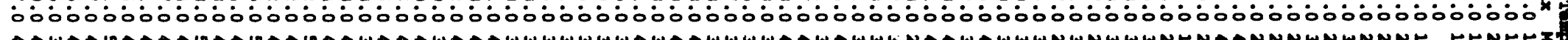

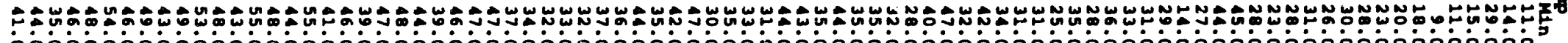

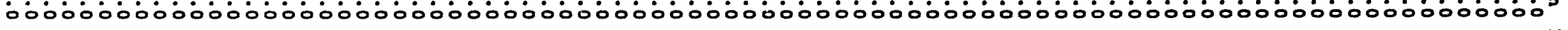

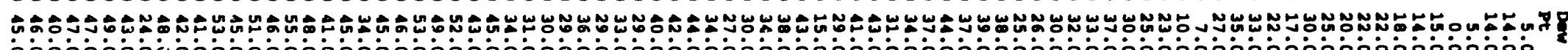

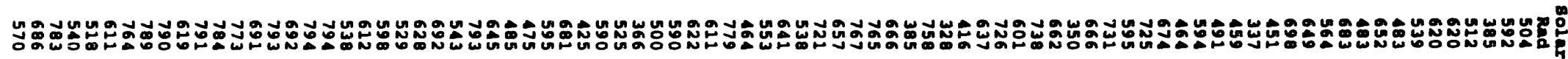

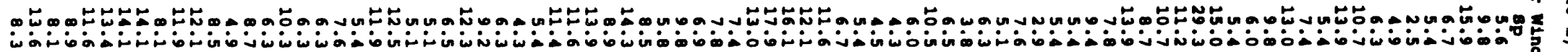

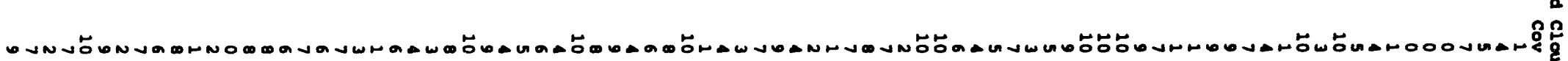
00000000000000000000000000000000000000000000000000000000000000000000000000000000000000

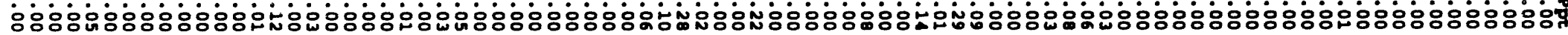

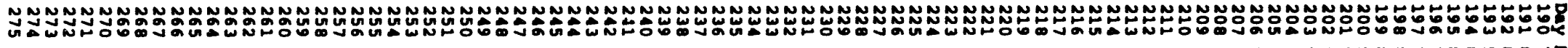

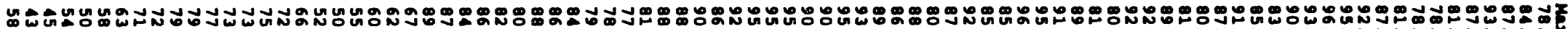

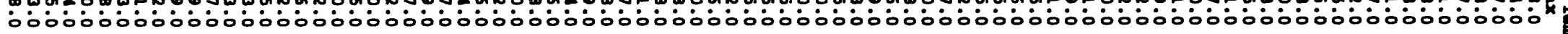

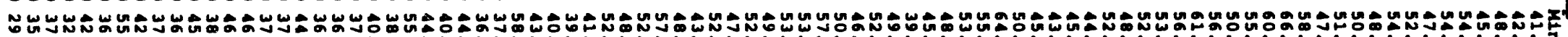

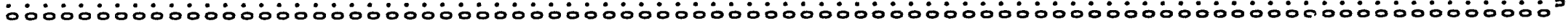

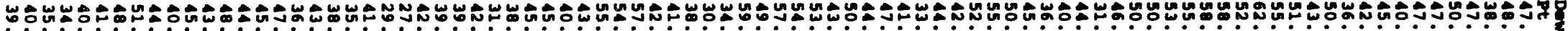
бo

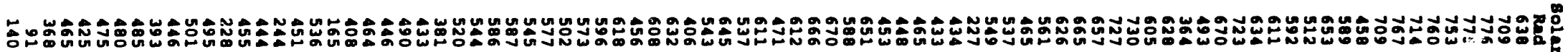

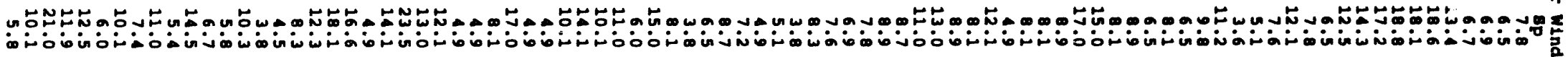

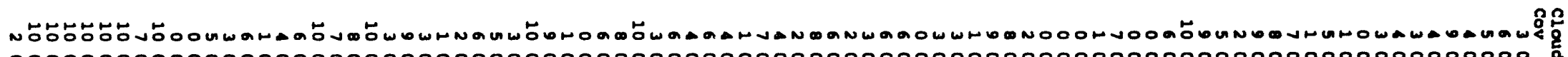
ஸें

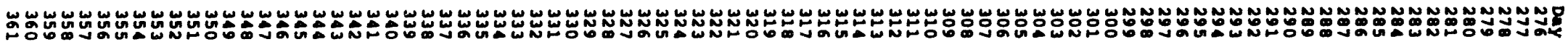

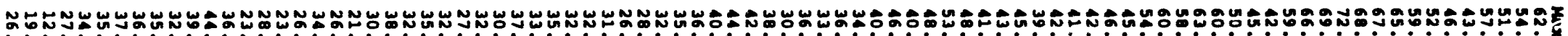

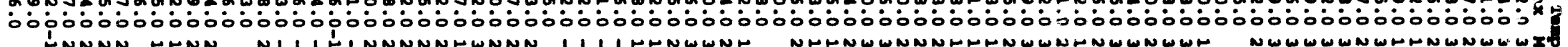

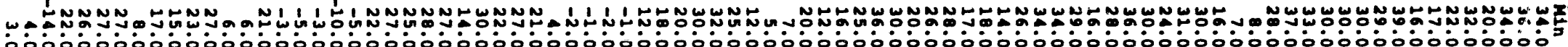

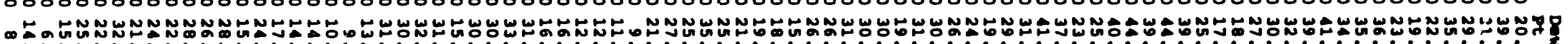

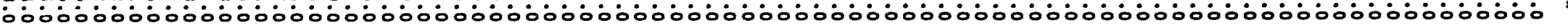

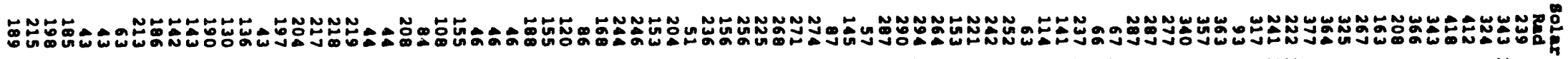

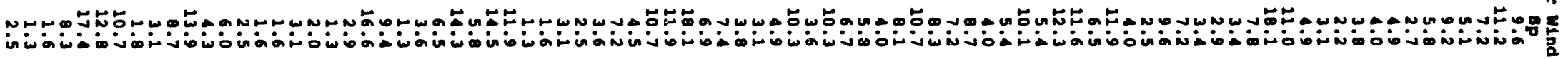

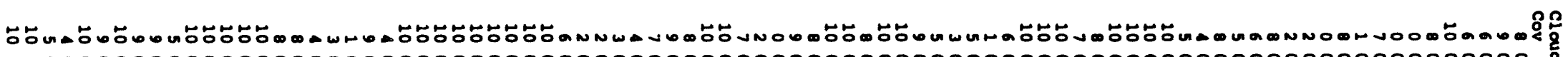

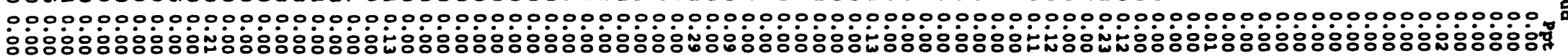




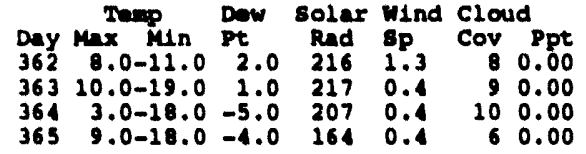

Year 1983

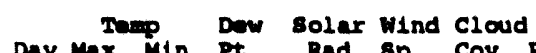

Day Max Min Pt Rad 8p Cov Ppt $20.0-15.0 \quad 3.01700 .7$ 6 0.00 $213.0-17.0 \quad 5.0 \quad 177 \quad 0.4 \quad 60.00$

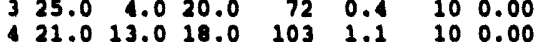

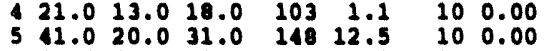
$639.033 .0 \quad 31.0 \quad 14312.1 \quad 100.24$ $736.0 \quad 34.0 \quad 32.0 \quad 18311.0 \quad 100.18$ $\begin{array}{lllllll}11.0 & 31.0 & 32.0 & 164 & 10.1 & 7 & 0.24\end{array}$

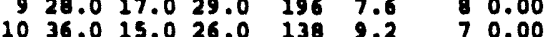

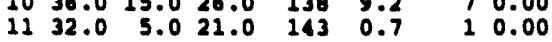

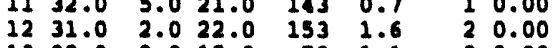

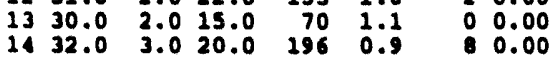

$\begin{array}{llllllll}14 & 32.0 & 3.0 & 20.0 & 196 & 0.9 & 8 & 0.00 \\ 15 & 32.0 & 0.0 & 18.0 & 189 & 0.4 & 3 & 0.00\end{array}$

$\begin{array}{llllllll}16 & 29.0 & 2.0 & 16.0 & 141 & 0.7 & 10 & 0.00\end{array}$

$\begin{array}{llllllll}17 & 32.0 & 20.0 & 25.0 & 50 & 0.7 & 10 & 0.00 \\ 18 & 35.0 & 27.0 & 27.0 & 120 & 0.4 & 10 & 0.00\end{array}$

$1935.028 .028 .0 \quad 151 \quad 2.9 \quad 100.00$

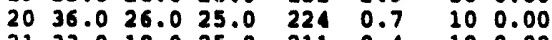

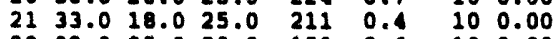

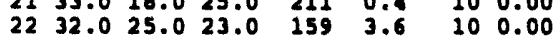

$2336.024 .027 .0 \quad 64 \quad 7.8 \quad 9600$

$2436.018 .0 \quad 25.0 \quad 144 \quad 0.9 \quad 100.00$

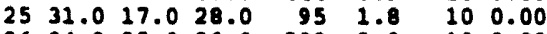

$\begin{array}{llllllll}26 & 34.0 & 25.0 & 26.0 & 232 & 2.0 & 10 & 0.00 \\ 27 & 10.0 & 18.0 & 30.0 & 276 & 1.6 & 10 & 0.00\end{array}$

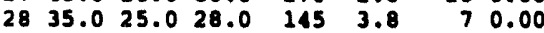

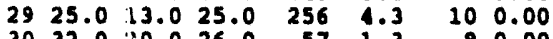

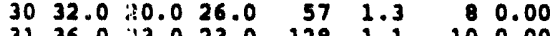

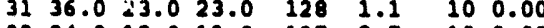

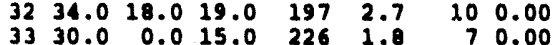

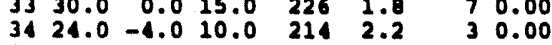

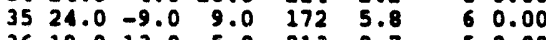

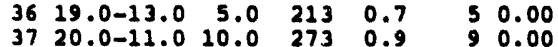

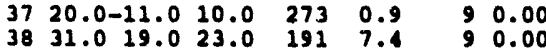

$3931.0 \quad 18.022 .0 \quad 105 \quad 2.9 \quad 100.00$

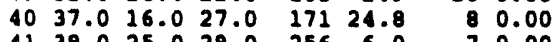

$4138.025 .0 \quad 29.0 \quad 256 \quad 6.0 \quad 7 \quad 0.00$

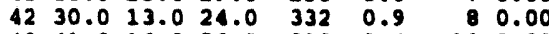

$\begin{array}{llllllll}43 & 11.0 & 16.0 & 26.0 & 310 & 0.4 & 10 & 0.00 \\ 44 & 35.0 & 29.0 & 32.0 & 256 & 9.2 & 10 & 0.00\end{array}$

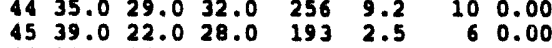

$\begin{array}{llllll}46 & 38.023 .026 .0 & 303 & 0.9 & 8 & 0.00\end{array}$

$4738.028 .030 .0 \quad 71 \quad 7.6 \quad 80.08$

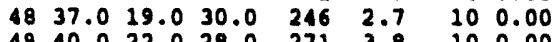

$50 \quad 12.025 .026 .0 \quad 312 \quad 2.2 \quad 70.00$

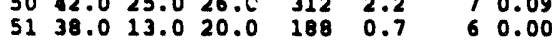

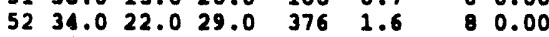

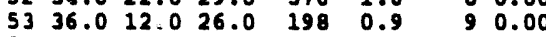

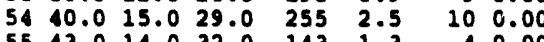

$\begin{array}{llllllll}55 & 43.0 & 14.0 & 32.0 & 143 & 1.3 & 40.00 \\ 56 & 39.0 & 20.0 & 30.0 & 202 & 1.6 & 9 & 0.00\end{array}$

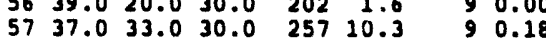

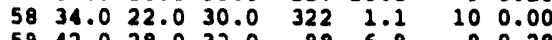

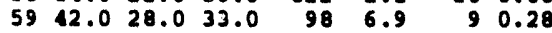

$\begin{array}{llllllll}60 & 47.0 & 32.0 & 37.0 & 301 & 4.3 & 10 & 0.45\end{array}$

$\begin{array}{llllllll}61 & 43.0 & 37.0 & 32.0 & 183 & 4.7 & 9 & 0.35\end{array}$

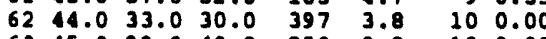

$\begin{array}{llllllll}63 & 45.0 & 29.0 & 40.0 & 253 & 3.8 & 10 & 0.00\end{array}$

$\begin{array}{llllllll}64 & 38.0 & 30.0 & 34.0 & 435 & 2.2 & 8 & 0.00 \\ 65 & 43.0 & 25.0 & 22.0 & 205 & 5.6 & 7 & 0.00\end{array}$

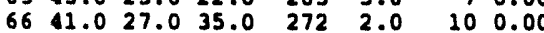

$\begin{array}{llllllll}67 & 44.0 & 22.0 & 31.0 & 451 & 0.7 & 8 & 0.00\end{array}$

$\begin{array}{llllllll}68 & 53.0 & 28.0 & 35.0 & 105 & 1.1 & 10 & 0.00\end{array}$

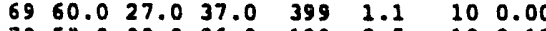

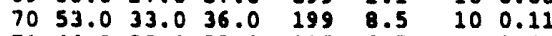

$\begin{array}{lllllll}71 & 46.0 & 28.0 & 29.0 & 115 & 6.7 & 0.08\end{array}$

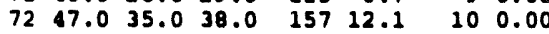

$\begin{array}{llllllll}73 & 43.0 & 32.0 & 28.0 & 351 & 8.9 & 8 & 0.43 \\ 74 & 43.0 & 21.0 & 23.0 & 401 & 4.0 & 8 & 0.00\end{array}$

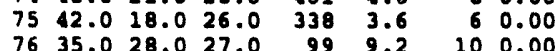

Tow Dew solar wind cloud

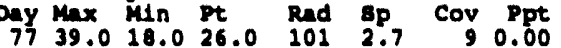
$7833.024 .0 \quad 18.0 \quad 485 \quad 2.7 \quad 100.00$

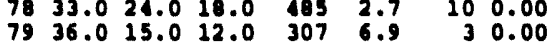
$8044.0 \quad 18.018 .0 \quad 202 \quad 0.7 \quad 8000$

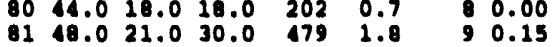

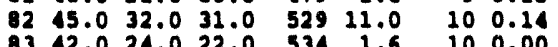

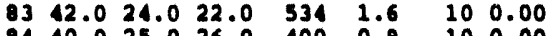

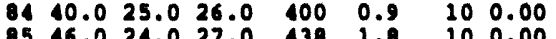
$8546.024 .027 .0 \quad 138 \quad 1.8 \quad 100.00$ $8743.024 .021 .0 \quad 209 \quad 4.3 \quad 80.11$ $8844.0 \quad 24.0 \quad 27.0 \quad 542 \quad 5.4 \quad 200.00$

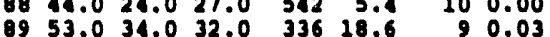

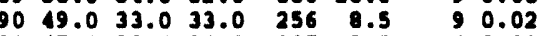
$9147.023 .024 .0 \quad 337 \quad 2.5 \quad 40.00$ $\begin{array}{llllllll}92 & 12.0 & 32.0 & 33.0 & 372 & 5.6 & 9 & 0.00\end{array}$ $9339.0 \quad 31.0 \quad 34.0 \quad 276 \quad 13.4 \quad 100.14$

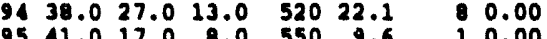

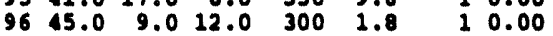
$9752.0 \quad 18.0 \quad 20.0 \quad 385 \quad 1.6 \quad 30.00$

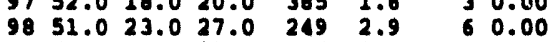
$9951.026 .035 .0 \quad 3943.1 \quad 90.00$

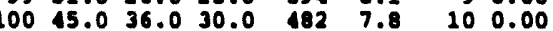
$\begin{array}{llllllll}101 & 45.0 & 30.0 & 23.0 & 584 & 1.3 & 10 & 0.00\end{array}$

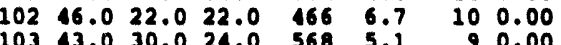
$103 \quad 43.0 \quad 30.024 .0 \quad 568 \quad 5.1 \quad 90.00$

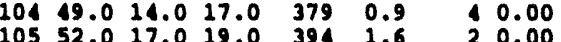
$\begin{array}{lllllll}10657.0 & 18.0 & 22.0 & 504 & 3.8 & 1 & 0.00\end{array}$

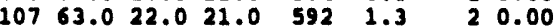

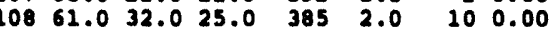

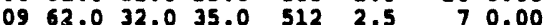

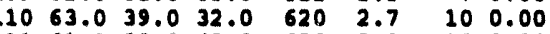

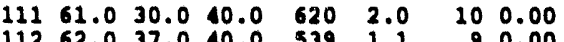
$\begin{array}{llllllll}112 & 62.0 & 37.0 & 40.0 & 539 & 1.1 & 9 & 0.00 \\ 113 & 63.0 & 32.0 & 35.0 & 293 & 4.0 & 9 & 0.03\end{array}$

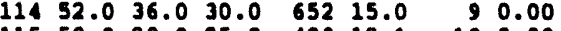

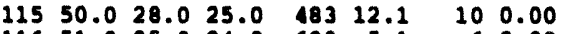

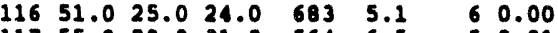

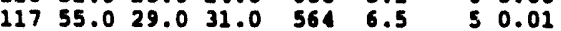

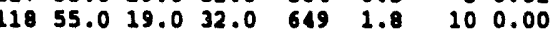
$1954.0 \quad 34.0 \quad 35.0 \quad 698 \quad 2.9 \quad 90.24$

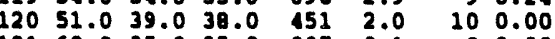

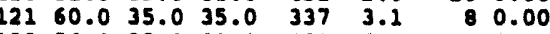

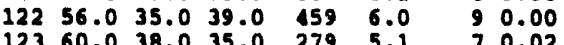

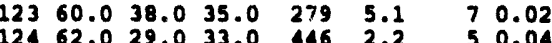
$\begin{array}{rrrrrrr}125 & 49.0 & 29.0 & 33.0 & 446 & 2.2 & \\ 125 & 99.0 & 40.0 & 229 & 15.7 & 10 & 0.12\end{array}$ $\begin{array}{llllllll}126 & 59.0 & 38.0 & 32.0 & 573 & 4.5 & 7 & 0.06\end{array}$ $\begin{array}{llllllll}127 & 64.0 & 30.0 & 33.0 & 725 & 14.3 & 70.00\end{array}$

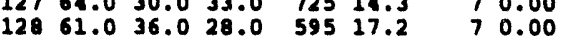
$129 \quad 12.0 \quad 30.0 \quad 26.0 \quad 731 \quad 12.8 \quad 70.00$

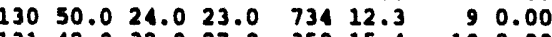

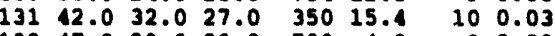
$\begin{array}{llllllll}132 & 47.0 & 29.0 & 23.0 & 733 & 4.3 & 9 & 0.00 \\ 133 & 50.0 & 26.0 & 24.0 & 743 & 3.8 & 8 & 0.00\end{array}$

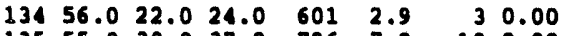
$\begin{array}{llllllll}135 & 55.0 & 30.0 & 37.0 & 726 & 7.2 & 10 & 0.00\end{array}$

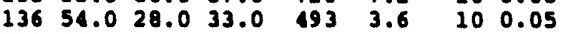
$\begin{array}{llllllll}137 & 62.0 & 30.0 & 28.0 & 593 & 6.9 & 2 & 0.00\end{array}$ $\begin{array}{llllllll}138 & 58.0 & 45.0 & 43.0 & 543 & 6.3 & 10 & 0.00\end{array}$

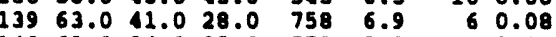

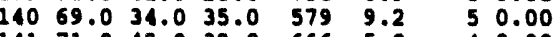
$\begin{array}{llllllll}141 & 71.0 & 42.0 & 32.0 & 666 & 5.8 & 0.00\end{array}$ $\begin{array}{llllllll}142 & 73.0 & 31.0 & 34.0 & 765 & 2.2 & 0 & 0.00\end{array}$ $\begin{array}{llllll}14379.0 & 35.0 & 22.0 & 767 & 7.6 & 40.00\end{array}$

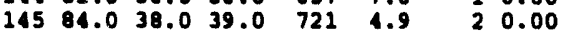
$\begin{array}{llllllll}146 & 84.0 & 40.0 & 40.0 & 538 & 4.0 & 1 & 0.00\end{array}$

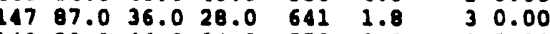

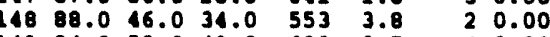
$\begin{array}{llllllll}149 & 84.0 & 52.0 & 43.0 & 633 & 8.7 & 4 & 0.00\end{array}$ $\begin{array}{llllllll}150 & 73.0 & 52.0 & 34.0 & 779 & 16.8 & 2 & 0.00\end{array}$ $\begin{array}{llllllll}151 & 66.0 & 44.0 & 33.0 & 611 & 7.4 & 9 & 0.00 \\ 152 & 66.0 & 43.0 & 12.0 & 726 & 3.8 & 6 & 0.00\end{array}$

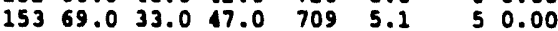
$\begin{array}{llllllll}154 & 71.0 & 17.0 & 46.0 & 657 & 3.8 & 9 & 0.00\end{array}$ $\begin{array}{llllllll}155 & 72.0 & 47.0 & 48.0 & 582 & 1.8 & 10 & 0.00\end{array}$ $\begin{array}{llllllll}156 & 66.0 & 46.0 & 46.0 & 525 & 2.9 & 5 & 0.00\end{array}$ $\begin{array}{llllllll}157 & 68.0 & 54.0 & 45.0 & 379 & 0.9 & 6 & 0.63 \\ 158 & 72.0 & 16.0 & 42.0 & 125 & 2.0 & 2 & 0.00\end{array}$

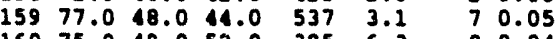
$\begin{array}{llllllll}160 & 75.0 & 49.0 & 52.0 & 385 & 6.3 & 8 & 0.04\end{array}$ $\begin{array}{llllll}16281.0 & 16.0 & 42.0 & 485 & 14.8 & 9\end{array}$
Tomp Dew solar Wind Cloud

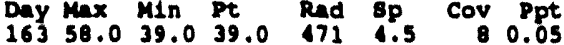

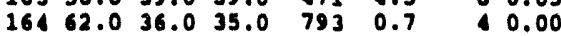

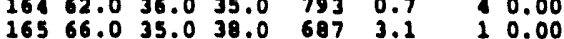

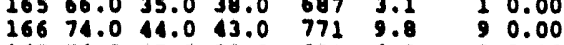

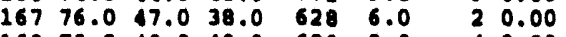
$\begin{array}{lllllll}168 & 73.0 & 43.0 & 43.0 & 680 & 8.3 & 0.00\end{array}$

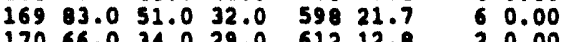

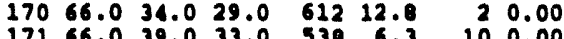

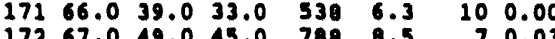
$17365.0 \quad 33.0 \quad 50.0 \quad 794 \quad 4.5 \quad 10.15$ $17482.0 \quad 14.0 \quad 39.0 \quad 692 \quad 9.2 \quad 80.00$

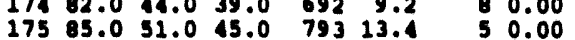

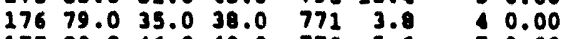
$\begin{array}{llllllll}177 & 83.0 & 46.0 & 43.0 & 773 & 5.6 & 7 & 0.00\end{array}$

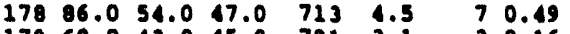

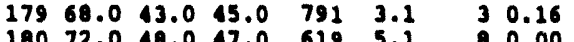
$\begin{array}{lllllll}180 & 72.0 & 48.0 & 47.0 & 619 & 5.1 & 0.00 \\ 181 & 77.0 & 47.0 & 42.0 & 790 & 6.7 & 0.00\end{array}$ $\begin{array}{lllllllll}182 & 75.0 & 55.0 & 42.0 & 789 & 8.7 & 10 & 0.00\end{array}$

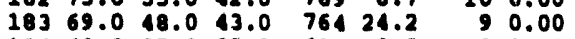
$\begin{array}{llllllll}184 & 68.0 & 37.0 & 35.0 & 611 & 0.5 & 0 & 0.00\end{array}$

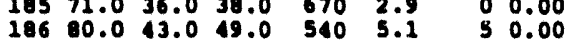

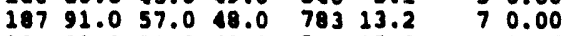

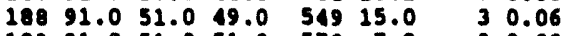

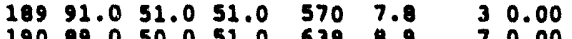

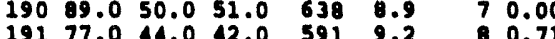

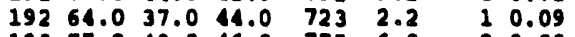

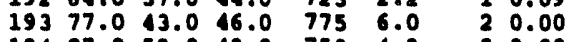
$\begin{array}{rlllllll}194 & 87.0 & 52.0 & 49.0 & 753 & 4.9 & 2 & 0.00 \\ 195 & 89.0 & 53.0 & 52.0 & 760 & 13.2 & 3 & 0.00\end{array}$

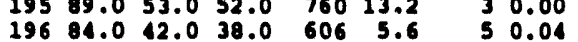

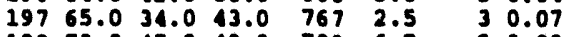

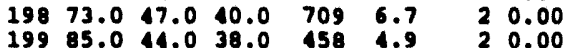
$\begin{array}{llllllll}200 & 88.0 & 44.0 & 45.0 & 589 & 11.0 & 2 & 0.00\end{array}$ $\begin{array}{lllllll}201 & 89.0 & 54.0 & 40.0 & 653 & 13.0\end{array}$ $\begin{array}{llllll}202 & 78.0 & 34.0 & 39.0 & 512 & 2.0\end{array}$ $20388.0 \quad 52.0 \quad 48.0 \quad 701 \quad 5.4$ $20485.0 \quad 57.0 \quad 52.0 \quad 611 \quad 4.3$ $\begin{array}{llllll}205 & 83.0 & 52.0 & 47.0 & 482 & 6.3\end{array}$ $\begin{array}{llllll}206 & 86.0 & 58.0 & 52.0 & 747 & 8.3\end{array}$ $20786.0 \quad 47.050 .0 \quad 670 \quad 5.8$ $\begin{array}{llllll}208 & 83.0 & 17.0 & 12.0 & 493 & 7.6\end{array}$ $20984.0 \quad 49.0 \quad 44.0 \quad 560 \quad 4.9$ $\begin{array}{llllll}210 & 88.0 & 50.0 & 43.0 & 715 & 4.0 \\ 211 & 92.0 & 49.0 & 42.0 & 605 & 2.7\end{array}$ $21294.0 \quad 57.0 \quad 56.0 \quad 730 \quad 3.8$ $21378.0 \quad 52.056 .0 \quad 7276.0$ $21487.0 \quad 47.052 .0 \quad 657 \quad 4.0$ $\begin{array}{llllll}215 & 89.0 & 44.0 & 53.0 & 665 & 3.1\end{array}$ $\begin{array}{llllll}216 & 90.0 & 52.0 & 57.0 & 626 & 4.7\end{array}$ $\begin{array}{llllll}217 & 90.0 & 47.0 & 53.0 & 561 & 2.7\end{array}$ $21896.0 \quad 51.0 \quad 56.0 \quad 465 \quad 3.4$ $\begin{array}{llllll}219 & 98.0 & 55.0 & 54.0 & 537 & 3.4\end{array}$ $\begin{array}{llllll}220 & 98.0 & 67.0 & 59.0 & 549 & 10.1\end{array}$ $\begin{array}{llllll}221 & 86.0 & 60.0 & 54.0 & 227 & 3.4\end{array}$ $\begin{array}{llllll}222 & 89.0 & 58.0 & 56.0 & 434 & 3.1\end{array}$ $22393.062 .058 .0 \quad 189 \quad 9.4$ $22482.0 \quad 47.0 \quad 47.0 \quad 465 \quad 4.5$ $\begin{array}{llllll}225 & 87.0 & 43.0 & 47.0 & 448 & 6.5\end{array}$ $\begin{array}{rrrrrr}226 & 88.0 & 56.0 & 49.0 & 453 & 10.5 \\ 227 & 88.0 & 60.0 & 58.0 & 651 & 4.7\end{array}$ $\begin{array}{llllll}228 & 75.0 & 51.0 & 56.0 & 588 & 3.4\end{array}$ $22985.0 \quad 56.0 \quad 58.0 \quad 670 \quad 3.8$ $\begin{array}{llllll}230 & 77.0 & 51.0 & 55.0 & 666 & 4.5\end{array}$ $\begin{array}{lllllll}231 & 85.0 & 59.0 & 60.0 & 612 & 4.3\end{array}$ $23267.0 \quad 58.0 \quad 56.0 \quad 277 \quad 10.7$ $23377.0 \quad 51.0 \quad 54.0 \quad 611 \quad 5.1$ $23475.0 \quad 46.0 \quad 45.0 \quad 388 \quad 3.4$ $\begin{array}{llllll}235 & 78.0 & 49.0 & 49.0 & 645 & 4.3\end{array}$ $23677.0 \quad 17.0 \quad 43.0 \quad 543 \quad 4.0$ $\begin{array}{llllll}237 & 81.0 & 48.0 & 43.0 & 406 & 3.8\end{array}$ $\begin{array}{llllll}239 & 86.0 & 11.0 & 38.0 & 608 & 4.3\end{array}$ $240 \quad 88.0 \quad 48.0 \quad 39.0 \quad 456 \quad 6.9$ $\begin{array}{lllllll}241 & 88.0 & 49.0 & 45.0 & 618 & 4.7\end{array}$ $\begin{array}{llllll}242 & 85.0 & 52.0 & 42.0 & 596 & 4.9\end{array}$ $\begin{array}{lllllll}243 & 87.0 & 47.0 & 43.0 & 573 & 5.8\end{array}$ $24489.0 \quad 51.0 \quad 45.0 \quad 502 \quad 18.8$ $\begin{array}{llllll}24592.0 & 54.0 & 41.0 & 473 & 6.5 \\ 246 & 77.0 & 42.0 & 38.0 & 545 & 3.4\end{array}$ $24778.0 \quad 40.0 \quad 39.0 \quad 587 \quad 5.4$ $248 \quad 76.0 \quad 50.0 \quad 29.0 \quad 586 \quad 9.2$
0.00

20.00

90.00

10.34

9.00
40.00

10.00

$\begin{array}{ll}1 & 0.00 \\ 2 & 0.00\end{array}$

20.00

90.00

60.00

20.00

70.00

10.00

$\begin{array}{ll}5 & 0.00\end{array}$

70.00

70.14

$\begin{array}{ll}2 & 0.00 \\ 8 & 0.02\end{array}$

00.00

0.00
4

10.00
100.00

80.00 $10 \quad 0.00$ 90.00 $\begin{array}{rl}10 & 0.00 \\ 8 & 0.60\end{array}$ - 0.00 30.06 50.00 10.00 $\begin{array}{ll}3 & 0.00 \\ 5 & 0.00\end{array}$ 50.00 70.00 30.00 10.06
40.00 30.00 60.03 30.00 10.00 00.00 
Yoar 1983 (Cont'd)

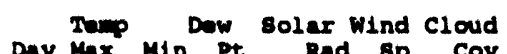

$\begin{array}{llllllll}249 & 74.0 & 32.0 & 29.0 & 544 & 3.4 & 6 & 0.00\end{array}$

$25005.0 \quad 42.0 \quad 40.0 \quad 520 \quad 4.3$

25105.051 .042 .041942 .9

25278.047 .025 .0

$25366.0 \quad 25.025 .0 \quad 490 \quad 8.1$

$25472.0 \quad 52.0 \quad 39.0 \quad 146 \quad 1.6$

$\begin{array}{llllll}255 & 77.0 & 42.0 & 38.0 & 464 & 2.0\end{array}$

$\begin{array}{llllll}256 & 00.0 & 35.0 & 37.0 & 521 & 2.0\end{array}$

$\begin{array}{llllll}257 & 03.0 & 12.0 & 34.0 & 349 & 5.6\end{array}$

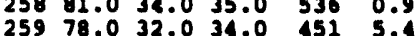

$26083.053 .0 \quad 30.0 \quad 24417.0$

26173.047 .036 .0

26275.034 .025 .0

26346.014 .011 .0

26456.016 .015 .0

26570.022 .024 .0

$\begin{array}{llll}26676.0 & 32.0 & 33.0 \\ 267 & 78.0 & 40.0 & 43.0\end{array}$

$\begin{array}{llll}267 & 78.0 & 40.0 & 43.0 \\ 268 & 75.0 & 33.0 & 37.0\end{array}$

$26979.0 \quad 35.0 \quad 12.0$

$27076.0 \quad 52.0 \quad 52.0$

$\begin{array}{lllll}271 & 62.0 & 37.0 & 35.0\end{array}$

$\begin{array}{lllll}272 & 62.0 & 42.0 & 47.0 \\ 273 & 60.0 & 18.0 & 43.0\end{array}$

$27453.037 .0 \quad 42.0$

$275 \quad 59.0 \quad 10.0 \quad 42.0$

$27657.0 \quad 38.0 \quad 34.0$

$27764.0 \quad 34.0 \quad 45.0$

$\begin{array}{llll}278 & 72.0 & 32.0 & 40.0 \\ 279 & 72.0 & 34.0 & 39.0\end{array}$

$280 \quad 69.0 \quad 45.0 \quad 38.0$

$28172.0 \quad 31.0 \quad 38.0$

$\begin{array}{llll}282 & 62.0 & 49.0 & 49.0\end{array}$

$28458.029 .0 \quad 35.0$

$28563.0 \quad 27.0 \quad 31.0$

$28653.0 \quad 34.0 \quad 39.0$

$\begin{array}{lllll}287 & 14.0 & 40.0 & 37.0 \\ 288 & 52.0 & 31.0 & 32.0\end{array}$

$\begin{array}{lllll}288 & 52.0 & 31.0 & 32.0 \\ 289 & 57.0 & 24.0 & 33.0\end{array}$

$29061.0 \quad 26.0 \quad 34.0$

1412.5

45511.9

$\begin{array}{ll}228 & 4.0 \\ 495 & 2.2\end{array}$

5013.6

$\begin{array}{ll}446 & 3.1 \\ 393 & 2.0\end{array}$

4852.0

2395.8

1632.0

$\begin{array}{ll}325 & 1.3 \\ 235 & 2.5\end{array}$

2221.6

$\begin{array}{lllllll}292 & 57.0 & 22.0 & 24.0 & 235 & 1.1\end{array}$

29365.020 .027 .0

29468.025 .033 .0

29569.028 .035 .0

$29650.0 \quad 44.0 \quad 42.0$

$29857.0 \quad 20.0 \quad 32.0$

$29966.0 \quad 20.0 \quad 32.0$

$30068.0 \quad 20.0 \quad 33.0$

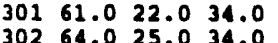

30356.024 .034 .0

$30463.0 \quad 32.0 \quad 43.0$

$\begin{array}{lllll}305 & 58.0 & 38.0 & 44.0\end{array}$

$\begin{array}{llllll}306 & 57.0 & 12.0 & 42.0\end{array}$

$\begin{array}{lllll}307 & 61.0 & 38.0 & 42.0 \\ 308 & 62.0 & 32.0 & 39.0\end{array}$

$\begin{array}{llll}308 & 62.0 & 32.0 & 39.0 \\ 309 & 53.0 & 44.0 & 39.0\end{array}$

$30953.0 \quad 44.0 \quad 39.0$

$\begin{array}{lllll}310 & 61.0 & 37.0 & \$ 2.0 \\ 311 & 45.0 & 38.0 & 20.0\end{array}$

$31243.024 .0 \quad 20.0$

31338.017 .028 .0

31446.028 .028 .0

$315 \quad 47.0 \quad 38.0 \quad 38.0$

$\begin{array}{llll}316 & 48.028 .0 \quad 29.0\end{array}$

$\begin{array}{lllll}317 & 42.0 & 32.0 & 25.0 \\ 318 & 42.0 & 28.0 & 25.0\end{array}$

$319 \quad 42.028 .0 \quad 28.0$

$\begin{array}{llllll}320 & 46.0 & 22.0 & 31.0 \\ 32 & & 31.0 & 38\end{array}$

$321 \quad 43.0 \quad 38.0 \quad 35.0$

32244.026 .028 .0

$\begin{array}{llll}323 & 32.0 & 16.0 & 26.0\end{array}$

32535.011 .025 .0

$\begin{array}{llll}326 & 29.0 & 7.0 & 10.0\end{array}$

$\begin{array}{llll}326 & 29.0 & 7.0 & 10.0 \\ 327 & 31.0 & 7.0 & 21.0\end{array}$

$\begin{array}{llll}328 & 33.0 & 27.0 & 23.0\end{array}$

$\begin{array}{llll}329 & 37.0 & 16.0 & 27.0\end{array}$

$\begin{array}{llll}330 & 35.0 & 8.0 & 19.0 \\ 331 & 32.0 & 12.0 & 16.0\end{array}$

$\begin{array}{rrrr}332 & 26.0 & 6.0 & 22.0\end{array}$ $\begin{array}{ll}480 & 1.6 \\ 75 & 4.3\end{array}$

$298 \quad 1.6$

631.8

$\begin{array}{ll}2.6 & 5.4 \\ 91 & 2.2\end{array}$

105.1

$324 \quad 1.8$

$\begin{array}{ll}12 & 6.3 \\ 18 & 2.5\end{array}$

1191.3

824.3

671.1

491.6

80.02
10.00

$\begin{array}{ll}1 & 0.00 \\ 1 & 0.00\end{array}$

10.00

$\begin{array}{ll}1 & 0.00 \\ 2 & 0.00\end{array}$

20.00

$\begin{array}{ll}1 & 0.00 \\ 0 & 0.00\end{array}$

100.00

10.00

70.00

10.00

$\begin{array}{ll}1 & 0.02 \\ 5 & 0.00\end{array}$

8.00

$\begin{array}{ll}1 & 0.00 \\ 0 & 0.00\end{array}$

100.00

100.22

100.05

90.36

100.58

$\begin{array}{ll}9 & 0.26 \\ 9 & 0.00\end{array}$

20.00

$\begin{array}{ll}1 & 0.00 \\ 3 & 0.00\end{array}$

20.00

60.00

$\begin{array}{ll}9 & 0.39 \\ 7 & 0.05\end{array}$

$\begin{array}{ll}7 & 0.05 \\ 3 & 0.00\end{array}$

$\begin{array}{ll}3 & 0.00 \\ 3 & 0.00\end{array}$

90.00

100.14

$\begin{array}{ll}7 & 0.13 \\ 3 & 0.00\end{array}$

60.00

70.00

10.00

50.00

o 0.00

30.00

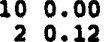

$\begin{array}{ll}2 & 0.12 \\ 0 & 0.00\end{array}$

10.00

10.00

$\begin{array}{ll}1 & 0.00 \\ 5 & 0.00\end{array}$

$\begin{array}{rr}5 & 0.00 \\ 10 & 0.00\end{array}$

100.00

$\begin{array}{ll}7 & 0.00 \\ 8 & 0.00\end{array}$

$\begin{array}{ll}8 & 0.00 \\ 6 & 0.09\end{array}$

60.00

100.00

$\begin{array}{ll}9 & 0.00 \\ 7 & 0.00\end{array}$

$\begin{array}{rl}7 & 0.00 \\ 10 & 0.10\end{array}$

100.10

70.00
100.00

10
9 0.000

100.30

60.00

$\begin{array}{ll}8 & 0.16 \\ 7 & 0.02\end{array}$

$\begin{array}{rr}7 & 0.02 \\ 10 & 0.00\end{array}$

80.00

100.16

70.03

$\begin{array}{rrrr}58 & 1.9 & 9 & 0.00 \\ 70 & 2.0 & 10 & 0.00\end{array}$

100.00

$\begin{array}{rr}10 & 0.00 \\ 6 & 0.00\end{array}$

100.00

100.00

100.00

30.00

$\begin{array}{ll}10 & 0.00 \\ 10 & 0.00\end{array}$
Tomp Daw solar wind cloud

Day Max Min Pt $\quad$ Rad 8 p Cov Ppt $33419.0-15.011 .0 \quad 108 \quad 5.1 \quad 100.00$

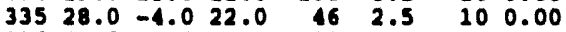

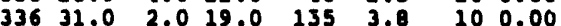
$33727.019 .022 .0 \quad 108 \quad 4.9 \quad 100.00$

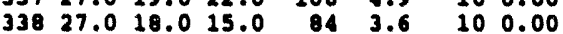

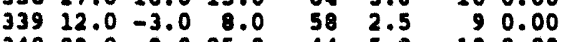

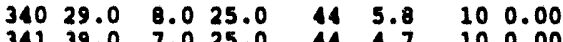

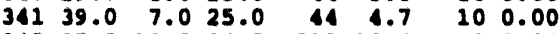

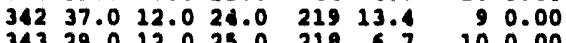

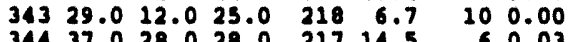
$34437.028 .028 .0 \quad 217 \quad 14.5 \quad 6 \quad 0.03$

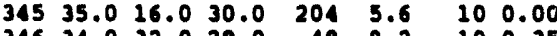

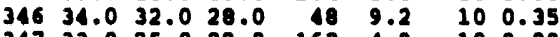

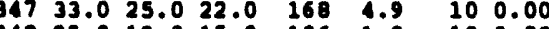

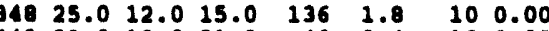

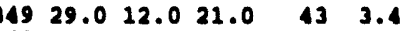

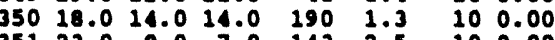

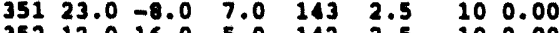

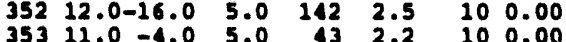
354 5.0-19.0-17.0 $54 \quad 3.190 .00$

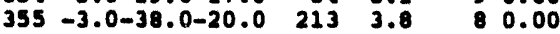
$356 \quad 6.0-36.0-23.0 \quad 164 \quad 4.3 \quad 30.00$ $357-8.0-47.0-30.0 \quad 124 \quad 11.0 \quad 100.00$ $35811.0-38.0-3.0 \quad 18512.1 \quad 100.00$ $35925.011 .018 .0 \quad 19810.5 \quad 100.00$

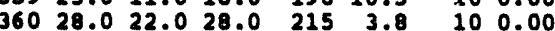

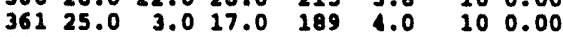

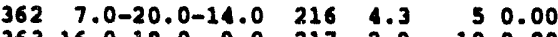

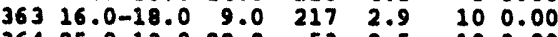

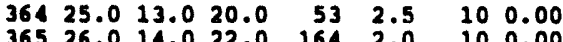

Year 1984

Day Max Min Pt Bolar Wind Cloud

$124.013 .021 .4 \quad 170 \quad 3.4 \quad 100.00$

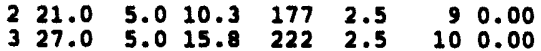

$\begin{array}{lllll}29.0 & 10.025 .6 & 103 & 2.5 & 100.00\end{array}$

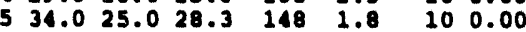

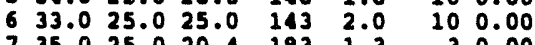

$\begin{array}{lllllll}735.0 & 25.0 & 20.4 & 183 & 1.3 & 3 & 0.00\end{array}$

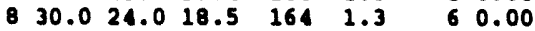

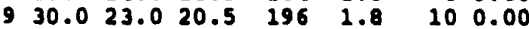

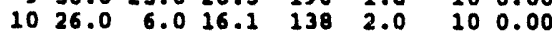

$1122.0-2.021 .2143 \quad 3.1 \quad 100.00$

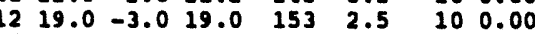

$1324.013 .014 .4 \quad 4812.3 \quad 100.00$

$1421.013 .014 .4 \quad 19616.1 \quad 100.00$

$159.0-12.0 \quad 4.4 \quad 1893.1 \quad 40.00$

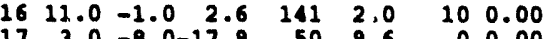

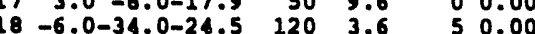

$19 \quad 2.0-29.0-18.1 \quad 151 \quad 3.6 \quad 6 \quad 0.00$

$20 \quad 0.0-31.0-13.0 \quad 2243.8 \quad 90.00$

$2116.0-6.03 .32112 .2 \quad 100.00$

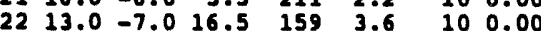

$2316.0 \quad 0.020 .2 \quad 64 \quad 3.6 \quad 100.00$

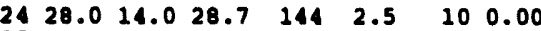

$\begin{array}{llllllll}25 & 36.0 & 22.0 & 31.3 & 234 & 10.1 & 9 & 0.00\end{array}$

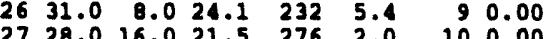

$2728.016 .021 .5 \quad 276 \quad 2.0$

$\begin{array}{llllllll}28 & 24.0 & 20.0 & 17.6 & 279 & 1.6 & 2 & 0.00\end{array}$

$\begin{array}{llllllll}29 & 24.0 & 21.0 & 14.1 & 256 & 2 . & 7 & 0.00\end{array}$

$\begin{array}{llllllll}30 & 21.0 & 0.0 & 11.0 & 162 & 2.0 & 7 & 0.00\end{array}$

$\begin{array}{llllllll}31 & 19.0 & -6.0 & 8.5 & 128 & 1.8 & 2 & 0.00 \\ 32 & 23.0 & 1.0 & 13.6 & 197 & 2.0 & 5 & 0.00\end{array}$

$\begin{array}{llllllll}32 & 23.0 & 1.0 & 13.6 & 197 & 2.0 & 5 & 0.00 \\ 33 & 14.0 & -7.0 & 12.5 & 226 & 1.8 & 9 & 0.00\end{array}$

$\begin{array}{llllllll}34 & 17.0 & 5.0 & 8.5 & 214 & 1.8 & 8 & 0.00\end{array}$

$\begin{array}{llllllll}35 & 22.0 & -8.0 & 6.7 & 172 & 2.0 & 8 & 0.00\end{array}$

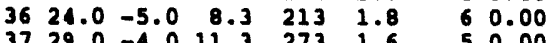

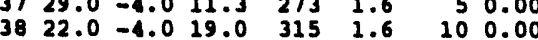

$\begin{array}{llllllll}39 & 18.0 & 17.0 & 16.7 & 238 & 0.9 & 7 & 0.00\end{array}$

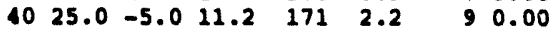

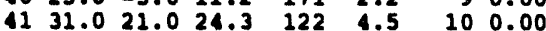

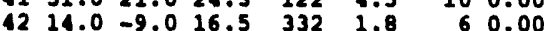

$\begin{array}{lllllll}421.0 & 7.0 & 22.3 & 175 & 2.0 & 10 & 0.00\end{array}$

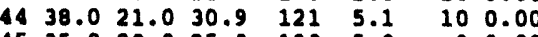

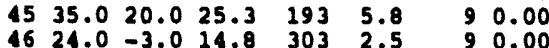

$4729.0 \quad 19.026 .0 \quad 71 \quad 4.3 \quad 100.00$

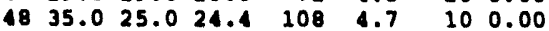

Tomp Dow solar wind Cloud

Day Max Min Pt $\quad$ Rad 8p Cov Ppt

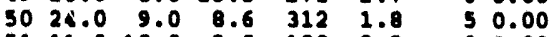

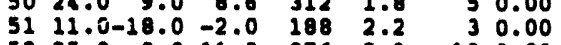

$\begin{array}{llllll}52 & 25.0 & 0.0 & 11.0 & 376 & 2.9\end{array}$

5324.019 .017 .97612 .1

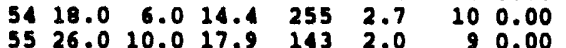

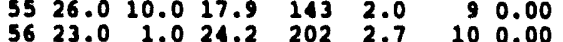

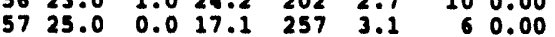

5820.015 .0 7.5 $322 \quad 2.7$

$\begin{array}{llllll}59 & 26.0 & -8.0 & 7.2 & 249 & 2.0\end{array}$

$6029.0-4.0 \quad 10.8 \quad 3012.0$

$6130.0 \quad 4.022 .6 \quad 323 \quad 2.0$

$62 \quad 32.0 \quad 5.021 .9 \quad 397 \quad 5.4$

$6329.0 \quad 10.020 .1 \quad 96 \quad 3.4$

$\begin{array}{llllll}64 & 28.0 & -6.0 & 10.7 & 435 & 5.4\end{array}$

$\begin{array}{llllll}65 & 17.0 & -7.0 & 8.7 & 205 & 3.8\end{array}$

$\begin{array}{llllll}66 & 32.0 & 6.0 & 16.4 & 272 & 2.0\end{array}$

$\begin{array}{llllll}67 & 32.0 & 0.0 & 14.3 & 451 & 2.5\end{array}$

$\begin{array}{llllll}69 & 11.0 & 17.0 & 27.5 & 399 & 2.0\end{array}$

$\begin{array}{llllll}70 & 10.0 & 19.0 & 30.5 & 345 & 1.6\end{array}$

$\begin{array}{llllll}71 & 36.0 & 25.0 & 30.8 & 282 & 10.3\end{array}$

$\begin{array}{llllll}72 & 38.0 & 23.0 & 30.0 & 95 & 9.2\end{array}$

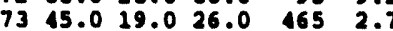

$\begin{array}{llllll}74 & 38.0 & 34.0 & 31.6 & 264 & 15.4\end{array}$

$\begin{array}{llllll}75 & 38.0 & 30.0 & 31.5 & 179 & 4.3\end{array}$

$\begin{array}{llllll}76 & 36.0 & 30.0 & 29.2 & 107 & 16.1\end{array}$

$\begin{array}{llllll}77 & 34.0 & 26.0 & 29.7 & 101 & 12.8\end{array}$

$\begin{array}{llllll}78 & 37.0 & 15.0 & 24.9 & 372 & 10.2\end{array}$

$\begin{array}{lllllll}79 & 43.0 & 13.0 & 26.3 & 307 & 2.2\end{array}$

$\begin{array}{lllllr}80 & 44.0 & 32.0 & 32.8 & 202 & 2.2 \\ 81 & 39.0 & 24.0 & 27.7 & 361 & 12.3\end{array}$

$\begin{array}{llllll}82 & 10.0 & 26.0 & 27.2 & 529 & 3.6\end{array}$

$8344.0 \quad 15.027 .4 \quad 534 \quad 2.5$

$8438.023 .026 .4 \quad 100 \quad 8.5$

$85 \quad 36.019 .023 .0 \quad 438 \quad 5.8$

$86 \leq 3.025 .028 .5 \quad 110 \quad 5.6$

$8743.022 .024 .0 \quad 436 \quad 4.0$

$\begin{array}{lllllll}88 & 40.0 & 14.0 & 24.7 & 542 & 4.0\end{array}$

$\begin{array}{llllll}89 & 44.0 & 22.0 & 26.0 & 471 & 6.0\end{array}$

$\begin{array}{llllll}90 & 47.0 & 25.0 & 22.7 & 417 & 6.7\end{array}$

$\begin{array}{lllllll}91 & 45.0 & 20.0 & 23.8 & 337 & 3.8\end{array}$

$93 \quad 46.036 .025 .7 \quad 436 \quad 3$.

$9449.0 \quad 19.024 .3 \quad 520 \quad 2.9$

$9553.022 .024 .7550 \quad 2.2$

$9655.025 .029 .9 \quad 300 \quad 2.7$

$9747.033 .033 .0 \quad 188 \quad 6.0$

$98 \quad 49.026 .023 .8 \quad 249 \quad 5.8$

$9953.031 .027 .4 \quad 394 \quad 7.2$

$100 \quad 45.027 .0 \quad 27.4 \quad 326 \quad 6.3$

$10149.0 \quad 30.0 \quad 30.1 \quad 584 \quad 11.2$

$\begin{array}{lllllll}102 & 41.0 & 22.0 & 21.3 & 466 & 4.9\end{array}$ 
Yoar 1984 (Cont'd)

Day Max Min De solar wind cloud

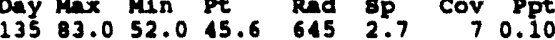

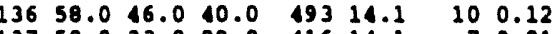

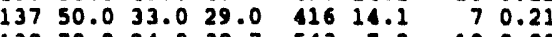

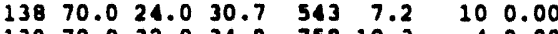

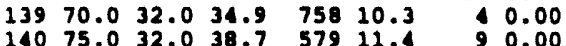

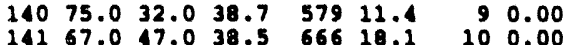

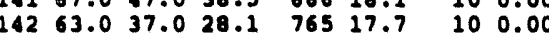

$14366.025 .0 \quad 30.5 \quad 7672.7 \quad 00.00$

$14474.0 \quad 33.0 \quad 39.8 \quad 657 \quad 10.3 \quad 80.00$

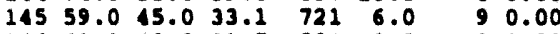

$\begin{array}{llllllll}146 & 61.0 & 40.0 & 31.7 & 534 & 3.8 & 8 & 0.00\end{array}$

$14769.036 .0 \quad 36.0 \quad 641 \quad 9.2 \quad 40.00$

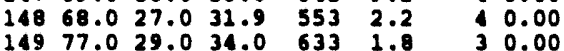

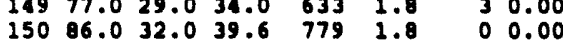

$\begin{array}{llllllll}151 & 04.0 & 44.0 & 44.6 & 611 & 5.6 & 7 & 0.00\end{array}$

$\begin{array}{llllllll}152 & 64.0 & 11.0 & 27.4 & 726 & 16.3 & 6 & 0.00\end{array}$

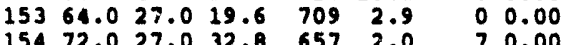

$\begin{array}{rrrrrrr}154 & 72.0 & 27.0 & 32.8 & 657 & 2.0 & 7 \\ 15558.0 & 11.0 & 41.1 & 366 & 2.7 & 8 & 0.25\end{array}$

$\begin{array}{llllllll}156 & 52.0 & 35.0 & 42.3 & 525 & 5.4 & 10 & 0.00\end{array}$

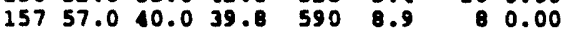

$\begin{array}{llllllll}158 & 59.0 & 40.0 & 42.4 & 158 & 10.7 & 9 & 0.40\end{array}$

$\begin{array}{llllllll}159 & 59.0 & 38.0 & 39.8 & 537 & 1.7 & 7 & 0.26 \\ 160 & 55.0 & 37.0 & 31.8 & 385 & 5.8 & 5 & 0.55\end{array}$

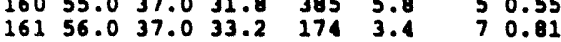

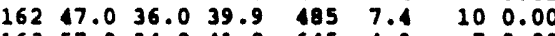

$\begin{array}{llllllll}163 & 57.0 & 34.0 & 41.0 & 645 & 1.9 & 7 & 0.00\end{array}$

$16470.0 \quad 30.0 \quad 42.3 \quad 793 \quad 2.9 \quad 80.00$

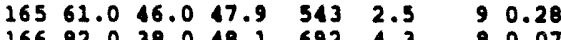

$\begin{array}{llllllll}166 & 82.0 & 38.0 & 48.1 & 692 & 4.3 & 8 & 0.07\end{array}$

$16874.0 \quad 48.0 \quad 42.6 \quad 680 \quad 1.3 \quad 60.16$

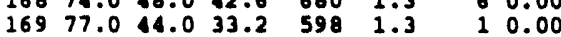

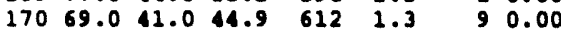

$17179.0 \quad 38.0 \quad 44.1 \quad 538 \quad 3.6 \quad 40.00$

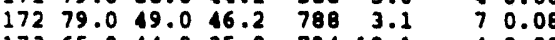

$\begin{array}{llllll}173 & 65.0 & 44.0 & 35.0 & 794 & 10.1\end{array}$

$17468.0 \quad 36.0 \quad 35.6 \quad 692 \quad 2.7$

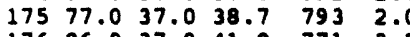

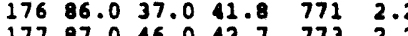

$1787.0 \quad 46.042 .7 \quad 7732.2$

$\begin{array}{llllll}178 & 86.0 & 45.0 & 42.3 & 784 & 2.0\end{array}$

$18090.0 \quad 44.0 \quad 12.4 \quad 619 \quad 2.0$

$\begin{array}{llllll}181 & 87.0 & 50.0 & 47.8 & 790 & 4.0\end{array}$

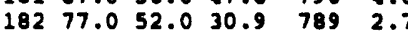

$18380.033 .031 .6 \quad 764 \quad 1.1$

$18485.0 \quad 40.0 \quad 39.6 \quad 6112.7$

$\begin{array}{lllllll}185 & 82.0 & 46.0 & 39.1 & 670 & 2.0\end{array}$

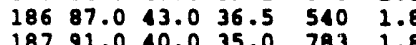

$\begin{array}{llllll}187 & 91.0 & 10.0 & 35.0 & 783 & 1.8\end{array}$

$\begin{array}{llllll}188 & 90.0 & 49.0 & 46.6 & 686 & 2.9\end{array}$

19082.050 .042 .463814 .1

$19193.039 .0 \quad 38.5 \quad 709 \quad 2.9$

$13281.0 \quad 38.0 \quad 10.5 \quad 776 \quad 1.8$

19388.038 .040 .37752 .0

$19487.047 .0 \quad 43.47534 .3$

$\begin{array}{llllll}195 & 86.0 & 43.0 & 37.1 & 760 & 1.8\end{array}$

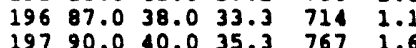

$\begin{array}{lllllll}198 & 92.0 & 43.0 & 36.5 & 709 & 1.6\end{array}$

$\begin{array}{llllll}199 & 93.0 \quad 43.0 \quad 36.8 \quad 458 & 2.0\end{array}$

$\begin{array}{llllll}200 & 96.0 & 50.0 & 44.3 \quad 589 & 2.5\end{array}$

$20187.061 .050 .5 \quad 5072.0$

$\begin{array}{llllll}202 & 84.0 & 50.0 & 51.3 & 512 & 6.3\end{array}$

$20373.0 \quad 53.0 \quad 53.6 \quad 5926.7$

$20467.052 .054 .8 \quad 4111$.

20573.058 .058 .46341 .3

$\begin{array}{lllllll}206 & 89.0 & 47.0 & 55.7 & 747 & 1.8\end{array}$

$20792.0 \quad 49.0 \quad 55.5 \quad 670 \quad 2.0$

$\begin{array}{llllll}208 & 90.0 & 56.0 & 55.6 & 249 & 2.7\end{array}$

$\begin{array}{llllll}209 & 80.0 & 63.0 & 60.3 & 364 & 1.3\end{array}$

$21178.058 .058 .3 \quad 4441.1$

$21283.0 \quad 50.0 \quad 54.3 \quad 730 \quad 1.3$

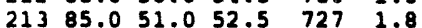

$\begin{array}{lllll}21483.0 & 61.0 & 53.8 & 657 & 4.0\end{array}$

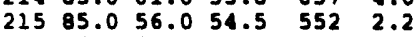

$\begin{array}{llllll}216 & 86.0 & 58.0 & 50.1 & 626 & 1.8\end{array}$

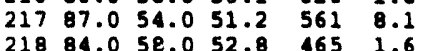

Tump Dow solar wind Cloud

Day Max Min Pt Rad 8p Cov Ppt $22087.0 \quad 45.0 \quad 42.5 \quad 549 \quad 1.1 \quad 20.00$

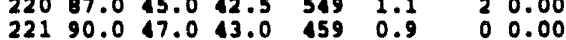

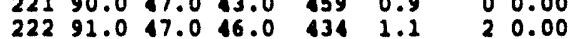

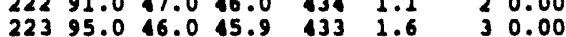

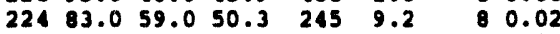
$\begin{array}{lllllll}225 & 89.0 & 51.0 & 48.2 & 48 & 7.4 & 0.00\end{array}$

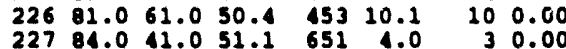
$22888.053 .054 .9 \quad 454 \quad 4.7$

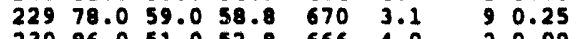

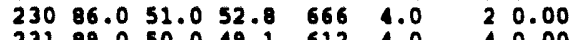
$\begin{array}{lllllll}231 & 89.0 & 50.0 & 99.1 & 612 & 4.0 & 0.00\end{array}$

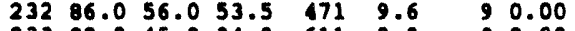

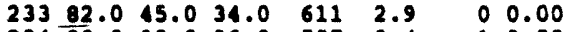

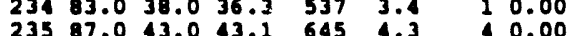

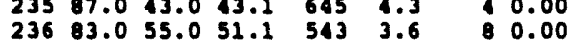

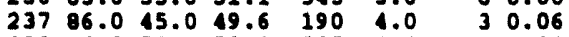
$\begin{array}{llllllll}238 & 66.0 & 53.0 & 52.8 & 587 & 2.0 & 9 & 0.03 \\ 239 & 84.0 & 49.0 & 48.5 & 608 & 2.0 & 3 & 0.00\end{array}$ $408.0 \quad 47.047 .6 \quad 45613.0$ $24183.0 \quad 54.0 \quad 41.5 \quad 618 \quad 27.1$ $24287.0 \$ 4.0 \quad 41.5 \quad 6147.2$ $\begin{array}{llllll}242 & 87.0 & 51.0 & 11.5 & 614 & 7.2 \\ 243 & 88.0 & 47.0 & 46.6 & 573 & 3.8\end{array}$

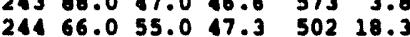
$24572.0 \quad 40.0 \quad 40.5 \quad 47311.4$ $24678.0 \quad 35.0 \quad 37.4 \quad 545 \quad 5.1$ $\begin{array}{llllll}246 & 78.0 & 35.0 & 37.4 & 545 & 5.1 \\ 247 & 84.0 & 37.0 & 38.4 & 587 & 3.1\end{array}$

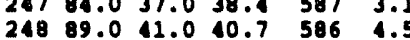
$\begin{array}{llllll}24983.0 & 51.0 & 49.8 & 544 & 5.1\end{array}$ $\begin{array}{lllllll}250 & 65.0 & 50.0 & 11.7 & 520 & 17.7\end{array}$ $\begin{array}{llllll}251 & 69.0 & 32.0 & 35.8 & 381 & 8.1\end{array}$ $\begin{array}{llllll}252 & 78.0 & 38.0 & 44.5 & 433 & 7.4\end{array}$ 25475.039 .036 .3446 255 75.039 .036 .3 $\begin{array}{llll} & 464 & 9.6\end{array}$

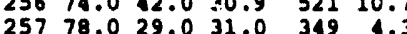
$\begin{array}{llllll}257 & 78.0 & 29.0 & 31.0 & 349 & 4.3 \\ 258 & 76.0 & 33.0 & 31.9 & 536 & 5.4\end{array}$ $\begin{array}{llllll}258 & 76.0 & 33.0 & 31.9 & 536 & 5.4 \\ 259 & 83.0 & 49.0 & 41.5 & 451 & 3.8\end{array}$ $\begin{array}{cccccc}259 & 83.0 & 49.0 & 41.5 & 451 & 3.8 \\ 260 & 83.0 & 40.0 & 41.5 & 244 & 2.5\end{array}$ $\begin{array}{lllllll}260 & 83.0 & 40.0 & 11.5 & 244 & 2.5 \\ 261 & 86.0 & 36.0 & 36.5 & 44 & 2.0\end{array}$ $\begin{array}{llllll}262 & 88.0 & 37.0 & 39.0 & 455 & 2.9\end{array}$ $\begin{array}{lllllll}263 & 87.0 & 38.0 & 40.8 & 384 & 2.7\end{array}$ $\begin{array}{llllll}264 & 79.0 & 48.0 & 47.5 \quad 195 & 10.3\end{array}$ $\begin{array}{lllllll}265 & 57.0 & 14.0 & 34.4 & 501 & 7.8\end{array}$ $26657.026 .027 .1 \quad 319 \quad 3.4$ $26757.0 \quad 37.028 .9 \quad 393 \quad 4.7$ $268 \quad 48.0 \quad 16.025 .3 \quad 485 \quad 3.8$ $26957.0 \quad 16.023 .3 \quad 480 \quad 1.0$ $\begin{array}{llllll}269 & 57.0 & 16.0 & 23.3 & 480 & 1.0 \\ 270 & 66.0 & 34.0 & 23.1 & 475 & 5.6\end{array}$ $\begin{array}{lllllll}271 & 62.0 & 24.0 & 25.7 & 125 & 7.4\end{array}$

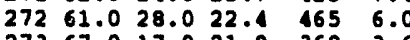
$\begin{array}{llllll}273 & 67.0 & 17.0 & 21.8 & 368 & 3.6\end{array}$ $\begin{array}{llllll}274 & 72.0 & 22.0 & 26.8 & 199 & 5.4\end{array}$ $\begin{array}{llllll}275 & 76.0 & 43.0 & 42.2 & 298 & 6.0\end{array}$ $\begin{array}{llllll}276 & 73.0 & 37.0 & 39.0 & 239 & 4.5\end{array}$ $\begin{array}{lllllll}277 & 72.0 & 35.0 & 37.2 & 343 & 2.9\end{array}$ $\begin{array}{llllll}278 & 74.0 & 30.0 & 33.8 & 324 & 3.1\end{array}$

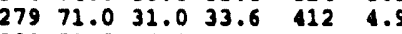

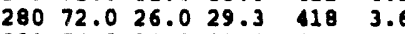

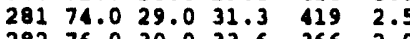
$\begin{array}{llllll}282 & 76.0 & 30.0 & 33.6 & 366 & 2.0\end{array}$ $\begin{array}{llllll}283 & 77.0 & 29.0 & 34.7 & 208 & 3.6\end{array}$ $\begin{array}{llllll}284 & 75.0 & 29.0 & 34.0 & 163 & 4.5\end{array}$ 28569.030 .034 .0426

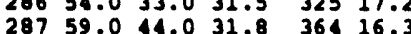

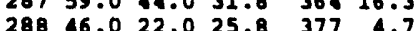
$\begin{array}{llllll}288 & 46.0 & 22.0 & 25.8 & 377 & 4.7\end{array}$ $\begin{array}{rrrrrr}289 & 44.0 & 10.0 & 25.0 & 222 & 6.5 \\ 290 & 45.0 & 9.0 & 21.3 & 241 & 4.5\end{array}$

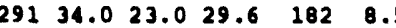
$\begin{array}{llllll}292 & 39.0 & 15.0 & 23.1 & 93 & 9.6\end{array}$ $29340.0 \quad 18.0 \quad 24.8 \quad 363 \quad 5.1$ $29440.024 .020 .9 \quad 357 \quad 4.9$ $\begin{array}{llllll}295 & 43.0 & 25.0 & 21.5 & 340 & 2.7\end{array}$

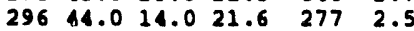
$\begin{array}{llllll}297 & 47.0 & 10.0 & 21.8 & 287 & 6.9\end{array}$ $\begin{array}{llllll}298 & 13.0 & 31.0 & 28.8 & 287 & 4.7\end{array}$

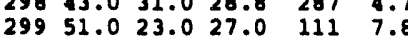
$\begin{array}{llllll}300 & 41.0 & 37.0 & 28.5 & 173 & 12.1\end{array}$

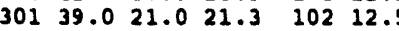
$\begin{array}{llllll}302 & 43.0 & 15.0 & 20.8 & 141 & 14.5\end{array}$ $30348.0 \quad 31.0 \quad 30.6 \quad 24919.5$

60.00

50.00

10.00

60.00

0.00

10.00

$\begin{array}{ll}1 & 0.00 \\ 2 & 0.00\end{array}$

20.00

100.00

80.00

$\begin{array}{ll}9 & 0.00 \\ 5 & 0.00\end{array}$

90.00

50.00

100.00

$\begin{array}{ll}9 & 0.00 \\ 9 & 0.00\end{array}$

90.00

50.12

60.00

$\begin{array}{ll}2 & 0.00 \\ 9 & 0.20\end{array}$

70.00

100.00

70.00

$\begin{array}{ll}5 & 0.00 \\ 9 & 0.12\end{array}$
Thap Dow solar Wind cloud Day Max Min Pt Rad 8p Cov Ppt $\begin{array}{lllllll}306 & 49.0 & 17.0 & 18.9 & 242 & 5.4 & 70.00\end{array}$

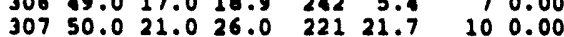
$30847.0 \quad 34.029 .5 \quad 6020.1 \quad 40.00$ $\begin{array}{lllllll}308 & 47.0 & 34.0 & 29.5 & 60 & 20.1 & 0.16\end{array}$

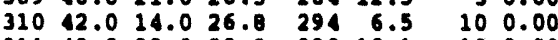
$\begin{array}{lllllll}311 & 19.022 .029 .8 & 290 & 10.1 & 10 & 0.00\end{array}$ $\begin{array}{lllllllll}312 & 46.0 & 32.0 & 29.2 & 287 & 11.2 & 7 & 0.00\end{array}$

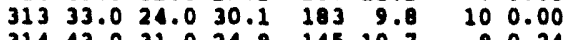

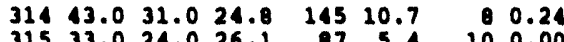

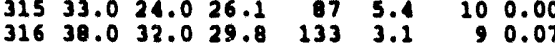
31742.031 .028 .92583 .9 $31841.0 \quad 27.0 \quad 31.0 \quad 268 \quad 13.0$ $\begin{array}{rrrrrr}318 & 41.0 & 27.0 & 31.0 & 268 & 13.0 \\ 319 & 13.0 & 29.0 & 23.9 & 88 & 11.9\end{array}$ $\begin{array}{llllll}319 & 13.0 & 29.0 & 23.9 & 88 & 11.9\end{array}$ $\begin{array}{llllll}320 & 37.0 & 10.0 & 19.3 & 256 & 5.4 \\ 321 & 13.0 & 20.0 & 22.2 & 156 & 3.1\end{array}$

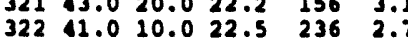

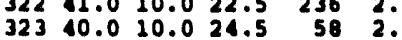
$32430.024 .027 .6 \quad 204 \quad 2.5$ $\begin{array}{llllll}325 & 36.0 & 19.0 & 22.3 & 153 & 3.8\end{array}$ $\begin{array}{llllll}326 & 45.0 & 24.0 & 26.1 & 246 & 2.0\end{array}$ $\begin{array}{lllllll}327 & 40.0 & 13.0 & 25.4 & 244 & 2.9\end{array}$ $\begin{array}{llllll}328 & 46.0 & 8.0 & 22.1 & 168 & 2.2\end{array}$ $329 \quad 35.0 \quad 17.027 .5 \quad 86 \quad 3.0$

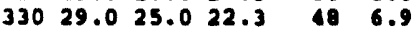
$\begin{array}{lllllll}331 & 29.0 & -1.0 & 16.4 \quad 47 \quad 3.8\end{array}$ $\begin{array}{llllll}332 & 21.0 & -6.0 & 15.4 & 180 & 2.9\end{array}$ $\begin{array}{llllll}333 & 32.0 & 20.0 & 25.1 & 46 & 8.1\end{array}$

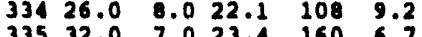
$\begin{array}{llllll}335 & 32.0 & 7.0 & 23.4 & 160 & 6.7\end{array}$

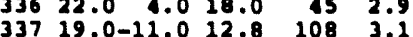
338 18.0-16.0 3.9 2242.9 $33914.0-23.0 \quad 1.1 \quad 208 \quad 2.9$ $\begin{array}{lllll}340 & 16.0-15.0 & 1.5 & 133 & 3.6\end{array}$ $34116.0-17.0 \quad 2.0 \quad 123 \quad 4.0$ $34223.0-12.0 \quad 6.0219 \quad 3.4$ $\begin{array}{llllll}343 & 31.0 & -3.0 & 11.5 & 218 & 2.7\end{array}$ $\begin{array}{llllll}344 & 26.0 & -1.0 & 17.9 & 217 & 2.9 \\ 345 & 37.0 & 16.0 & 27.2 & 204 & 6.9\end{array}$ 34632.011 .021 .319712 .5

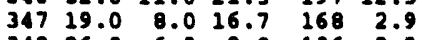
$\begin{array}{llllll}348 & 26.0 & -6.0 & 9.8 & 136 & 2.9\end{array}$ 349 9.0-14.0 $3.4 \quad 130 \quad 3.1$ $350 \quad 18.0-12.0 \quad 5.7 \quad 190 \quad 2.7$

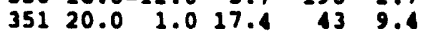
$35211.0-13.0 \quad 1.2 \quad 1420$ $\begin{array}{lllll}352 & 11.0-13.0 & 1.2 & 142 & 4.0 \\ 353 & 19.0-18.0 & -3.8 & 186 & 2.2\end{array}$ $\begin{array}{lllll}354 & 15.0-21.0 & 0.2 & 213 & 2.7\end{array}$

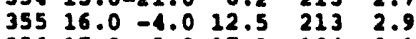
$\begin{array}{llllll}356 & 17.0 & -2.0 & 17.9 & 164 & 3.1 \\ 357 & 26.0 & -4.0 & 18.9 & 124 & 7.6\end{array}$ $\begin{array}{llllll}358 & 28.0 & 17.0 & 22.3 & 185 & 22.4\end{array}$ $\begin{array}{lllllll}359 & 27.0 & 2.0 & 19.7 & 198 & 3.6\end{array}$ $\begin{array}{llllll}360 & 27.0 & -4.0 & 10.8 & 115 & 3.4\end{array}$ $\begin{array}{llllll}361 & 17.0 & -4.0 & 10.0 & 189 & 1.8\end{array}$ $\begin{array}{llllll}362 & 33.0 & 17.0 & 24.8 & 216 & 4.9\end{array}$ 36326.013 .019 .821721 .0 $36426.0 \quad 9.018 .1207119$ $\begin{array}{lllllll}365 & 31.0 & 10.0 & 26.5 & 164 & 10.3\end{array}$

100.13

100.00

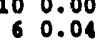
90.00

90.00

30.00
40.00

0.00
0.00

100.00

100.00

60.00

20.00

$\begin{array}{ll}10 & 0.00 \\ 10 & 0.00\end{array}$

10.00

100.00

$10 \quad 0.00$

$\begin{array}{rl}9 & 0.00 \\ 10 & 0.00\end{array}$

80.00

50.00

90.00

50.00

$\begin{array}{ll}3 & 0.00 \\ 3 & 0.00\end{array}$

100.00

100.00

90.00

100.00

10.00

60.00

100.00

100.00

50.00

$\begin{array}{ll}9 & 0.00 \\ 8 & 0.00\end{array}$

90.00

50.00

100.00

9
6
0.000

30.00

100.00

$\begin{array}{ll}9 & 0.12 \\ 9 & 0.00\end{array}$
Year 1985

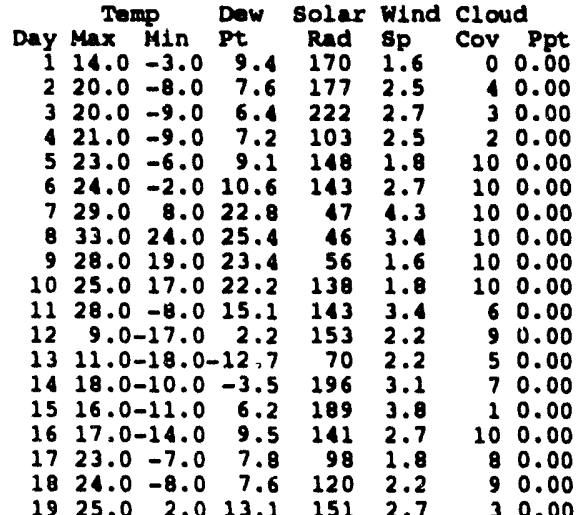

$\begin{array}{ll}10 & 0.00 \\ 8 & 0.00\end{array}$

0.00 100.00 
Year 1985 (Cont'd)

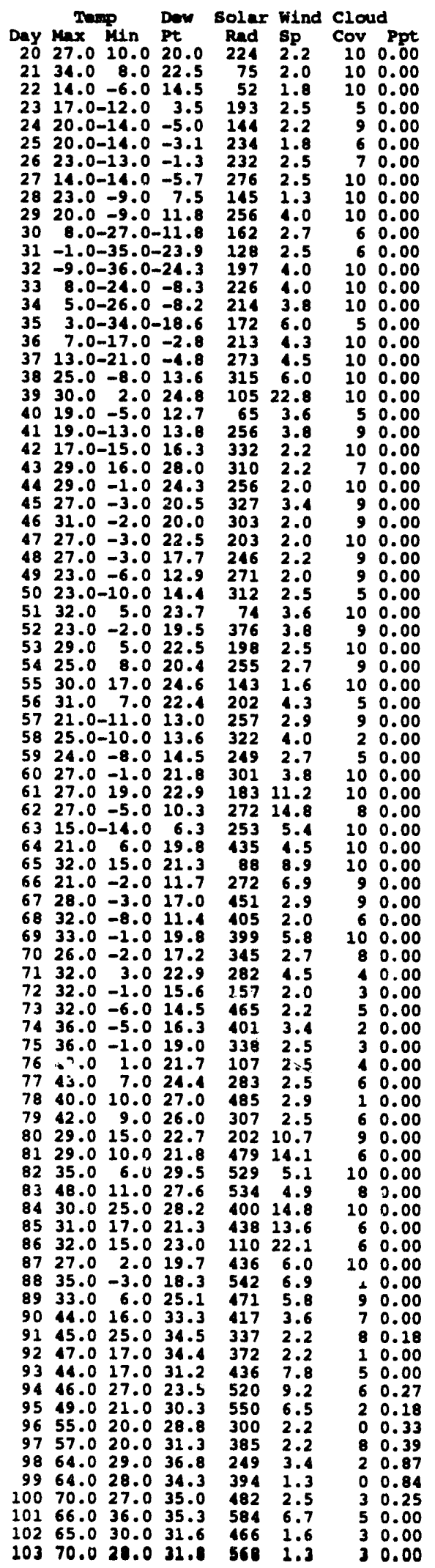

Tump Dow solar wind cloud

Dey Max Min Pt Rad 8p Cov Ppt $\begin{array}{llllllll}104 & 76.0 & 30.0 & 32.4 & 379 & 1.6 & 1 & 0.00 \\ 105 & 77.0 & 35.0 & 34.3 & 394 & 1.6 & 9 & 0.00\end{array}$

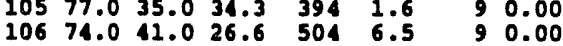
$\begin{array}{rrrrrrrr}106 & 74.0 & 41.0 & 26.6 & 504 & 6.5 & 9 & 0.00 \\ 107 & 70.0 & 12.0 & 34.3 & 592 & 11.6 & 9 & 0.00\end{array}$

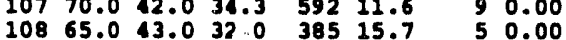

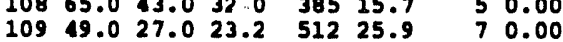
$\begin{array}{llllllll}110 & 43.0 & 22.0 & 17.0 & 620 & 17.9 & 7 & 0.00\end{array}$ $\begin{array}{llllllll}111 & 47.0 & 30.0 & 27.9 & 620 & 15.4 & 10 & 0.00\end{array}$

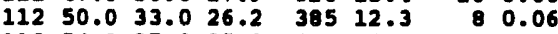

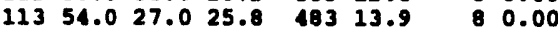
$11449.0 \quad 20.0 \quad 17.0 \quad 652 \quad 8.7 \quad 80.00$

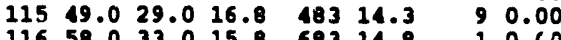

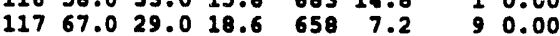

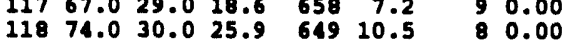

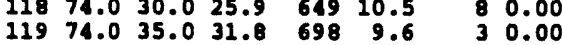
$\begin{array}{llllllll}119 & 74.0 & 35.0 & 31.8 & 698 & 9.6 & 3 & 0.00 \\ 120 & 76.0 & 35.0 & 30.4 & 451 & 6.0 & 0 & 0.00\end{array}$

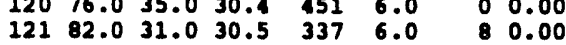

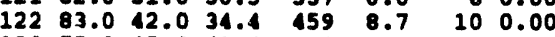
$\begin{array}{llllllll}123 & 75.0 & 45.0 & 11.4 & 491 & 16.1 & 9 & 0.00 \\ 124 & 57.0 & 31.0 & 19.8 & 46 & 15.4 & 1 & 0.02\end{array}$

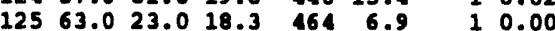

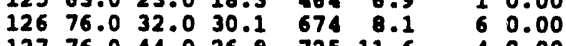

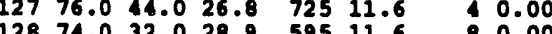
$\begin{array}{rrrrrrrr}128 & 74.0 & 32.0 & 28.9 & 595 & 11.6 & 8 & 0.00 \\ 129 & 67.0 & 40.0 & 36.4 & 731 & 8.3 & 10 & 0.00\end{array}$ $\begin{array}{llllllll}129 & 67.0 & 40.0 & 36.4 & 731 & 8.3 & 10 & 0.00 \\ 130 & 53.0 & 40.0 & 41.9 & 666 & 6.9 & 10 & 0.08\end{array}$ $\begin{array}{rrrrrrrr}130 & 53.0 & 40.0 & 41.9 & 666 & 6.9 & 10 & 0.08 \\ 131 & 55.0 & 36.0 & 27.3 & 350 & 21.9 & 6 & 0.17\end{array}$ $\begin{array}{rrrrrrrr}131 & 55.0 & 36.0 & 27.3 & 350 & 21.9 & 6 & 0.17 \\ 132 & 55.0 & 30.0 & 20.7 & 733 & 6.9 & 2 & 0.00\end{array}$

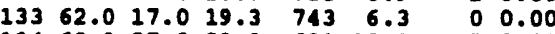
$13460.027 .029 .8 \quad 601 \quad 10.1 \quad 70.00$ $13558.0 \quad 41.0 \quad 39.3 \quad 645 \quad 8.3 \quad 96.22$

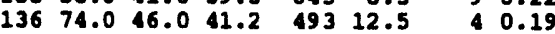
$\begin{array}{lllllll}137 & 68.0 & 43.0 & 10.7 & 593 & 8.1 & 30.00\end{array}$

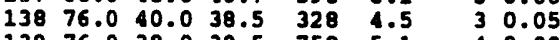
$\begin{array}{lllllll}139 & 76.0 & 38.0 & 38.5 & 758 & 5.1 & 4 \\ 0.00\end{array}$ $14066.0 \quad 40.042 .9 \quad 579 \quad 8.9 \quad 90.00$ $14174.0 \quad 38.0 \quad 42.5 \quad 666 \quad 5.4 \quad 50.00$

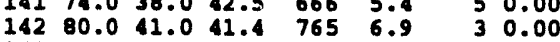

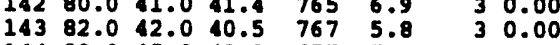
$\begin{array}{llllllll}14483.0 & 85.0 & 42.0 & 657 & 7.2 & 6 & 0.00\end{array}$ $\begin{array}{llllllll}145 & 78.0 & 48.0 & 47.1 & 622 & 8.5 & 8 & 0.08\end{array}$ $\begin{array}{lllllll}14676.0 & 42.0 & 44.8 & 303 & 6.9 & 8 & 0.02\end{array}$

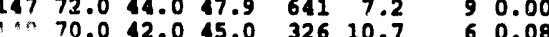
$\begin{array}{lllll}.0 & 38.0 & 32.5 & 633 & 19.9\end{array}$ $037.0 \quad 30.5 \quad 779 \quad 18.3$ $34.034 .2 \quad 611 \quad 7.2$ $\begin{array}{lllll}3 & 34.0 & 34.2 & 611 & 7.2 \\ 0 & 42.0 & 40.1 & 622 & 14.8\end{array}$ $\begin{array}{rrrrr}0 & 42.0 & 40.1 & 622 & 14.9 \\ 0 & 37.0 & 35.3 & 590 & 6.3\end{array}$ $\begin{array}{lllll}74.0 & 35.0 & 38.7 & 657 & 5.4\end{array}$ $\begin{array}{llllll}155 & 72.0 & 46.0 & 41.6 \quad 582 & 9 .\end{array}$ $\begin{array}{llllll}156 & 74.0 & 56.0 & 45.8 & 525 & 17.9\end{array}$ $\begin{array}{lllllll}157 & 77.0 & 53.0 & 46.5 & 590 & 18.3\end{array}$ $\begin{array}{llllll}158 & 92.0 & 46.0 & 45.6 & 425 & 14.1\end{array}$ $\begin{array}{lllllll}159 & 76.0 & 52.0 & 37.8 & 681 & 18.8\end{array}$ $\begin{array}{llllll}161 & 76.0 & 48.0 & 31.1 & 475 & 10.3\end{array}$ $\begin{array}{llllll}162 & 79.0 & 38.0 & 32.7 & 485 & 4.9\end{array}$ $\begin{array}{llllll}162 & 79.0 & 38.0 & 32.7 & 485 & 4.9 \\ 163 & 83.0 & 39.0 & 36.7 & 645 & 8.1\end{array}$ $\begin{array}{rrrrrr}163 & 83.0 & 39.0 & 36.7 & 645 & 8.1 \\ 164 & 84.0 & 18.0 & 39.3 & 793 & 13.9\end{array}$ $\begin{array}{rrrrrr}165 & 82.0 & 44.0 & 39.05 & 687 & 8.9 \\ 166 & 85.0 & 47.0 & 42.9 & 771 & 14.3\end{array}$ $\begin{array}{llllll}167 & 85.0 & 52.0 & 39.8 & 628 & 7.2\end{array}$ $\begin{array}{llllll}168 & 87.0 & 53.0 & 40.6 & 680 & 7.2\end{array}$ $\begin{array}{llllll}169 & 89.0 & 51.0 & 39.5 & 598 & 7.8\end{array}$ $\begin{array}{llllll}170 & 93.0 & 48.0 & 40.0 & 612 & 6.7\end{array}$ $17280.052 .0 \quad 31.3 \quad 79412.8$ $17387.044 .033 .3 \quad 79413.4$ $\begin{array}{llllll}173 & 87.0 & 44.0 & 33.3 & 794 & 13.4 \\ 174 & 89.0 & 48.0 & 39.5 & 692 & 13.9\end{array}$ $\begin{array}{llllll}174 & 89.0 & 48.0 & 39.5 & 692 & 13.9 \\ 175 & 55.0 & 13.0 & 34.8 & 793 & 14.8\end{array}$ $\begin{array}{rrrrrr}175 & 55.0 & 43.0 & 34.8 & 793 & 14.8 \\ 176 & 57.0 & 43.0 & 40.0 & 771 & 8.5\end{array}$ $17768.0 \quad 35.0 \quad 34.2 \quad 695 \quad 5.4$ $\begin{array}{llllll}178 & 78.0 & 37.0 & 36.3 & 713 & 5.8\end{array}$ $\begin{array}{lllllr}179 & 86.0 & 46.0 & 40.4 & 791 & 6.7\end{array}$ $\begin{array}{llllll}180 & 88.0 & 45.0 & 42.3 & 619 & 10.1\end{array}$ $\begin{array}{llllll}181 & 90.0 & 41.0 & 40.3 & 790 & 8.3\end{array}$ $18396.046 .042 .6 \quad 7646.0$ $\begin{array}{llllll}183 & 96.0 & 46.0 & 42.6 & 764 & 6.9 \\ 98.0 & 49.0 & 40.3 & 611 & 7.4\end{array}$ $\begin{array}{llllll}184 & 98.0 & 49.0 & 40.3 & 611 & 7.4 \\ 189.0 & 19.0 & 42.8 & 670 & 9.6\end{array}$

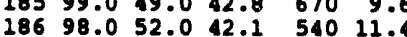
$\begin{array}{llllll}186 & 98.0 & 52.0 & 42.1 & 540 & 11.4 \\ 187 & 98.0 & 60.0 & 44.8 & 783 & 11.0\end{array}$ $18895.0 \quad 71.0 \quad 46.2 \quad 686 \quad 12.8$ $18995.0 \quad 60.0 \quad 49.7 \quad 570 \quad 6.9$
Tomp Daw solar wind Cloud Day Max Min Pt Rad Sp Cov Ppt

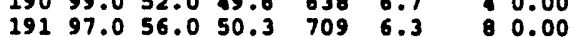

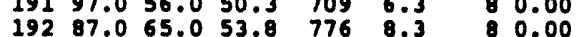

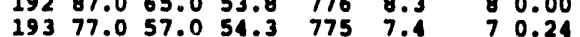

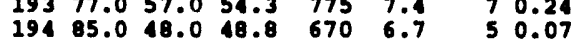

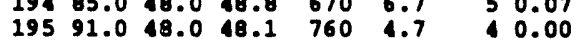
$\begin{array}{lllllll}196 & 96.0 & 54.0 & 46.2 & 606 & 6.7 & 0.38\end{array}$

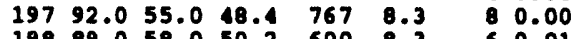

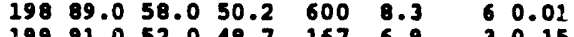

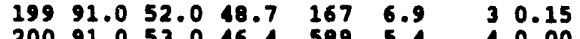

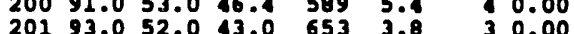
$20290.054 .0 \quad 51.5 \quad 512 \quad 6.7 \quad 80.00$ $20388.055 .052 .8 \quad 701 \quad 7.4 \quad 100.00$

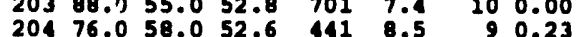

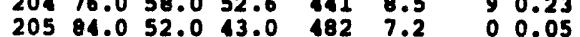

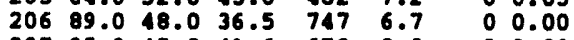
$\begin{array}{llllllll}207 & 95.0 & 45.0 & 41.6 & 670 & 8.3 & 2 & 0.00\end{array}$ $\begin{array}{lllllll}20892.0 & 60.0 & 40.6 & 493 & 6.0 & 8 & 0.00\end{array}$

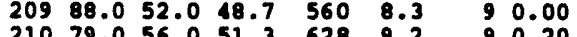

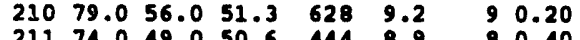

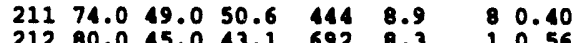

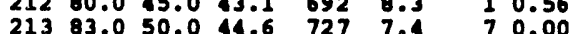
$\begin{array}{rrrrrrrr}214 & 72.0 & 18.0 & 10.0 & 537 & 17.2 & 6 & 0.02\end{array}$

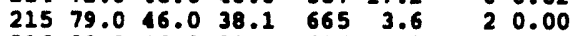

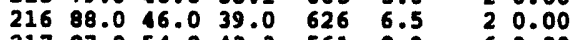
$\begin{array}{llllllll}217 & 87.0 & 54.0 & 13.3 & 561 & 8.9 & 6 & 0.00\end{array}$

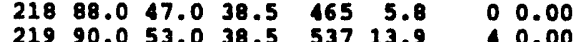
$\begin{array}{llllll}219 & 90.053 .0 & 38.5 & 537 & 13.9 & 0.00 \\ 220 & 71.055 .0 & 29.0 & 549 & 25.5 & 0.00\end{array}$ $\begin{array}{llllllll}221 & 74.0 & 35.0 & 31.3 & 459 & 11.6 & 0 & 0.00\end{array}$ $\begin{array}{lllllll}222 & 83.0 & 40.0 & 28.6 & 434 & 13.9\end{array}$ $\begin{array}{lllllll}223 & 64.0 & 42.0 & 35.4 & 433 & 8.9\end{array}$ $22476.0 \quad 38.0 \quad 33.9 \quad 465 \quad 13.6$ $22574.0 \quad 43.0 \quad 35.0 \quad 4487.8$

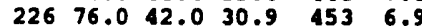
$22784.0 \quad 39.028 .165115 .2$ $\begin{array}{lllllll}228 & 79.0 & 13.0 & 33.1 & 588 & 6.7\end{array}$ $229 \$ 7.0 \quad 41.0 \quad 31.3 \quad 670 \quad 6.0$ $\begin{array}{lllllll}23 r & 88.0 & 50.0 & 40.0 & 666 & 5.8\end{array}$ $\begin{array}{llllll}231 & 82.0 & 53.0 & 37.0 & 612 & 12.8\end{array}$ $\begin{array}{llllll}232 & 84.0 & 44.0 & 34.2 & 471 & 10.1 \\ 233 & 79.0 & 48.0 & 37.0 & 611 & 19.9\end{array}$ $23480.0 \quad 47.0 \quad 34.0 \quad 53711.0$ $23585.0 \quad 37.0 \quad 26.5 \quad 645 \quad 4.0$ $\begin{array}{llllll}236 & 91.0 & 38.0 & 28.3 & 543 & 5.6\end{array}$ $23796.0 \quad 41.0 \quad 35.5 \quad 406 \quad 0.7$ $\begin{array}{llllll}238 & 94.0 & 47.0 & 36.7 & 632 & 6.7\end{array}$

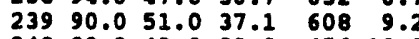
$\begin{array}{llllll}240 & 88.0 & 49.0 & 33.0 & 456 & 10.3\end{array}$ $\begin{array}{llllll}241 & 88.0 & 40.0 & 27.8 & 618 & 8.9\end{array}$ $24285.0 \quad 42.0 \quad 38.2 \quad 614 \quad 15.4$ $\begin{array}{llllll}243 & 78.0 & 56.0 & 32.3 & 573 & 20.8\end{array}$ $\begin{array}{lllllll}244 & 75.0 & 46.0 & 41.8 & 562 & 6.5\end{array}$ $\begin{array}{llllll}246 & 76.0 & 36.0 & 45.2 & 427 & 3.8\end{array}$ $24780.0 \quad 41.0 \quad 44.1 \quad 587 \quad 9.8$ $24871.052 .0 \quad 43.2 \quad 58624.2$ $24973.050 .038 .3 \quad 54412.1$ $25074.0 \quad 47.0 \quad 39.2 \quad 520 \quad 6.7$ $\begin{array}{llllll}251 & 60.0 & 47.0 & 48.0 & 194 & 9.2\end{array}$ $\begin{array}{llllll}252 & 64.0 & 45.0 & 47.3 & 273 & 11.0\end{array}$ $\begin{array}{llllll}253 & 70.0 & 42.0 & 39.7 & 359 & 8.1\end{array}$ $\begin{array}{llllll}254 & 65.0 & 46.0 & 44.5 \quad 446 & 10.3\end{array}$ $\begin{array}{llllll}255 & 57.0 & 38.0 & 36.8 & 325 & 17.6\end{array}$ $\begin{array}{llllll}256 & 70.0 & 33.0 & 33.3 & 521 & 8.7\end{array}$ $\begin{array}{lllllll}257 & 72.0 & 43.0 & 36.0 & 349 & 6.7\end{array}$ $\begin{array}{llllllll}258 & 65.0 & 42.0 & 37.7 & 536 & 12.1\end{array}$

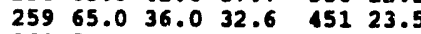
$26054.0 \quad 11.0 \quad 34.9 \quad 24417.4$ $\begin{array}{llllll}261 & 57.0 & 41.0 & 39.6 & 444 & 4.7\end{array}$ $\begin{array}{llllll}262 & 60.0 & 33.0 & 33.6 & 455 & 6.5\end{array}$ $\begin{array}{llllll}263 & 65.0 & 26.0 & 29.9 & 384 & 6.7\end{array}$ $26465.0 \quad 43.0 \quad 36.5 \quad 495 \quad 15.0$ $\begin{array}{llllll}265 & 59.0 & 35.0 & 28.0 & 501 & 6.3\end{array}$ $\begin{array}{llllll}266 & 61.0 & 22.0 & 22.3 & 446 & 8.7\end{array}$ $\begin{array}{llllll}267 & 69.0 & 40.0 & 24.0 & 393 & 12.5\end{array}$ $\begin{array}{lllllll}268 & 64.0 & 34.0 & 26.3 & 485 & 6.0\end{array}$ $26970.029 .026 .3 \quad 480 \quad 8.7$ $27055.0 \quad 30.026 .9 \quad 475 \quad 14.3$ $27148.026 .014 .4 \quad 4259.4$

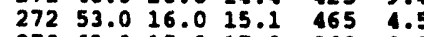
$\begin{array}{llllll}273 & 62.0 & 15.0 & 17.0 & 368 & 3.8 \\ 274 & 59.0 & 19.0 & 19.1 & 199 & 5.6\end{array}$

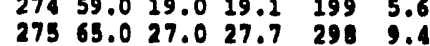

30.00

$\begin{array}{lll}6 & 0.00 \\ 0 & 0.00\end{array}$

20.00

90.00

10.00 0.000 0.00 80.00 30.00 $\begin{array}{ll}3 & 0.00 \\ 2 & 0.00\end{array}$ 30.00 20.00 50.00 50.00 $\begin{array}{ll}8 & 0.00 \\ 3 & 0.00\end{array}$ 20.00 $\begin{array}{ll}7 & 0.00 \\ 2 & 0.00\end{array}$ 70.00 80.00 60.14 $\begin{array}{lll}0 & 0.25 \\ 1 & 0.25\end{array}$ $10 \quad 0.00$ 4.00 40.00 $10 \quad 0.02$ $\begin{array}{ll}6 & 0.61 \\ 9 & 0.27\end{array}$ $90 .{ }^{2} 0$ 60.38 70.00 10.00 00.00 90.00
$10 \quad 0.00$ 40.00 10.00 $10 \quad 0.00$ 0.00
30.00 0.00 $\begin{array}{ll}8 & 0.00 \\ 0 & 0.00\end{array}$ $\begin{array}{ll}0 & 0.00 \\ 6 & 0.00\end{array}$ 0.00 20.00 0.00 20.00

9.00 


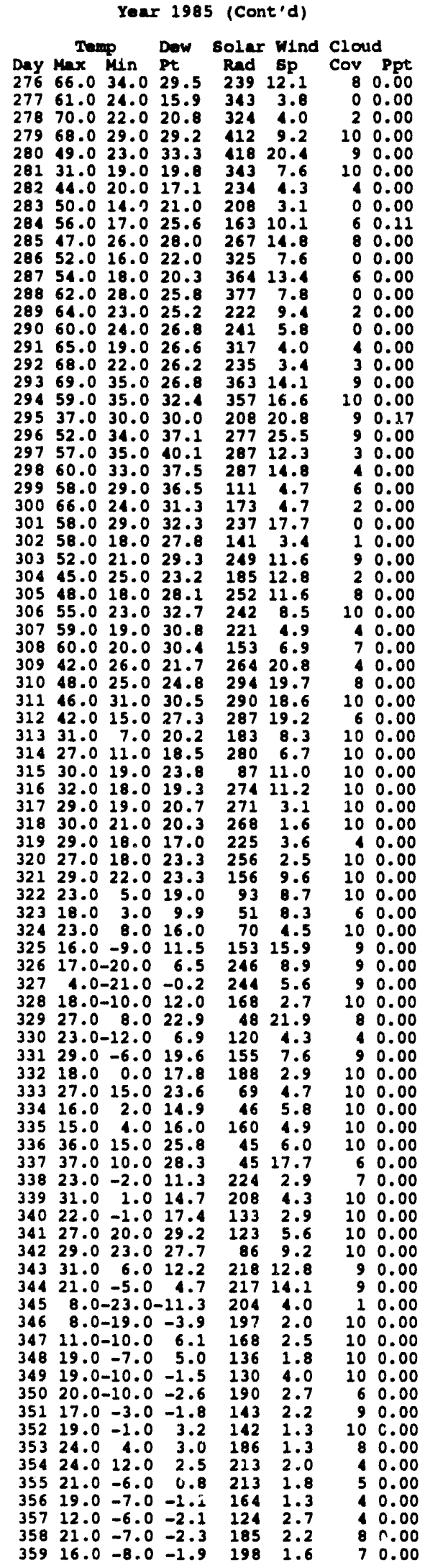

\begin{tabular}{|c|c|c|c|c|}
\hline 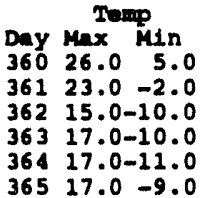 & $\begin{array}{r}\text { Dew } \\
\text { Pt } \\
1.1 \\
1.7 \\
-3.6 \\
0.8 \\
16.5\end{array}$ & $\begin{array}{l}\text { Solax } \\
\text { Rad } \\
215 \\
189 \\
216 \\
217 \\
207 \\
164\end{array}$ & $\begin{array}{l}\text { Wind } \\
\text { 8p } \\
1.3 \\
0.9 \\
2.0 \\
1.8 \\
2.8 \\
6.9\end{array}$ & $\begin{array}{rr}\text { Cloud } \\
\text { Cov } & \text { Ppt } \\
5 & 0.00 \\
6 & 0.00 \\
5 & 0.00 \\
8 & 0.00 \\
10 & 0.00 \\
10 & 0.00\end{array}$ \\
\hline
\end{tabular}

\section{Yoar 1986}

Tomp Dow solar wind Cloud

Day Max Min Pt Rad Sp Cov Ppt

$\begin{array}{lllllllllll}31.0 & 15.0 & 25.5 & 4 & 1.3 & 9 & 0.00\end{array}$

$\begin{array}{lllllll}2 & 20.0 & 2.0 & 15.7 & 44 & 4.5 & 70.00\end{array}$

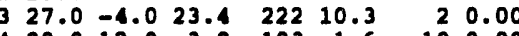

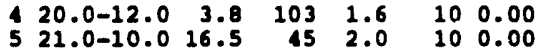

$\begin{array}{llllllll}6 & 30.0 & 2.0 & 24.1 & 143 & 2.7 & 6 & 0.00\end{array}$

$\begin{array}{llllll}720.0 & -6.0 & -4.1 & 183 & 1.8 & 70.00\end{array}$

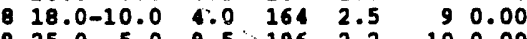

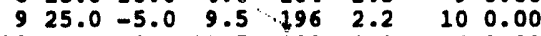

$\begin{array}{llllllll}10 & 30.0 & 0.0 & 11.5 & 138 & 3.1 & 6 & 0.00\end{array}$

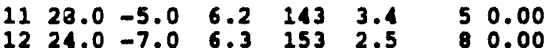

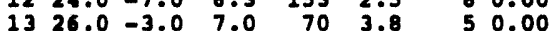

$1423.0=5.0 \quad 6.7 \quad 196 \quad 2.5 \quad 100.00$

$\begin{array}{llllllll}15 & 31.0 & 6.0 & 25.6 & 189 & 6.5 & 7 & 0.00\end{array}$

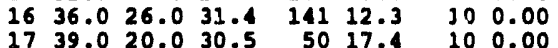

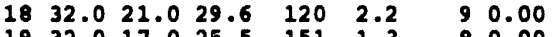

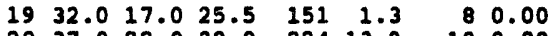

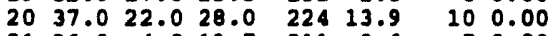

$\begin{array}{llllllll}21 & 26.0 & 4.0 & 19.7 & 211 & 3.6 & 7 & 0.00\end{array}$

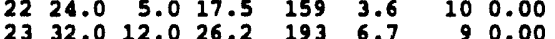

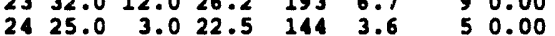

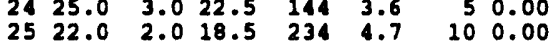

$\begin{array}{lllllllll}26 & 26.0 & -3.0 & 13.0 & 232 & 2.5 & 8 & 0.00\end{array}$

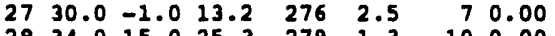

$\begin{array}{llllllll}28 & 34.0 & 15.0 & 25.3 & 279 & 1.3 & 10 & 0.00\end{array}$

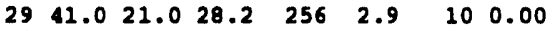

$\begin{array}{llllllll}30 & 41.0 & 24.0 & 30.3 & 162 & 4.0 & 10 & 0.03\end{array}$

$\begin{array}{llllllll}31 & 38.0 & 31.0 & 31.7 & 58 & 1.8 & 10 & 0.16\end{array}$

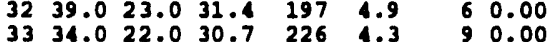

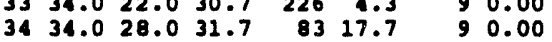

$\begin{array}{llllll}35 & 35.0 & 19.0 & 30.2 & 172 & 5.4\end{array}$

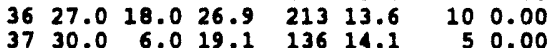

$38 \quad 23.0-16.0 \quad 9.8 \quad 315 \quad 3.4$

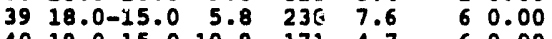

$\begin{array}{lllllll}40 & 19.0-15.0 & 10.9 & 171 & 4.7 & 6 & 0.00\end{array}$

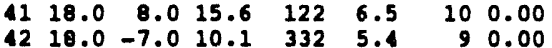

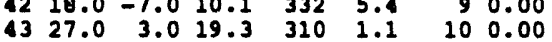

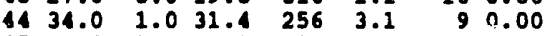

$\begin{array}{llllllll}45 & 31.0 & -2.0 & 31.9 & 193 & 2.2 & 10 & 0.00\end{array}$

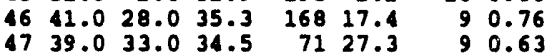

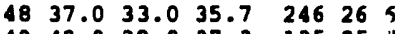

$\begin{array}{llllll}49 & 42.0 & 32.0 & 37.3 & 135 & 25.1\end{array}$

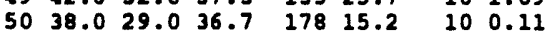

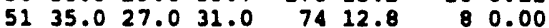

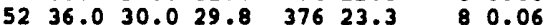

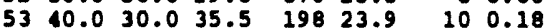

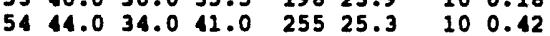

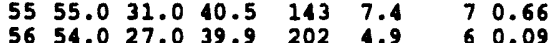

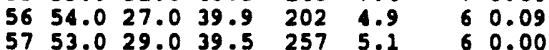

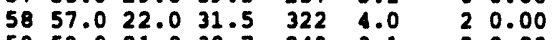

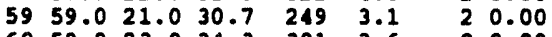

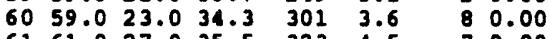

$\begin{array}{llllllll}61 & 61.0 & 27.0 & 35.5 & 323 & 4.5 & 7 & 0.00\end{array}$

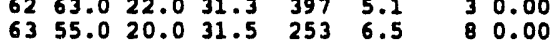

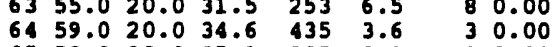

$\begin{array}{lllllll}65 & 58.0 & 20.0 & 35.1 & 205 & 3.1 & 90.00\end{array}$

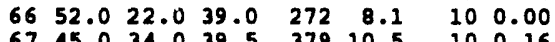

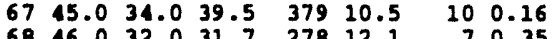

$\begin{array}{lllllllll}68 & 46.0 & 32.0 & 31.7 & 278 & 12.1 & 7 & 0.35\end{array}$

$70 \begin{array}{lllllll}48.0 & 33.0 & 34.0 & 199 & 4.5 & 9 & 0.50\end{array}$

$\begin{array}{llllllll}70 & 48.0 & 33.0 & 34.0 & 199 & 4.5 & 9 & 0.50 \\ 71 & 45.0 & 28.0 & 30.6 & 282 & 6.5 & 9 & 0.00\end{array}$

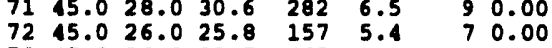

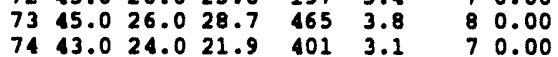

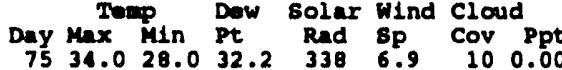
$\begin{array}{lllllll}76 & 43.029 .0 & 30.6 & 99 & 4.9 & 10 & 0.16\end{array}$

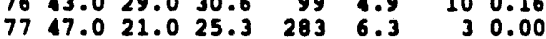
$78 \quad 51.0 \quad 27.0 \quad 32.0 \quad 485 \quad 2.9 \quad 30.00$ $7958.024 .033 .3 \quad 307 \quad 3.6 \quad 20.000$

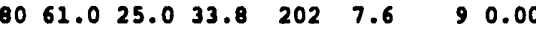
$8154.0 \quad 34.0 \quad 31.4 \quad 479 \quad 8.1 \quad 90.00$

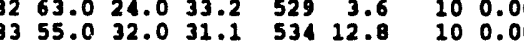
$8450.026 .026 .2 \quad 400 \quad 5.6 \quad \$ 0.00$

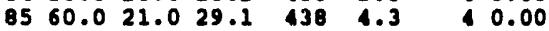
$8669.023 .030 .5 \quad 271 \quad 4.0 \quad 8 \quad 0.00$

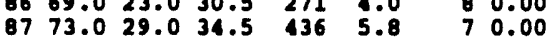

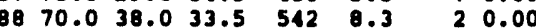
$8970.0 \quad 32.0 \quad 36.0 \quad 471 \quad 10.7 \quad 8 \quad 0.00$ $90 \quad 53.0 \quad 24.0 \quad 19.8 \quad 417 \quad 4.9 \quad 40.00$

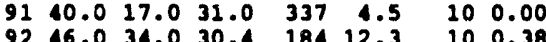

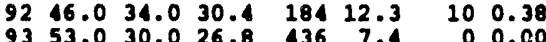
$\begin{array}{llllllll}94 & 54.0 & 20.0 & 30.8 & 520 & 3.4 & 7 & 0.00\end{array}$ $9561.0 \quad 23.0 \quad 35.2 \quad 550 \quad 4.0 \quad 8 \quad 80.00$ $\begin{array}{lllllllll}96 & 65.0 & 25.0 & 36.3 & 300 & 2.7 & 3 & 0.00\end{array}$ $9753.0 \quad 36.0 \quad 39.0 \quad 385 \quad 1.7 \quad 200.00$ $9850.0 \quad 36.0 \quad 39.0 \quad 122 \quad 6.5 \quad 10 \quad 0.21$ $9952.033 .039 .9 \quad 394 \quad 6.0 \quad 100.00$ $\begin{array}{llllllll}100 & 59.0 & 30.0 & 39.5 & 326 & 4.7 & 8 & 0.03\end{array}$

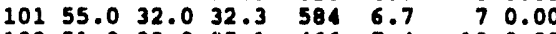

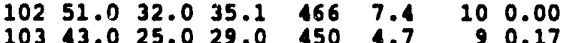

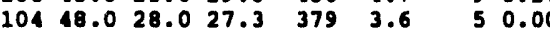
$\begin{array}{llllll}105 & 61.0 & 23.0 & 29.9 & 394 & 5.8\end{array}$ $\begin{array}{llllll}10654.033 .029 .3 & 504 & 10.1 & 70.00\end{array}$

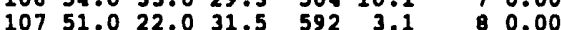

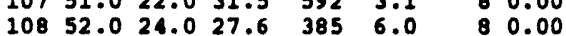
$10960.022 .028 .1 \quad 512 \quad 6.5 \quad 9 \quad 0.00$

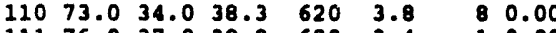

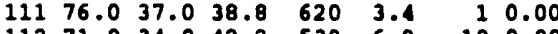

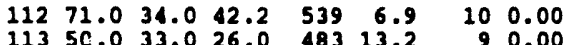

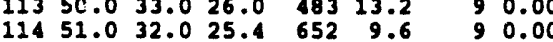

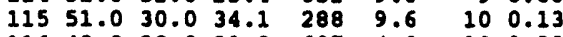
$\begin{array}{llllllll}116 & 48.0 & 28.0 & 29.3 & 607 & 4.0 & 10 & 0.28\end{array}$

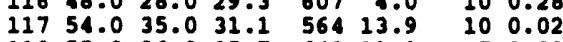

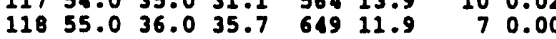
$11950.027 .027 .8 \quad 69813.9 \quad 6 \quad 0.03$

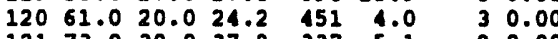

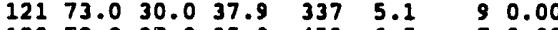

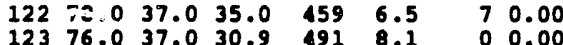

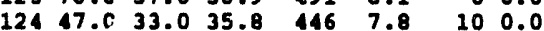

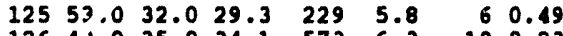
$\begin{array}{lllllllll}126 & 41.0 & 35.0 & 34.1 & 573 & 6.3 & 10 & 0.23\end{array}$ $\begin{array}{llllllll}127 & 48.0 & 33.0 & 36.0 & 690 & 4.7 & 10 & 0.02\end{array}$ $\begin{array}{llllllll}128 & 46.0 & 37.0 & 35.8 & 439 & 9.2 & 10 & 0.20\end{array}$ $\begin{array}{lllllllll}129 & 56.0 & 33.0 & 35.8 & 708 & 8.1 & 9 & 0.18\end{array}$

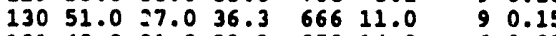

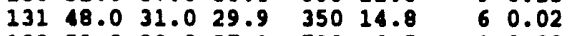

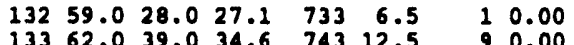

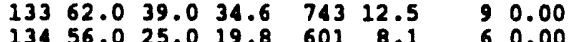

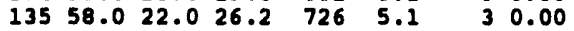

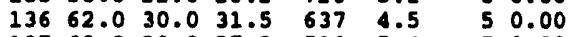
$13768.028 .027 .2 \quad 593 \quad 5.4 \quad 70.00$ $\begin{array}{lllllllll}138 & 74.0 & 36.0 & 33.4 & 543 & 4.3 & 10 & 0.00\end{array}$

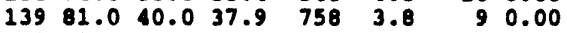

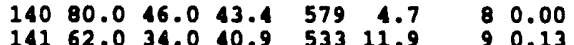
$\begin{array}{llllllll}141 & 62.0 & 34.0 & 40.9 & 533 & 11.9 & 9 & 0.13 \\ 142 & 50.0 & 30.0 & 26.9 & 765 & 8.1 & 4 & 0.00\end{array}$

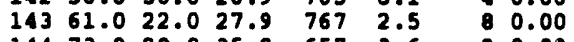

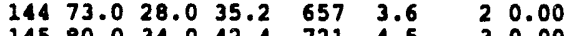
$\begin{array}{llllllll}145 & 80.0 & 34.0 & 42.4 & 721 & 4.5 & 3 & 0.00\end{array}$

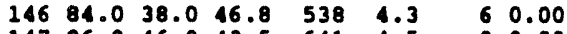

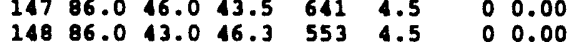

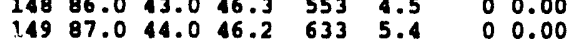

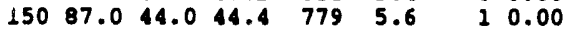
$\begin{array}{llllllll}151 & 90.0 & 43.0 & 46.0 & 611 & 4.7 & 1 & 0.00\end{array}$ $\begin{array}{llllllll}152 & 89.0 & 52.0 & 48.4 & 726 & 4.7 & 3 & 0.00\end{array}$

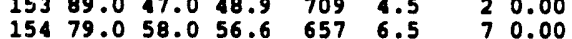
$15582.0 \quad 46.052 .8 \quad 582 \quad 6.0 \quad 100.00$

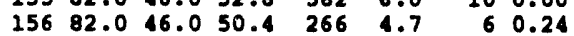
$\begin{array}{llllllll}156 & 82.0 & 46.0 & 50.4 & 266 & 4.7 & 6 & 0.24 \\ 15778.0 & 44.0 & 44.9 & 379 & 4.5 & 1 & 0.04\end{array}$ $15867.0 \quad 50.048 .4 \quad 158 \quad 6.5 \quad 960.03$

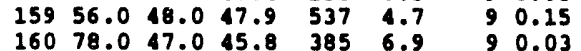


Year 1986 (Cont'd)

Day Max Min Pt Solar Wind Clo:id

$16178.0 \quad 36.0 \quad 41.5 \quad 475$ 4.3 00.00

$\begin{array}{llllllll}162 & 83.0 & 44.0 & 42.1 & 485 & 7.8 & 0 & 0.00 \\ 163 & 84.0 & 44.0 & 11.7 & 645 & 6.3 & 5 & 0.0\end{array}$

$\begin{array}{lllllll}16485.0 & 43.0 & 44.0 & 755 & 3.8 & 1 & 0.10\end{array}$

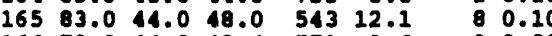

$\begin{array}{llllllll}166 & 78.0 & 14.0 & 48.4 & 771 & 9.6 & 6 & 0.00 \\ 167 & 89.0 & 43.0 & 42.0 & 628 & 7.4 & 2 & 0.00\end{array}$

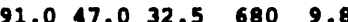

$\begin{array}{llllll}169 & 86.0 & 52.0 & 42.8 & 598 & 10.1\end{array}$

$\begin{array}{llllll}170 & 74.0 & 46.0 & 33.1 & 612 & 8.3\end{array}$

$\begin{array}{llllll}171 & 78.0 & 36.0 & 34.0 & 538 & 8.7\end{array}$

$17277.0 \quad 47.0 \quad 38.0 \quad 794 \quad 8.7$

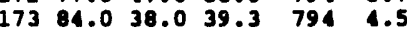

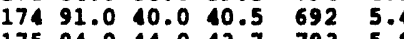

$\begin{array}{llllll}175 & 94.0 & 14.0 & 13.7 & 793 & 5.8 \\ 176 & 91.0 & 50.0 & 17.5 & 771 & 6.7\end{array}$

$\begin{array}{llllll}177 & 92.0 & 44.0 & 46.5 & 773 & 5.6\end{array}$

$\begin{array}{llllll}178 & 92.0 & 54.0 & 50.6 & 784 & 6.7\end{array}$

$\begin{array}{llllll}179 & 92.0 & 51.0 & 47.5 & 791 & 9.6\end{array}$

$\begin{array}{llllll}180 & 82.0 & 54.0 & 41.6 \quad 619 & 13.0\end{array}$

$\begin{array}{lllllll}181 & 82.0 & 41.0 & 41.4 \quad 790 & 8.9\end{array}$

$\begin{array}{lllllll}182 & 89.0 & 43.0 & 38.5 & 789 & 5.4\end{array}$

$\begin{array}{lllllll}103 & 96.0 & 46.0 & 45.9 & 764 & 6.5\end{array}$

$\begin{array}{llllll}184 & 82.0 & 60.0 & 49.0 & 611 & 17.0 \\ 185 & 82.0 & 14.0 & 41.0 & 670 & 17.7\end{array}$

$18668.0 \quad 35.0 \quad 30.2 \quad 54010.1$

$18778.0 \quad 28.0 \quad 35.1 \quad 7836.5$

$\begin{array}{lllllll}188 & 79.0 & 58.0 & 44.0 & 549 & 8.7\end{array}$

$\begin{array}{lllllll}189 & 84.0 & 51.0 & 49.7 & 570 & 7.6\end{array}$

$\begin{array}{llllll}190 & 79.0 & 46.0 & 47.4 & 638 & 11.2\end{array}$

$\begin{array}{lllllll}191 & 80.0 & 53.0 & 48.1 & 709 & 9.6\end{array}$

$\begin{array}{lllllll}192 & 79.0 & 51.0 & 46.6 & 776 & 12.5\end{array}$

$19382.0 \quad 38.0 \quad 37.37756 .7$

$19487.0 \quad 48.0 \quad 39.5 \quad 753 \quad 8.7$

$19590.0 \quad 54.0 \quad 46.4 \quad 760 \quad 12.5$

$\begin{array}{llllll}196 & 84.0 & 53.0 & 47.6 \quad 714 & 9.6\end{array}$

$\begin{array}{lllllll}197 & 80.0 & 46.0 & 44.3 & 767 & 13.4\end{array}$

$\begin{array}{llllll}198 & 76.0 & 37.0 & 35.2 & 709 & 6.9\end{array}$

$19984.0 \quad 54.0 \quad 43.9 \quad 458 \quad 8.9$

$\begin{array}{lllllll}200 & 92.0 & 46.0 & 40.7 & 589 & 8.1\end{array}$

$\begin{array}{llllll}201 & 89.0 & 46.0 & 41.8 & 653 & 4.9\end{array}$

$\begin{array}{llllll}202 & 89.0 & 54.0 & 39.9 & 512 & 6.9\end{array}$

$20385.0 \quad 50.0 \quad 18.3 \quad 592 \quad 7.8$

$20483.050 .0 \quad 53.9611 \quad 9.4$

$20579.0 \quad 54.0 \quad 53.8 \quad 6347.4$

$20679.054 .051 .2 \quad 7476.9$

$20778.0 \quad 46.0 \quad 46.6 \quad 670 \quad 6.5$

$20878.0 \quad 41.0 \quad 46.5 \quad 493 \quad 3.8$

$\begin{array}{llllll}209 & 88.0 & 42.0 & 48.0 & 560 & 8.9\end{array}$

$\begin{array}{llllll}210 & 82.0 & 48.0 & 45.3 & 715 & 16.6\end{array}$

$21183.0 \quad 45.0$

$\begin{array}{lllllll}212 & 88.0 & 12.0 & 39.3 & 730 & 7.2\end{array}$

$21390.0 \quad 44.037 .3727 \quad 4.0$

$21495.048 .0 \quad 38.7 \quad 657 \quad 5.6$

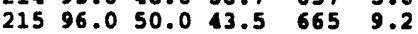

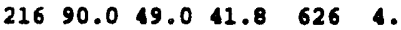

$21792.0 \quad 48.0 \quad 38.5 \quad 561 \quad 6.3$

$\begin{array}{lllllll}218 & 96.0 & 45.0 & 38.6 & 465 & 5.1 \\ 219 & 90.0 & 55.0 & 47.0 & 537 & 7.8\end{array}$

$\begin{array}{llllll}220 & 90.0 & 55.0 & 41.3 & 549 & 6.0\end{array}$

$\begin{array}{llllll}221 & 92.0 & 46.0 & 38.5 & 459 & 4.7\end{array}$

$\begin{array}{llllll}222 & 94.0 & 50.0 & 36.1 & 434 & 6.7\end{array}$

$22392.0 \quad 56.0 \quad 43.0 \quad 433 \quad 6.9$

$22483.0 \quad 46.0 \quad 39.4 \quad 465 \quad 10.1$

$22584.0 \quad 54.0 \quad 35.5 \quad 4486.0$

$\begin{array}{llllll}226 & 87.0 & 42.0 & 35.6 & 453 & 6.5\end{array}$

$\begin{array}{lllllll}227 & 92.0 & 43.0 & 37.0 & 651 & 6.9\end{array}$

$\begin{array}{lllllll}228 & 92.0 & 50.0 & 42.9 & 588 & 2.9\end{array}$

$\begin{array}{llllll}229 & 94.0 & 56.0 & 43.2 & 670 & 7.4\end{array}$

$\begin{array}{llllll}230 & 98.0 & 50.0 & 34.1 & 666 & 6.9\end{array}$

23196.054 .047 .1

$23290.0 \quad 14.051 .0$

$23380.0 \quad 46.0 \quad 51.1$

$23483.0 \quad 12.0 \quad 41.8$

$23579.0 \quad 52.0 \quad 49.8$

$23691.0 \quad 45.0 \quad 50.0$

$238 \quad 90.0 \quad 49.0 \quad 43.1$

$23994.0 \quad 47.042 .1$

$24094.0 \quad 48.0 \quad 47.1$

$\begin{array}{lllll}241 & 80.0 & 52.0 & 51.8 \\ 242 & 74.0 & 15.0 & 52.2\end{array}$

$243 \quad 68.0 \quad 45.0 \quad 42.0$

$244 \quad 76.0 \quad 45.0 \quad 43.5$
Toup Dow solar wind cloud

Day Max Min Pt Rad 8p Cov Ppt $24681.0 \quad 42.0 \quad 41.1 \quad 545 \quad 3.4 \quad 00.00$ $\begin{array}{llllllll}247 & 84.0 & 42.0 & 39.0 & 587 & 6.9 & 0 & 0.00\end{array}$

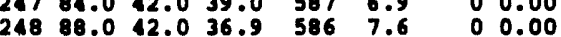

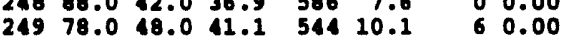

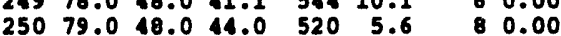

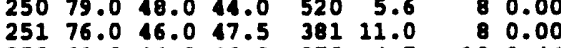
$\begin{array}{lllllll}252 & 63.0 & 44.0 & 16.8 & 273 & 4.7\end{array}$ $\begin{array}{llllll}253 & 66.0 & 38.0 & 39.5 & 490 & 9.2\end{array}$ $\begin{array}{llllll}254 & 72.0 & 39.0 & 36.7 & 446 & 8.9\end{array}$ $\begin{array}{llllll}255 & 78.0 & 40.0 & 34.8 & 464 & 6.0\end{array}$ $\begin{array}{llllll}256 & 74.0 & 51.0 & 38.1 & 521 & 8.7\end{array}$ $\begin{array}{llllll}257 & 60.0 & 47.0 & 43.3 & 165 & 1.8 \\ 258 & 69.0 & 43.0 & 40.7 & 536 & 7.4\end{array}$ $\begin{array}{lllllll}258 & 69.0 & 43.0 & 40.7 & 536 & 7.4 \\ 259 & 68.0 & 34.0 & 37.5 & 451 & 6.9\end{array}$ $\begin{array}{lllllll}259 & 68.0 & 34.0 & 37.5 & 451 & 6.9 \\ 260 & 65.0 & 35.0 & 37.0 & 244 & 6.9\end{array}$ $26159.0 \quad 34.0 \quad 40.1 \quad 4446.0$ $\begin{array}{lllllll}262 & 48.0 & 31.0 & 40.8 & 326 & 6.3\end{array}$ $\begin{array}{llllll}263 & 52.0 & 32.0 & 40.6 & 228 & 6.9\end{array}$ $26460.024 .0 \quad 33.9 \quad 495 \quad 4.5$ $26566.024 .0 \quad 31.0 \quad 5015.1$ $26670.022 .0 \quad 34.5 \quad 446 \quad 6.7$ $\begin{array}{llllll}268 & 53.0 & 37.0 & 32.5 & 485 & 19.2\end{array}$ 0 48014.8 $35.0 \quad 17514.1$ $\begin{array}{llllll}271 & 53.0 & 28.0 & 31.7 & 425 & 7.8 \\ 272 & 56.0 & 20.0 & 33.0 & 465 & 7.2\end{array}$ $\begin{array}{lllllll}272 & 56.0 & 20.0 & 33.0 & 465 & 7.2 \\ 273 & 46.0 & 40.0 & 39.9 & 226 & 5.4\end{array}$ $\begin{array}{llllll}273 & 46.0 & 40.0 & 39.9 & 226 & 5.4\end{array}$ $\begin{array}{llllll}274 & 52.0 & 33.0 & 37.7 & 199 & 5.1\end{array}$ $\begin{array}{llllll}275 & 54.0 & 28.0 & 34.5 & 298 & 13.4\end{array}$ $\begin{array}{llllll}276 & 60.0 & 24.0 & 33.0 & 239 & 4.3\end{array}$ $\begin{array}{llllll}277 & 64.0 & 26.0 & 35.3 & 343 & 4.7\end{array}$ $\begin{array}{lllllll}278 & 68.0 & 28.0 & 37.5 & 324 & 4.0\end{array}$ $\begin{array}{llllll}279 & 72.0 & 29.0 & 37.4 \quad 412 & 4.5\end{array}$ $28070.027 .0 \quad 39.2 \quad 418 \quad 6.0$ $\begin{array}{llllll}281 & 71.0 & 29.0 & 38.4 & 419 & 3.8\end{array}$ $\begin{array}{llllll}282 & 72.0 & 26.0 & 35.3 & 366 & 6.5\end{array}$ 28358.026 .031 .920813 .9

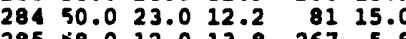
$\begin{array}{llllll}285 & 58.0 & 12.0 & 13.8 & 267 & 5.8\end{array}$ $\begin{array}{llllll}286 & 62.0 & 18.0 & 18.6 & 325 & 4.7\end{array}$ $28762.0 \quad 18.0 \quad 23.5 \quad 364 \quad 3.8$ $\begin{array}{llllll}288 & 67.0 & 16.0 & 26.2 & 377 & 3.8\end{array}$ $28969.019 .025 .8 \quad 222 \quad 4.7$

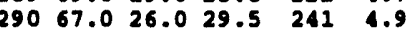
$\begin{array}{lllllll}291 & 53.0 & 40.0 & 43.1 & 182 & 7.4\end{array}$ $29264.0 \quad 37.0 \quad 44.0 \quad 235 \quad 10.3$ $\begin{array}{llllll}293 & 52.0 & 43.0 & 45.9 & 363 & 3.6\end{array}$ $\begin{array}{llllll}294 & 57.0 & 34.0 & 45.0 & 226 & 4.9\end{array}$ $\begin{array}{llllll}295 & 65.0 & 27.0 & 40.0 & 340 & 2.5\end{array}$ $\begin{array}{llllll}296 & 62.0 & 29.0 & 38.3 & 277 & 5.8\end{array}$ $\begin{array}{llllll}297 & 64.0 & 25.0 & 37.2 & 287 & 3.8\end{array}$ $\begin{array}{llllll}298 & 67.0 & 25.0 & 36.7 & 287 & 4.5\end{array}$ $\begin{array}{llllll}299 & 63.0 & 27.0 & 37.3 & 111 & 3.1\end{array}$

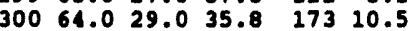

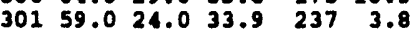
$\begin{array}{llllll}302 & 58.0 & 25.0 & 33.0 & 141 & 3.6\end{array}$ $\begin{array}{llllll}303 & 55.0 & 29.0 & 34.1 & 114 & 10.5\end{array}$

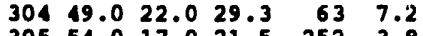
$\begin{array}{llllll}305 & 54.0 & 17.0 & 21.5 & 252 & 3.8\end{array}$ $\begin{array}{llllll}306 & 55.0 & 16.0 & 25.9 & 242 & 5.1\end{array}$

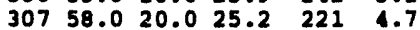

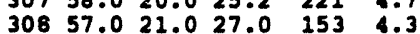
$30958.021 .0 \quad 28.6 \quad 264 \quad 11.6$ $\begin{array}{llllll}310 & 43.0 & 25.0 & 27.0 & 294 & 8.1\end{array}$ $\begin{array}{llllll}311 & 35.0 & 21.0 & 25.9 & 253 & 4.7\end{array}$

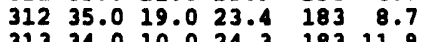

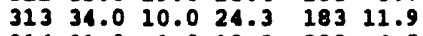
$\begin{array}{llllll}314 & 31.0 & 1.0 & 10.3 & 280 & 4.5\end{array}$ $\begin{array}{lllllll}315 & 10.0 & 30.0 & 24.8 & 220 & 6.5\end{array}$ $\begin{array}{llllll}316 & 36.0 & 12.0 & 20.1 & 274 & 6.3\end{array}$ $31744.013 .023 .8 \quad 271 \quad 4.0$ $\begin{array}{llllll}318 & 52.0 & 19.0 & 27.5 & 268 & 8.3\end{array}$ $\begin{array}{llllll}319 & 47.0 & 31.0 & 30.8 & 225 & 17.7\end{array}$ $\begin{array}{lllllll}320 & 43.0 & 33.0 & 29.7 & 256 & 18.8\end{array}$ $\begin{array}{llllll}321 & 48.0 & 35.0 & 31.8 & 156 & 15.2\end{array}$

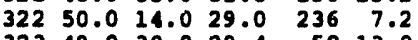

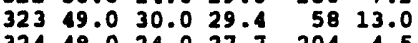
$\begin{array}{llllll}324 & 48.0 & 24.0 & 27.7 & 204 & 4.5\end{array}$ $\begin{array}{llllll}325 & 46.0 & 23.0 & 31.5 & 50 & 9.4\end{array}$ $\begin{array}{llllll}326 & 32.0 & 19.0 & 26.3 & 246 & 4.0\end{array}$ $\begin{array}{llllll}326 & 32.0 & 19.0 & 26.3 & 246 & 4.0 \\ 327 & 33.0 & 20.0 & 26.8 & 244 & 6.3\end{array}$ $\begin{array}{llllll}327 & 33.0 & 20.0 & 26.8 & 244 & 6.3 \\ 328 & 48.0 & 24.0 & 24.8 & 168 & 4.7\end{array}$

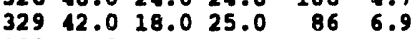
$\begin{array}{llllll}330 & 32.0 & 14.0 & 17.4 & 120 & 3.4\end{array}$ $\begin{array}{rr}10 & 0.44 \\ 3 & 0.00\end{array}$

50.00

$\begin{array}{lll}8 & 0.00 \\ 7 & 0.00\end{array}$

100.34

70.00

90.00

$\begin{array}{ll}6 & 0.00 \\ 8 & 0.00\end{array}$

100.15

$\begin{array}{lll}8 & 0.04 \\ 5 & 0.00 & 0.00 \\ 0 & 0.00\end{array}$

$\begin{array}{lll}5 & 0.00 \\ 0 & 0.00\end{array}$

20.00

100.00

$\begin{array}{rl}9 & 0.00 \\ 10 & 0.00\end{array}$

90.00

50.00

60.00

$\begin{array}{rl}10 & 0.23 \\ 8 & 0.00\end{array}$

100.00

20.00

30.00

00.00

0.00

$\begin{array}{ll}0 & 0.00 \\ 0 & 0.00\end{array}$

00.00

40.00

$\begin{array}{ll}1 & 0.09\end{array}$

30.00

100.00

40.00

0.00

100.00

$\begin{array}{ll}10 & 0.17 \\ 10 & 0.00\end{array}$

100.00

90.26

30.00

0.00
$0 \quad 0.00$

0.00

100.00

0.00

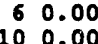

100.00

60.07

0 0 0.00

70.00

10.00

40.00

$\begin{array}{rl}2 & 0.00 \\ 10 & 0.00\end{array}$

$\begin{array}{ll}10 & 0.00 \\ 10 & 0.00\end{array}$

90.00

100.00

50.00

100.14

100.00

100.00

100.00

100.00

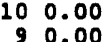

50.00

100.00

80.00

100.03

100.00

100.00

10.00

$\begin{array}{ll}3 & 0.00 \\ 9 & 0.00\end{array}$
Tom Dow solar wind cloud

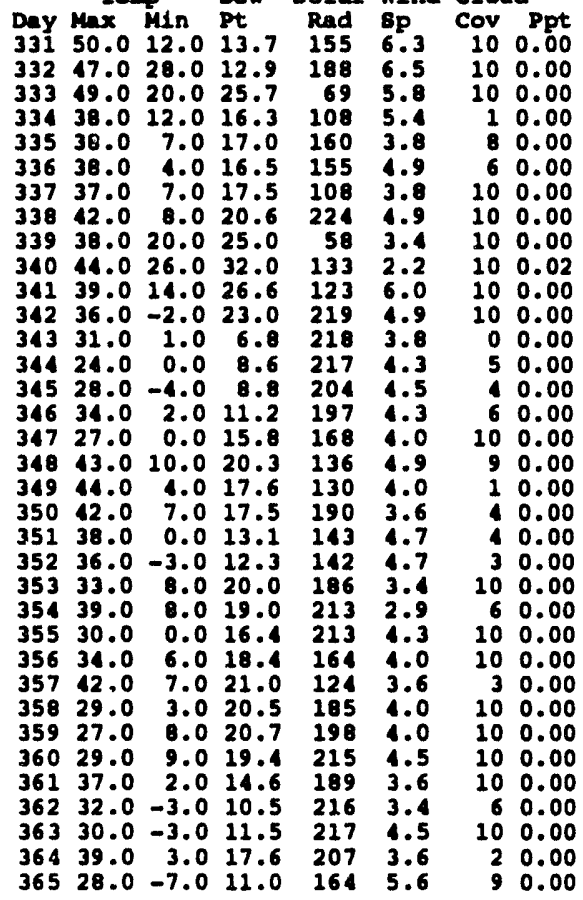

Yeax 1987

Temp Dew solar Wind cloud

\begin{tabular}{lllllll}
$\operatorname{Max}$ & Min & Pt & Rad & 8p & Cov Ppt \\
\hline 18.0 & 0.1 & 14.4 & 170 & 3.6 & 10 & 0.00
\end{tabular}

$\begin{array}{llllllll}2 & 37.0 & 8.1 & 18.7 & 177 & 6.3 & 6 & 0.00\end{array}$

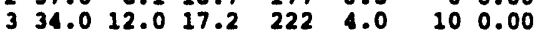

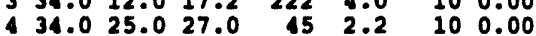

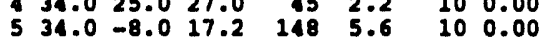

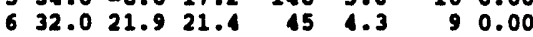

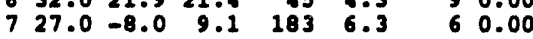

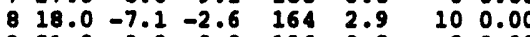

$921.0-0.9-0.8 \quad 196 \quad 3.8$

$1015.1-17.0-11.9 \quad 138 \quad 4.0$

$1127.0 \quad-8.0 \quad-3.6 \quad 143 \quad 5.1$

$1334.0 \quad 0.0 \quad 14.7 \quad 73 \quad 4.0$

$14 \quad 17.1-8.0 \quad 7.2 \quad 196 \quad 6.3$

$1521.9-9.9-5.1 \quad 18913.4$

$1621.9-9.9-9.4 \quad 1417.2$

$\begin{array}{lllll}17 & 21.9-17.0 & -8.3 & 98 & 3.8\end{array}$

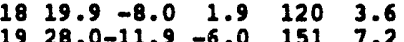

$2123.0-14.1-8.7 \quad 75 \quad 4.0$

$\begin{array}{llllll}22 & 21.0 & -9.9 & -2.0 & 159 & 4.7\end{array}$

$\begin{array}{lllllll}23 & 37.9 & 0.0 & 9.5 & 193 & 4.5\end{array}$

$\begin{array}{llllll}24 & 32.0 & -2.0 & 10.6 & 144 & 4.9\end{array}$

$\begin{array}{llllll}25 & 30.0 & 12.0 & 20.3 & 234 & 5.4\end{array}$

$\begin{array}{llllll}26 & 46.0 & 19.9 & 26.6 & 232 & 6.9\end{array}$

$\begin{array}{lllllll}27 & 43.0 & 16.0 & 20.3 & 276 & 4.0\end{array}$

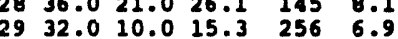

$\begin{array}{lllllll}30 & 32.0 & 10.0 & 16.7 & 162 & 5.6\end{array}$

$\begin{array}{llllll}31 & 37.9 & 19.9 & 21.7 & 128 & 5.6\end{array}$

$\begin{array}{llllll}32 & 46.0 & 21.9 & 24.6 & 197 & 10.5\end{array}$

$3344.130 .925 .3226 \quad 8.1$

3437.26 .128 .8214

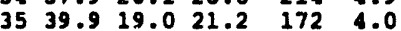

$3639.919 .923 .0 \quad 213 \quad 4.0$

$\begin{array}{llllll}37 & 44.1 & 14.0 & 16.7 & 273 & 5 .\end{array}$

$\begin{array}{llllll}38 & 46.0 & 12.9 & 18.0 & 315 & 4.5\end{array}$

$\begin{array}{llllll}39 & 46.0 & 12.9 & 18.1 & 238 & 4.9\end{array}$

$\begin{array}{llllll}40 & 42.1 & 18.0 & 19.6 & 171 & 4.0\end{array}$

$\begin{array}{llllll}48.0 & 19.9 & 22.3 & 256 & 4.3\end{array}$

$\begin{array}{lllllll}46.9 & 46.0 & 24.3 & 332 & 4.3\end{array}$

$\begin{array}{llllll}13 & 52.0 & 24.1 & 27.7 & 310 & 4.0\end{array}$

$\begin{array}{llllll}44 & 42.1 & 32.0 & 31.6 & 121 & 8.3 \\ 45 & 46.9 & 30.9 & 27.3 & 327 & 6.5\end{array}$

$\begin{array}{llllll}45 & 46.9 & 30.9 & 27.3 & 327 & 6.5 \\ 46 & 37.0 & 21.9 & 26.2 & 303 & 4.3\end{array}$

80.00

$\begin{array}{lll}6 & 0.00 \\ 8 & 0.00\end{array}$

$\begin{array}{ll}8 & 0.00 \\ 8 & 0.00 \\ 8 & 0.00\end{array}$

$\begin{array}{ll}8 & 0.00 \\ 8 & 0.00\end{array}$

$\begin{array}{rl}8 & 0.00 \\ 10 & 0.00\end{array}$

80.00

10.00

80.00

$\begin{array}{ll}0 & 0.00 \\ 2 & 0.00\end{array}$

70.00

90.00

100.00

100.00 
Year 1987 (Cont'd)

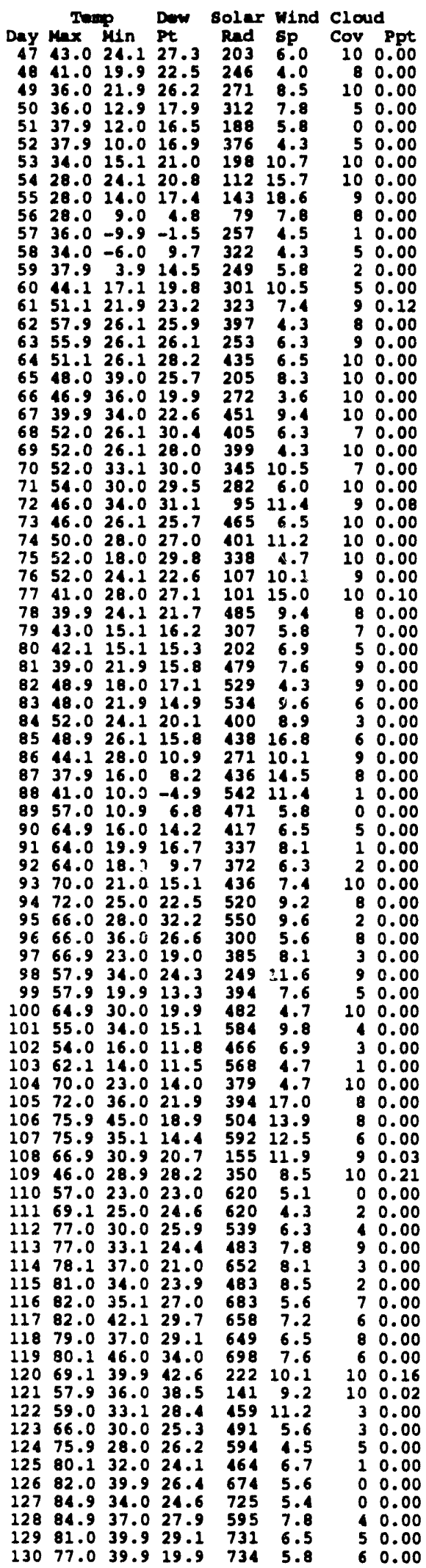

Tomp Daw solar wind cloud

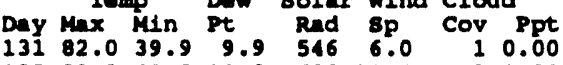

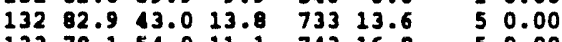
$13378.154 .011 .2 \quad 74316.8 \quad 50.00$

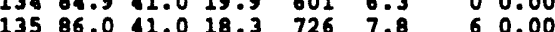

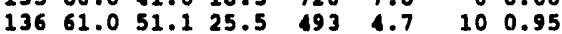

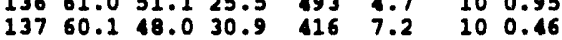
$\begin{array}{rlllllll}137 & 60.1 & 48.0 & 30.9 & 416 & 7.2 & 10 & 0.46 \\ 138 & 66.0 & 46.0 & 31.1 & 328 & 8.3 & 8 & 0.04\end{array}$ $\begin{array}{llllllll}138 & 66.0 & 46.0 & 31.1 & 328 & 8.3 & 8 & 0.04 \\ 139 & 59.0 & 39.9 & 29.7 & 758 & 8.5 & 9 & 0.07\end{array}$

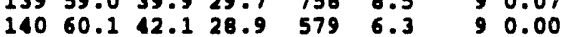

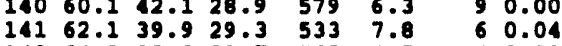
$14264.932 .0 \quad 29.7 \quad 765 \quad 4.7 \quad 40.00$

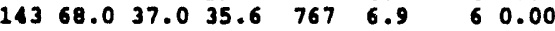

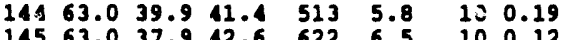

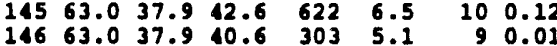

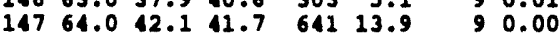

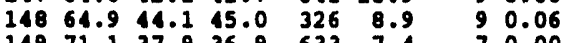
$\begin{array}{llllll}149 & 71.1 & 37.9 & 36.9 & 633 & 7.4\end{array}$ $\begin{array}{rrrrrrrr}150 & 72.0 & 41.0 & 10.6 & 779 & 10.1 & 10 & 0.00 \\ 151 & 64.0 & 11.0 & 33.6 & 611 & 17.7 & 9 & 0.00\end{array}$ $\begin{array}{llllllll}151 & 64.0 & 41.0 & 33.6 & 611 & 17.7 & 9 & 0.00 \\ 152 & 63.0 & 30.0 & 23.5 & 726 & 12.8 & 0 & 0.00\end{array}$

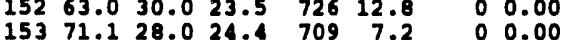
$\begin{array}{llllllll}153 & 71.1 & 28.0 & 24.4 & 709 & 7.2 & 0 & 0.00 \\ 154 & 79.0 & 34.0 & 27.0 & 657 & 6.3 & 5 & 0.00\end{array}$

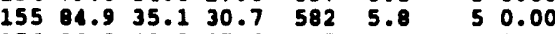

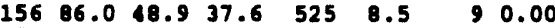
$15780.150 .0 \quad 44.2 \quad 590 \quad 7.4 \quad 100.00$

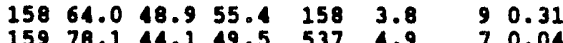
$\begin{array}{llllllll}160 & 73.9 & 45.0 & 50.0 & 385 & 5.8 & 9 & 0.11\end{array}$

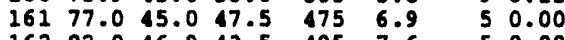
$\begin{array}{llllllll}162 & 82.0 & 46.9 & 43.5 & 485 & 7.6 & 5 & 0.00\end{array}$

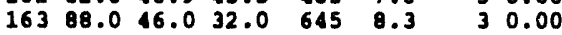
$\begin{array}{lllllll}16491.9 & 46.9 & 29.5 & 793 & 6.0 & 0 & 0.00\end{array}$

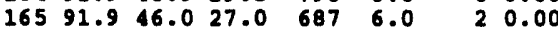
$\begin{array}{llllllll}166 & 91.9 & 59.0 & 34.7 & 692 & 18.8 & 5 & 0.05\end{array}$ $\begin{array}{llllllll}167 & 73.0 & 18.0 & 34.2 & 628 & 13.6 & 3 & 0.00\end{array}$ $\begin{array}{llllllll}168 & 81.0 & 42.1 & 37.0 & 680 & 7.4 & 3 & 0.00\end{array}$

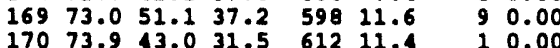

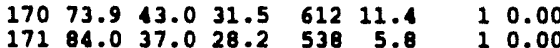
$\begin{array}{lllllll}172 & 84.0 & 48.0 & 32.5 & 788 & 11.9 & 0.01\end{array}$ $\begin{array}{llllllll}173 & 70.0 & 46.9 & 13.5 & 794 & 9.8 & 5 & 0.18\end{array}$ $17581.047 .919 .0 \quad 692 \quad 9.6 \quad 70.00$

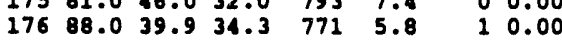
$\begin{array}{llllllll}176 & 88.0 & 39.9 & 34.3 & 771 & 5.8 & 1 & 0.00 \\ 177 & 91.9 & 46.0 & 31.1 & 773 & 6.3 & 6 & 0.00\end{array}$ $\begin{array}{llllllll}177 & 91.9 & 46.0 & 31.1 & 773 & 6.3 & 6 & 0.00 \\ 178 & 90.0 & 48.9 & 31.6 & 784 & 7.2 & 0.00\end{array}$ $\begin{array}{llllllll}178 & 90.0 & 48.9 & 31.6 & 784 & 7.2 & 0.00 \\ 179 & 86.0 & 50.0 & 34.9 & 791 & 7.2 & 7 & 0.00\end{array}$

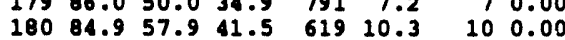
$\begin{array}{rrrrrrrr}180 & 84.9 & 57.9 & 41.5 & 619 & 10.3 & 10 & 0.00 \\ 181 & 82.0 & 48.9 & 49.6 & 774 & 5.4 & 10 & 0.06\end{array}$

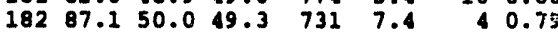

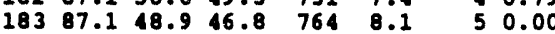

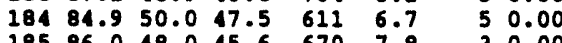

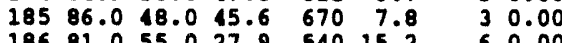

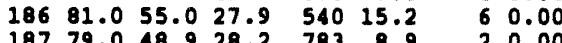
$18884.045 .0 \quad 32.4686 \quad 7.2 \quad 80.00$

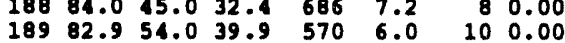

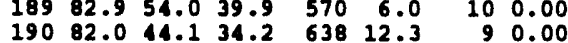
$\begin{array}{llllllll}190 & 82.0 & 44.1 & 34.2 & 638 & 12.3 & 9 & 0.00 \\ 191 & 69.1 & 46.9 & 46.0 & 591 & 14.1 & 9 & 0.07\end{array}$

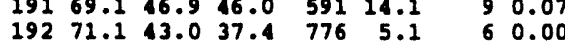

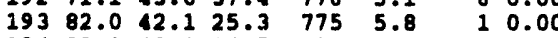

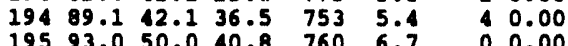

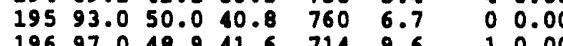

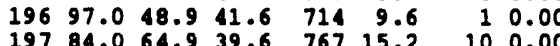

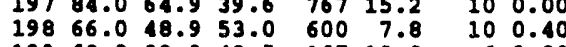
$19963.0 \quad 39.9 \quad 43.5 \quad 167 \quad 13.0 \quad 6 \quad 6.03$

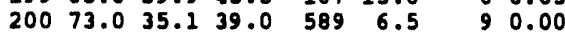

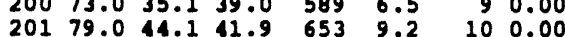

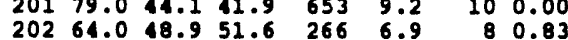
$\begin{array}{llllllll}202 & 64.0 & 18.9 & 51.6 & 266 & 6.9 & 8 & 0.83 \\ 203 & 75.0 & 43.0 & 49.3 & 701 & 7.8 & 2 & 0.00\end{array}$ $20482.944 .147 .8 \quad 611 \quad 6.3 \quad 00.00$ $\begin{array}{llllllll}205 & 89.1 & 51.1 & 42.7 & 634 & 8.1 & 3 & 0.00\end{array}$

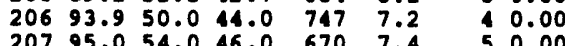

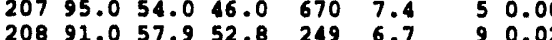
$20984.960 .158 .8 \quad 560 \quad 6.0 \quad 80.00$

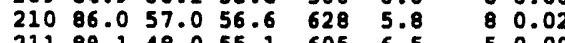
$\begin{array}{llllllll}211 & 89.1 & 48.0 & 55.1 & 605 & 6.5 & 5 & 0.00\end{array}$

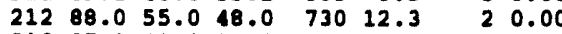

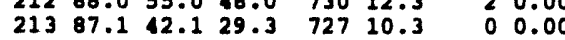

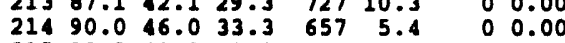
$\begin{array}{llllllll}215 & 90.0 & 41.0 & 32.2 & 665 & 5.4 & 0 & 0.00 \\ 216 & 95.0 & 42.1 & 35.1 & 626 & 7.8 & 0 & 0.00\end{array}$
Thmp Dew soler wind cloud

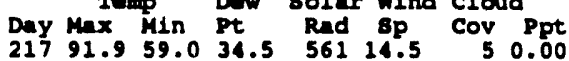

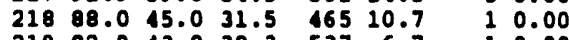

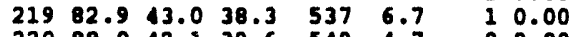

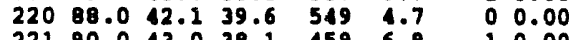
10.00

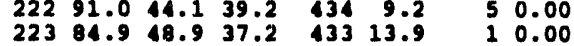

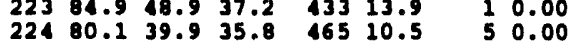

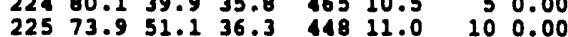

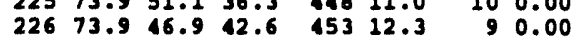
$\begin{array}{llllllll}227 & 70.0 & 48.9 & 40.3 & 651 & 12.5 & 4 & 0.00\end{array}$ $\begin{array}{llllllll}228 & 73.9 & 36.0 & 34.7 & 588 & 11.2 & 0 & 0.00\end{array}$

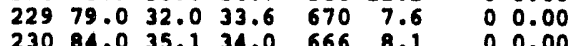
$\begin{array}{llllllll}230 & 84.0 & 35.1 & 34.0 & 666 & 8.1 & 0 & 0.00 \\ 231 & 88.0 & 39.0 & 37.9 & 612 & 6.7 & 5 & 0.00\end{array}$

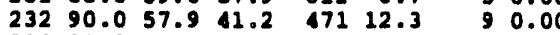
$23381.055 .941 .9 \quad 6117.4 \quad 90.00$ $\begin{array}{llllllll}234 & 87.1 & 46.0 & 43.3 & 537 & 8.3 & 8 & 0.00\end{array}$ $23588.051 .1 \quad 10.3 \quad 601 \quad 9.4 \quad 60.02$ $23677.052 .024 .4 \quad 401 \quad 8.5 \quad 100.18$ $\begin{array}{llllllll}237 & 71.1 & 11.0 & 31.6 & 190 & 7.8 & 3 & 0.01\end{array}$ $\begin{array}{llllllll}238 & 77.0 & 39.9 & 31.6 & 632 & 5.6 & 2 & 0.00\end{array}$

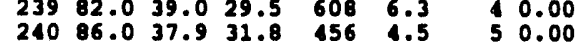
$\begin{array}{llllllll}240 & 86.0 & 37.9 & 31.8 & 456 & 4.5 & 5 & 0.00 \\ 241 & 91.0 & 39.9 & 33.5 & 618 & 8.9 & 1 & 0.00\end{array}$

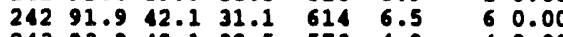
$24393.942 .132 .5 \quad 573 \quad 4.9 \quad 40.00$

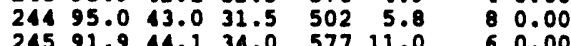
$24672.0 \quad 46.0 \quad 32.2 \quad 54515.2 \quad 60.00$

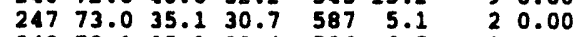
$24878.1 \quad 35.2 \quad 33.4 \quad 586 \quad 6.5 \quad 10.00$

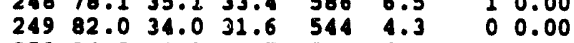
$\begin{array}{llllllll}249 & 82.0 & 34.0 & 31.6 & 544 & 4.3 & 0 & 0.00 \\ 250 & 84.0 & 39.9 & 36.7 & 520 & 6.5 & 0 & 0.00\end{array}$

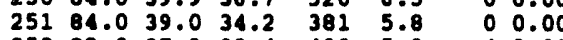
$\begin{array}{lllllll}252 & 82.0 & 37.9 & 32.4 & 433 & 5.8 & 40.00\end{array}$ $\begin{array}{llllllll}253 & 84.0 & 41.0 & 33.8 & 490 & 5.1 & 2 & 0.00 \\ 254 & 82.9 & 39.9 & 34.3 & 446 & 4.7 & 1 & 0.00\end{array}$ $\begin{array}{llllllll}254 & 82.9 & 39.9 & 34.3 & 446 & 1.7 & 1 & 0.00 \\ 255 & 86.0 & 36.0 & 34.7 & 164 & 6.0 & 1 & 0.00\end{array}$ $\begin{array}{lllllll}256 & 87.1 & 42.1 & 36.0 & 521 & 6.0\end{array}$

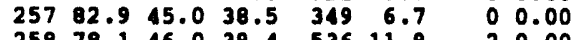

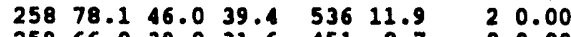

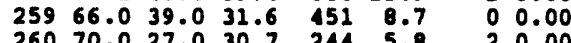

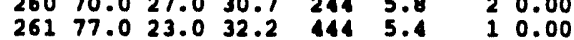

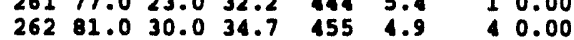

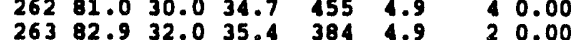

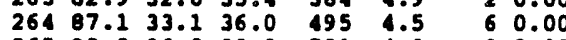

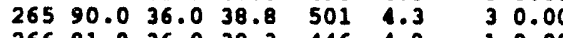
$\begin{array}{llllllll}266 & 91.9 & 36.0 & 38.3 & 446 & 4.9 & 1 & 0.00 \\ 267 & 91.0 & 37.0 & 37.2 & 39.3 & 5.1 & 3 & 0.00\end{array}$

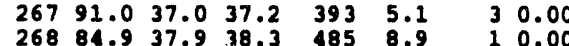
$\begin{array}{lllllll}269 & 66.0 & 36.0 & 58.7 & 480 & 16.6 & 0.00\end{array}$

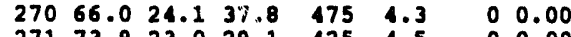

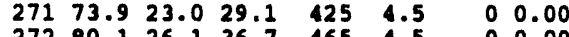

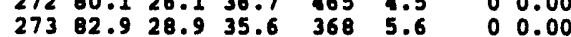

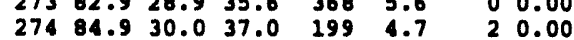

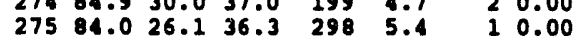

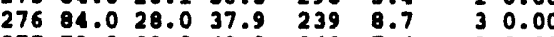
$\begin{array}{llllllll}277 & 79.0 & 39.0 & 40.8 & 343 & 7.4 & 9 & 0.00 \\ 278 & 78.1 & 30.9 & 35.4 & 324 & 5.1 & 3 & 0.00\end{array}$

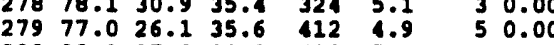

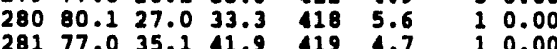
$\begin{array}{lllllll}282 & 68.0 & 36.0 & 10.5 & 366 & 7.4 & 9\end{array}$ $28366.021 .928 .0 \quad 208 \quad 4.7 \quad 00.00$

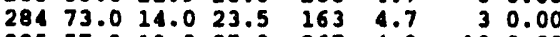
$\begin{array}{llllllll}285 & 57.9 & 19.0 & 27.0 & 267 & 4.0 & 10 & 0.00\end{array}$ $\begin{array}{rrrrrrrr}286 & 64.9 & 36.0 & 42.1 & 325 & 8.5 & 10 & 0.00 \\ 287 & 75.0 & 19.0 & 35.6 & 364 & 9.6 & 2 & 0.00\end{array}$

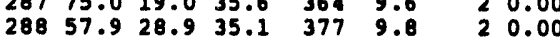

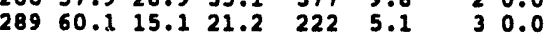
$\begin{array}{llllllll}290 & 64.9 & 15.1 & 24.3 & 241 & 7.4 & 3 & 0.00\end{array}$ $29162.128 .0 \quad 33.3 \quad 317 \quad 3.8 \quad 60.00$

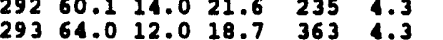

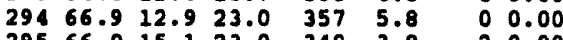

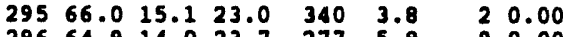

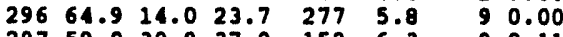

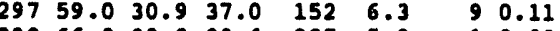
$\begin{array}{llllll}298 & 66.0 & 30.0 & 30.6 & 287 & 5.8\end{array}$

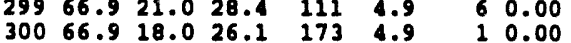
$\begin{array}{llllllll}300 & 66.9 & 18.0 & 26.1 & 173 & 4.9 & 1 & 0.00 \\ 301 & 70.0 & 19.0 & 28.2 & 237 & 4.7 & 1 & 0.00\end{array}$

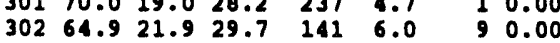


Year 1987 (Cont'd)

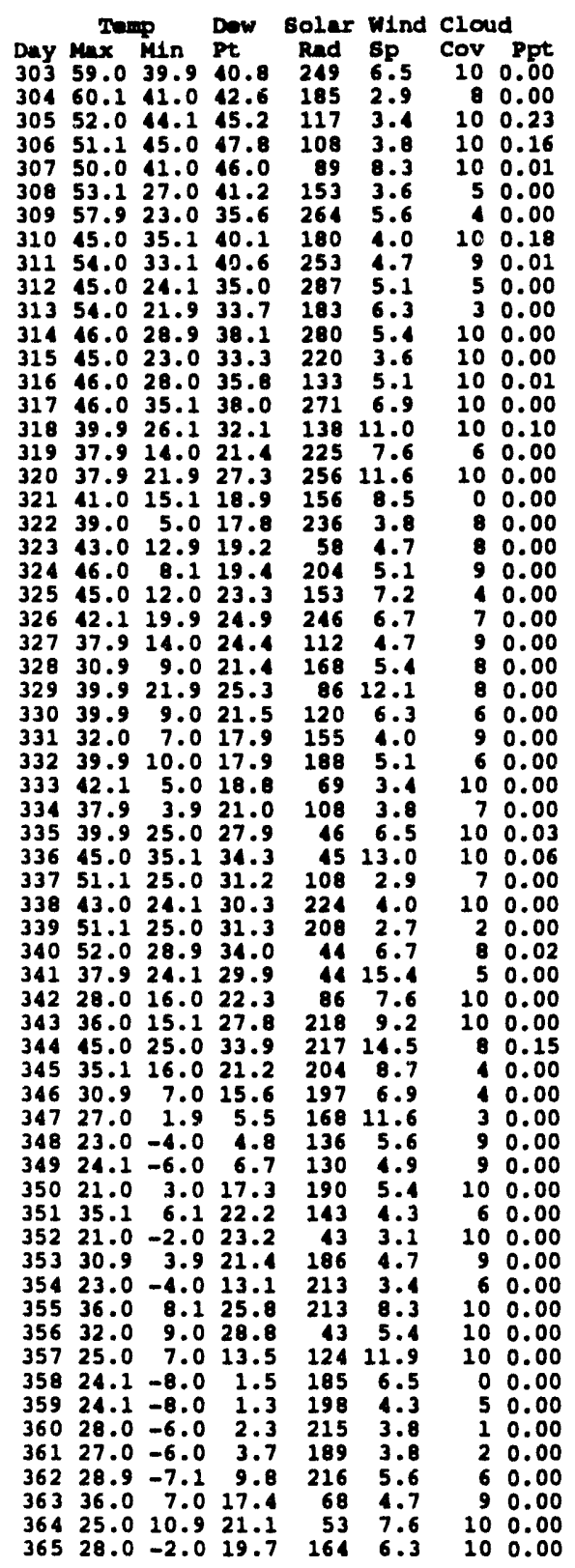

Year 1988
Damp Dow solar wind cloud

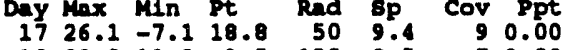
18 30.0-11.9 $9.5 \quad 120 \quad 8.5 \quad 70.00$

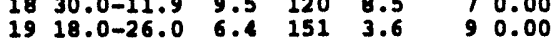

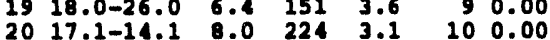

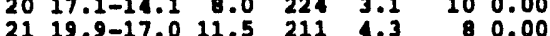

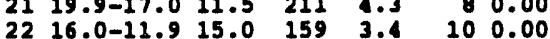

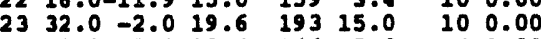
$2428.0-9.913 .4 \quad 1445.6 \quad 0.00$

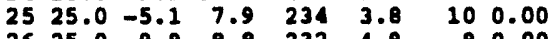

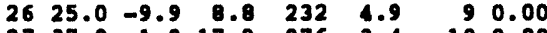

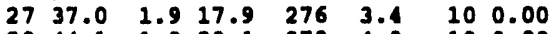

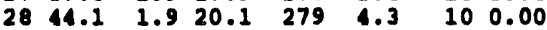
$2936.0 \quad 10.0 \quad 26.1 \quad 256 \quad 8.5 \quad 100.00$ $3032.018 .023 .9 \quad 162 \quad 19.2 \quad 70.00$

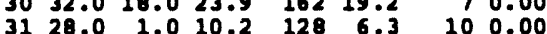

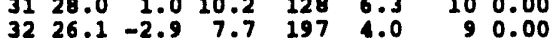
$\begin{array}{llllllll}32 & 26.1 & -2.9 & 7.7 & 197 & 4.0 & 9 & 0.00 \\ 33 & 25.0 & -6.0 & 6.6 & 226 & 4.9 & 40.00\end{array}$ $3423.0-6.0 \quad 6.4 \quad 214 \quad 4.9 \quad 60.00$ $\begin{array}{llllllll}35 & 30.0 & -8.0 & 4.5 & 172 & 4.7 & 3 & 0.00\end{array}$

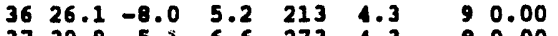

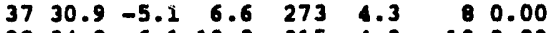
$\begin{array}{llllllll}38 & 34.0 & 6.1 & 13.3 & 315 & 4.3 & 10 & 0.00\end{array}$ $\begin{array}{llllllll}39 & 37.0 & 7.0 & 20.5 & 238 & 6.3 & 10 & 0.00\end{array}$ $\begin{array}{lllllllll}30 & 39.9 & 19.9 & 31.1 & 171 & 13.9 & 10 & 0.00\end{array}$

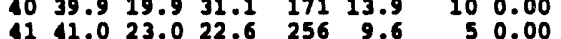
$\begin{array}{lllllll}12 & 11.0 & 23.0 & 28.8 & 332 & 8.9 & 9.00\end{array}$ $\begin{array}{lllllll}43.0 & 17.1 & 26.2 & 310 & 4.0 & 1 & 0.00\end{array}$

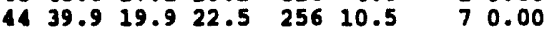

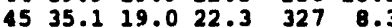
$4643.024 .125 .0 \quad 30314.1$

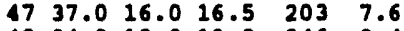
$4834.012 .019 .3 \quad 246 \quad 3.4$ $4939.914 .017 .8 \quad 2716.7$

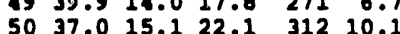
$\begin{array}{llllll}50 & 37.0 & 15.1 & 22.1 & 312 & 10.1 \\ 51 & 46.9 & 15.1 & 23.4 & 188 & 4.5\end{array}$ $\begin{array}{llllll}51 & 46.9 & 15.1 & 23.4 & 188 & 1.5 \\ 52 & 45.0 & 12.9 & 23.2 & 376 & 8.3\end{array}$ $\begin{array}{llllll}52 & 45.0 & 12.9 & 23.2 & 376 & 8.3 \\ 53 & 44.1 & 21.0 & 18.5 & 198 & 8.3\end{array}$ $\begin{array}{lllllll}54 & 41.0 & 12.9 & 17.1 & 255 & 6.7\end{array}$ $5546.0 \quad 12.0 \quad 17.8 \quad 143 \quad 5.1$

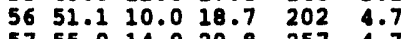
$\begin{array}{llllll}57 & 55.0 & 14.0 & 20.8 & 257 & 4.7\end{array}$ $\begin{array}{llllll}58 & 54.0 & 12.9 & 20.8 & 322 & 4.7\end{array}$ $\begin{array}{llllll}59 & 53.1 & 19.0 & 26.1 & 249 & 4.9\end{array}$ $60 \quad 45.0 \quad 26.1 \quad 32.2 \quad 301 \quad 4.5$ $\begin{array}{llllll}60 & 55.0 & 26.1 & 32.2 & 301 & 4.5 \\ 61 & 50.0 & 23.0 & 30.0 & 323 & 6.0\end{array}$ $6251.1 \quad 30.929 .5 \quad 397 \quad 13.6$

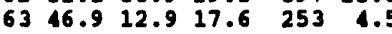
$\begin{array}{llllll}64 & 51.1 & 24.1 & 27.3 & 435 & 5.4\end{array}$ $\begin{array}{llllll}65 & 43.0 & 23.0 & 27.3 & 88 & 15.4\end{array}$ $\begin{array}{llllll}66 & 45.0 & 16.0 & 14.5 & 272 & 8.3\end{array}$ $\begin{array}{llllll}67 & 48.0 & 15.1 & 20.7 & 451 & 1.9\end{array}$ $\begin{array}{llllll}68 & 45.0 & 19.0 & 24.1 & 405 & 9.8\end{array}$ $\begin{array}{llllll}69 & 39.0 & 26.1 & 11.7 & 399 & 15.0\end{array}$ $\begin{array}{llllll}70 & 37.9 & 19.0 & 7.3 & 345 & 14.1\end{array}$ $\begin{array}{llllll}71 & 36.0 & 6.1 & 9.3 & 282 & 6.7\end{array}$ $\begin{array}{lllllll}72 & 43.0 & 7.0 & 12.2 & 157 & 7.8\end{array}$ $\begin{array}{llllll}73 & 36.0 & 10.0 & 20.5 & 351 & 6.7\end{array}$ $\begin{array}{llllll}74 & 43.021 .9 & 21.4 & 01 & 15.9\end{array}$

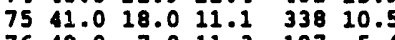
$\begin{array}{llllll}76 & 48.0 & 7.0 & 11.3 & 107 & 5.4\end{array}$ $\begin{array}{llllll}77 & 57.0 & 17.1 & 18.5 & 283 & 4.9\end{array}$ $\begin{array}{lllll}78 & 62.1 & 16.0 & 21.4 \quad 485 & 6.9\end{array}$ $\begin{array}{llllll}79 & 62.1 & 21.9 & 20.5 & 307 & 8.5\end{array}$ $\begin{array}{llllllll}80 & 53.1 & 32.0 & 27.7 & 202 & 15.2\end{array}$ $8148.927 .027 .0 \quad 479 \quad 15.2$ $\begin{array}{llllll}82 & 18.0 & 24.1 & 23.5 & 529 & 13.6\end{array}$ $\begin{array}{llllll}83 & 45.0 & 21.9 & 17.2 & 534 & 13.0\end{array}$ $8455.927 .026 .2 \quad 40013.9$ $8564.024 .1 \quad 27.5 \quad 43813.9$ $\begin{array}{llllll}86 & 51.1 & 19.0 & 30.4 & 271 & 21.3\end{array}$ $87 \quad \begin{array}{llllll}8.0 & 12.0 & 3.6 \quad 436 & 11.9\end{array}$ $\begin{array}{lllll}88 & 37.9 & 21.0 & 19.4 \quad 440 & 11.6\end{array}$ $8939.9 \quad 7.0$ 15.1 $471 \quad 7.8$ $\begin{array}{rrrrrr}89 & 39.9 & 7.0 & 15.1 & 471 & 7.8 \\ 90 & 50.0 & 10.0 & 11.8 & 417 & 6.3\end{array}$ $\begin{array}{llllll}90 & 50.0 & 10.0 & 11.8 & 117 & 6.3 \\ 91 & 60.1 & 15.1 & 17.8 & 337 & 5.1\end{array}$ $\begin{array}{llllll}91 & 60.1 & 15.1 & 17.8 & 337 & 5.1 \\ 92 & 64.9 & 17.1 & 22.5 & 372 & 9.4\end{array}$ $9350.0 \quad 37.027 .9 \quad 276 \quad 11.4$ $9457.928 .016 .5 \quad 52021.0$ $9557.010 .917 .4 \quad 550 \quad 7.2$ 9671.123 .023 .43009 .2 $9763.028 .0 \quad 27.3 \quad 188 \quad 17.0$ $\begin{array}{lllllll}98 & 13.0 & 14.0 & 16.5 & 249 & 7.2\end{array}$ $9948.018 .0 \quad 8.1 \quad 394 \quad 6.7$ $10063.0 \quad 9.0 \quad 9.3 \quad 482 \quad 5.1$ $\begin{array}{llllll}101 & 72.0 & 16.0 & 15.8 & 584 & 4.9\end{array}$ $\begin{array}{llllll}102 & 77.0 & 21.9 & 20.1 & 466 & 5.6\end{array}$ 60.00 50.00
Tomp Dow solar wind Cloud Day Max Min Pt Red sp Cov Ppt $10468.0 \quad 34.0 \quad 31.3 \quad 379 \quad 7.4 \quad 100.00$ $10566.937 .0 \quad 37.0 \quad 394 \quad 5.8 \quad 100.00$ $10673.937 .057 .0 \quad 3945.8 \quad 100.00$ $10673.928 .0 \quad 30.9$ 504 $5.4 \quad 960.00$ $10775.940 .131 .1 \quad 59210.3$ $\begin{array}{llllll}108 & 55.0 & 39.0 & 39.7 & 155 & 13.9\end{array}$ $10957.0 \quad 34.0 \quad 37.8 \quad 350 \quad 7.2$ $\begin{array}{llllll}110 & 54.0 & 39.0 & 44.8 & 518 & 7.4\end{array}$ $11250.0 \quad 32.0 \quad 34.9 \quad 620 \quad 8.5$ $\begin{array}{llllll}112 & 45.0 & 32.0 & 37.9 & 385 & 4.7\end{array}$ $\begin{array}{llllll}113 & 54.0 & 28.9 & 35.2 & 483 & 9.2\end{array}$ $11455.0 \quad 25.0 \quad 28.9 \quad 652 \quad 13.0$ $\begin{array}{llllll}115 & 48.0 & 26.1 & 23.9 & 288 & 11.6\end{array}$ 11657.017 .123 .0 $11766.927 .0 \quad 30.4$ $\begin{array}{lllll}118 & 70.0 & 37.0 & 32.4\end{array}$ $11966.0 \quad 39.0 \quad 32.2$ $\begin{array}{llll}120 & 54.0 & 36.0 & 26.2\end{array}$ $\begin{array}{lllll}121 & 48.0 & 28.9 & 11.8\end{array}$ $\begin{array}{lllll}122 & 52.0 & 19.0 & 13.1\end{array}$

12461.032 .026 .0

$12566.941 .0 \quad 30.9$ $12648.0 \quad 34.0 \quad 35.1$ 12748.935 .137 .4 $\begin{array}{llll}128 & 55.9 & 37.9 & 38.3\end{array}$ $12961.0 \quad 30.9 \quad 33.3$ $\begin{array}{llll}130 & 72.0 & 25.0 & 30.2 \\ 131 & 80.1 & 30.0 & 30.9\end{array}$ $\begin{array}{llll}132 & 84.9 & 35.1 & 33.4\end{array}$ $13372.036 .0 \quad 30.0$ 13466.028 .926 .8 $\begin{array}{llll}135 & 81.0 & 28.9 & 29.8\end{array}$ $\begin{array}{llll}136 & 87.1 & 44.1 & 33.3 \\ 137 & 63.0 & 44.1 & 37.0\end{array}$ 13763.064 .1037 .0 $\begin{array}{llll}138 & 61.0 & 28.0 & 27.9 \\ 139 & 66.9 & 11.0 & 23.4\end{array}$ $\begin{array}{llll}139 & 66.9 & 41.0 & 23.4 \\ 140 & 73.0 & 25.0 & 23.5\end{array}$ 14073.025 .023 .5 $\begin{array}{llll}141 & 79.0 & 42.1 & 24.6 \\ 142 & 82.9 & 35.1 & 26.6\end{array}$ $14387.1 \quad 41.031 .1$ $144 \quad 84.9 \quad 46.9 \quad 34.2$ $14584.0 \quad 39.0 \quad 35.4$ $14684.0 \quad 11.0 \quad 38.5$ $\begin{array}{llll}146 & 84.0 & 1.0 & 38.5 \\ 147 & 75.9 & 42.1 & 33.6\end{array}$ $148 \quad 80.1 \quad 39.0 \quad 32.9$ $\begin{array}{lllll}149 & 55.9 & 39.0 & 38.1\end{array}$ $\begin{array}{llll}150 & 44.1 & 35.1 & 39.2\end{array}$ $15157.0 \quad 34.0 \quad 36.9$ $\begin{array}{lllll}152 & 64.0 & 43.0 & 45.5\end{array}$ $\begin{array}{lllll}153 & 75.0 & 42.1 & 44.2\end{array}$ $\begin{array}{lllll}154 & 89.1 & 43.0 & 43.3\end{array}$ $\begin{array}{llll}155 & 91.9 & 46.0 & 41.0 \\ 156 & 86.0 & 45.0 & 38.3\end{array}$ $\begin{array}{llll}156 & 86.0 & 45.0 & 38.3 \\ 157 & 80.1 & 41.0 & 33.3\end{array}$ $\begin{array}{llll}157 & 80.1 & 11.0 & 33.3 \\ 158 & 75.0 & 39.9 & 30.9\end{array}$ 15966.932 .025 .3 $16084.0 \quad 33.125 .5$ $16181.0 \quad 37.028 .9$ $\begin{array}{llll}162 & 84.9 & 46.9 & 32.2\end{array}$ $\begin{array}{llll}163 & 79.0 & 48.0 & 37.8\end{array}$ $16478.145 .0 \quad 36.5$ $\begin{array}{lllll}165 & 84.0 & 44.1 & 32.2\end{array}$ $\begin{array}{lllll}166 & 90.0 & 42.1 & 34.0\end{array}$ $\begin{array}{lllll}167 & 93.9 & 44.1 & 36.9\end{array}$ $\begin{array}{lllll}168 & 88.0 & 48.9 & 40.3\end{array}$ $\begin{array}{llll}169 & 90.0 & 45.0 & 43.5 \\ 170 & 97.0 & 50.0 & 40.3\end{array}$ $17193.066 .0 \quad 48.6$ $17298.1 \quad 55.0 \quad 49.8$ 17497.069 .146 .2

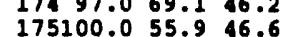
$176100.063 .0 \quad 48.6$ 17788.060 .152 .5 $\begin{array}{llll}178 & 93.9 & 51.1 & 51.1 \\ 179 & 90.0 & 60.1 & 48.9\end{array}$ $\begin{array}{llll}179 & 90.0 & 60.1 & 48.9 \\ 180 & 75.9 & 48.9 & 32.9\end{array}$ $\begin{array}{llll}181 & 82.9 & 37.0 & 29.1\end{array}$ $\begin{array}{llll}182 & 90.0 & 41.0 & 32.4\end{array}$ $\begin{array}{lllll}183 & 95.0 & 14.1 & 37.6\end{array}$ $18495.0 \quad 55.9 \quad 43.2$ 18593.055 .949 .5 $\begin{array}{llll}186 & 84.9 & 51.1 & 42.3 \\ 187 & 79.0 & 48.9 & 34.9\end{array}$ $\begin{array}{llllllll}187 & 79.0 & 48.9 & 34.9 & 783 & 15.7\end{array}$ $\begin{array}{llllll}188 & 87.1 & 33.1 & 30.0 & 686 & 6.3\end{array}$

$\begin{array}{rr}6 & 0.00 \\ 10 & 0.13\end{array}$

$\begin{array}{rr}10 & 0.13 \\ 8 & 0.12\end{array}$ 100.54 90.00 100.38 70.00 60.00

80.02

60.00 $\begin{array}{rr}9 & 0.00 \\ 10 & 0.00\end{array}$ 10.00 100.00 100.00 $\begin{array}{ll}6 & 0.00 \\ 5 & 0.00\end{array}$ 100.00 90.00 $10 \quad 0.00$ $10 \quad 0.14$ 10.14
0.00 60.00 $\begin{array}{ll}1 & 0.00 \\ 5 & 0.00\end{array}$

10.00

60.00

$\begin{array}{ll}6 & 0.00 \\ 1 & 0.00\end{array}$

$\begin{array}{ll}1 & 0.00 \\ 1 & 0.00\end{array}$ $10 \quad 0.00$ 50.00 20.00

$\begin{array}{ll}1 & 0.00 \\ 1 & 0.00\end{array}$

10.00

90.00 100.00 60.00

$\begin{array}{ll}9 & 0.00 \\ 8 & 0.00\end{array}$ 100.00 $10 \quad 0.20$ $10 \quad 0.22$ 90.00 100.00 100.00 $\begin{array}{ll}1 & 0.00 \\ 2 & 0.00\end{array}$ $\begin{array}{ll}2 & 0.00 \\ 3 & 0.00\end{array}$ 30.00
40.00 10.00 10.00 $\begin{array}{ll}3 & 0.00 \\ 5 & 0.00\end{array}$ $\begin{array}{ll}5 & 0.00 \\ 5 & 0.00\end{array}$ 50.00 10.00 10.00 $10 \quad 0.00$ $\begin{array}{ll}10 & 0.00 \\ 10 & 0.04\end{array}$ 00.00 $\begin{array}{ll}2 & 0.00 \\ 5 & 0.00\end{array}$ 50.00 60.00 20.00 $\begin{array}{ll}2 & 0.00 \\ 0 & 0.08\end{array}$ 80.01 90.00 10.00
100.00 10.00 10.00 $\begin{array}{ll}8 & 0.00 \\ 0 & 0.00\end{array}$ 10.00 $\begin{array}{ll}1 & 0.00 \\ 3 & 0.00\end{array}$ 10.00 70.00

00.00 
Your 1988 (Cont'd)

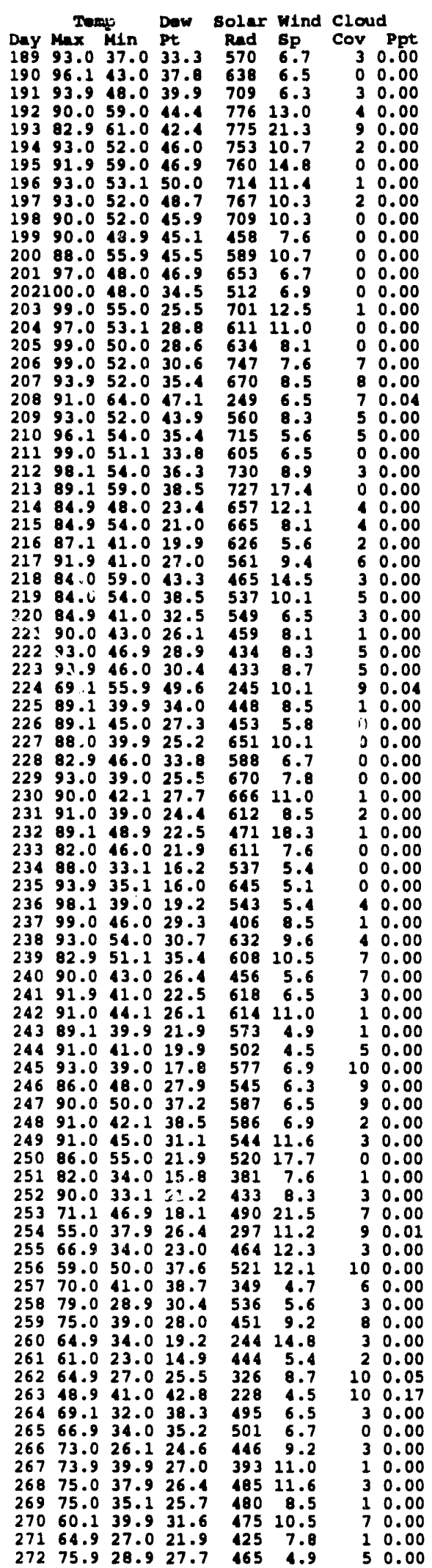

Toup Dow solar Wind Cloud Day Max Min Pt Rad sp Cov Ppt $\begin{array}{llll}9 & 29.7 & 368 & 5\end{array}$

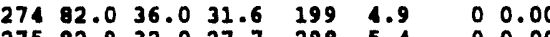

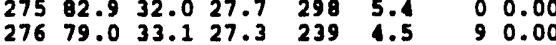

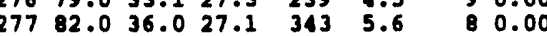
$\begin{array}{llllll}278 & 82.0 & 33.1 & 23.9 & 324 & 4.5\end{array}$

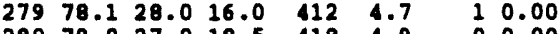
$28079.0 \quad 27.018 .5 \quad 48$ $\begin{array}{llllll}281 & 81.0 & 28.0 & 21.2 & 419 & 4.7\end{array}$ $\begin{array}{lllllll}282 & 77.0 & 46.0 & 26.8 & 366 & 10.3\end{array}$ $28373.932 .0 \quad 26.2 \quad 208 \quad 4.9$ $28477.023 .021 .4 \quad 163 \quad 4.3$ 28568.028 .028 .62676 .9 $\begin{array}{llllll}286 & 69.1 & 28.9 & 36.0 & 325 & 4.9\end{array}$ $\begin{array}{llllll}287 & 69.1 & 35.1 & 32.2 & 364 & 11.2\end{array}$ $28869.1 \quad 41.0 \quad 35.2 \quad 377 \quad 14.1$ $29066.939 .938 .1 \quad 241 \quad 8.9$ $29168.028 .0 \quad 30.2 \quad 317 \quad 5.4$ $\begin{array}{llllll}292 & 69.1 & 37.9 & 35.8 & 93 & 5.8\end{array}$ $\begin{array}{llllll}293 & 66.0 & 26.1 & 31.3 & 363 & 4.5 \\ 294 & 70.0 & 23.0 & 29.3 & 357 & 6.7\end{array}$ $29470.023 .029 .3 \quad 3576.7$ $29568.034 .028 .4 \quad 34011.6$ $\begin{array}{llllll}296 & 69.1 & 23.0 & 24.4 & 277 & 5.8 \\ 297 & 69.1 & 23.0 & 25.0 & 287 & 5.4\end{array}$

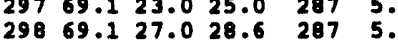
$\begin{array}{llllll}298 & 69.1 & 27.0 & 28.6 & 287 & 5.8\end{array}$ $29966.927 .026 .4 \quad 11111.4$ $\begin{array}{llllll}301 & 64.0 & 19.0 & 16.7 & 237 & 6.7\end{array}$ $\begin{array}{llllll}302 & 66.0 & 27.0 & 17.4 & 141 & 4.5\end{array}$ $\begin{array}{llllll}303 & 68.0 & 21.9 & 21.0 & 249 & 6.3\end{array}$

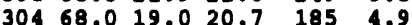
30564.921 .024 .1252 $\begin{array}{llllll}306 & 54.0 & 39.9 & 31.5 & 242 & 18.1\end{array}$ $\begin{array}{llllll}307 & 54.0 & 37.0 & 27.5 & 221 & 17.2\end{array}$ $\begin{array}{llllll}308 & 55.0 & 30.9 & 22.6 & 153 & 12.5\end{array}$

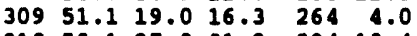
$\begin{array}{llllll}310 & 53.1 & 27.0 & 31.8 & 294 & 13.4\end{array}$ $\begin{array}{llllll}311 & 41.0 & 15.1 & 27.2 & 290 & 4.3\end{array}$ $\begin{array}{llllll}312 & 42.1 & 30.0 & 31.7 & 183 & 8.9\end{array}$ $\begin{array}{llllll}313 & 42.1 & 21.9 & 29.4 & 183 & 6.5\end{array}$ $31439.027 .0 \quad 33.5 \quad 145 \quad 5.8$ $\begin{array}{llllll}315 & 43.026 .1 & 30.0 & 220 & 12.5\end{array}$ $\begin{array}{lllllll}316 & 35.1 & 25.0 & 30.4 & 133 & 11.6\end{array}$

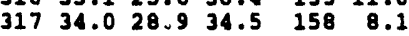
$\begin{array}{rrrrrr}318 & 35.1 & 21.9 & 27.3 & 268 & 9.4 \\ 319 & 30.0 & 7.0 & 15.1 & 225 & 4.9\end{array}$ $\begin{array}{llllll}319 & 30.0 & 7.0 & 15.1 & 225 & 4.9\end{array}$ $\begin{array}{rrrrrr}320 & 30.0 & 5.0 & 19.9 & 110 & 5.1 \\ 321 & 33.1 & 21.9 & 28.8 & 52 & 5.8\end{array}$

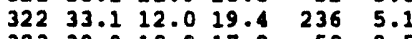
$\begin{array}{llllll}323 & 30.9 & 10.9 & 17.8 & 58 & 2.5\end{array}$ $\begin{array}{llllll}324 & 28.0 & 12.9 & 19.8 & 204 & 2.0\end{array}$ $32530.910 .920 .3 \quad 153 \quad 3.4$ $\begin{array}{llllll}326 & 36.0 & 30.9 & 34.2 & 246 & 13.0\end{array}$ $\begin{array}{llllll}327 & 39.9 & 27.0 & 35.4 & 112 & 15.7\end{array}$ $\begin{array}{rrrrrr}328 & 37.9 & 16.0 & 21.2 & 168 & 13.4 \\ 329 & 26.1 & 7.0 & 16.9 & 48 & 3.8\end{array}$ $\begin{array}{llll}330 & 28.0 & 1.9 & 10.9\end{array}$

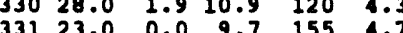
33236.010 .919 .0546 .9 33327.010 .919 .0000 $33424.1 \quad 9.016 .9 \quad 108 \quad 2.9$ $33526.1 \quad 0.010 .4160$ $\begin{array}{llllll}336 & 33.1 & -2.9 & 6.8 & 155 & 4.3\end{array}$ $\begin{array}{llllll}337 & 39.0 & 5.0 & 10.4 & 108 & 4.0\end{array}$ $\begin{array}{llllll}338 & 37.9 & 3.0 & 10.0 & 224 & 4.9\end{array}$ $33928.9 \quad 1.9 \quad 4.3 \quad 20 \mathrm{a} \quad 4.9$ $\begin{array}{llllll}341 & 33.1 & 3.0 & 13.5 & 123 & 1.6\end{array}$

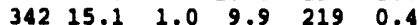
$\begin{array}{llllll}343 & 25.0 & 12.0 & 19.0 & 218 & 0.4\end{array}$ $34426.1 \quad 19.922 .8 \quad 217 \quad 0.4$

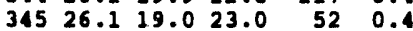
$\begin{array}{llllll}346 & 27.0 & 21.9 & 26.2 & 197 & 0.4\end{array}$

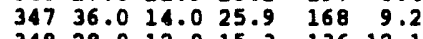
$34828.012 .0 \quad 15.3 \quad 136 \quad 12.1$ $\begin{array}{llllll}349 & 21.9 & -2.9 & 3.7 & 130 & 9.8\end{array}$ $\begin{array}{llllll}350 & 25.0 & -2.9 & 3.9 & 190 & 5.1\end{array}$ $\begin{array}{llllll}351 & 32.0 & -2.0 & 8.1 & 143 & 6.0\end{array}$ $\begin{array}{llllll}352 & 32.0 & -2.0 & 7.0 & 142 & 4.7 \\ 353 & 34.0 & -2.9 & 9.7 & 186 & 4.5\end{array}$ $\begin{array}{llllll}354 & 19.9 & 12.0 & 16.3 & 54 & 4.0\end{array}$

$\begin{array}{rrrrrrrr}355 & 30.0 & 12.0 & 23.7 & 63 & 15.0 & 10 & 0.00 \\ 356 & 17.1 & -2.0 & 12.6 & 43 & 3.6 & 10 & 0.00\end{array}$

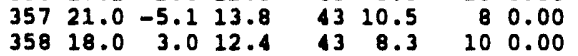

10.00

$\begin{array}{lll}3 & 0.00 \\ 0 & 0.00\end{array}$

10.00

$\begin{array}{ll}9 & 0.00 \\ 9 & 0.00\end{array}$

0.00

0.00
9 0.00

70.00

40.00

$\begin{array}{lll}5 & 0.01 \\ 8 & 0.00\end{array}$

$\begin{array}{ll}8 & 0.00 \\ 3 & 0.00\end{array}$

90.00

$\begin{array}{ll}1 & 0.00 \\ 5 & 0.00\end{array}$

30.00

100.00

$\begin{array}{ll}5 & 0.00 \\ 8 & 0.00\end{array}$

100.00

10.00

$\begin{array}{ll}1 & 0.00 \\ 8 & 0.00\end{array}$

100.00

80.00

0.00
100.00

80.00

90.00

90.12

100.06

60.00

100.00

100.00

100.00

100.00

100.00

80.00

100.00

100.09

100.45

$\begin{array}{ll}7 & 0.00 \\ 9 & 0.00\end{array}$

90.00

70.00

100.00

$\begin{array}{ll}10 & 0.00 \\ 10 & 0.00\end{array}$

$\begin{array}{ll}7 & 0.00 \\ 8 & 0.00\end{array}$

80.00

$\begin{array}{ll}5 & 0.00 \\ 0 & 0.00\end{array}$

100.00

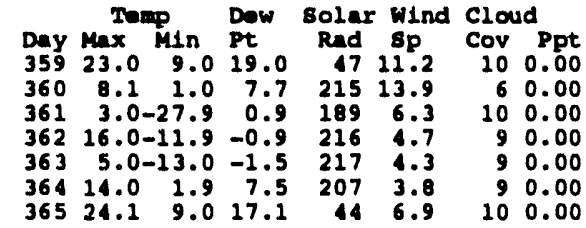

Year 1989

60.00

100.00

100.00

100.00

100.00

$\begin{array}{rr}7 & 0.00 \\ 10 & 0.00\end{array}$

00.00

10.00

10.00

30.00

100.00

Temp Dow solar wind Closd

Day Max Min Pt Rad Sp Cov Ppt

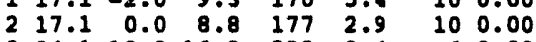

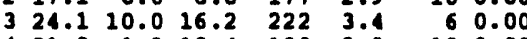

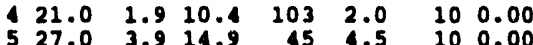

$\begin{array}{llllllll}6 & 26.1 & 3.9 & 16.2 & 45 & 1.5 & 10 & 0.00\end{array}$

$79.0-23.1 \quad-6.2 \quad 183 \quad 4.3 \quad 99.00$

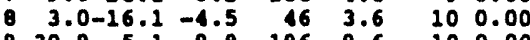

$\begin{array}{llllllll}9 & 30.9 & -5.1 & 9.3 & 196 & 9.6 & 10 & 0.00\end{array}$

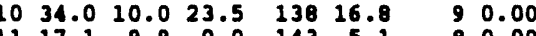

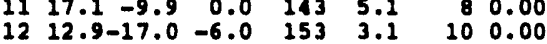

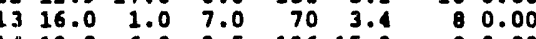

$14 \quad 19.0-6.0 \quad 9.5 \quad 196 \quad 15.0 \quad 8 \quad 0.00$

15 19.9-15.0 $3.0 \quad 1896.5 \quad 6 \quad 6.00$

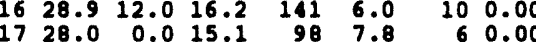

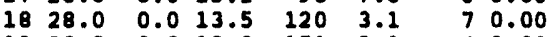

$\begin{array}{llllllll}19 & 23.0 & 0.0 & 13.8 & 151 & 2.9 & 40.00\end{array}$

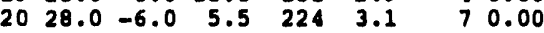

$\begin{array}{llllllllll}21 & 24.1 & -5.1 & 6.1 & 211 & 2.9 & 9 & 0.00\end{array}$

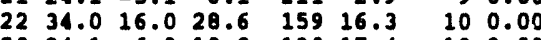

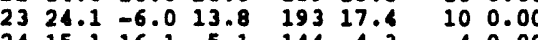

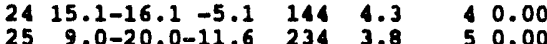

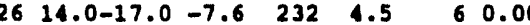

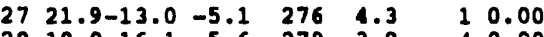

$\begin{array}{llllll}28 & 18.0-16.1 & -5.6 & 279 & 3.8 & 0.00\end{array}$

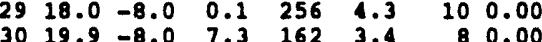

$\begin{array}{rrrrrrrr}30 & 19.9 & -8.0 & 7.3 & 162 & 3.4 & 8 & 0.00 \\ 31 & 39.9 & 15.1 & 23.5 & 128 & 16.8 & 6 & 0.00\end{array}$

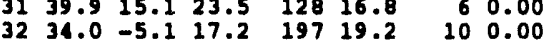

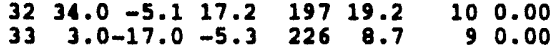

$34 \quad 1.9-18.0-12.6 \quad 214 \quad 8.5 \quad 90.00$

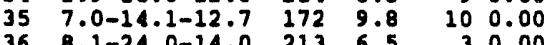

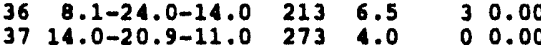

$38 \quad 8.1-27.0-16.4 \quad 315 \quad 4.0 \quad 50.00$

39 10.9-24.0-12.5 238 4.9 40.00

$4017.1-20.9^{-4.4} \quad 171 \quad 4.7 \quad 80.00$

$4130.914 .0 \quad 16.3 \quad 256 \quad 3.6 \quad 100.00$

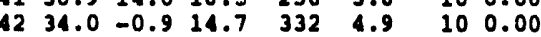

$4321.914 .017 .1 \quad 310 \quad 8.3 \quad 100.00$

$\begin{array}{lllllll}28.9 & 8.1 & 14.5 & 121 & 6.0 & 10 & 0.00\end{array}$

$4523.0-11.0 \quad 1.8 \quad 327 \quad 4.0 \quad 6 \quad 600$

$4616.0-16.1-4.0 \quad 303 \quad 4.0$

$4830.018 .022 .5246 \quad 4.5$

$4934.024 .128 .5 \quad 246 \quad 4.5$

$50 \quad 41.028 .9 \quad 31.5 \quad 178 \quad 6.9$

$5133.1 \quad 17.1 \quad 24.4 \quad 188 \quad 10.7$

$\begin{array}{llllll}52 & 34.0 & 5.0 & 17.6 & 376 & 2.2\end{array}$

$53 \quad 30.9 \quad 15.124 .1 \quad 198 \quad 4.5$

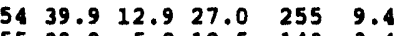

$\begin{array}{llllll}55 & 39.9 & 5.0 & 18.5 & 143 & 3.4\end{array}$

$57 \quad 37.0 \quad 17.125 .7 \quad 25712.5$

$\begin{array}{lllllll}58 & 32.0 & 10.0 & 17.2 & 322 & 8.3\end{array}$

$\begin{array}{llllll}59 & 33.1 & 1.9 & 13.8 & 249 & 5.4\end{array}$

$\begin{array}{llllll}60 & 37.0 & 5.0 & 18.3 & 301 & 6.3\end{array}$

$\begin{array}{llllll}61 & 35.1 & 28.9 & 11.7 & 183 & 13.2\end{array}$

$\begin{array}{llllll}62 & 24.1 & 1.9 & 3.7 & 397 & 5.4\end{array}$

$\begin{array}{llllll}63 & 18.0 & -4.0 & 11.7 & 253 & 4.7\end{array}$

$\begin{array}{llllll}65 & 27.0 & 5.0 & 24.8 & 435 & 4.9\end{array}$

$\begin{array}{llllll}66 & 37.9 & 28.9 & 34.2 & 113 & 4.7\end{array}$

$6743.0 \quad 30.0 \quad 35.8 \quad 379$

$\begin{array}{lllllll}68 & 43.0 & 30.9 & 32.4 & 405 & 4.7\end{array}$

$6950.026 .131 .1399 \quad 5.8$

$\begin{array}{llllll}70 & 53.1 & 28.9 & 29.5 & 345 & 4.9\end{array}$

$\begin{array}{llllll}71 & 55.0 & 21.9 & 30.2 & 282 & 11.4\end{array}$

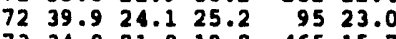

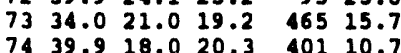

100.00

100.00

100.00

100.40

$\begin{array}{rl}9 & 0.00 \\ 10 & 0.00\end{array}$

100.00

50.00

100.00

70.00

40.00
100.00

100.00 $\begin{array}{rr}8 & 0.00 \\ 10 & 0.00\end{array}$

60.00

70.00

$10 \quad 0.00$

$\begin{array}{ll}9 & 0.00 \\ 10 & 0.12\end{array}$

100.16

$10 \quad 0.30$

8 0.36

60.54

$\begin{array}{lll}1 & 0.39\end{array}$

$\begin{array}{ll}9 & 0.00 \\ 5 & 0.00\end{array}$

90.00 
Year 1989 (Cont'd)

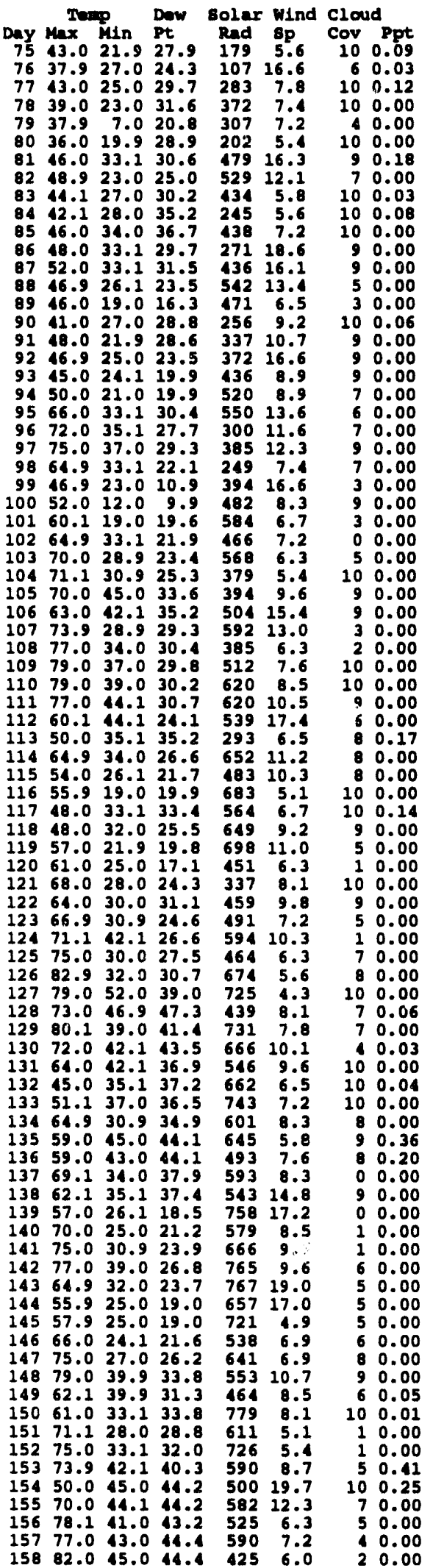

Tomp Dow solar wind cloud

Day Max Min Pt Rad 8p Cov Ppt $\begin{array}{lllllllll}160 & 02 & 0 & 11.0 & 44.1 & 595 & 6.0 & 7 & 0.00\end{array}$

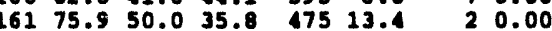

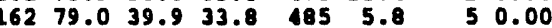

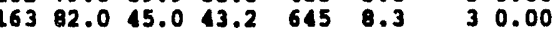

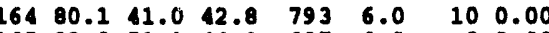
$\begin{array}{lllllll}165 & 82.0 & 51.1 & 46.8 & 687 & 6.0\end{array}$

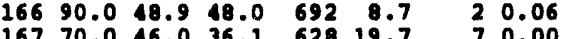
$\begin{array}{llllllll}168 & 77.0 & 34.0 & 34.5 & 680 & 9.6 & 0 & 0.00\end{array}$ $16986.037 .934 .2 \quad 59810.5 \quad 00.00$ 1700.937 .934 .259810 .5

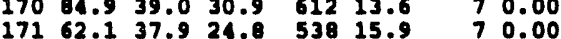

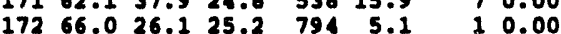

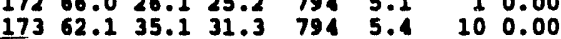

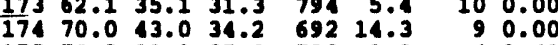

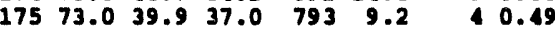
$\begin{array}{llllllll}176 & 75.9 & 36.0 & 39.6 & 771 & 6.0 & 1 & 0.00\end{array}$

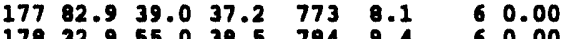
$\begin{array}{llllllll}178 & 22.9 & 55.0 & 38.5 & 784 & 9.4 & 6 & 0.00\end{array}$ 1807.951 .1 35.2 7917.0 $\begin{array}{rrrrrrrr}180 & 87.1 & 11.0 & 31.1 & 619 & 7.6 & 0 & 0.00 \\ 181 & 84.0 & 13.0 & 32.2 & 790 & 10.5 & 0 & 0.00\end{array}$ $\begin{array}{llllllll}181 & 84.0 & 13.0 & 32.2 & 790 & 10.5 & 0 & 0.00 \\ 182 & 82.0 & 44.1 & 27.7 & 789 & 12.3 & 2 & 0.00\end{array}$

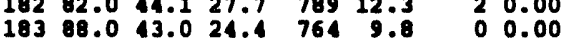
$\begin{array}{llllllll}183 & 88.0 & 13.0 & 24.4 & 764 & 9.8 & 0 & 0.00 \\ 184 & 96.1 & 39.0 & 27.9 & 611 & 5.8 & 1 & 0.00\end{array}$

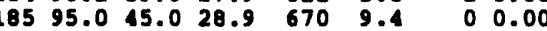

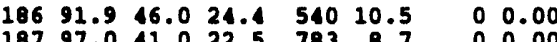
$\begin{array}{llllllll}187 & 97.0 & 11.0 & 22.5 & 783 & 8.7 & 0 & 0.00\end{array}$ $18993.959 .0 \quad 34.5 \quad 570 \quad 13.6 \quad 10.00$

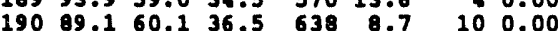

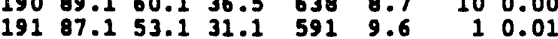
$\begin{array}{llllllll}191 & 87.1 & 53.1 & 31.1 & 591 & 9.6 & 1 & 0.01 \\ 192 & 95.0 & 43.0 & 28.8 & 776 & 5.6 & 2 & 0.00\end{array}$ $\begin{array}{llllllll}192 & 95.0 & 43.0 & 28.8 & 776 & 5.6 & 2 & 0.00 \\ 193 & 81.0 & 55.0 & 47.7 & 775 & 8.1 & 9 & 0.03\end{array}$ $19489.155 .0 \quad 48.9 \quad 670 \quad 6.3 \quad 40.01$

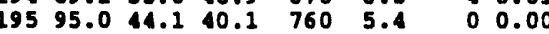

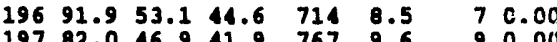
$\begin{array}{llllll}197 & 82.0 & 46.9 & 41.9 & 767 & 9.6\end{array}$ $\begin{array}{rrrrrr}198 & 82.0 & 45.0 & 39.0 & 600 & 10.3 \\ 199 & 91.0 & 43.0 & 38.7 & 458 & 5.6\end{array}$ $20099.0 \quad 50.0 \quad 37.6 \quad 5895.1$ $20195.0 \quad 57.0 \quad 42.3 \quad 653 \quad 8.7$

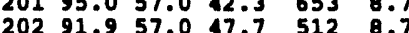
20393.054 .047 .17016 .0 $20495.0 \quad 55.944 .6 \quad 6117.8$ $\begin{array}{llllll}205 & 96.1 & 46.9 & 39.6 & 634 & 6.5\end{array}$ $\begin{array}{llllll}206 & 97.0 & 59.0 & 39.0 & 747 & 6.9\end{array}$ $\begin{array}{llllll}207 & 96.1 & 57.9 & 44.2 & 670 & 10.7\end{array}$ $\begin{array}{llllll}208 & 96.1 & 59.0 & 45.5 & 193 & 9.2\end{array}$ $20995.0 \quad 48.942 .6$ $\begin{array}{lllllll}210 & 93.9 & 57.9 & 43.3 & 715 & 7.8\end{array}$ $\begin{array}{llllll}211 & 95.0 & 57.0 & 47.3 & 444 & 8.7\end{array}$ $\begin{array}{lllllll}212 & 93.9 & 60.1 & 49.5 & 730 & 7.8 \\ 213 & 84.9 & 53.1 & 42.4 & 727 & 8.9\end{array}$ $21481.0 \quad 50.027 .1 \quad 65713.2$ $21582.0 \quad 46.9 \quad 31.6 \quad 66513.9$ $\begin{array}{llllll}216 & 87.1 & 43.0 & 27.9 & 626 & 8.7\end{array}$ $\begin{array}{llllll}217 & 91.0 & 44.1 & 30.2 & 561 & 6.7\end{array}$ $\begin{array}{llllll}218 & 93.9 & 46.9 & 33.3 & 465 & 7.2\end{array}$

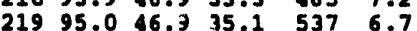
$\begin{array}{llllll}220 & 88.0 & 62.1 & 45.5 & 549 & 7.8\end{array}$ 22186.057 .051 .445912 .5

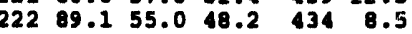
$\begin{array}{llllll}223 & 88.0 & 53.1 & 48.0 & 433 & 5.6\end{array}$ $22489.152 .0 \quad 48.4 \quad 245 \quad 8.5$ $\begin{array}{llllll}225 & 90.0 & 48.9 & 48.4 & 448 & 8.5\end{array}$ $\begin{array}{llllll}226 & 80.1 & 48.9 & 44.1 & 453 & 5.4\end{array}$ $\begin{array}{lll}588 & 13.6\end{array}$ $22991.0 \quad 42.1 \quad 26.4 \quad 6707.2$ $23080.148 .046 .9666 \quad 8.9$ $\begin{array}{llllll}231 & 82.0 & 39.9 & 44.6 & 612 & 7.2\end{array}$ $\begin{array}{llllll}232 & 77.0 & 45.0 & 44.2 & 471 & 7.6\end{array}$ $\begin{array}{llllll}233 & 77.0 & 39.9 & 37.8 & 611 & 9.8\end{array}$ $\begin{array}{llllll}234 & 84.9 & 46.9 & 39.4 & 537 & 8.3\end{array}$ $\begin{array}{llllll}235 & 61.0 & 44.1 & 47.3 & 601 & 9.4\end{array}$ $\begin{array}{lllllll}236 & 57.9 & 42.1 & 42.6 & 543 & 11.6\end{array}$ $23766.0 \quad 36.0 \quad 38.8 \quad 106 \quad 7.4$ $23875.0 \quad 33.1 \quad 35.4 \quad 632 \quad 7.4$ $\begin{array}{llllll}238 & 75.0 & 33.1 & 35.4 & 632 & 7.4\end{array}$ $240 \quad 78.1 \quad 34.0 \quad 32.5 \quad 456 \quad 6.3$ $\begin{array}{llllll}24189.1 & 41.0 & 30.7 & 618 & 7.6\end{array}$ $24279.0 \quad 11.026 .6 \quad 614 \quad 13.4$ $\begin{array}{llllll}243 & 77.0 & 39.9 & 35.1 & 573 & 5.1 \\ 244 & 84.9 & 36.0 & 28.9 & 502 & 7.6\end{array}$
Twap Dow solar Wind Cloud Day Max Min Pt $\quad$ Rad 8p Cov Ppt $24677.0 \quad 36.0 \quad 25.5 \quad 545 \quad 4.7 \quad 00.00$

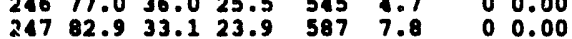

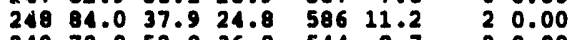

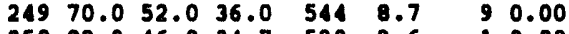

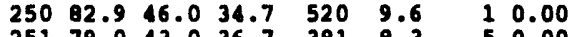
$\begin{array}{llllllll}251 & 79.0 & 13.0 & 36.7 & 381 & 8.3 & 5 & 0.00\end{array}$

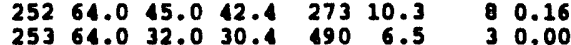

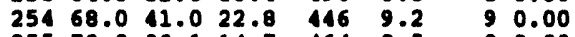
$\begin{array}{llllllll}255 & 70.0 & 33.1 & 14.7 & 464 & 8.5 & 0 & 0.00\end{array}$

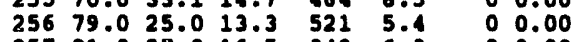

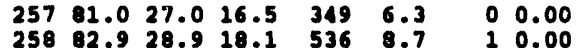

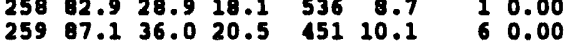

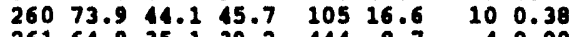
$\begin{array}{lllllll}261 & 64.9 & 35.1 & 39.2 & 44 & 8.7 & 0.00\end{array}$

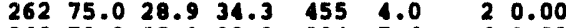

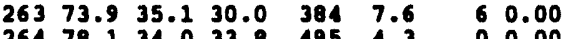
$26578.135 .133 .3 \quad 501 \quad 6.5$ $26681.0 \quad 37.0 \quad 32.0 \quad 446 \quad 5.8 \quad 0000$ $26784.0 \quad 37.028 .9 \quad 393 \quad 4.3 \quad 30.00$

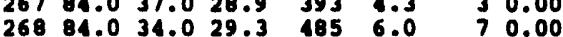
$26980.1 \quad 46.942 .6 \quad 480 \quad 6.3 \quad 50.13$

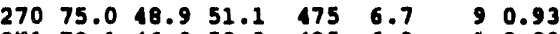
$\begin{array}{llllllll}271 & 78.1 & 46.0 & 50.0 & 425 & 6.9 & 1 & 0.00\end{array}$ $\begin{array}{llllllll}272 & 84.0 & 39.0 & 39.4 & 465 & 6.0 & 0 & 0.00\end{array}$ $\begin{array}{lllllllll}274 & 61.0 & 42.1 & 42.3 & 199 & 13.0 & 8 & 0.00\end{array}$ $\begin{array}{llllllll}275 & 16.9 & 39.0 & 38.5 & 140 & 11.2 & 10 & 0.04\end{array}$

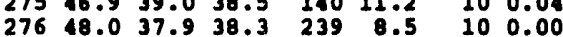

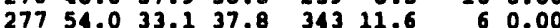
$27860.125 .032 .4 \quad 3243.8 \quad 40.00$ $27962.130 .935 .1 \quad 412 \quad 4.7 \quad 10.00$

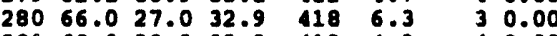

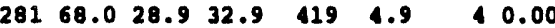

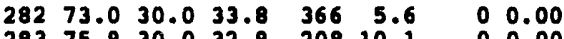
$\begin{array}{llllllll}283 & 75.9 & 30.0 & 32.9 & 208 & 10.1 & 0 & 0.00\end{array}$ $\begin{array}{lllllll}284 & 78.0 & 46.9 & 31.6 & 163 & 19.9 & 6 \\ 285 & 73.0 & 46.0 & 29.5 & 267 & 10.5 & 40.00\end{array}$ $28668.037 .024 .4 \quad 32510.5 \quad 100.00$

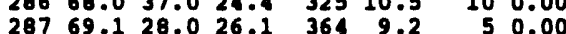

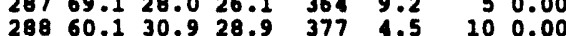

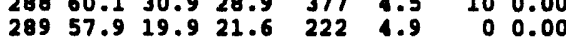

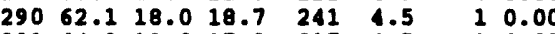

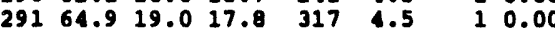

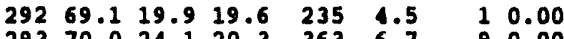

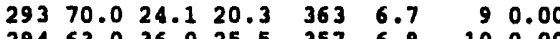

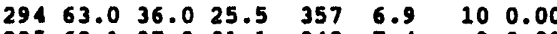

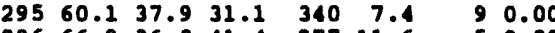

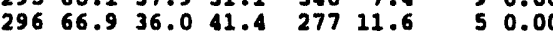
$29754.042 .137 .8 \quad 15210.3 \quad 0.08$

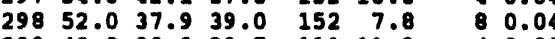
$29948.030 .929 .7 \quad 11111.9 \quad 0.00$

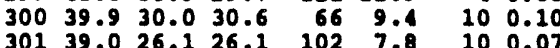
$\begin{array}{llllll}301 & 39.0 & 26.1 & 26.1 & 102 & 7.8\end{array}$ $\begin{array}{llllll}302 & 39.0 & 16.0 & 22.1 & 141 & 6.5\end{array}$ $\begin{array}{llllll}303 & 42.1 & 16.0 & 21.9 & 249 & 3.6\end{array}$ $304 \quad 14.1 \quad 18.0 \quad 19.0 \quad 185 \quad 9.2$ $\begin{array}{llllll}305 & 43.0 & 8.1 & 12.7 & 252 & 4.0\end{array}$ $\begin{array}{llllll}306 & 46.9 & 9.0 & 14.2 & 242 & 4.7\end{array}$ $\begin{array}{llllll}307 & 46.9 & 19.0 & 20.5 & 221 & 5.1\end{array}$ $\begin{array}{rrrrrr}308 & 55.9 & 23.0 & 24.4 & 153 & 11.6 \\ 309 & 16.9 & 25.0 & 23.7 & 264 & 6.7\end{array}$ $\begin{array}{llllll}309 & 16.9 & 25.0 & 23.7 & 264 & 6.7\end{array}$ $\begin{array}{llllll}310 & 43.0 & 17.1 & 24.3 & 294 & 13.4\end{array}$ $\begin{array}{llllll}311 & 53.1 & 30.0 & 22.5 & 290 & 14.3\end{array}$ $\begin{array}{llllll}312 & 46.0 & 23.0 & 23.0 & 287 & 11.9\end{array}$ $\begin{array}{llllll}313 & 52.0 & 25.0 & 25.3 & 183 & 4.9\end{array}$ $31452.021 .928 .2 \quad 280 \quad 4.0$ $31562.118 .025 .9220 \quad 4.9$ 31659.019 .026 .827413 .6 $\begin{array}{llllll}317 & 52.0 & 30.0 & 26.8 & 271 & 17.7\end{array}$ $\begin{array}{lllllll}318 & 44.1 & 18.0 & 12.7 & 268 & 10.3\end{array}$ $\begin{array}{llllll}319 & 12.1 & 12.0 & 11.5 & 225 & 4.0\end{array}$ $\begin{array}{llllll}320 & 18.0 & 19.9 & 15.3 & 256 & 5.4\end{array}$ $\begin{array}{llllll}321 & 48.9 & 25.0 & 24.6 & 156 & 5.6\end{array}$ $\begin{array}{llllll}322 & 39.9 & 26.1 & 30.6 & 236 & 4.7\end{array}$ $\begin{array}{llllll}323 & 53.1 & 18.0 & 25.9 & 58 & 3.6\end{array}$ $32455.915 .1 \quad 21.9 \quad 204 \quad 4.5$ 32555.917 .123 .2153 $\begin{array}{llllll}326 & 44.1 & 15.1 & 22.6 & 246^{\circ} & 3.1\end{array}$ $\begin{array}{llllll}327 & 48.9 & 14.0 & 22.8 & 244 & 8.5\end{array}$ $\begin{array}{lllllll}328 & 13.0 & 28.0 & 26.6 & 168 & 17.0\end{array}$

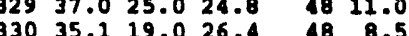

50.00

0.00
7 0.00

$\begin{array}{ll}7 & 0.00 \\ 8 & 0.00\end{array}$

10.00

100.00

$\begin{array}{rr}8 & 0.00 \\ 10 & 0.00\end{array}$

60.00

60.00

100.00

50.00

90.00

$\begin{array}{ll}0 & 0.00 \\ 8 & 0.00\end{array}$

100.00

$\begin{array}{ll}3 & 0.00 \\ 7 & 0.00\end{array}$

70.00

$10 \quad 0.00$

100.00

10.00

$\begin{array}{ll}3 & 0.00 \\ 1 & 0.00\end{array}$

10.00

70.00

$\begin{array}{ll}9 & 0.00 \\ 9 & 0.00\end{array}$

100.00 
Year 1989 (Cont'd)

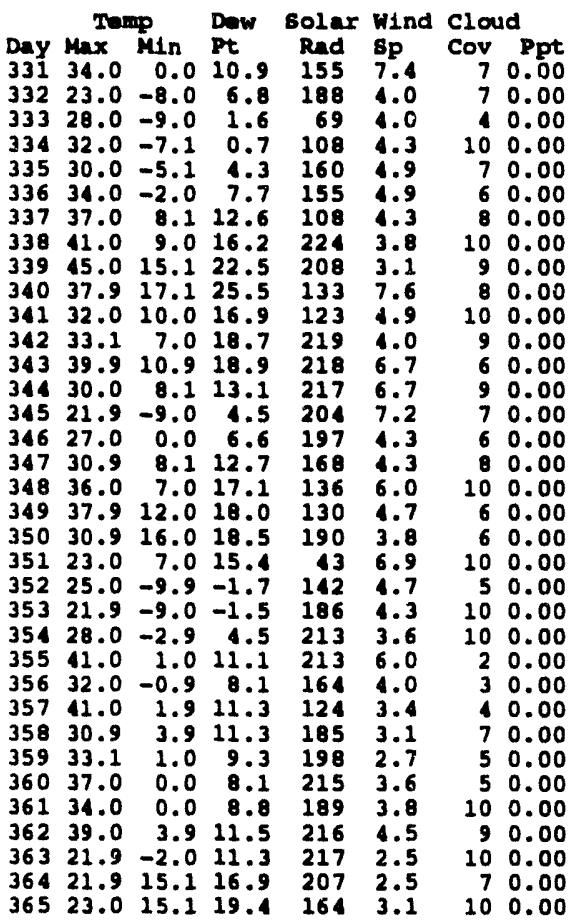

Year 1990

\begin{tabular}{|c|c|c|c|c|c|c|c|}
\hline & $\mathrm{Te}$ & pm & Dow & solax & Aind & $\mathrm{Cla}$ & \\
\hline & $\operatorname{Max}$ & $M 1 n$ & & Rad & & & Ppt \\
\hline & 27.0 & 14.0 & $1 ! 1.8$ & 170 & 4.0 & 10 & 0.0 \\
\hline & 30.9 & -0.9 & 17.1 & 177 & 10.5 & 10 & 0. \\
\hline 3 & 24.1 & -6.0 & 1.8 & 222 & 4.3 & 6 & 0. \\
\hline & & & & 103 & 3. & 10 & 30 \\
\hline 6 & 0 & & & & & 10 & \\
\hline & 37.0 & .0 & & & 8 . & 9 & \\
\hline 8 & 45.0 & 32.0 & 30.9 & 16 & 17. & 10 & 0.44 \\
\hline & & & 28.6 & 196 & 8. & 10 & 0.1 \\
\hline 10 & 50.0 & & 25.5 & 138 & 15 & 9 & \\
\hline 11 & 11.0 & 2 & 2 & 14 & 6. & 8 & 0.0 \\
\hline 12 & & & & & & 10 & 0.00 \\
\hline & & & & & & 8 & \\
\hline 15 & .0 & & & 37 & & 6 & \\
\hline 16 & 35.1 & 19.0 & 26.8 & 141 & 5.8 & 10 & 0.1 \\
\hline & & & 16.2 & & 3.6 & & 0.1 \\
\hline & & -7 & 1.6 & 120 & & 7 & \\
\hline 19 & & & 0.5 & 151 & & 4 & 0 \\
\hline & 21.0 & -7.1 & 6.6 & 224 & 4. & 7 & 0.00 \\
\hline & & 1 & .7 & & & 9 & 0. \\
\hline 2 & & 3 & 13 & 159 & & 10 & \\
\hline 24 & $\begin{array}{l}35.1 \\
26.1\end{array}$ & 3.0 & $\begin{array}{l}17 \\
11\end{array}$ & & & 10 & \\
\hline 2 & 34.0 & 9.0 & 16.0 & 234 & & 5 & 0. \\
\hline & 5.1 & -0.9 & 15. & 232 & 12 & 6 & 0.1 \\
\hline & & & & 276 & & 1 & \\
\hline 28 & & & 20.5 & 279 & & 4 & 0.0 \\
\hline 2 & & & & 256 & & 10 & 0.00 \\
\hline & & & & & & 8 & \\
\hline 32 & & & & & & 10 & \\
\hline 33 & 0 & & & & & 10 & \\
\hline & .0 & & & 214 & & & 0. \\
\hline & 33.1 & & 19. & 172 & 11.2 & 10 & 0. \\
\hline & 26.1 & & & & & 3 & 0.0 \\
\hline & & & & & & 0 & \\
\hline & & & & & & 5 & \\
\hline & .0 & & & & & & \\
\hline & & & & & & & 0.00 \\
\hline & & & & 256 & & 10 & \\
\hline & & & 30. & 332 & & 10 & \\
\hline & & & 17 & & & 10 & \\
\hline & & & & 256 & & 10 & \\
\hline
\end{tabular}

Temp Daw solar Wind cloud Day Max Min Pt Rad 8p Cov Ppt $4525.0-0.9 \quad 1.8 \quad 327 \quad 8.1$ 4726.10 .915 .4 30 14.5 $4826.1-9.0 \quad 14.7 \quad 246 \quad 15.9 \quad 100.00$ $1924.1-22.0-4.4271 \quad 10.1 \quad 100.00$

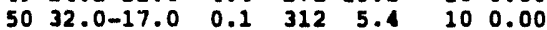
$\begin{array}{lllllll}51 & 23.0-15.0 & 2.7 & 188 & 5.4 & 9 & 0.00\end{array}$ $\begin{array}{llllllll}52 & 33.1 & 3.0 & 16.0 & 376 & 1.9 & 10 & 0.00\end{array}$ $\begin{array}{lllll}23.9 & 198 & 4.5 & 10 & 0.00\end{array}$

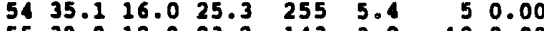
$\begin{array}{llllllll}55 & 39.9 & 12.9 & 23.2 & 143 & 3.8 & 10 & 0.00\end{array}$ $\begin{array}{llllllll}56 & 42.1 & 15.1 & 24.1 & 202 & 3.6 & 7 & 0.00\end{array}$

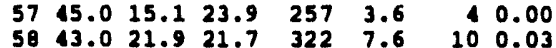
$\begin{array}{llllllll}58 & 43.0 & 21.9 & 21.7 & 322 & 7.6 & 10 & 0.03 \\ 59 & 43.0 & 21.9 & 21.9 & 249 & 8.9 & 10 & 0.03\end{array}$ $6044.121 .921 .4 \quad 301 \quad 6.9$

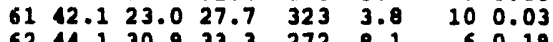
$\begin{array}{llllllll}62 & 14.1 & 30.9 & 33.3 & 272 & 8.1 & 6 & 0.19\end{array}$

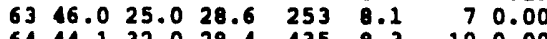

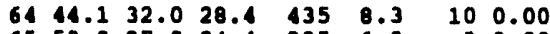
$6550.027 .024 .4 \quad 2056.3 \quad 90.00$

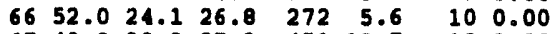
$6748.028 .927 .9 \quad 45110.7 \quad 100.00$

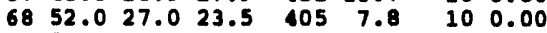

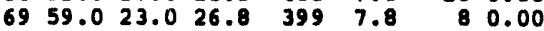

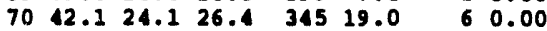

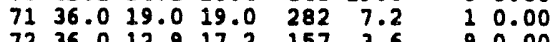

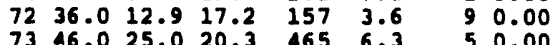

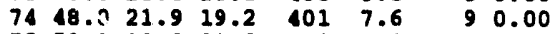

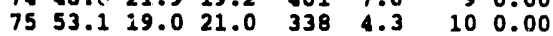

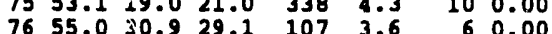

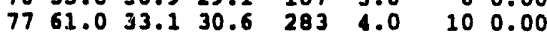

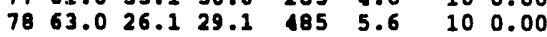

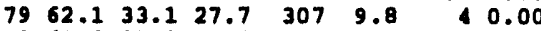

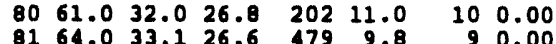
1027.152910 .5 $8345.014 .0 \quad 18.0 \quad 534 \quad 6.5$ $8451.119 .016 .2 \quad 4006.9$ 8560.119 .016 .24006 .9 $8651.1 \quad 37.926 .8 \quad 271 \quad 6.9$ $\begin{array}{llllll}86 & 51.1 & 37.9 & 26.8 & 271 & 8.9\end{array}$ $8756.928 .920 .8 \quad 43615.9$ $\begin{array}{llllll}88 & 55.9 & 17.1 & 18.1 & 542 & 4.3 \\ 89 & 63.0 & 19.9 & 19.8 & 471 & 5.4\end{array}$ $\begin{array}{llllll}89 & 63.0 & 19.9 & 19.8 & 471 & 5.4\end{array}$

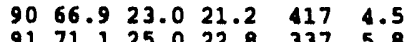
$9171.125 .022 .8 \quad 337 \quad 5.8$

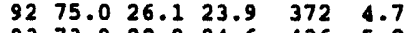
$93 \quad 73.928 .9 \quad 24.6 \quad 436 \quad 5.8$ $9472.0 \quad 28.0 \quad 20.7 \quad 520 \quad 6.3$ $9560.1 \quad 33.124 .8 \quad 550 \quad 10.7$ 9560.153 .124 .8 550 10.7 $\begin{array}{llllll}96 & 66.9 & 18.0 & 17.4 & 300 & 4.0 \\ 97 & 64.0 & 33.1 & 28.8 & 385 & 6.9\end{array}$ $\begin{array}{llllll}98 & 52.0 & 37.0 & 40.3 & 122 & 5.4\end{array}$ $9960.1 \quad 36.0 \quad 33.1 \quad 394 \quad 8.9$

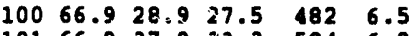
$\begin{array}{llllll}101 & 66.9 & 37.9 & 33.3 & 584 & 6.0\end{array}$ $\begin{array}{llllll}102 & 64.0 & 37.9 & 31.6 & 466 & 8.5\end{array}$ $\begin{array}{llllll}103 & 64.9 & 27.0 & 27.0 & 568 & 8.3\end{array}$ $\begin{array}{llllll}104 & 78.1 & 39.9 & 31.1 & 379 & 13.0\end{array}$

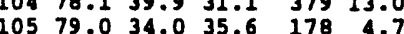
$10579.034 .0035 .6 \quad 178 \quad 4.7$

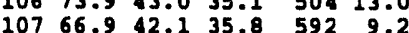

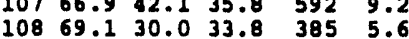
$\begin{array}{llllll}109 & 72.0 & 36.0 & 34.9 & 512 & 5.6\end{array}$ $11073.0 \quad 39.0 \quad 36.1 \quad 620 \quad 5.8$ $\begin{array}{llllll}111 & 59.2 & 39.9 & 43.9 & 516 & 6.0\end{array}$ $\begin{array}{llllll}112 & 64.9 & 41.0 & 43.2 & 539 & 9.2\end{array}$ $\begin{array}{lllllll}113 & 60.1 & 43.0 & 41.0 & 293 & 9.6\end{array}$ $\begin{array}{lllllll}114 & 54.0 & 43.0 & 37.8 & 560 & 6.7\end{array}$ $115 \quad 59.0 \quad 33.1 \quad 32.9 \quad 288 \quad 11.9$ $11654.0 \quad 34.0 \quad 18.0 \quad 683 \quad 8.5$ $\begin{array}{llllll}117 & 53.1 & 35.1 & 32.5 & 658 & 13.6\end{array}$ $\begin{array}{llllll}118 & 48.0 & 27.0 & 23.5 & 649 & 16.8\end{array}$ $119 \quad 48.9 \quad 19.0 \quad 16.0 \quad 698 \quad 6.0$

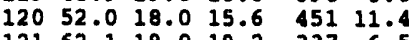

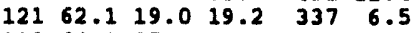
$\begin{array}{llllll}122 & 64.0 & 37.0 & 30.2 & 459 & 5.8\end{array}$ $\begin{array}{llllll}123 & 69.1 & 32.0 & 27.1 & 991 & 6.9\end{array}$ $\begin{array}{llllll}124 & 73.0 & 35.1 & 27.5 & 594 & 6.9\end{array}$ $12577.0 \quad 30.927 .5 \quad 5946.9$ $\begin{array}{llllll}126 & 80.1 & 37.9 & 31.1 & 674 & 14.5\end{array}$ $\begin{array}{llllll}127 & 55.0 & 33.1 & 16.9 & 725 & 13.4\end{array}$ $\begin{array}{llllll}128 & 53.1 & 30.9 & 23.5 & 595 & 6.5\end{array}$ $12963.026 .122 .6 \quad 731 \quad 5.8$
10.00

100.00 100.00 90.00 90.00 50.00 30.00 100.00 $\begin{array}{ll}9 & 0.00 \\ 9 & 0.00\end{array}$ $\begin{array}{ll}9 & 0.00 \\ 9 & 0.00\end{array}$ 90.00 $\begin{array}{ll}7 & 0.00 \\ 6 & 0.00\end{array}$ 70.00 90.00 $\begin{array}{lll}7 & 0.54 \\ 3 & 0.00\end{array}$ 90.00 30.00

00.00

$\begin{array}{rr}5 & 0.00 \\ 10 & 0.000\end{array}$

$\begin{array}{rl}10 & 0.00 \\ 9 & 0.01\end{array}$

90.00

30.00

20.00
100.00

100.00

$\begin{array}{ll}9 & 0.26 \\ 6 & 0.00\end{array}$

60.00

$\begin{array}{ll}8 & 0.13 \\ 8 & 0.02\end{array}$

$\begin{array}{ll}8 & 0.02 \\ 8 & 0.01\end{array}$

100.00 100.00
90.00

$\begin{array}{ll}9 & 0.00 \\ 5 & 0.00\end{array}$

10.00

100.00 $\begin{array}{ll}9 & 0.00 \\ 5 & 0.00\end{array}$ 50.00

$\begin{array}{ll}1 & 0.00 \\ 7 & 0.00\end{array}$

$\begin{array}{ll}7 & 0.00 \\ 8 & 0.00\end{array}$ 100.00 70.00 70.00
Tomp Dow Solar Wind Cloud

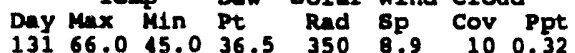

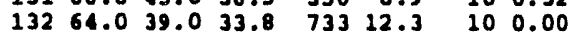
$\begin{array}{llllllll}132 & 64.0 & 39.0 & 33.8 & 733 & 12.3 & 10 & 0.00 \\ 133 & 62.1 & 11.0 & 26.6 & 743 & 11.4 & 10 & 0.00\end{array}$

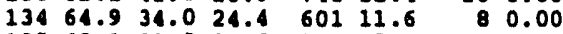

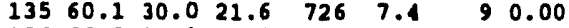
$\begin{array}{llllllll}136 & 66.0 & 33.1 & 25.9 & 637 & 8.9 & 8 & 0.00\end{array}$ $\begin{array}{llllllll}137 & 75.0 & 33.1 & 23.5 & 593 & 6.9 & 0 & 0.00\end{array}$

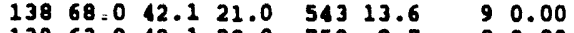

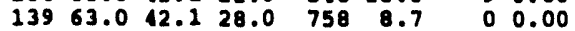

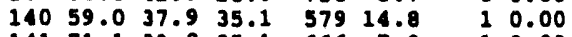
$\begin{array}{llllllll}141 & 71.1 & 39.0 & 35.1 & 666 & 7.8 & 1 & 0.00\end{array}$

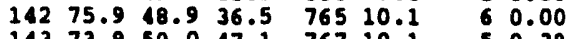

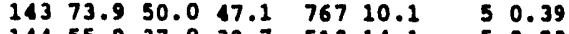
$\begin{array}{llllllll}144 & 55.9 & 37.0 & 39.7 & 513 & 14.1 & 5 & 0.23 \\ 145 & 62.1 & 33.1 & 28.0 & 721 & 11.4 & 5 & 0.00\end{array}$

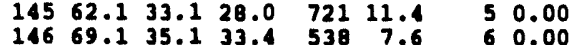
$14773.9 \quad 39.0 \quad 37.9641 \quad 5.8 \quad 80.00$

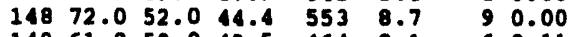

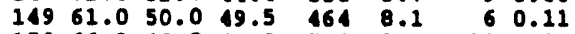

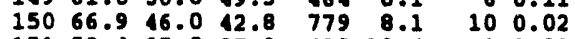

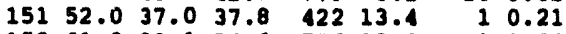
$\begin{array}{llllllll}152 & 61.0 & 33.1 & 26.6 & 726 & 10.3 & 1 & 0.00\end{array}$ $\begin{array}{rrrrrrrr}153 & 68.0 & 39.0 & 32.9 & 709 & 11.0 & 5 & 0.00 \\ 154 & 82.0 & 34.0 & 36.7 & 657 & 8.3 & 10 & 0.00\end{array}$

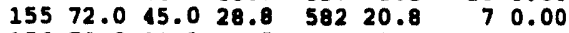

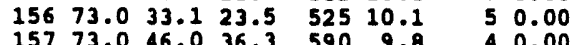
$\begin{array}{lllllll}157 & 73.0 & 46.0 & 36.3 & 590 & 9.8 & 40.00\end{array}$

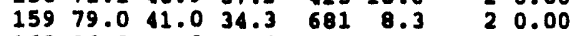
$\begin{array}{llllllll}160 & 86.0 & 43.0 & 43.0 & 385 & 8.9 & 7 & 0.03\end{array}$

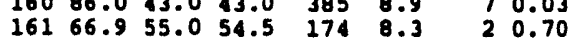

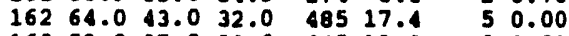

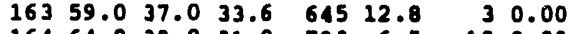

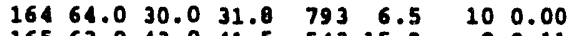

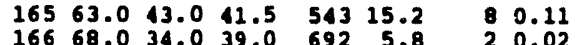

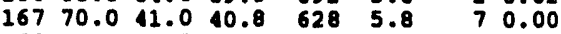

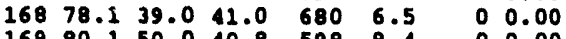

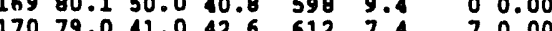
$\begin{array}{llllllll}179 & 79.0 & 41.0 & 42.6 & 612 & 7.4 & 7 & 0.00 \\ 171 & 82.9 & 46.9 & 40.1 & 538 & 8.1 & 7 & 0.00\end{array}$

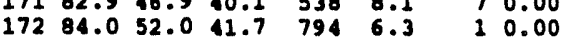

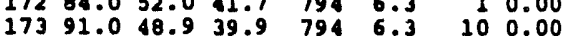

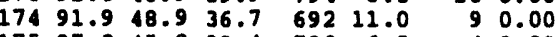
$\begin{array}{lllllll}175 & 97.0 & 45.0 & 32.4 & 733 & 6.5 & 0.00\end{array}$

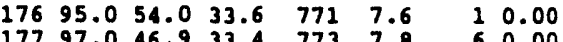
$\begin{array}{lllllll}178 & 87.1 & 48.9 & 28.4 & 784 & 11.6 & 6\end{array}$

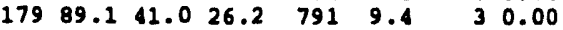

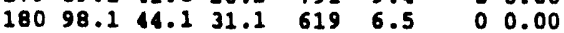

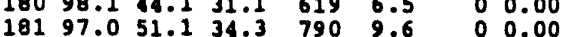

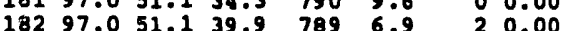

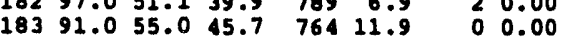

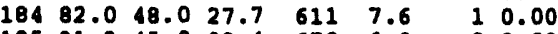
$\begin{array}{lllllllll}185 & 91.9 & 45.0 & 32.4 & 670 & 6.0 & 0 & 0.00\end{array}$

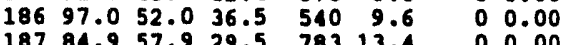

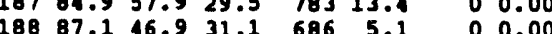

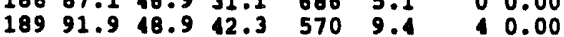
$19086.0 \quad 57.053 .1 \quad 466 \quad 6.7 \quad 100.51$

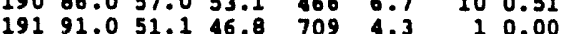

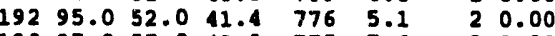

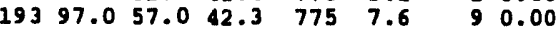
$19491.0 \quad 55.0 \quad 46.2 \quad 753 \quad 5.4 \quad 40.00$ $\begin{array}{lllllllll}196 & 95.0 & 53.1 & 39.7 & 714 & 7.2 & 7 & 0.00\end{array}$

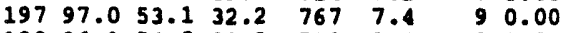
$19896.154 .0 \quad 30.9 \quad 709 \quad 9.4 \quad 30.00$ $19991.060 .135 .2 \quad 458 \quad 5.4 \quad 40.00$

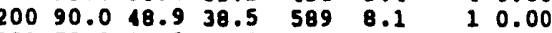

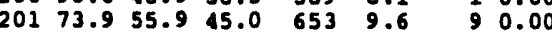

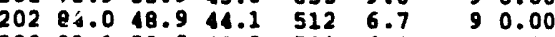
$20389.150 .0 \quad 43.0 \quad 701 \quad 6.9 \quad 40.00$ $20484.0 \quad 51.1 \quad 45.7 \quad 441 \quad 9.6 \quad 40.08$ $20681.051 .1 \quad 35.8 \quad 74714.5 \quad 40.00$ $20773.946 .041 .5 \quad 67011.6 \quad 60.00$ $\begin{array}{llllllll}208 & 84.0 & 43.0 & 41.2 & 493 & 6.5 & 5 & 0.00\end{array}$ $\begin{array}{llllllll}208 & 84.0 & 43.0 & 11.2 & 493 & 6.5 & 5 & 0.00 \\ 209 & 87.1 & 46.9 & 40.6 & 560 & 8.5 & 4 & 0.00\end{array}$ $\begin{array}{llllllll}209 & 87.1 & 46.9 & 40.6 & 560 & 8.5 & 4 & 0.00 \\ 210 & 89.1 & 52.0 & 40.1 & 715 & 7.8 & 3 & 0.00\end{array}$

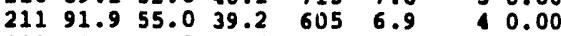
$21293.955 .936 .7 \quad 73011.6 \quad 40.00$

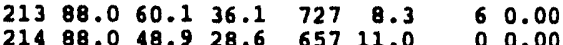

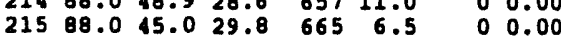

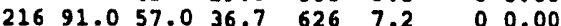


Yiar 1990 (Cont'd)

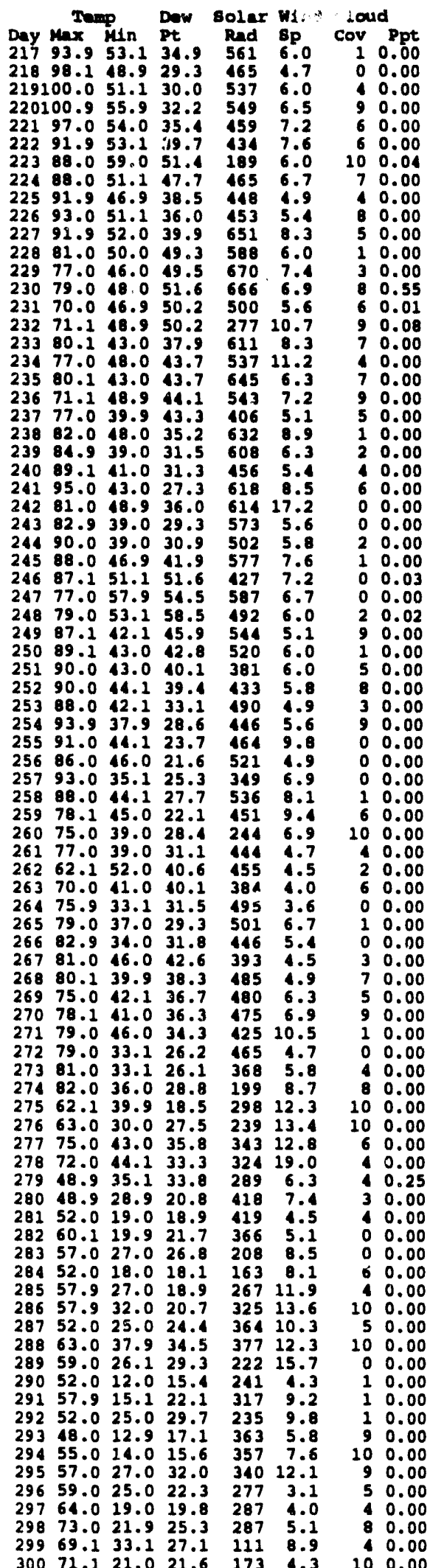

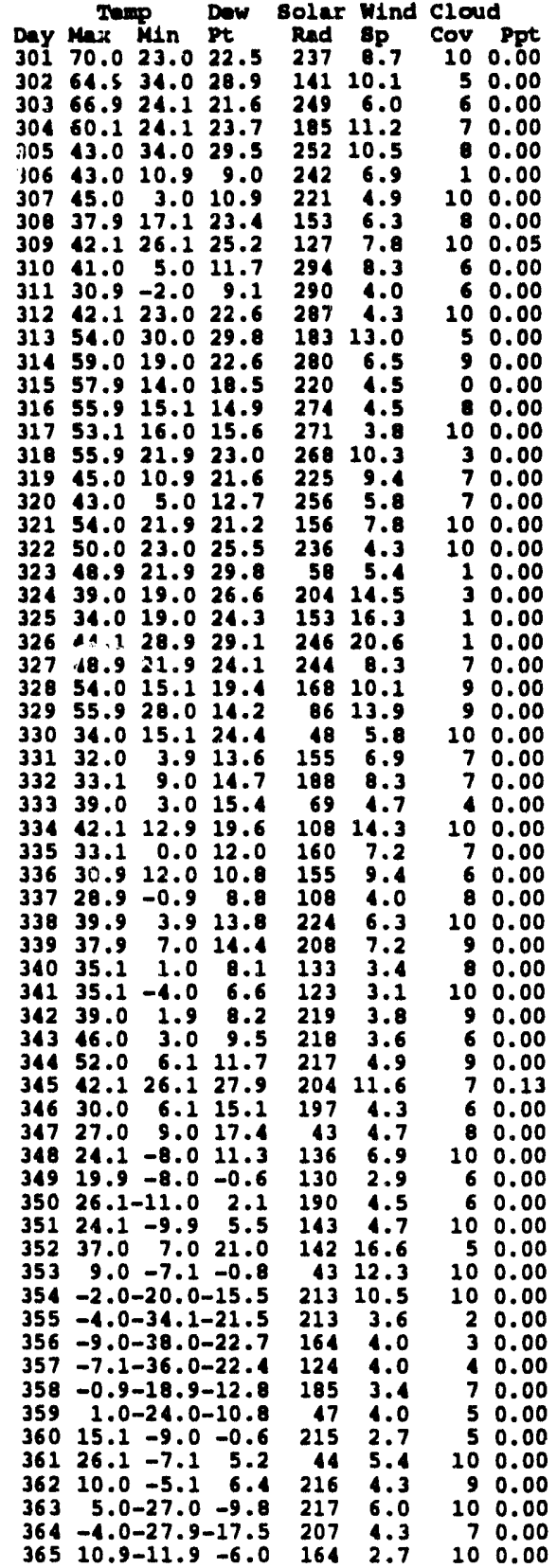
Day Max Min pt Rad 8p Cov P 30264534.028 .92110 .150 .00 $30264.5 \quad 34.028 .9 \quad 14110.1 \quad 50.00$ $30366.924 .121 .6 \quad 249.0 \quad 60.00$ $\begin{array}{llllll}05 & 43.034 .0 & 29.5 & 252 & 10.5 & 0.00\end{array}$

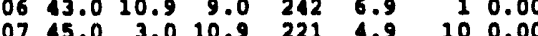

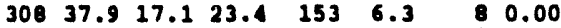

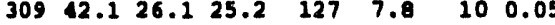
$\begin{array}{llllllll}10 & 11.0 & 5.0 & 11.7 & 294 & 8.3 & 6 & 0.00\end{array}$

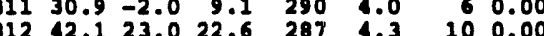
$\begin{array}{llllllll}313 & 54.0 & 30.0 & 29.8 & 183 & 13.0 & 5 & 0.00\end{array}$

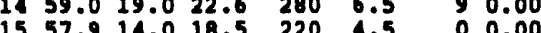
1655.915 .114 .9

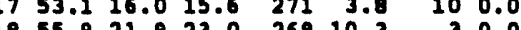
$31945.010 .921 .6 \quad 225 \quad 9.4 \quad 70.00$

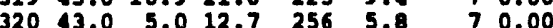
$32154.021 .921 .2 \quad 156 \quad 7.8 \quad 100.00$ $\begin{array}{llllllll}322 & 50.0 & 23.0 & 25.5 & 236 & 4.3 & 10 & 0.00\end{array}$

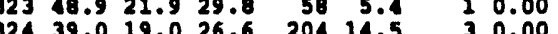

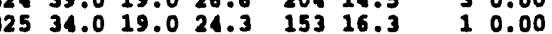

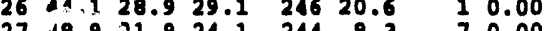

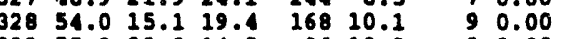

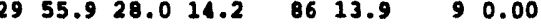

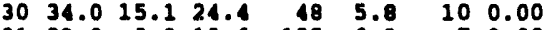

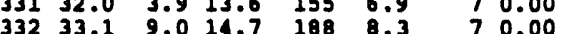
$\begin{array}{llllllll}333 & 39.0 & 3.0 & 15.4 & 69 & 4.7 & 0.00\end{array}$

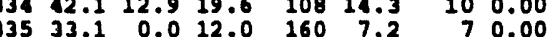

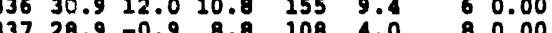
$\begin{array}{llllllll}338 & 39.9 & 3.9 & 13.8 & 224 & 6.3 & 10 & 0.00\end{array}$ $\begin{array}{llllll}3 & & & & & \\ 3 & 34.4 & 208 & 7.2\end{array}$

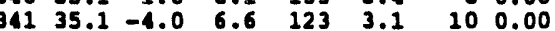

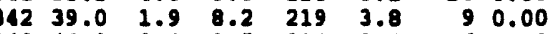

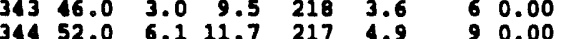

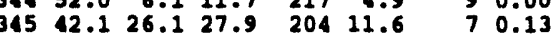
$\begin{array}{rrrrrr}347 & 30.0 & 6.1 & 15.1 & 197 & 4.3\end{array}$

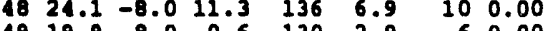
$35026.1-11.0 \quad 2.1 \quad 190 \quad 4.5 \quad 60.00$ $\begin{array}{llllllll}351 & 24.1 & -9.9 & 5.5 & 143 & 4.7 & 10 & 0.00\end{array}$

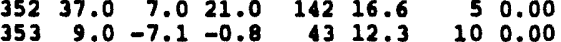
$\begin{array}{llllll}354 & -2.0-20.0-15.5 & 213 & 10.5 & 10 & 0.00\end{array}$

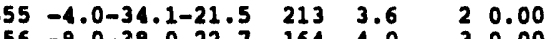
$357-7.1-36.0-22.4 \quad 124 \quad 1.0$ $\begin{array}{llllll}358 & -0.9-18.9-12.8 & 185 & 3.4 & 7 & 0.00\end{array}$ $\begin{array}{llllll}5 & 1.0-24.0-10.8 & 4 & 4.0 & 5 & 0.00\end{array}$

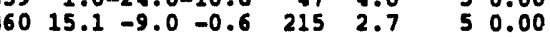

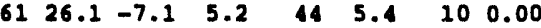

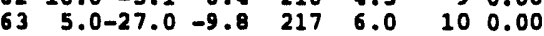
$36510.9-11.9-6.0 \quad 164 \quad 2.7 \quad 100.00$ 


\section{Appendix B}

\section{UNSAT-H Capillary Barrier Simulation Data Deck}




\section{Appendix B}

\section{UNSAT-H Capillary Barrler Simulation Data Deck}

This appendix contains the UNSAT-H data deck for the capillary barrier simulations. It includes transpiration and reduced evaporation due to a snow cover. The meteorological input for the data deck is not included because it is given for each year in Appendix A.

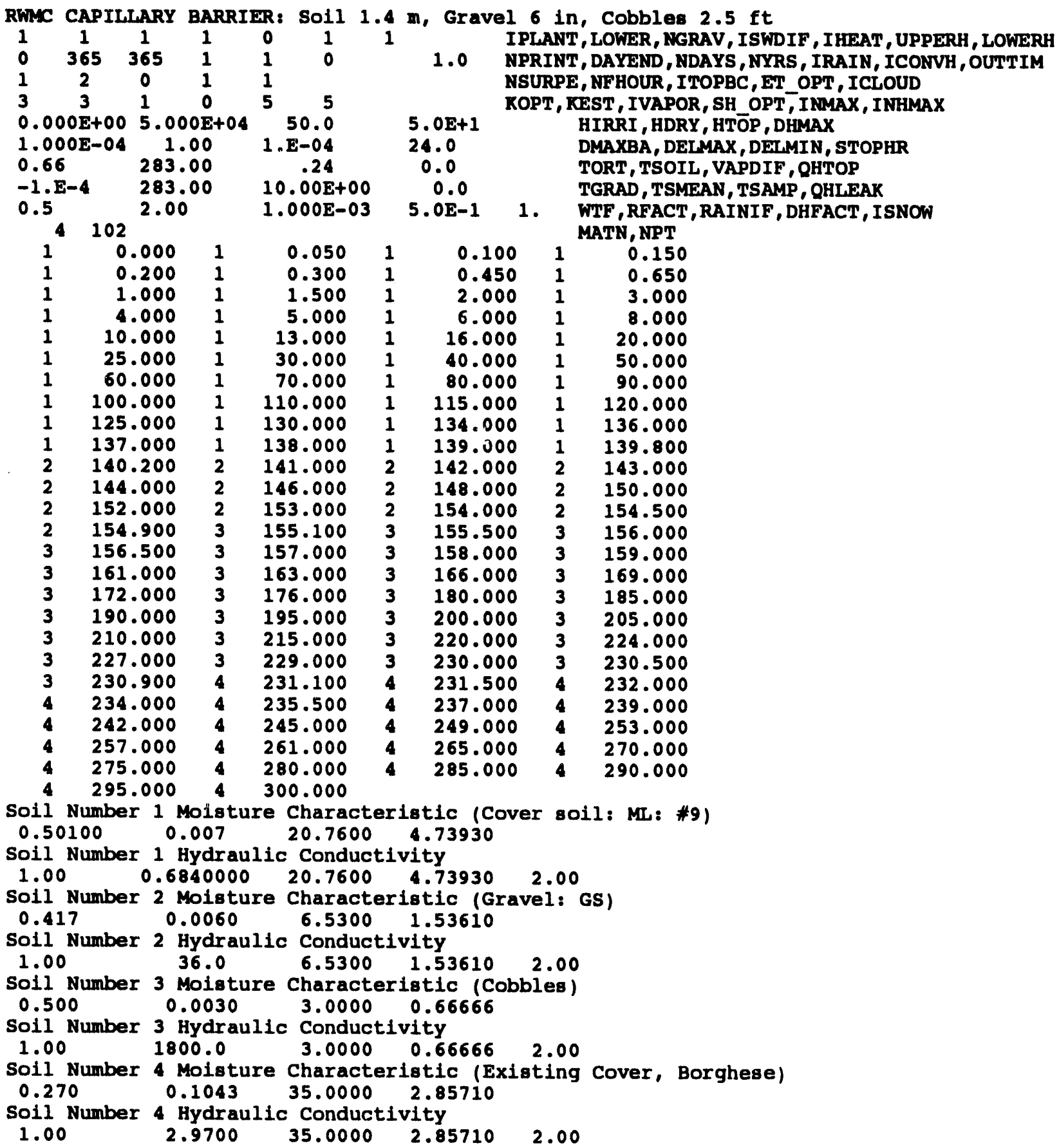




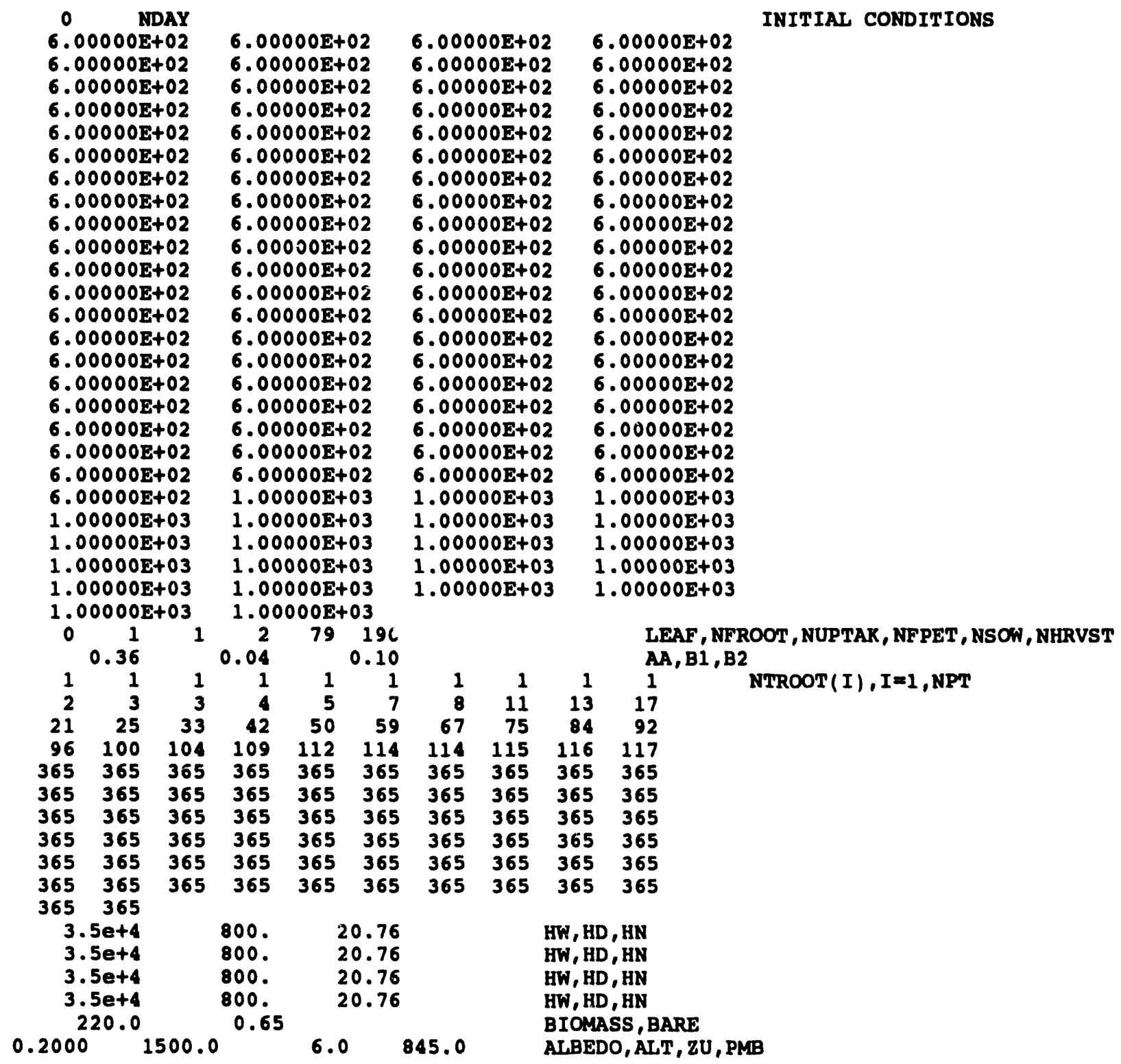




\section{Appendix C}

\section{UNSAT-H Thick Soll Barrier Simulation Data Deck}




\section{Appendix C}

\section{UNSAT-H Thick Soll Barrler SImulation Data Deck}

This appendix contains the UNSAT-H data deck for the thick soil barrier simulations. It includes transpiration and reduced evaporation due to a snow cover. The meteorological input for the data deck is not included because it is given for each year in Appendix A.

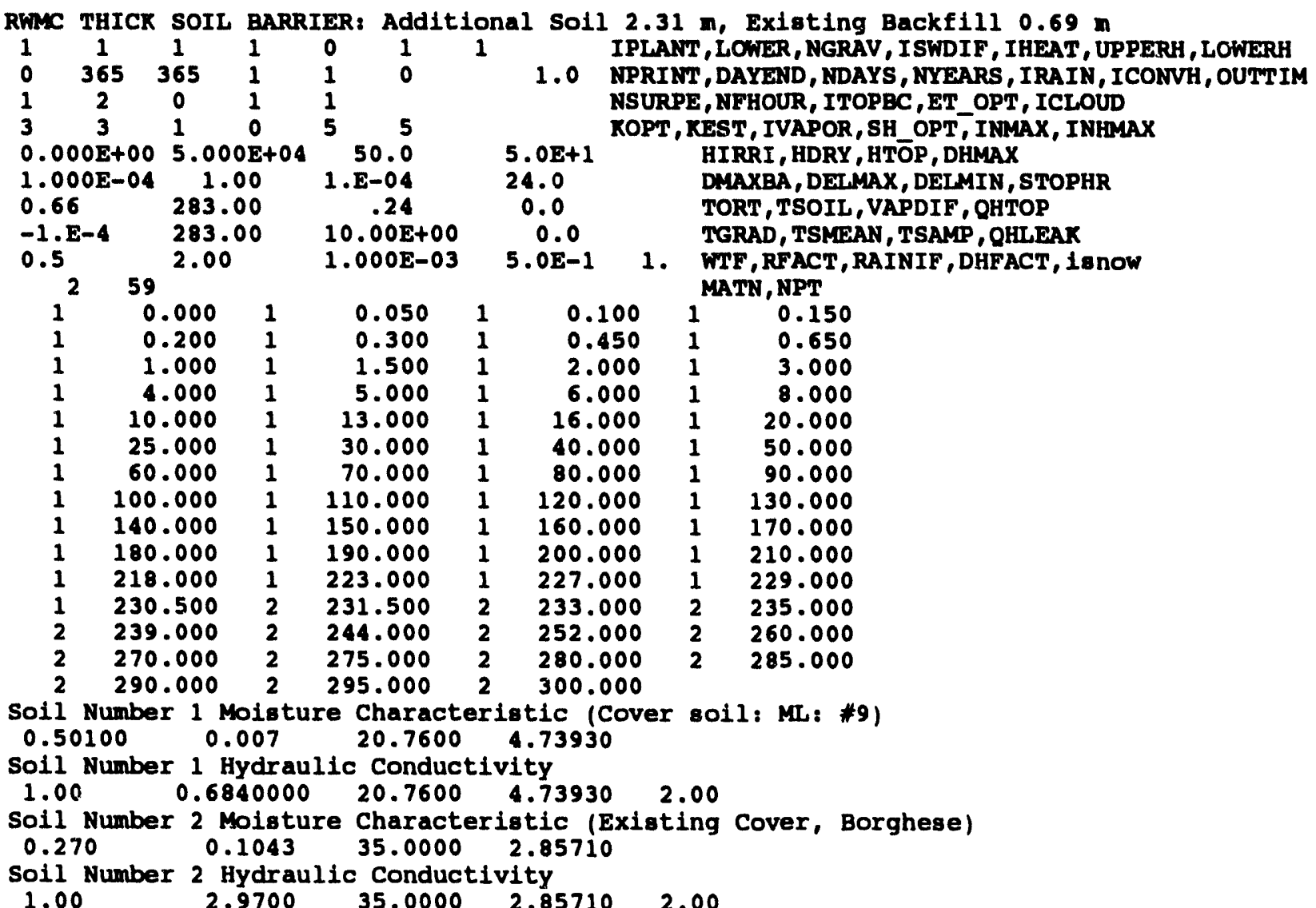




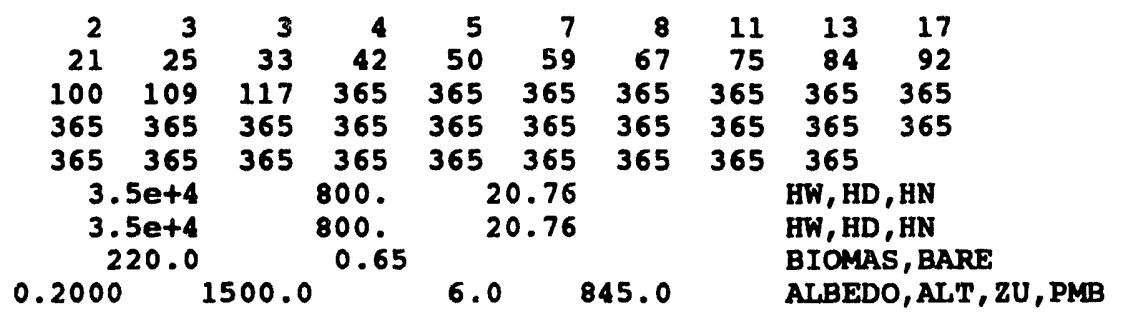


11
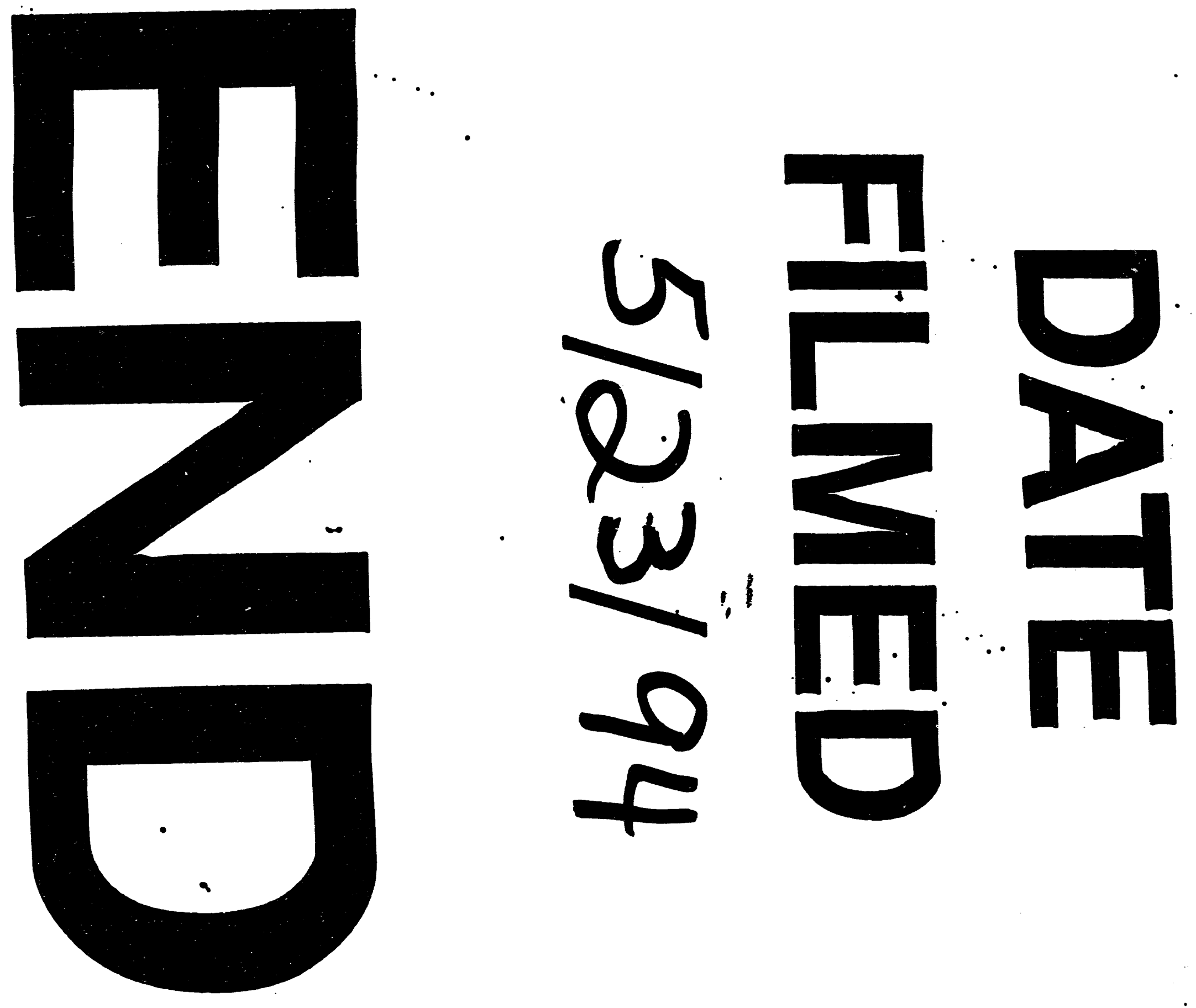
